NBSIR 87-3594

\title{
Fenestration Design for Building Atria
}
S. J. Treado
D. B. Holland
J. W. Bean
G. L. Gillette

U.S. DEPARTMENT OF COMMERCE

National Bureau of Standards

National Engineering Laboratory

Center for Building Technology

Building Physics Division

Gaithersburg, MD 20899

September 1987

Prepared for:

U.S. Department of Energy

American Architectural Manufacturers Association 



\section{FENESTRATION DESIGN FOR BUILDING}

ATRIA
S. J. Treado
D. B. Holland
J. W. Bean
G. L. Gillette

\section{U.S. DEPARTMENT OF COMMERCE \\ National Bureau of Standards \\ National Engineering Laboratory \\ Center for Building Technology \\ Building Physics Division \\ Gaithersburg, MD 20899}

\section{September 1987}

Prepared for:

U.S. Department of Energy

American Architectural Manufacturers Association

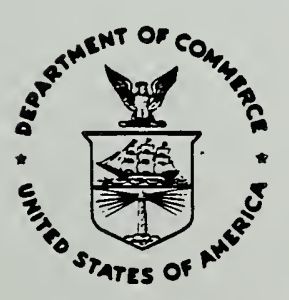

U.S. DEPARTMENT OF COMMERCE, Clarence J. Brown, Acting Secretary NATIONAL BUREAU OF STANDARDS, Ernest Ambler, Director 



\section{ABSTRACT}

The influence of fenestration design on building energy performance is evaluated, based on measurements in four atrium buildings and a series of detailed computer simulations using TARP and CEL-1. The impact of glazing area and solar-optical properties is examined for a linear and central atrium building for eight geographical locations. The usefulness of automatic solar shading and heat storage strategies is also investigated. Guidelines are presented for effective design of atrium fenestration.

The results indicate that when daylighting is used, appropriate fenestration design will result in lower building energy requirements than would occur with no fenestration. Reductions in annual building energy requirements of over 20 percent were observed, although the total savings potential varied with geographical location.

Keywords: atrium; building energy; daylighting; glazing; heat storage; solar shading 
This report documents work performed for the American Architectural Manufacturers Association and the U.S. Department of Energy, and is part of a continuing research program investigating the effective use of building fenestration and daylighting strategies. 


\section{ACKNOWLEDGMENTS}

The authors wish to acknowledge the advice and consultations provided by Mr. J. W. Griffith and an AAMA technical group, and the administrative assistance from the National Fenestration council and Mr. W. Birch. Special appreciation goes to Mrs. Donna Shoemaker and Mrs. Beth Burdette for typing and editing this manuscript.

\section{DISCLAIMER}

References to any commercial equipment or materials are given to describe the conduct of the research, and do not imply recommendation or endorsement by the National Bureau of Standards. 


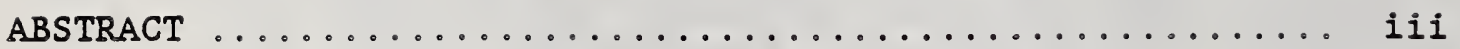

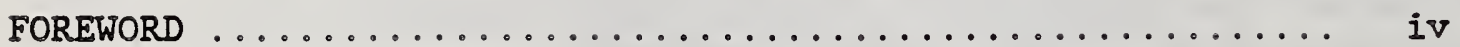

ACKNOWLEDGMENTS $\ldots \ldots \ldots \ldots \ldots \ldots \ldots \ldots \ldots \ldots \ldots \ldots \ldots \ldots \ldots \ldots$

DISCLAIMER $\ldots \ldots \ldots \ldots \ldots \ldots \ldots \ldots \ldots \ldots \ldots \ldots \ldots \ldots$

TABLE OF CONTENTS $\ldots \ldots \ldots \ldots \ldots \ldots \ldots \ldots \ldots \ldots \ldots \ldots \ldots \ldots$

LIST OF TABLES $\ldots \ldots \ldots \ldots \ldots \ldots \ldots \ldots \ldots \ldots \ldots \ldots \ldots \ldots \ldots \ldots$

LIST OF FIGURES $\ldots \ldots \ldots \ldots \ldots \ldots \ldots \ldots \ldots \ldots \ldots \ldots \ldots \ldots \ldots \ldots$

1. INTRODUCTION $\ldots \ldots \ldots \ldots \ldots \ldots \ldots \ldots \ldots \ldots \ldots \ldots \ldots \ldots$

2. BACKGROUND $\ldots \ldots \ldots \ldots \ldots \ldots \ldots \ldots \ldots \ldots \ldots \ldots \ldots \ldots \ldots \ldots \ldots$

3. FIELD MEASUREMENTS OF ATRIUM CONDITIONS ........... 3

4. COMPUTER SIMULATION OF ATRIUM PERFORMANCE $\ldots \ldots \ldots \ldots \ldots \ldots 6$

4.1 Linear Atrium Building Simulation .............. 6

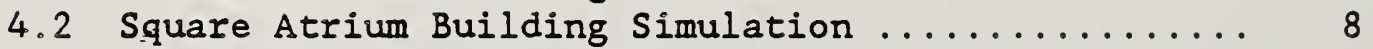

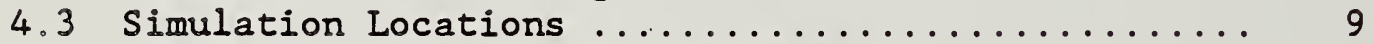

4.4 Simulation Variation of Parameters .............. 9

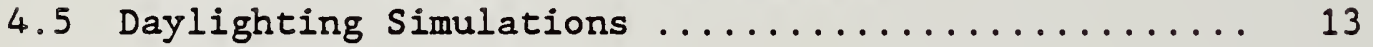

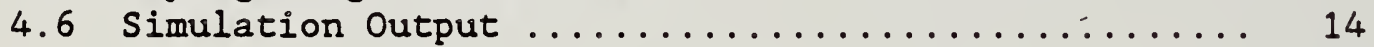

5. COMPUTER SIMULATION RESULTS $\ldots \ldots \ldots \ldots \ldots \ldots \ldots \ldots \ldots \ldots$

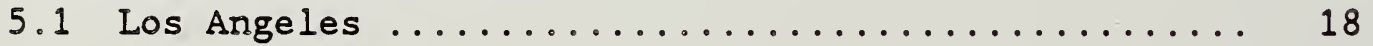

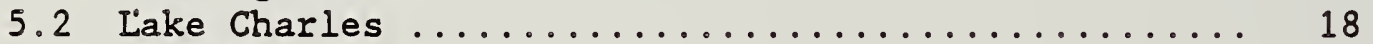

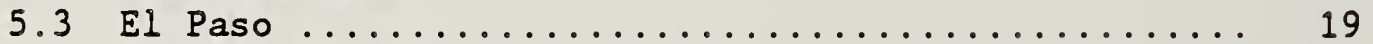

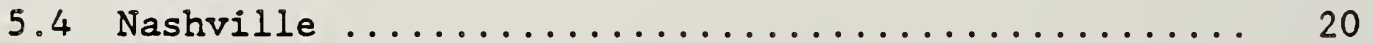

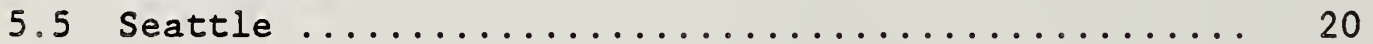

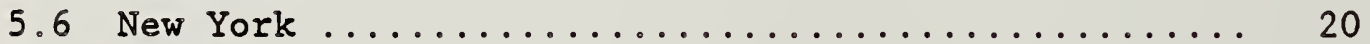

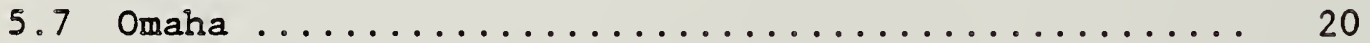

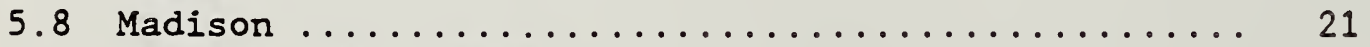

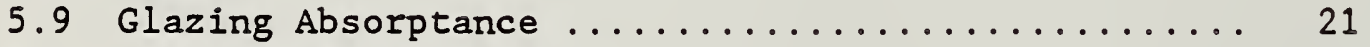

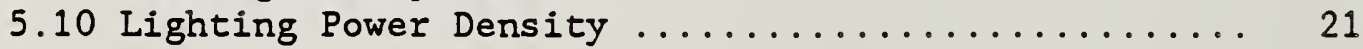

6. CONCLUSIONS $\ldots \ldots \ldots \ldots \ldots \ldots \ldots \ldots \ldots \ldots \ldots \ldots \ldots \ldots \ldots \ldots$

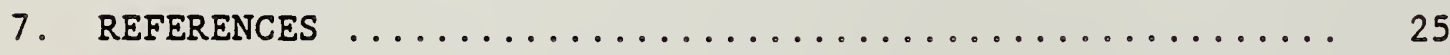




\section{LIST OF TABLES}

Table 1. Atrium Measurement Buildings .............. 3

Table 2. Variables Measured - Building D ............. 5

Table 3. Linear Atrium Simulation Building ............ 6

Table 4. Square Atrium Simulation Building ........... 8

Table 5 . Simulation Locations .................... 9

Table 6. Values for Parametric Studies .............. 10

Table 7. Parameter Values for Each Simulation ........... 11

Table 8. Daylighting CU Pre-Calculations ............. 13

Table 9. Surface Reflectance Values for Atrium Buildings .. 14 
Figure 1. Temperature variations in building A atrium (Hughes Justice Complex) ...............

Figure 2. Temperature variations in buildings $B$ and $C$ (Enerplex North and South) ............. 28

Figure 3. Hourly temperature variations in building $D$ (AT\&T Long Lines) .................... 29

Figure 4. Hourly irradiance and illuminance levels in building $\mathrm{D}$ (AT\&T Long Lines) ............ 30

Figure $5 . \quad$ Linear atrium building .............. 31

Figure $6 . \quad$ Square atrium building $\ldots \ldots \ldots \ldots \ldots \ldots \ldots \ldots$

Figure 7a. Total energy ratio for transmittance of 0.8 ,

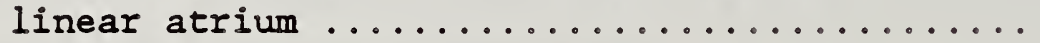

Figure 7b. Total energy ratio for transmittance of 0.5 , linear atrium ......................... 34

Figure 7c. Total energy ratio for transmittance of 0.2 ,

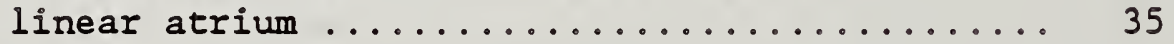

Figure 8a. Total energy ratio for transmittance of 0.8 , square atrium .................... 36

Figure 8b. Total energy ratio for transmittance of 0.5 ,

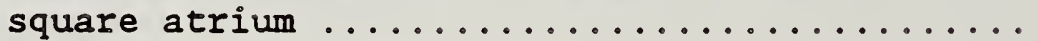

Figure 8c. Total energy ratio for transmittance of 0.2 ,

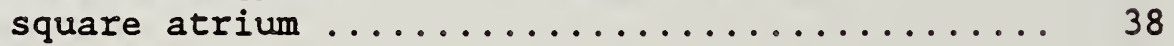

Figure 9a. Total energy ratio with solar shading, heat storage and single pane, linear atrium ...... 39

Figure 9b. Total energy ratio with solar shading, heat storage and single pane, square atrium ...... 40

Figure 10a. Total energy versus glazing area and transmittance, Los Angeles, linear atrium ....... 41

Figure 10b. Heating, cooling and lighting energy versus glazing area and transmittance, Los Angeles, linear atrium 
Figure 10c. Peak heating and cooling loads versus glazing area and transmittance, Los Angeles,

linear atrium ....................... 43

Figure 10d. Energy usage versus glazing transmittance,

Los Angeles, linear atrium .............. 44

Figure 10e. Energy usage with solar shading, heat storage

and single pane glazing, Los Angeles,

linear atrium ..................... 45

Figure 11a. Total energy versus glazing area and trans-

mittance, Los Angeles, square atrium ........

Figure 11b. Heating, cooling and lighting energy versus

glazing area and transmittance, Los Angeles,

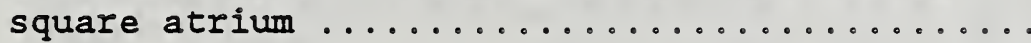

Figure 11c. Peak heating and cooling loads versus glazing

area and transmittance, Los Angeles,

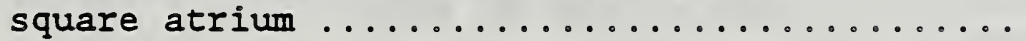

Figure 11d. Energy usage versus glazing transmittance,

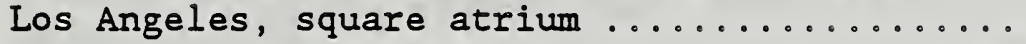

Figure 11e. Energy usage with solar shading, heat storage and single pane glazing, Los Angeles,

Figure 12a. Total energy versus glazing area and transmittance, Lake Charles, linear atrium ........

Figure 12b. Heating, cooling and lighting energy versus glazing area and transmittance, Lake Charles, linear atrium

Figure 12c. Peak heating and cooling loads versus glazing area and transmittance, Lake Charles,

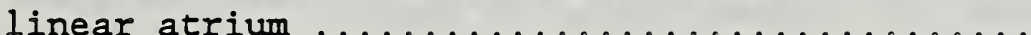

Figure 12d. Energy usage versus glazing transmittance, Lake Charles, linear atrium

Figure 12e. Energy usage with solar shading, heat storage and single pane glazing, Lake Charles, linear atrium

Figure 13a. Total energy versus glazing area and transmittance, Lake Charles, square atrium 
Figure 13b. Heating, cooling and lighting energy versus glazing area and transmittance, Lake Charles,

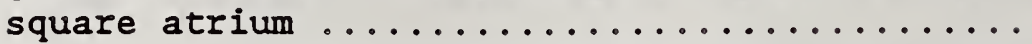

Figure 13c. Peak heating and cooling loads versus glazing area and transmittance, Lake Charles,

Figure 13d. Energy usage versus glazing transmittance,

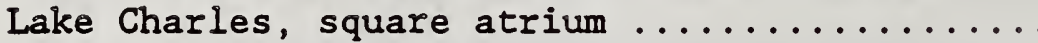

Figure 13e. Energy usage with solar shading, heat storage and single pane glazing, Lake Charles, square atrium $\ldots \ldots \ldots \ldots \ldots \ldots \ldots \ldots \ldots \ldots$

Figure 14a. Total energy versus glazing area and transmittance, El Paso, linear atrium ...........

Figure 14b. Heating, cooling and lighting energy versus glazing area and transmittance, El Paso,

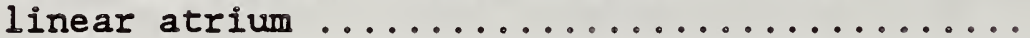

Figure 14c. Peak heating and cooling loads versus glazing area and transmittance, El Paso,

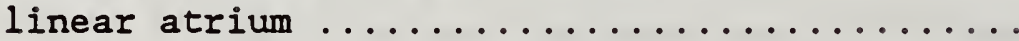

Figure 14d. Energy usage versus glazing transmittance,

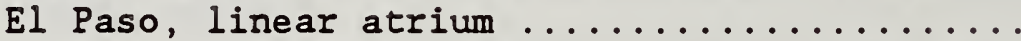

Figure 14e. Energy usage with solar shading, heat storage and single pane glazing, El Paso,

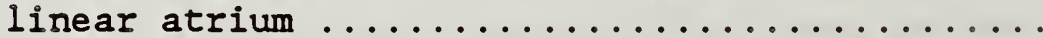

Figure 15a. Total energy versus glazing area and transmittance, El Paso, square atrium ..........

Figure 15b. Heating, cooling and lighting energy versus glazing area and transmittance, El Paso, square atrium $\ldots \ldots \ldots \ldots \ldots \ldots \ldots \ldots \ldots \ldots$

Figure 15c. Peak heating and cooling loads versus glazing area and transmittance, El Paso, square atrium $\ldots \ldots \ldots \ldots \ldots \ldots \ldots \ldots \ldots$

Figure 15d. Energy usage versus glazing transmittance, El Paso, square atrium ...............

Figure 15e. Energy usage with solar shading, heat storage and single pane glazing, El Paso,

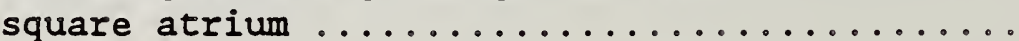


Figure 16a. Total energy versus glazing area and trans-

mittance, Nashville, linear atrium ..........

Figure 16b. Heating, cooling and lighting energy versus glazing area and transmittance, Nashville, linear atrium

Figure 16c. Peak heating and cooling loads versus glazing area and transmittance, Nashville, linear atrium

Figure 16d. Energy usage versus glazing transmittance, Nashville, linear atrium

Figure 16e. Energy usage with solar shading, heat storage and single pane glazing, Nashville,

Figure 17a. Total energy versus glazing area and trans-

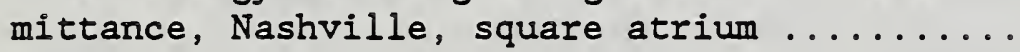

Figure 17b. Heating, cooling and lighting energy versus glazing area and transmittance, Nashville,

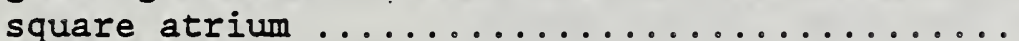

Figure 17c. Peak heating and cooling loads versus glazing area and transmittance, Nashville, square atrium $\ldots \ldots \ldots \ldots \ldots \ldots \ldots \ldots \ldots$

Figure 17d. Energy usage versus glazing transmittance,

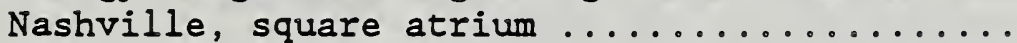

Figure 17e. Energy usage with solar shading, heat storage and single pane glazing, Nashville,

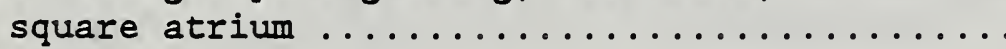

Figure 18a. Total energy versus glazing area and trans-

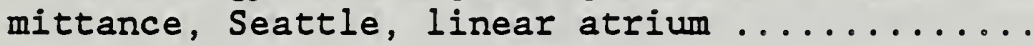

Figure 18b. Heating, cooling and lighting energy versus glazing area and transmittance, Seattle,

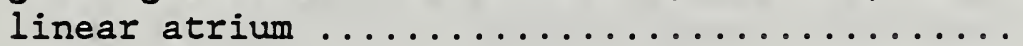

Figure 18c. Peak heating and cooling loads versus glazing area and transmittance, Seattle,

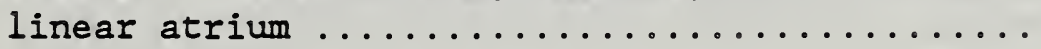

Figure 18d. Energy usage versus glazing transmittance, Seattle, linear atrium ............... 84 
Figure 18e. Energy usage with solar shading, heat storage and single pane glazing, Seattle,

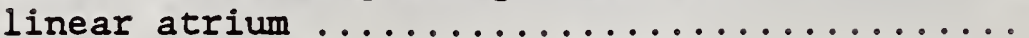

Figure 19a. Total energy versus glazing area and trans-

mittance, Seattle, square atrium ...........

Figure 19b. Heating, cooling and lighting energy versus

glazing area and transmittance, Seattle,

square atrium $\ldots \ldots \ldots \ldots \ldots \ldots \ldots \ldots \ldots \ldots$

Figure 19c. Peak heating and cooling loads versus glazing

area and transmittance, Seattle,

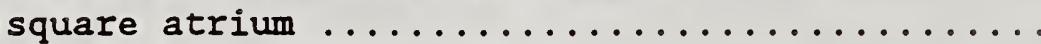

Figure 19d. Energy usage versus glazing transmittance,

Seattle, square atrium $\ldots \ldots \ldots \ldots \ldots \ldots \ldots$

Figure 19e. Energy usage with solar shading, heat storage and single pane glazing, Seattle,

Figure 20a. Total energy versus glazing area and transmittance, New York, linear atrium

Figure 20b. Heating, cooling and lighting energy versus glazing area and transmittance, New York,

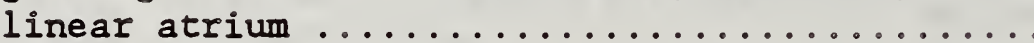

Figure 20c. Peak heating and cooling loads versus glazing area and transmittance, New York,

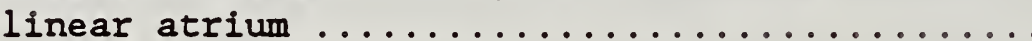

Figure 20d. Energy usage versus glazing transmittance,

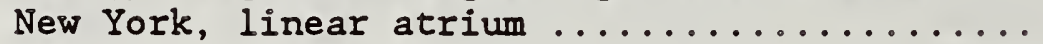

Figure 20e. Energy usage with solar shading, heat storage and single pane glazing, New York,

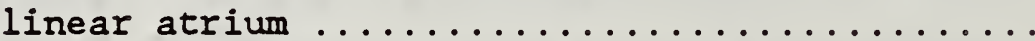

Figure 21a. Total energy versus glazing area and trans-

mittance, New York, square atrium ..........

Figure 21b. Heating, cooling and lighting energy versus glazing area and transmittance, New York, square atrium $\ldots \ldots \ldots \ldots \ldots \ldots \ldots \ldots \ldots$

Figure 21c. Peak heating and cooling loads versus glazing area and transmittance, New York, square atrium $\ldots \ldots \ldots \ldots \ldots \ldots \ldots \ldots$ 
Figure 21d. Energy usage versus glazing transmittance,

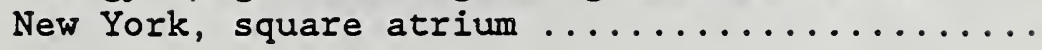

Figure 21e. Energy usage with solar shading, heat storage and single pane glazing, New York,

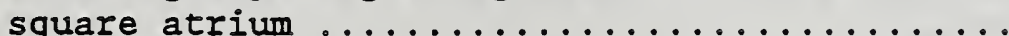

Figure 22a. Total energy versus glazing area and transmittance, Omaha, linear atrium .......... 101

Figure 22b. Heating, cooling and lighting energy versus glazing area and transmittance, Omaha,

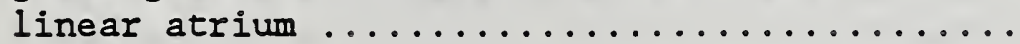

Figure 22c. Peak heating and cooling loads versus glazing area and transmittance, Omaha, linear atrium .. 103

Figure 22d. Energy usage versus glazing transmittance,

Omaha, linear atrium ............... 104

Figure 22e. Energy usage with solar shading, heat storage and single pane glazing, Omaha,

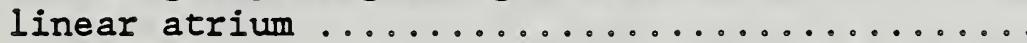

Figure 23a. Total energy versus glazing area and trans-

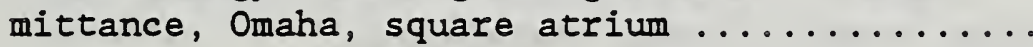

Figure 23b: Heating, cooling and lighting energy versus glazing area and transmittance, Omaha,

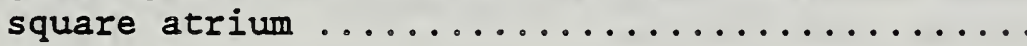

Figure 23c. Peak heating and cooling loads versus glazing area and transmittance, Omaha, square atrium .. 108

Figure 23d. Energy usage versus glazing transmittance,

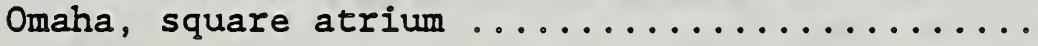

Figure 23e. Energy usage with solar shading, heat storage and single pane glazing, Omaha, square atrium

Figure 24a. Total energy versus glazing area and transmittance, Madison, linear atrium ...........

Figure 24b. Heating, cooling and lighting energy versus glazing area and transmittance, Madison,

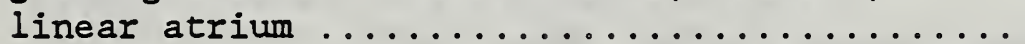

Figure 24c. Peak heating and cooling loads versus glazing area and transmittance, Madison, 
Figure 24d. Energy usage versus glazing transmittance,

Madison, linear atrium ............... 114

Figure 24e. Energy usage with solar shading, heat storage

and single pane glazing, Madison,

linear atrium

Figure 25a. Total energy versus glazing area and trans-

mittance, Madison, square atrium .......... 116

Figure 25b. Heating, cooling and lighting energy versus

glazing area and transmittance, Madison,

square atrium

Figure 25c. Peak heating and cooling loads versus glazing

area and transmittance, Madison,

Figure 25d. Energy usage versus glazing transmittance,

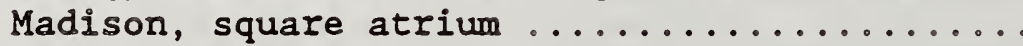

Figure 25e. Energy usage with solar shading, heat storage

and single pane glazing, Madison,

square atrium ........................ 120

Figure 26a. Energy usage versus glazing absorptance,

linear atrium, Los Angeles .............. 121

Figure 26b. Energy usage versus glazing absorptance,

linear atrium, Lake Charles .............. 122

Figure 26c. Energy usage versus glazing absorptance,

linear atrium, El Paso .................. 123

Figure 26d. Energy usage versus glazing absorptance,

linear atrium, Nashville ................. 124

Figure 26e. Energy usage versus glazing absorptance,

linear atrium, Seattle ................. 125

Figure 26f. Energy usage versus glazing absorptance,

linear atrium, New York ................. 126

Figure 26g. Energy usage versus glazing absorptance,

linear atrium, Omaha .................. 127

Figure 26h. Energy usage versus glazing absorptance,

linear atrium, Madison ............... 128

Figure 27a. Total energy ratio vs lighting power density,

Los Angeles ......................... 129 
Figure 27b. Heating, cooling and lighting energy vs

lighting power density, Los Angeles .........

Figure 27c. Peak heating and cooling loads vs lighting

power density, Los Angeles ...............

Figure 28a. Total energy ratio vs lighting power density, Lake Charles ........................

Figure 28b. Heating, cooling and lighting energy vs lighting power density, Lake Charles .........

Figure 28c. Peak heating and cooling loads vs lighting power density, Lake Charles .............. 134

Figure 29a. Total energy ratio vs lighting power density,

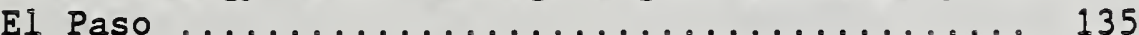

Figure 29b. Heating, cooling and lighting energy vs lighting power density, El Paso ........... 136

Figure 29c. Peak heating and cooling loads vs lighting power density, El Paso .................

Figure 30a. Total energy ratio vs lighting power density,

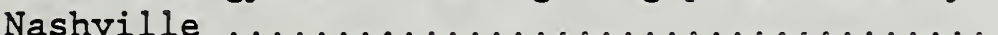

Figure 30b. Heating, cooling and lighting energy vs lighting power density, Nashville ..........

Figure 30c. Peak heating and cooling loads vs lighting power density, Nashville

Figure 31a. Total energy ratio vs lighting power density,

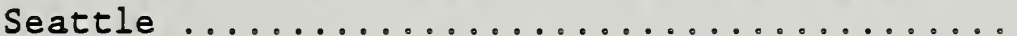

Figure 31b. Heating, cooling and lighting energy vs

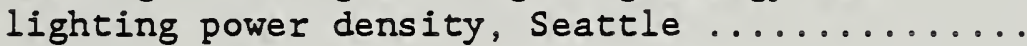

Figure 31c. Peak heating and cooling loads vs lighting power density, Seattle .................

Figure 32a. Total energy ratio vs lighting power density, New York

Figure 32b. Heating, cooling and lighting energy vs lighting power density, New York

Figure 32c. Peak heating and cooling loads vs lighting power density, New York 
Figure 33a. Total energy ratio vs lighting power density,

Omaha ......................... 147

Figure 33b. Heating, cooling and lighting energy vs

lighting power density, Omaha .......... 148

Figure 33c. Peak heating and cooling loads vs lighting

power density, Omaha .................. 149

Figure 34a. Total energy ratio vs lighting power density,

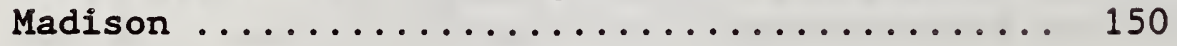

Figure 34b. Heating, cooling and lighting energy vs

lighting power density, Madison .......... 151

Figure 34c. Peak heating and cooling loads vs lighting

power density, Madison ................ 152 


\section{INTRODUCTION}

The inclusion of atrium spaces in buildings has been increasing in recent years for several reasons. Building atria are dramatic architectural features, providing for a significant change of scale within the enclosing structure, and allowing flexibility in interior layout. The aesthetic qualities of building atrium spaces are difficult to overlook, and atria can provide for large volumes of interior space at a relatively modest cost. Atria can also be efficiently incorporated with airflow and smoke control strategies. However, perhaps the most important atrium performance aspect is the ability of atria to allow significant amounts of daylight to penetrate building interior spaces. Indeed, one of the most pleasing uses of atrium spaces involves the replication of an attractive park-like setting within a controlled interior environment, complete with trees, plants and flowers. While the psychological benefits of interior daylight are well documented, building energy benefits through daylight utilization are also possible. [1,2]

This report examines the daylighting and energy performance of building atrium spaces, based on measurements in four buildings and a series of computer simulations using the TARP (Thermal Analysis Research Program) and CEL-1 (Conservation of Electric Lighting) computer programs. The results are analyzed and guidelines are presented to aid building designers in designing effective atrium spaces. The focus of the analysis is on the best use of atrium fenestration, particularly glazing characteristics. The use of solar shading and heat storage strategies is also examined. The effect of atrium design on energy usage for heating, cooling and lighting, and peak heating and cooling loads, is examined. 


\section{BACKGROUND}

In the design of buildings, the determination of the most effective combination of envelope components requires considerable effort. Consideration must be given to the influences of geographical location, building type and size, site constraints and occupant related factors. The dependence of building energy requirements for heating, cooling, lighting and equipment on the thermal properties of the building envelope and internal loads makes it difficult to determine an optimal design. Many times, an envelope feature may increase one form of energy use for building conditioning, but decrease another. In particular, when fenestration is considered, different glazing sizes or characteristics will affect energy usage for heating, cooling and lighting, and an optimum design can only be determined by evaluating the net performance. To aid in the selection of the most effective fenestration design, various design alternatives can be compared using an hour-by-hour building energy computer simulation for a typical year. Such a computer program simulates the dynamic thermal and energy performance of a building, which is represented by a suitable input file containing a description of building components, equipment, operating schedules and occupancy patterns, along with a computer tape of weather conditions.

With regard to the problem at hand, while building energy simulation computer programs have been utilized successfully for many different building types, it is essential that the validity of a particular program for evaluating atrium performance be established to ensure that any conclusions drawn from the simulations are themselves valid. However, it is nearly impossible to validate all aspects of a detailed building energy simulation program, due to the complexity of the programs and the difficulty in obtaining accurate thermal and energy performance measurements of occupied buildings over a long time.

The focus of this study is on the evaluation of fenestration design on building atrium performance, including the impact of daylight utilization to offset electric lighting requirements. Thus, accurate procedures for computing interior daylight levels are required, along with appropriate routines for modeling thermal processes within the atrium and surrounding space. A limited set of measurements were taken to provide information about daylight levels and energy flows with atrium spaces, to assist in the development of the appropriate computer algorithms for modeling buildings with atrium spaces. These measurements, and the subsequent simulations and results, are described in the succeeding sections. 
A literature search uncovered few prior detailed studies of atria, but did yield some data on atrium performance.[3-9] The smoke control characteristics and qualitative evaluation of HVAC performance and air flow patterns in building atria were described, as were some aspects of HVAC design for atria.

\section{FIELD MEASUREMENTS OF ATRIUM CONDITIONS}

Systematic measurements were taken in four buildings containing a total of six atria The purpose of the measurements was to obtain a feel for thermal and visual conditions within some atrium buildings, and to compile data for comparison to computer calculations. A brief description of each building is given in table 1.

\section{Table 1. Atrium Measurement Buildings}

A. Hughes Justice Complex

Trenton, New Jersey

8 floor central atrium, fully conditioned

B. Enerplex North

Plainsboro, New Jersey

3 floor, south facing atrium with heat recovery

3 floor central, linear light well, fully conditioned

C. Enerplex South

Plainsboro, New Jersey

3 floor, north facing atrium, unconditioned

3 floor central, linear light well, fully conditioned

D. AT\&T Long Lines Building

Oakton, Virginia

3 floor linear atrium, fully conditioned

Temperatures were measured within the atrium and adjacent spaces to assist the modeling effort. Of particular concern was the extent of vertical temperature stratification in the atrium, since TARP (and other simulation programs) treat each thermal zone as having uniform air temperature at any instant in time. If significant variations in atrium air temperature with vertical location were observed, special modeling procedures would be required. Additional measurements of surface temperatures, daylight levels and solar radiation levels were intended to provide a general picture of thermal and illumination conditions within the atrium spaces.

Measurements were conducted by hand in buildings A, B and C over a twoday period using thermometers, illuminance meters, irradiance meters and spot radiometers. With generally clear skies (global irradiance of $260 \mathrm{Btu} / \mathrm{h}$ ft $\left(820 \mathrm{wm}^{-2}\right)$ and an outdoor temperature of $84^{\circ} \mathrm{F}\left(29^{\circ} \mathrm{C}\right)$, air temperature within the eight ft (2.44m) floor atrium in building $A$ 
averaged about $71^{\circ} \mathrm{F}\left(22^{\circ} \mathrm{C}\right)$. The maximum air temperature was $74^{\circ} \mathrm{F}$ $\left(23^{\circ} \mathrm{C}\right)$ at the eighth floor level, while the minimum was $68^{\circ} \mathrm{F}\left(20^{\circ} \mathrm{C}\right)$ at floors five through seven. However, the variation in air temperature with horizontal location on any floor averaged $3^{\circ} \mathrm{F}\left(1.7^{\circ} \mathrm{C}\right)$. Thus, as shown in figure 1 , vertical temperature variations were very similar to horizontal temperature variations, with most of the stratification occurring at the top fioor of the atrium. In the same figure, atrium wall surface temperature is seen to vary through a considerably wider range, due to the incidence of solar radiation. The underside of the atrium glazing was approximately $100^{\circ} \mathrm{F}\left(38^{\circ} \mathrm{C}\right)$. The variation in air temperature with horizontal location can be attributed to the proximity to the air supply registers on each floor.

The results of similar measurements in buildings $B$ and $C$ are shown in figure 2. Outdoor air temperature was $79^{\circ} \mathrm{F}\left(26^{\circ} \mathrm{C}\right)$ with a global irradiance of $257 \mathrm{Btu} . \mathrm{h}^{-1} \mathrm{ft}^{-2}\left(810 \mathrm{wm}^{-2}\right)$. Building B is a specially designed structure with heat collection from the south-facing atrium, underground rock storage and airflow double-wall construction on the north face.[3] However, the forced air circulation system was not in operation at the time of the measurements because the building was not yet completed or occupied. Surface temperatures ranged from $75^{\circ} \mathrm{F}$ to $79.5^{\circ} \mathrm{F}\left(23.9\right.$ to $\left.26.4^{\circ} \mathrm{C}\right)$. Air temperature within the unconditioned central atrium/lightwell varied from $74^{\circ} \mathrm{F}\left(23.3^{\circ} \mathrm{C}\right)$ at the floor to $79.5^{\circ} \mathrm{F}\left(26.4^{\circ} \mathrm{C}\right)$ near the top. Building $C$ had a north-facing unconditioned sunspace, which had air temperatures ranging from 77 to $80^{\circ} \mathrm{F}\left(25^{\circ}\right.$ to $26.7^{\circ} \mathrm{C}$ ) vertically. The central atrium/lightwell, which was conditioned, ranged in temperature from 71 to $75.5^{\circ} \mathrm{F}$ (21.7 to $24.2^{\circ} \mathrm{C}$ ), with most of the increase occurring near the top of the space.

The most detailed measurements were taken in building $D$, the AT\&T Long Lines building. Automated measurement equipment was installed and data were collected hourly for a period of one month. Table 2 lists the variables measured. 
Table 2. Variables Measured - Building D.

1. Glazing surface temperature

2. Outdoor air temperature

3. Third floor air temperature

4. Third floor wall temperature

5. Second floor air temperature

6. Second floor wall temperature

7. First floor air temperature

8. First floor wall temperature

9. Return air temperature

10. Atrium floor temperature

11. Exterior global irradiance

12. Vertical irradiance, third floor

13. Vertical illuminance, third floor

14. Vertical irradiance, second floor

15. Vertical illuminance, second floor

16. Vertical irradiance, first floor

17. Vertical illuminance, first floor

18. Horizontal irradiance, first floor

19. Horizontal illuminance, first floor

20. Glazing Iuminance, zenith

Figure 3 displays hourly temperature variations for a typical summer day. The outdoor air temperature reached a high of $90^{\circ} \mathrm{F}$ $\left(32.2^{\circ} \mathrm{C}\right)$ and ranged as low as $61^{\circ} \mathrm{F}\left(16.1^{\circ} \mathrm{C}\right)$. The maximum vertical temperature stratification was observed to be $5^{\circ} \mathrm{F}\left(2.8^{\circ} \mathrm{C}\right)$ from the first to third floors, while the first and second floors differed by only $1^{\circ} \mathrm{F}\left(.6^{\circ} \mathrm{C}\right)$. Third floor wall surface temperature ranged as high as $77.5^{\circ} \mathrm{F}\left(25.3^{\circ} \mathrm{C}\right)$. Figure 4 shows the various illuminance and irradiance levels observed on the same day. Considerable variations over time are apparent, as would be expected. Light levels on a horizontal surface near the atrium floor exceed $93 \mathrm{fc}$ (1000 lux) for most of the day, and peak at over $279 \mathrm{fc}$ (3000 lux). Solar radiation levels at the same location follow a similar pattern, exceeding .95 $\mathrm{Btu} / \mathrm{hft}^{2}\left(3 \mathrm{wm}^{-2}\right)$ for most of the day, and peaking at over $30 \mathrm{wm}^{-2}$.

Several general conclusions can be drawn from these measurements. First, in fully conditioned atrium spaces vertical temperature variations, or stratification, is similar in magnitude to horizontal variations. Thus, modeling the atrium space as a single thermal zone should not introduce any more uncertainty due to stratification than due to typical variations encountered in non-atrium spaces. Second, irradiance and illuminance levels can be high in large glazed atria, with significant heating of wall surfaces due to absorption of solar radiation. Third, most of the elevated atrium air and surface temperatures occur near the top of the atrium, in conditioned atria. 
The computer simulations of atrium building performance were implemented using custom versions of TARP and CEL-1. TARP is a detailed thermal analysis program,[10] while CEL-1 is a detailed lighting and daylighting simulation program.[11,12] Two types of three story buildings with atrium spaces were simulated, namely a linear atrium and a central, square atrium. Simulations were performed for eight geographical locations, four glazing areas, three glazing transmittances, two glazing absorptances, and three lighting power densities, for single and double glazings. Solar shading and heat storage strategies were also simulated. Not all combinations of parameters were simulated, with the main emphasis being given to glazing area and transmittance. Other combinations were selected to reflect what were considered to be the most useful configurations, while still allowing the determination of the sensitivity of the results to all the various parameters. Thirty-eight simulations were run for each location for a total of 304 simulations.

\subsection{LINEAR ATRIUM BUILDING SIMULATION}

The largest number of simulations were executed for a three floor building with a linear atrium. As shown in figure 5, this building was 150 by 120 feet $(45.72$ by $36.576 \mathrm{~m})$, with a linear atrium $30 \mathrm{ft}(9.14 \mathrm{~m})$ wide, situated in the center of the building along a north-south axis and extending ten feet (3.048m) above the roof to a total height of 40 feet $(12.192 \mathrm{~m})$. The three floors on each side of the atrium were without wâlls for a distance of 30 feet $(9.144 \mathrm{~m})$ from the atrium, so light from the atrium could penetrate those areas. An additional 30 feet ( $9.144 \mathrm{~m})$ of office space was located beyond an opaque wall on each side extending to the building exterior walls. Thus, no portion of the office space was more than 30 feet (9.144m) from either the atrium or exterior wall, the latter being 30 per cent glazed. The floor-to-floor height of each story was 10 feet (3.048m), with a floor to ceiling height of 8 feet (2.4m). Pertinent information regarding the linear atrium building is summarized in table 3 .

Table 3. Linear Atrium Simulation Building

1. Exterior dimensions

120 by 150 by $30 \mathrm{ft}$ (37x46x9m)

2. Atrium dimensions

3. Floor area-office space -atrium

4. Exterior wall construction
120 by 30 by $40 \mathrm{ft}$ (37×9x12m)

$$
\begin{aligned}
& \text { 43, } 200 f t^{2}\left(4013 m^{2}\right) \\
& 3,600 \mathrm{ft}^{2}\left(334 \mathrm{~m}^{2}\right)
\end{aligned}
$$

$4^{\prime}$ (1.22m) Face Brick

$1 / 2^{\prime \prime}(.0127 \mathrm{~m})$

Cement Mortar 
$8^{\prime \prime}(.2032 \mathrm{~m})$

Cinder Block

$2^{n}$ (.0508m)

Poly Insulation

$1 / 2^{n}$ (.0127m)

Gypsum Drywall

5. Roof Construction

$3 / 8 n(.009525 m)$

Builtup Roof

2" (.0508m)

Rigid Insulation

2" (.0508m)

Concrete Slab

$3 / 4 n$ (.019m) Air Space

$3 / 4^{n}(.019 \mathrm{~m})$

Metal Lath

$1 / 2^{n}$ (.0127m)

Gypsum Drywall

6. Occupant density

$1 / 90$ persons $/ \mathrm{ft}^{2}$

$\left(1 / 8.361\right.$ persons $\left./ \mathrm{m}^{2}\right)$

7. Electrical equipment power density

1.5 watts $/ \mathrm{ft}^{2}$

$\left(16.146 \mathrm{w} / \mathrm{m}^{2}\right)$

8. Temperature control

$\begin{array}{llll} & 12-6 \text { a.m. } & 6 \text { a.m. }-6 \text { p.m.* } & 6-12 \text { p.m. } \\ \text { Heating } & 60 F(15.55 \mathrm{C}) & 68 \mathrm{~F}(20 \mathrm{C}) & 60 \mathrm{~F}(15.55 \mathrm{C}) \\ \text { Cooling } & 85 \mathrm{~F}(29.44 \mathrm{C}) & 78 \mathrm{~F}(25.55 \mathrm{C}) & 85 \mathrm{~F}(29.44 \mathrm{C}) \\ \text { * Workdays only } & & \end{array}$

9. Occupancy schedule

$\begin{array}{ccccc}12-6 \text { a.m. } & 6-7 \text { a.m. } & 7 \text { a.m. }-5 \text { p.m. } & 5-6 \text { p.m. } & 6-12 \text { p.m. } \\ 0 & .5 * & 1 * & .5 * & 0\end{array}$

* Workdays only

10. Illuminance Setpoint - atrium 120 fc (1292 lux)

- offices $80 \mathrm{fc}(861 \mathrm{lux})$

11. Heating Efficiency - 0.80 , Cooling COP -3.0

A general fluorescent lighting system was modeled, with the base runs using a lighting power density of 2 watts $/ \mathrm{ft}^{2}\left(21.6 \mathrm{w} / \mathrm{m}^{2}\right)$. Other lighting power densities were also simulated, as described in a later section on parametric variations. A conditioned basement was modeled beneath the entire building. The exterior wall fenestration, on the east and west facades, was fixed for all the simulations. The atrium fenestration, however, was varied extensively, as is described later. Daylight utilization was simulated for all parts of the building. The details of the daylighting calculation procedures are also described later. The setpoint of $120 \mathrm{fc}$ (1292 lux) for the atrium was chosen to 
provide adequate light for indoor plants, based on information from U.S. Department of Agriculture publications. $[13,14]$

\subsection{SOUARE ATRIUM BUILDING SIMULATION}

The square atrium simulation building was similar to the linear atrium building in most respects, except for the geometrical layout. As shown in figure 6 , the exterior dimensions of the building were 180 by $180 \mathrm{ft}$ (54.9x54.9m), with a central atrium of 60 by 60 feet $(18.3 \times 18.3 \mathrm{~m})$. The portions of the office space within 30 feet $(9.144 \mathrm{~m})$ of the atrium were open plan to allow the penetration of daylight from the atrium. The outside 30 feet $(9.144 \mathrm{~m})$ of the building was separated on all sides from the inner portion of the building by an opaque wall. Thus, no portion of the office space was more than 30 feet ( $9.144 \mathrm{~m})$ from either the atrium or the exterior wall windows. The floor areas of the square and linear atrium spaces were identical; however, the square atrium building had more office space. Details of the square atrium simulation building are contained in table 4.

Table 4. Square Atrium Simulation Building

1. Exterior dimensions

2. Atrium dimensions

3. Floor area - office space - atrium

4. Exterior wall construction

5. Roof Construction

6. Occupant density
180 by 180 by $30 \mathrm{ft}$.

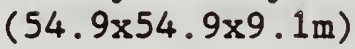

60 by 60 by $40 \mathrm{ft}$.

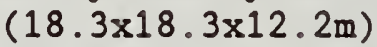

$86,400 \mathrm{ft}^{2}\left(8027 \mathrm{~m}^{2}\right)$ $3,600 \mathrm{ft}^{2}\left(334 \mathrm{~m}^{2}\right)$

$4^{\prime}$ (1.22m) Face Brick

$1 / 2^{n}(.0127 \mathrm{~m})$

Cement Mortar

$8^{\prime \prime}$ (.2036m)

Cinder Block

$2^{\text {" }}(.0508 \mathrm{~m})$

Poly Insulation

3/8" Builtup Roof

(.009525m)

2" Rigid Insulation

(.0508m)

2" Concrete Slab

(.0508m)

$1 / 2 "(.0127 \mathrm{~m})$

Gypsum Drywall

3/4" (.019m) Air Space

$3 / 4^{\prime \prime}(.019 \mathrm{~m})$ Metal Lath

$1 / 2 " \quad(.0127 \mathrm{~m})$

Gypsum Drywall

$1 / 90$ persons/ft ${ }^{2}$ 


$$
\left(1 / 8.361 \text { persons } / \mathrm{m}^{2}\right)
$$

7. Electrical equipment power density

1.5 watts $/ \mathrm{ft} \mathrm{t}^{2}$

$\left(16.146 \mathrm{w} / \mathrm{m}^{2}\right)$

8. Temperature control

$\begin{array}{llll} & 12-6 \text { a.m. } & 6 \text { a.m. }-6 \text { p.m.* } & 6-12 \text { p.m. } \\ \text { Heating } & 60 \mathrm{~F}(15.55 \mathrm{C}) & 68 \mathrm{~F}(20 \mathrm{C}) & 60 \mathrm{~F}(15.55 \mathrm{C}) \\ \text { Cooling } & 85 \mathrm{~F}(29.44 \mathrm{C}) & 78 \mathrm{~F}(25.55 \mathrm{C}) & 85 \mathrm{~F}(29.44 \mathrm{C}) \\ \text { * Workdays only } & & & \end{array}$

9. Occupancy schedule

$\begin{array}{ccccc}12-6 \text { a.m. } & 6-7 \text { a.m. } & 7 \text { a.m. }-5 \text { p.m. } & 5-6 \text { p.m. } & 6-12 \text { p.m. } \\ 0 & .5 * & 1 * & .5 * & 0\end{array}$

* Workdays only

10. Illuminance Setpoint - atrium 120 fc (1292 lux)

$$
\text { - offices } 80 \mathrm{fc}(861 \mathrm{lux})
$$

11. Heating Efficiency - 0.80, Cooling COP - 3.0

\subsection{SIMULATION LOCATIONS}

Simulations were executed for eight geographical locations, chosen to cover a wide range of climate conditions. The locations, and their heating and cooling degree days, are listed in table 5.

Table 5. Simulation Locations

$\begin{array}{lcc}\text { Los Angeles, CA } & \begin{array}{c}\text { City } \\ \text { Heating }\end{array} & \frac{\text { Cooling }}{615(342)} \\ \text { Lake Charles, LA } & 1819(1011) & 2739(1522) \\ \text { El Paso, TX } & 1498(832) & 2098(1166) \\ \text { Nashville, TN } & 2678(1488) & 1694(941) \\ \text { Seatrle, WA } & 3696(2053) & 129(72) \\ \text { New York, NY } & 5185(2881) & 861(478) \\ \text { Omaha, NB } & 5184(2880) & 1173(652) \\ \text { Madison, WI } & 6049(3361) & 460(256)\end{array}$

\subsection{SIMULATION VARIATION OF PARAMETERS}

The primary emphasis of the variation of parameters was on atrium glazing area and transmittance; however, numerous other parameters were 
also varied. Table 6 lists the various values used for the parametric studies.

\section{Table 6. Values for Parametric Studies}

1. Fraction of Atrium Roof Glazed

2. Glazing Transmittance

3. Number of Glazing Panes

4. Glazing Absorptance

5. Lighting Power Density

6. Automatic Solar Shading

7. Automatic Heat Storage
$0,0.3,0.6,0.9$

$0.2,0.5,0.8$

1,2

$0.1,0.4$

$1, \dot{2}, 3$ watts $/ \mathrm{ft}^{2}$

$\left(10.8,21.5,32.3 \mathrm{w} / \mathrm{m}^{2}\right)$

Yes, No

Yes, No 
Table 7 lists the values of each parameter for each of the 38 simulations executed per geographical location.

Table 7. Parameter Values for Each Simulation

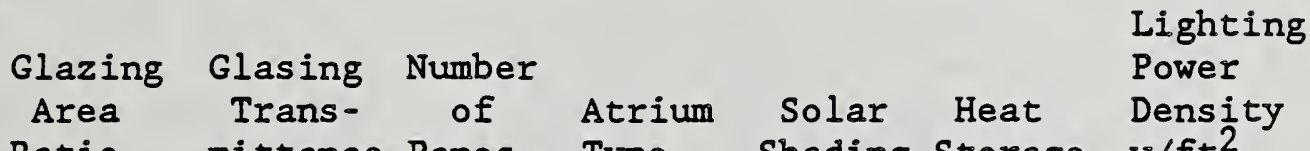

$\frac{\text { Run }}{B} \frac{\text { Ratio }}{0} \quad \frac{\text { mittance Panes }}{-} \quad \frac{\text { Type }}{\mathrm{L}} \quad \frac{\text { Shading Storage }}{\mathrm{N}} \frac{\mathrm{w} / \mathrm{ft}}{2}$

$\begin{array}{llllllll}1 & 0.9 & 0.8 & 2 & \mathrm{~L} & \mathrm{~N} & \mathrm{~N} & 2\end{array}$

$\begin{array}{lllllllll}2 & .6 & .8 & 2 & \mathrm{~N} & \mathrm{~N} & \mathrm{~N} & 2\end{array}$

$\begin{array}{llllllllll}3 & .3 & .8 & . & 2 & & L & N & N & 2\end{array}$

$\begin{array}{lllllllll}4 & .9 & .5 & 2 & \mathrm{~N} & \mathrm{~N} & \mathrm{~N} & 2\end{array}$

$\begin{array}{lllllllll}5 & .9 & .2 & 2 & \mathrm{~L} & \mathrm{~N} & \mathrm{~N} & 2\end{array}$

$\begin{array}{lllllllll}6 & .6 & .5 & 2 & \mathrm{~L} & \mathrm{~N} & \mathrm{~N} & 2\end{array}$

$\begin{array}{llllllll}7 & .6 & .2 & 2 & \text { I } & N & N & 2\end{array}$

$\begin{array}{llllllll}8 & .3 & .5 & 2 & \text { L } & \text { N } & \text { N } & 2\end{array}$

$\begin{array}{lllllllll}9 & .3 & 2 & 2 & \mathrm{~L} & \mathrm{~N} & \mathrm{~N} & 2\end{array}$

$\begin{array}{llllllll}10 & .9 & .8 & 2 & \text { L } & \text { Y } & \text { N } & 2\end{array}$

$\begin{array}{lllllllll}11 & .9 & .8 & 1 & \mathrm{~N} & \mathrm{~N} & \mathrm{~N} & 2\end{array}$

$\begin{array}{llllllll}12 & .9 & .8 & 1 & \mathrm{~L} & \mathrm{Y} & \mathrm{N} & 2\end{array}$

$\begin{array}{llllllll}13 & .9 & .8 & 2 & \text { L } & \text { N } & \text { Y } & 2\end{array}$

$\begin{array}{llllllll}14 & .9 & .8 & 2 & \text { L } & Y & Y & 2\end{array}$

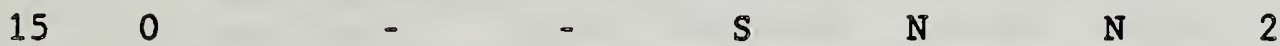

$\begin{array}{lllllll}16 & .9 & .8 & 2 & \mathrm{~S} & \mathrm{~N} & \mathrm{~N}\end{array}$

$\begin{array}{lllllll}17 & .6 & .8 & 2 & \mathrm{~S} & \mathrm{~N} & \mathrm{~N}\end{array}$

$\begin{array}{llllllll}18 & .3 & .8 & 2 & \mathrm{~S} & \mathrm{~N} & \mathrm{~N} & 2\end{array}$

$19 \quad .9$

$2 \quad S$

N 2

20

$.9 \quad .2$

2

$S \quad N$

N $\quad 2$ 


\begin{tabular}{|c|c|c|c|c|c|c|}
\hline 21 & .6 & .5 & 2 & $\mathrm{~S}$ & $\mathrm{~N}$ & $\mathrm{~N}$ \\
\hline 22 & .6 & .2 & 2 & $S$ & $\mathrm{~N}$ & $\mathrm{~N}$ \\
\hline 23 & .3 & .5 & 2 & $\mathrm{~S}$ & $\mathrm{~N}$ & $\mathrm{~N}$ \\
\hline 24 & .3 & .2 & 2 & $\mathrm{~S}$ & $\mathrm{~N}$ & $\mathrm{~N}$ \\
\hline 25 & .9 & .8 & 2 & $\mathrm{~S}$ & $Y$ & $\mathrm{~N}$ \\
\hline 26 & .9 & .8 & 1 & $S$ & $\mathrm{~N}$ & $\mathrm{~N}$ \\
\hline 27 & .9 & .8 & 1 & $\mathrm{~s}$ & $\mathrm{Y}$ & $\mathrm{N}$ \\
\hline 28 & .9 & .8 & 2 & $S$ & $\mathrm{~N}$ & $Y$ \\
\hline 29 & .9 & .8 & 2 & $\mathbf{S}$ & $Y$ & $Y$ \\
\hline 30 & .9 & .8 & 2 & L & $\mathrm{N}$ & $\mathrm{N}$ \\
\hline 31 & .9 & .8 & 2 & L & $\mathrm{N}$ & $\mathrm{N}$ \\
\hline 32 & 0 & - & - & L & $\mathrm{N}$ & $\mathrm{N}$ \\
\hline 33 & .3 & .8 & 2 & $L$ & $\mathrm{~N}$ & $\mathrm{~N}$ \\
\hline 34 & 3 & .8 & 2 & L & $\mathrm{N}$ & $\mathrm{N}$ \\
\hline 35 & 0 & - & - & L & $\mathrm{N}$ & $\mathrm{N}$ \\
\hline 37 & .9 & .2 & 2 & L & $\mathrm{N}$ & $\mathrm{N}$ \\
\hline 38 & .3 & .2 & 2 & L & $\mathrm{N}$ & $\mathrm{N}$ \\
\hline
\end{tabular}

Key: L-linear, S-square, N-no, Y-yes

The base cases, used for comparison and as normalization factors, are atrium-type spaces with solid, opaque, insulated roofs. Thus the volume and geometrical configuration of the baseline buildings are identical to the buildings with glazed atrium spaces. Separate base runs were made for each building type and lighting power density (runs B, 15, 32, and 35). The rationale for using this type of baseline building was the desire to maintain a constant building size and configuration, particularly with respect to floor area and enclosed volume.

Several of the parameters merit additional description. The solar shading option refers to a simplified automatic control function designed to simulate the performance of a movable shading system. This shading system deploys to reduce glazing transmittance to 20 percent 
when the atrium is in the cooling mode, thereby reducing solar radiation gain into the atrium. Shading is activated if the following conditions are met. First, the sun must be above the horizon. Second, either the outdoor air temperature must exceed the atrium maximum air temperature set-point, or cooling must have been used the previous hour. This shading strategy mimics the performance of operable shades or louvers, but is not an optimal shading technique. Such an optimal technique would shade as required to minimize energy usage, using a continuous range of transmittances. The intent of the shading strategy was to allow the evaluation of the potential of a simple shading system.

The heat storage option is intended to simulate the performance of thermal storage techniques such as air circulation through rock beds, phase change materials or direct gain thermal mass. The heat storage option is activated only when the outdoor air temperature is below the minimum atrium air temperature set-point, at which time any excess heat which would become a cooling load is shifted into storage. Losses from storage are taken to be 10 percent per hour, so heat stored one day cannot be used the next, but can be reclaimed if a heating load occurs while some heat remains in storage. The heat storage option is intended to reduce overheating in the atrium during cool or cold days, and to allow reclamation of some of the heat when needed. Heat storage was not allowed on hot days, since it would represent unreasonable free cooling. The three levels of lighting power density are all used with the same illumination set-points, thus simulating lighting systems of varying luminous efficacy.

\subsection{DAYLIGHTING SIMULATIONS}

The effects of daylight utilization were modeled using specially designed versions of TARP and CEL-1. CEL-1 was used to compute daylight coefficients of utilization (CU's) throughout the building interior. $C U$ is defined as the ratio of interior to exterior illuminance on a horizontal plane. A matrix of.CU's was pre-computed for each point for three sky types, for various days and hours, as listed in table 8.

Table 8. Daylighting CU Pre-calculations

Sky Types - clear, partly cloudy, overcast

Hours $\quad-6,8,10,12,14,16,18$

Days - one day each month

The matrix of CU's was made available to TARP as a computer file. During its hourly loop, TARP selected the appropriate CU based on sky type and month, interpolating in the haur dimension. 
The accuracy of the daylighting CU's was validated by analytical calculations and scale model measurements.

Using the $C U$ value and the hourly exterior global illuminance value, determined from the global irradiance value from the weather tape and luminous efficacy relations, daylight levels at each interior location were computed for each hour. Then the lighting power needed to maintain the required illuminance level was computed assuming a linear relationship between electric lighting system power consumption and light output. The luminaires were constrained to require a minimum of 30 percent of full lighting power. This simulates the performance of a photometrically controlled dimming or switching system. The calculated lighting power was used for the thermal calculations.

Table 9 displays the surface reflectance values for the atrium buildings.

Table 9. Surface Reflectance Values for Atrium Buildings

Ceiling Reflectance $\quad 0.80$

Wall Reflectance $\quad 0.50$

Floor Reflectance $\quad 0.30$

The atrium fenestration was modeled as a flat, horizontal surface of non-diffusing glazing.

\subsection{SIMULATION OUTPUT}

The simulation output included detailed information about heating, cooling and lighting loads for each of the thermal zones, in monthly and annual tabulations. This represents a great deal of information, more than can be adequately discussed in a report of reasonable length. However, the most important, and useful, results consist of a much smaller subset of the total simulation output. In evaluating the effect of fenestration design on atrium building energy performance, the most important parameter probably is the total annual energy usage for the entire building. Also of critical interest are the separate breakdowns of heating, cooling and lighting energy, and peak heating and cooling loads.

Total energy usage is of interest because it represents the amount of energy required to operate the building as specified. Total energy costs, however, require the weighting of each energy type by the appropriate cost, since heating energy may be purchased as fuel, and cooling and lighting energy as electricity. Due to the wide variations and uncertainty in energy costs, dollar costs of energy were not computed for this report. The reader can however, translate the heating, cooling and lighting energy usage figures into energy costs quite easily by using the appropriate energy unit costs. The effects of peak heating and cooling loads on equipment sizing and demand 
charges for energy are not explicitly examined; however, these factors can be considered through reference to the peak load plots.

The conversion of the TARP-computed thermal loads into the associated energy usages was accomplished using a simple model of a heating and cooling system. A heating efficiency of 80 percent and a cooling coefficient of performance of 3.0 were used to convert loads to energy. While the performance of actual heating and cooling systems may vary somewhat from these simplified assumptions, such a procedure is adequate for assessing the relative performance of fenestration design options. In addition, if a detailed systems model were used, it would be logical to vary the system to match the expected loads, which change with fenestration design.. Such a variation in heating and cooling systems would tend to obscure the changes in energy requirements due to fenestration design, which is the primary concern of the investigation. 


\section{COMPUTER SIMULATION RESULTS}

In all cases, the simulation results indicated that the use of some fenestration, along with daylight utilization, resulted in lower building energy requirements than would occur if the atrium roof were an insulated, opaque surface. For the linear atrium, see figures $7 a, b$ and $c$, the greatest percentage energy reductions occurred for the Los Angeles location, about 20 percent, and the least for Madison, about five percent. In general, the locations with higher ratios of cooling energy to heating energy experienced greater decreases in total energy requirements as atrium glazing area increased. This effect can be attributed to the reductions in cooling and lighting energy with fenestration usage, as will be shown in later figures. Figure 7 does not include the solar shading or heat storage runs, which will also be discussed later, and includes only double pane glazings, and lighting power density of 2 watts $/ \mathrm{ft}^{2}\left(21.5 \mathrm{w} / \mathrm{m}^{2}\right)$.

It should be noted that while Los Angeles has the greatest percent energy reductions, the absolute values of the energy reductions of some of the other cities are similar. This is due to the fact that the total energy requirements for Los Angeles are low compared to the other locations. Thus, a ten percent reduction in energy usage for, say, Nashville, may be similar to a 20 percent reduction in energy usage for Los Angeles. It is the absolute energy savings that translates into dollar savings.

A comparison of figures $7 \mathrm{a}, \mathrm{b}$ and $\mathrm{c}$ shows the glazing transmittance, $T$, of 0.8 to be most effective for these simulations. This can be attributed directly to the daylighting benefits of the increased interior daylight levels. For the 0.8 transmittance, the total energy curves are fairly flat in the glazing area ratio region 0.3 to 0.9 . This indicates that nearly equivalent energy performance would be expected through a wide range of glazing areas, allowing the building designer significant leeway in selecting glazing size. Slight minima are seen at the $0: 6$ glazing area ratio for this transmittance. This is due to interior daylight saturation, which occurs when interior daylight levels meet or exceed the illumination set-point, beyond which no additional dimming of the lights is possible. For the lower transmittances, the total energy ratios are lowest at the largest glazing areas, particularly for the transmittance of 0.2 . This can be attributed to the fact that interior daylight levels did not saturate at the smaller glazing sizes. The lowest transmittance was not effective at the colder locations, as the daylighting benefits were more than offset by the increased thermal losses with larger glazing areas.

Figure 8 a, b and c contain similar information for the square atrium building. The general trends are very similar to the linear building, but the percentage energy reductions are larger. This is due to a slightly better utilization of daylight over a larger portion of the office space adjacent to the atrium. For the transmittance of 0.8 , the total energy ratio curves are nearly flat between the glazing area 
ratios of 0.6 and 0.9 indicating that daylight saturation begins to occur near a glazing area ratio of 0.6 . Larger glazing areas are more effective for the lower transmittance values.

The effects of solar shading, heat storage and single versus double pane glazings are summarized in figure $9 a$ for the linear atrium building and $9 b$ for the square atrium building. On these plots, the abscissa is the log of the ratio of heating degree days to cooling degree days for the indicated locations. The significance of the $\log$ function is simply to compress the range of the horizontal axis. Climates in which cooling dominates lie towards the left, and heating dominated climates towards the right of these plots. In these plots, glazing area ratio is fixed at 0.9 , and transmittance at 0.8 .

The best-performing options seem to be the double pane glazing with heat storage, followed closely by the double pane with no special features. As would be expected, single pane glazing is not effective, particularly in the cold climates, and, surprisingly, the solar shading was not beneficial. The reason for the poor performance of the solar shading option, as will be discussed in greater detail later in this report, is that while the shading decreased cooling requirements, it also reduced daylighting benefits. This does not mean that another shading strategy might not be effective, only that the strategy used in these simulations did not reduce energy requirements. It did, however, reduce direct solar gain into the atrium and adjacent office spaces, and thereby improved comfort conditions within those spaces. A more energy effective shading strategy would have been to shade only enough to minimize energy requirements for lighting and cooling, a significantly more complicated strategy to implement, although certainly possible.

The effectiveness of the heat storage strategy can be traced to its ability to reduce cooling and heating energy requirements on swing days. That is, days when solar heating leads to cooling loads during the daylight hours, but low outdoor air temperatures at night cause heating loads. Instead of cooling on a sunny afternoon, excess heat is stored and reclaimed when needed to heat the atrium at night.

The following sections describe in greater detail the results for each geographic location. Included are the individual heating, cooling and lighting energies, and peak heating and cooling loads. 


\subsection{LOS ANGELES}

Figure 10a shows total energy ratio for the linear atrium building as a function of glazing area ratio and transmittance. The 0.8 transmittance is most effective, although not very different from the 0.5 transmittance. All glazing transmittances provided energy reductions of nearly 20 percent or better.

The heating cooling and lighting energy breakdowns are shown in figure $10 \mathrm{~b}$, which indicates that most of the energy savings are due to reduced lighting energy requirements. Cooling energy remains fairly constant, except for the high transmittance glazing, which shows much higher cooling requirements for large glazing areas. Heating energy doubles for the low transmittance, large glazing area. However, heating loads are negligible for Los Angeles, so this effect is inconsequential.

Figure 10c displays peak heating and cooling loads. Peak cooling loads steadily increase with glazing area and transmittance, and are 15 percent greater for the high transmittance, large glazing area than for no fenestration. Thus, the energy reductions shown in the previous figures can only be achieved at the expense of larger peak cooling loads, indicating that a compromise must be reached in selecting the best glazing area. Higher peak loads mean more HVAC capacity and higher demand charges. Peak cooling loads are only 10 percent higher, or less, at the glazing area ratio of 0.6 .

Figure 10d shows the variation in energy usage for the large glazing area with various transmittances versus the base case (no fenestration). Cooling energy increases, and lighting energy decreases, for higher glazing transmittances, with total energy exhibiting a minimum for a transmittance of 0.5 . Solar shading, heat storage and single pane glazing are compared in figure $10 \mathrm{e}$. In this figure, it can be seen that solar shading reduces cooling energy at the expense of increasing lighting energy, compared to the non-shading case. Heat storage reduces cooling energy without affecting lighting energy, to provide the least total energy usage.

Figures 11a through e present the same results for the square atrium, which are very similar to the linear atrium results. The percent increase in peak cooling loads is less, because the baseline peak cooling load is greater for the larger square atrium building.

\subsection{LAKE CHARLES}

Figure 12 a shows the variation in total energy ratio with glazing area and transmittance for the linear atrium building. Maximum energy reductions of nearly 20 percent are apparent, with the best performance for the 0.8 and 0.5 glazing transmittances. The heating, cooling and lighting energy breakdowns are displayed in figure $12 \mathrm{~b}$, where the energy reductions are seen to be due to lower lighting energy requirements. Cooling loads remain fairly constant, except for the large glazing area with high transmittance. Heating energy 
requirements increase with glazing area, particularly for the low transmittance, however, heating energy usage remains small in relation to cooling energy at this location.

In figure 12c, peak cooling loads increase gradually with glazing area, being nearly 20 percent above the base case for the large glazing area with high transmittance. Again, a compromise must be struck between energy usage and peak loads. Peak heating load is unaffected by glazing parameters, for the configurations studied.

Figures $12 d$ and e reflect the same trends as for Los Angeles, except heating energy is no longer negligible, albeit still relatively small. The double pane with heat storage gives the best performance by a small margin.

Figures $13 a$ through $e$ indicate similar results for the square atrium building, although peak cooling loads increase by less than 10 percent at their maximum. The double pane with and without heat storage gives the best performances, with a glazing area ratio of 0.5 to 0.8 .

\subsection{EL PASO}

El Paso climate produces cooling energy requirements over three times greater than heating energy. In figure 14a, reductions in total energy usage of 15 percent were possible for the high transmittance glazing for all three glazing areas. All of the savings were due to lighting energy reductions from daylighting. Heating and cooling energies increased by 12 to 25 percent for the largest glazing area, while lighting decreased to 60 percent, as shown in figure 14b. Peak cooling loads were 20 percent higher for the large area, high transmittance case, as indicated in figure 14c. Peak heating loads increased only slightly.

The usual tradeoffs between lighting and cooling energy usage are apparent in figure 14d, with the 0.5 transmittance using slightly less total energy than the other transmittances for the large glazing area. Figure $14 \mathrm{e}$ displays the results for the special atrium features, where the heat storage option is seen to require the least energy usage by a small margin.

Similar results for the square atrium building can be found in figures $15 a$ through $15 e$, although slight reductions in cooling energy occurred at the smaller glazing areas, and peak cooling loads increased less than 10 percent at maximum. 


\subsection{NASHVILLE}

As can be seen in figures 16 a through $16 \mathrm{e}$ for the linear atrium and $17 \mathrm{a}$ through $17 \mathrm{e}$ for the square atrium the results for Nashville are similar to those for the previous cities. Nashville's climate, however, produces heating energy requirements slightly greater than cooling energy usage, a distinct departure from the earlier cities. Maximum energy savings of about 13 percent are seen at the 0.6 glazing area with high transmittance. Peak cooling loads increase as much as 20 percent for the linear atrium and 10 percent for the square atrium.

\subsection{SEATTLE}

Figures $18 \mathrm{a}$ through $18 \mathrm{e}$ and $19 \mathrm{a}$ through $19 \mathrm{e}$ display the results for Seattle for the linear and square atrium, respectively. Heating energy is two and one-half times cooling energy for the base building. Maximum energy reductions were about 12 percent, with nearly equal performance for all glazing areas. Some cooling energy reductions were observed through the use of small fenestration areas, exceeding five percent for the square atrium. Heating energy usage increased measurably with addition of glazing, but heat storage was effective.

\subsection{NEW YORK}

The New York results are presented in figures $20 \mathrm{a}$ through $20 \mathrm{e}$ for the linear atrium and $21 \mathrm{a}$ through $e$ for the square atrium. Heating energy requirements were three times cooling energy usage for the base building. Maximum reductions in total energy usage of ten percent were observed, with little variation with glazing area. The 0.8 transmittance performed slightly better than the 0.5 transmittance. Heating energy increased significantly for the large glazing areas, as did cooling energy for the high transmittance., Peak cooling loads increased significantly only for the high transmittance, large glazing area. Heat storage was effective, but only slightly better than the standard configuration (Run 1). Some cooling energy reductions were seen for the square atrium building.

\subsection{OMAHA}

Figures 22a through $22 \mathrm{e}$ and $23 \mathrm{a}$ through $23 \mathrm{e}$ present the results for Omaha for the linear and square atrium, respectively. Heating energy usage for the baseline building was four times the cooling energy requirements. Maximum reductions in total energy usage of eight percent were observed, with little variation with glazing area. The low transmittance glazing was not effective, due to higher heating energy usage, and relatively moderate lighting energy reductions. Peak cooling increased significantly for the high transmittance, large glazing area. Heat storage was slightly more effective than the standard configuration (Run 1). 


\subsection{MADISON}

The Madison results are presented in figures $24 \mathrm{a}$ through $24 \mathrm{e}$ for the linear atrium, and $25 \mathrm{a}$ through $25 \mathrm{e}$ for the square atrium. Heating energy is six times the cooling energy for the baseline building. Total energy reductions of four percent are seen, with slight variation with glazing area. The low transmittance glazing was not effective at reducing total energy usage. Maximum cooling energy is over 20 percent greater for the high transmittance, large glazing area. Heating energy increased as much as ten percent. Peak heating loads remained fairly constant, but peak cooling loads increased significantly for the high glazing transmittance. Heat storage was slightly more effective than the standard configuration (Run 1). The single pane glazings were not effective, nor were the low transmittance glazings.

\subsection{GLAZING ABSORPTANCE}

The effect of glazing absorptance was evaluated by varying that parameter from 0.1 to 0.4 for the large and small glazing areas, keeping transmittance to a constant 0.2 . Thus the low transmittance was maintained while varying the ratio of absorptance to reflectance. Figures 26 a through $h$ display the resulting heating, cooling, lighting and total energy requirements for each location. Examination of these figures reveals that atrium glazing absorptance exerted little effect on energy requirements. Glazing temperatures, however, were higher for the high absorptance glass.

\subsection{LIGHTING POWER DENSITY}

In addition to the previously described simulations with a lighting power density of $2 \mathrm{w} / \mathrm{ft}^{2}\left(21.5 \mathrm{w} / \mathrm{m}^{2}\right)$, values of 1 and $3 \mathrm{w} / \mathrm{ft} \mathrm{t}^{2}(10.8$ and $32.3 \mathrm{w} / \mathrm{m}^{2}$ ) were simulated, while holding illumination level constant. This corresponds to varying lighting system luminous efficacy. Simulations were executed for the 30 and 90 percent glazing areas and the 0.8 glazing transmittance, for all geographical locations. The impact of lighting power density on heating, cooling, lighting and total energies, and peak loads, was evaluated.

Figures 27 a through 27 c present the results for Los Angeles. As shown in figure 27 a total energy reductions are greatest for the highest lighting power density, and decrease with decreasing lighting power density. In addition, the slope of the total energy ratio within the glazing area ratio range of 0.3 to 0.9 is clearly negative for the highest lighting power density, nearly flat at the middle lighting power density, and positive for the lowest lighting power density. These effects are due to the relatively greater benefits of daylight for the least efficient lighting system (highest lighting power density). More energy savings are possible through the substitution of daylight for the inefficient electric lighting compared to the most efficient lighting system. The largest glazing area is most effective for the least efficient lighting system, even though some daylight saturation occurs, since small lighting energy reductions and 
associated cooling energy savings have a relatively large effect on total energy usage. Conversely, with the lowest lighting power density the 30 percent glazing area is most effective, since reductions in lighting energy are less important. (The heating, cooling and lighting energy ratios are shown in figure $27 \mathrm{~b}$, and peak heating and cooling loads in figure 27c.) Reductions in lighting energy are similar, although somewhat less for the lowest lighting power density. The heating energy plots indicate reductions for the lowest lighting power density compared to heating energy increases for the highest lighting power density. This trend is, however, reversed for cooling, with large increases for the lowest lighting power density. This is due to the fact that, relatively speaking, the lighting power is not as great a contributor to the cooling load, so that higher solar gains with larger glazing areas had a greater effect. Regarding peak loads, peak heating load was unaffected by lighting power density, while peak cooling loads ratios varied inversely with lighting power density.

Results were generally similar for other locations. For example, Figures 29a through 29 c are for El Paso. Total energy ratios are least for the highest lighting power density. Lighting and heating energies are not strongly affected by lighting power density, however, cooling energy ratio is noticeably higher for the lowest lighting power density. Peak cooling loads ratios vary inversely with lighting power density, while peak heating loads are unaffected. Figures 28a through $28 c, 30 a$ through $30 c, 31 a$ through $31 c, 32 a$ through $31 c, 33 a$ through $33 \mathrm{c}$, and $34 \mathrm{a}$ through $34 \mathrm{c}$ present similar results for Lake Charles, Nashville, Seattle, New York, Omaha and Madison, respectively. The effect of lighting power density on the slopes and magnitude of the various energy ratio plots is not strongly affected by geographical location. 


\section{CONCLUSIONS}

Several general conclusions can be drawn from the detailed simulation results. These conclusions are strictly applicable only to atrium buildings which are similar to the simulated buildings.

- The utilization of daylight produced most of the energy savings, due to reductions in lighting energy to as little as 60 percent of full lighting energy. The magnitude of the lighting energy savings did not vary significantly with geographical location.

- The highest glazing transmittance usually yielded the maximum reductions in total energy usage, due to the large decreases in lighting energy requirements. However, the high glazing transmittance also produced higher cooling energies and peak cooling loads, especially for large glazing areas.

- Total energy requirements were not particularly sensitive to glazing area, within the range of 30 to 90 percent of atrium roof surface. This indicates that lighting energy reductions were approximately offset by heating and cooling energy increases with increasing glazing area.

- Slight reductions in cooling energy requirements were observed for the 30 and 60 percent glazing areas, particularly for the cooler climates.

- Peak heating loads did not vary significantly with fenestration design, due to their dependence on other unrelated factors.

- Heat storage during cool, sunny days with cold nights was effective at reducing heating, cooling and total energy requirements, although by a small amount. More sophisticated heat storage procedures have the potential for greater savings.

- The solar shading strategy used for these simulations was not effective at reducing total energy usage, due to reductions in lighting energy savings which offset cooling energy savings. Other shading strategies hold more potential, and should be evaluated. Peak cooling loads were, however, reduced considerably.

- Single-pane glazing was found to be more effective than double-pane for Los Angeles only. 
- The magnitude of the total energy reduction ratio varied inversely with the ratio of heating to cooling energy requirements. Thus, the largest percentage energy reductions occurred for Los Angeles (20 percent) and the smallest for Madison ( 4 percent). However, total energy usage for Madison was nearly two and one half times that for Los Angeles, so the differences in the absolute values of the energy savings are not as great. The smaller percent total energy savings at the colder locations can be attributed to larger increases in heating energy requirements.

- Since total energy usage remained fairly constant for glazing area ratios of 30 to 90 percent, but peak cooling loads were greatest for the 90 percent area, the 30 or 60 percent glazing areas may be the best choices with high transmittance glazing. The transmittance of 0.5 performed almost as well as the 0.8 transmittance as total energy usage was concerned, but produced lower cooling energy and peak cooling loads at the expense of higher lighting energy requirements. If peak cooling loads or cooling energy usage are limitations, the moderate transmittance may be the appropriate choice. 


\section{REFERENCES}

1.Treado, S., Gillette, G., and Kusuda, T., "Evaluation of the Daylighting and Energy Performance of Windows, Skylights and Clerestories." NBSIR 83-2726, National Bureau of Standards, Gaithersburg, MD, June 1983.

2.Treado, S., Holland, D., and Remmert, W., "Daylighting and Energy Evaluation of Industrial Buildings." NBSIR 85-3241, National Bureau of Standards, Gaithersburg, MD, February 1986.

3.Norford, L., "An Analysis of Energy Use in Office Buildings: The Case of Enerplex." Princeton University, Center for Energy and Environmental Studies, Report No. 158, January 1984.

4.Boggarm, S.V. and Setty, P.E., "Atriums: The HVAC Factor." ASHRAE Journal, July 1983.

5.Schutrum, L.F. and Ozfsik, N., "Solar Heat Gains Through Domed Skylights." ASHRAE Journal, August 1971.

6.Leung, et. al., "Thermally-Induced Ventilation Applications in Atria: A State of the Art Report." Eureka Labs, DoE/SF/1154-T3, October 1981 .

7.Hunn, B.D. and Peterson, J.L., "Use of an Atrium for the Passive Solar Retrofit of an Office Building Design and Installation Experience." Los Alamos National Lab, LA-UR-82-2040.

8.Ueland, M., "Solar Atrium: A Hybrid Solar Heating and Cooling System." DoE/EG/34135-1.

9.Peterson, J. and Hunn, B., "Design of an Atrium for a Passive Solar Retrofit of an Office Building." Los Alamos Laboratory, LA-UR-80-1080.

10.Walton, G., "Thermal Analysis Research Program Reference Manual." NBSIR 83-2655, National Bureau of Standards, Gaithersburg, MD, March 1983.

11. CEL-1 Lighting Computer Program - User's Guide, CR 81.026, Naval Civil Engineering Laboratory, Port Hueneme, CA, September 1981.

12. Treado, S., Francisco, C., and Holland, D., "CEL-1 User's Guide Update." NBSIR 84-2974, National Bureau of Standards, Gaithersburg, MD, November 1984.

13. Cathey, H.M., Campbell, L.E., and Thimijan R., "The Basics of Light Rays," U.S. National Arboretum, U.S. Department of Agriculture, February 1984 . 
14.Cathey, H.M., Campbell, L.E., and Thimijan, R., "Comparative Development of 11 Plants Grown Under Various Fluorescent Lamps and Different Durations of Irradiation." J. Amer. Soc. of Hort. Sci., $103(\mathrm{~b}): 781-791,1978.7$ 
6/5/84 HUGHES JUSTICE COMPLEX

1400 TRENTON, N.J.

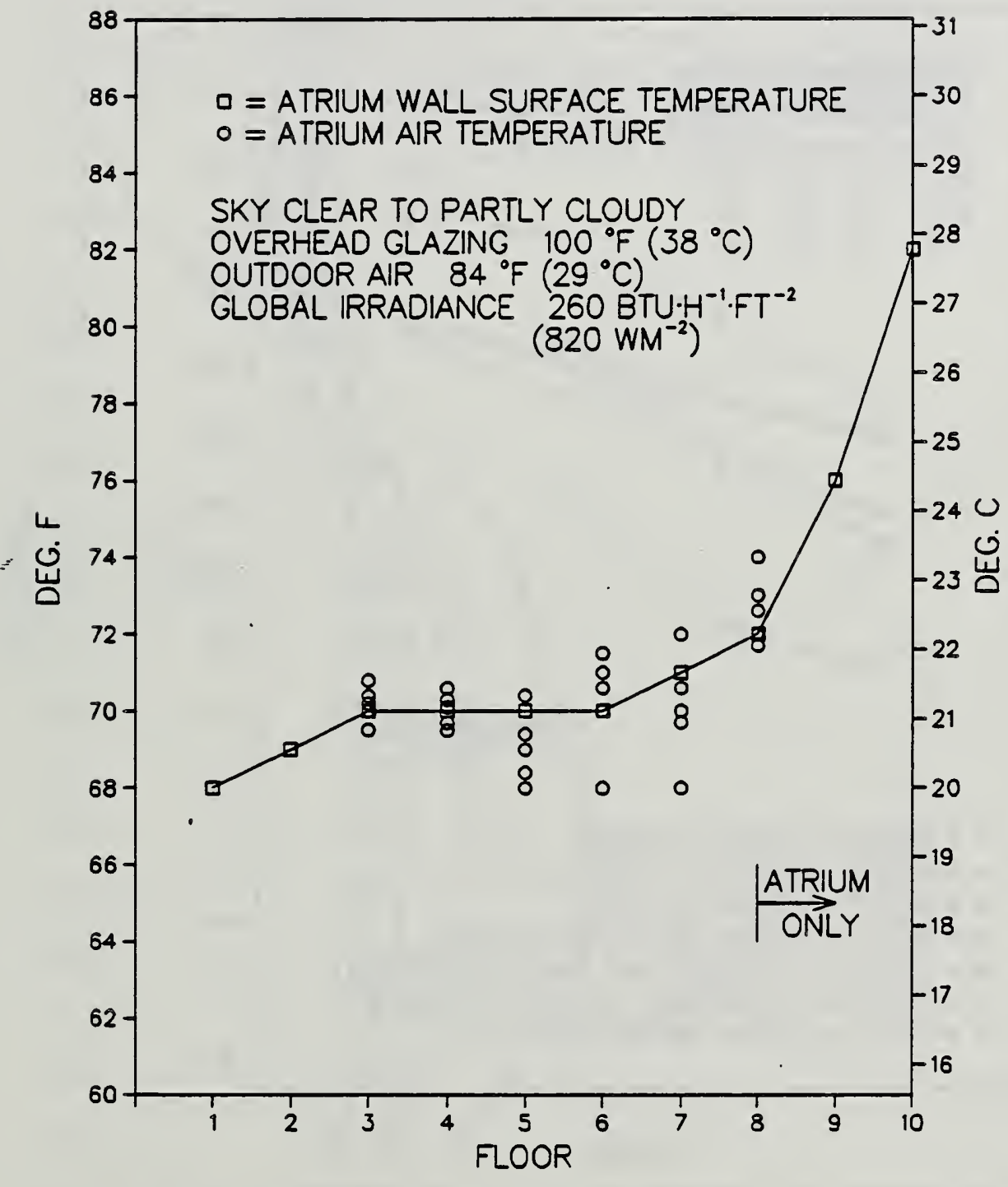

Figure 1. Temperature variations in building A atrium (Hughes Justice Complex) 
ENERPLEX NORTH AND SOUTH

PRINCETON, N.J.

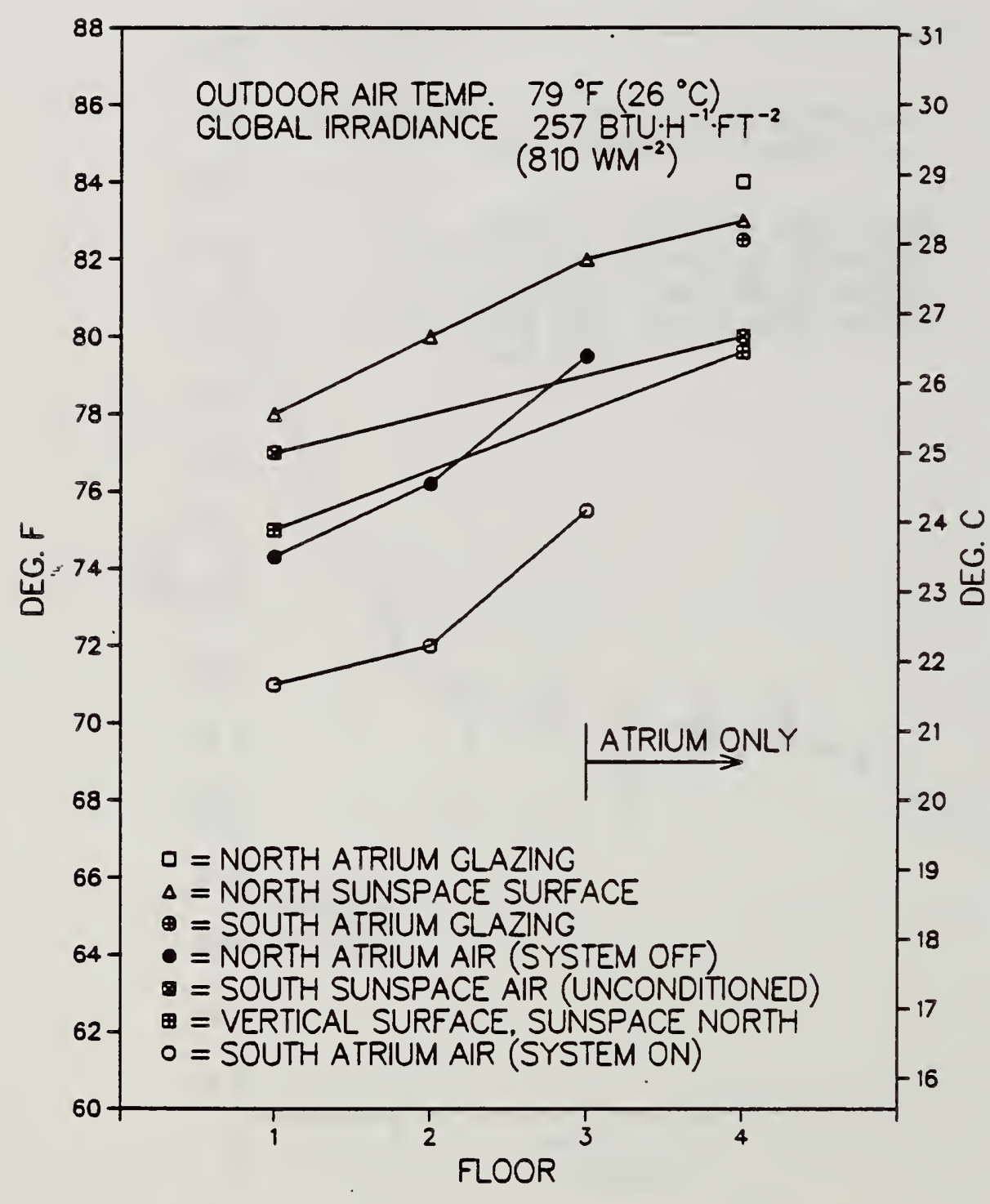

Figure 2. Temperature variations in buildings $\mathrm{B}$ and $\mathrm{C}$ (Enerplex North and South) 


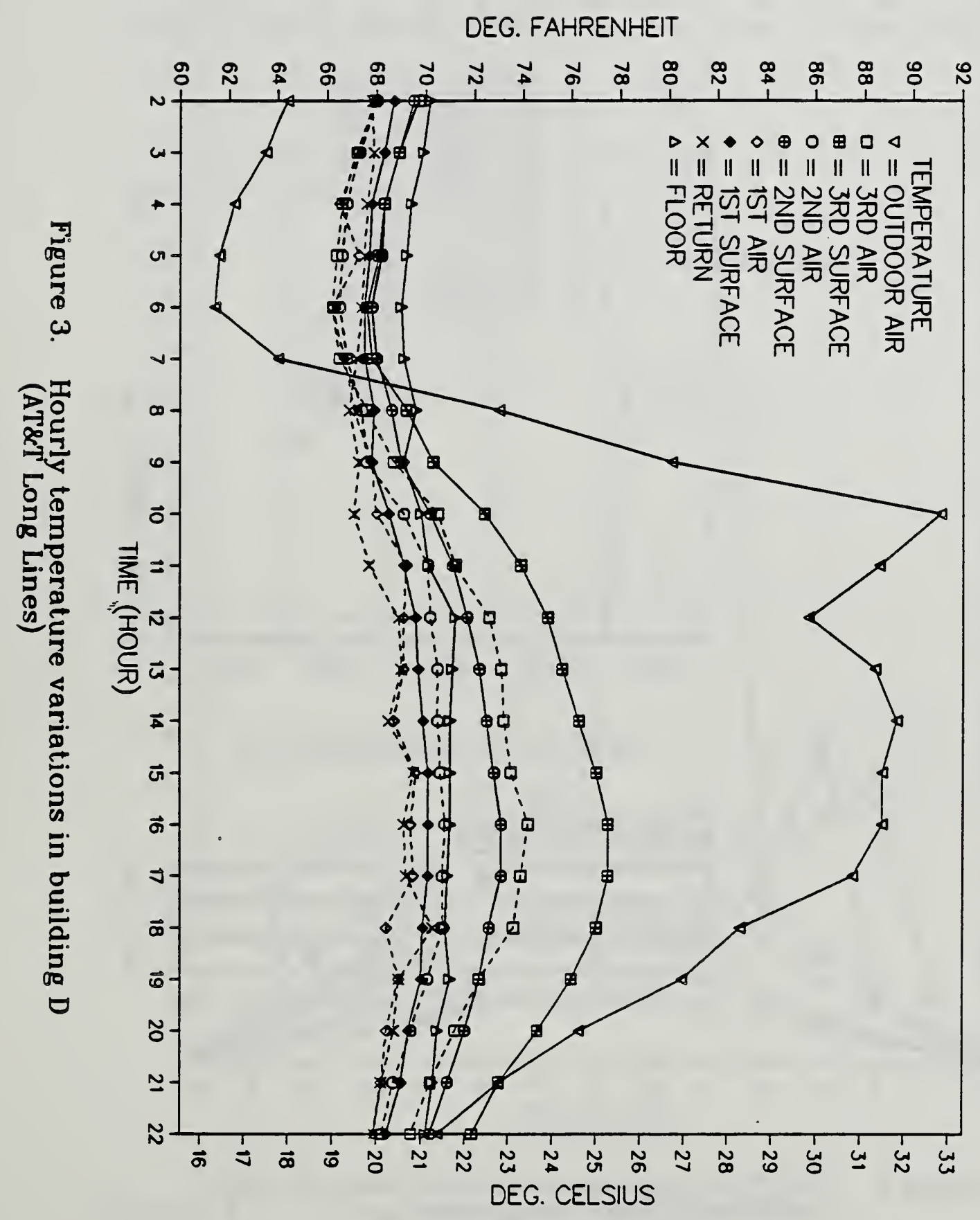




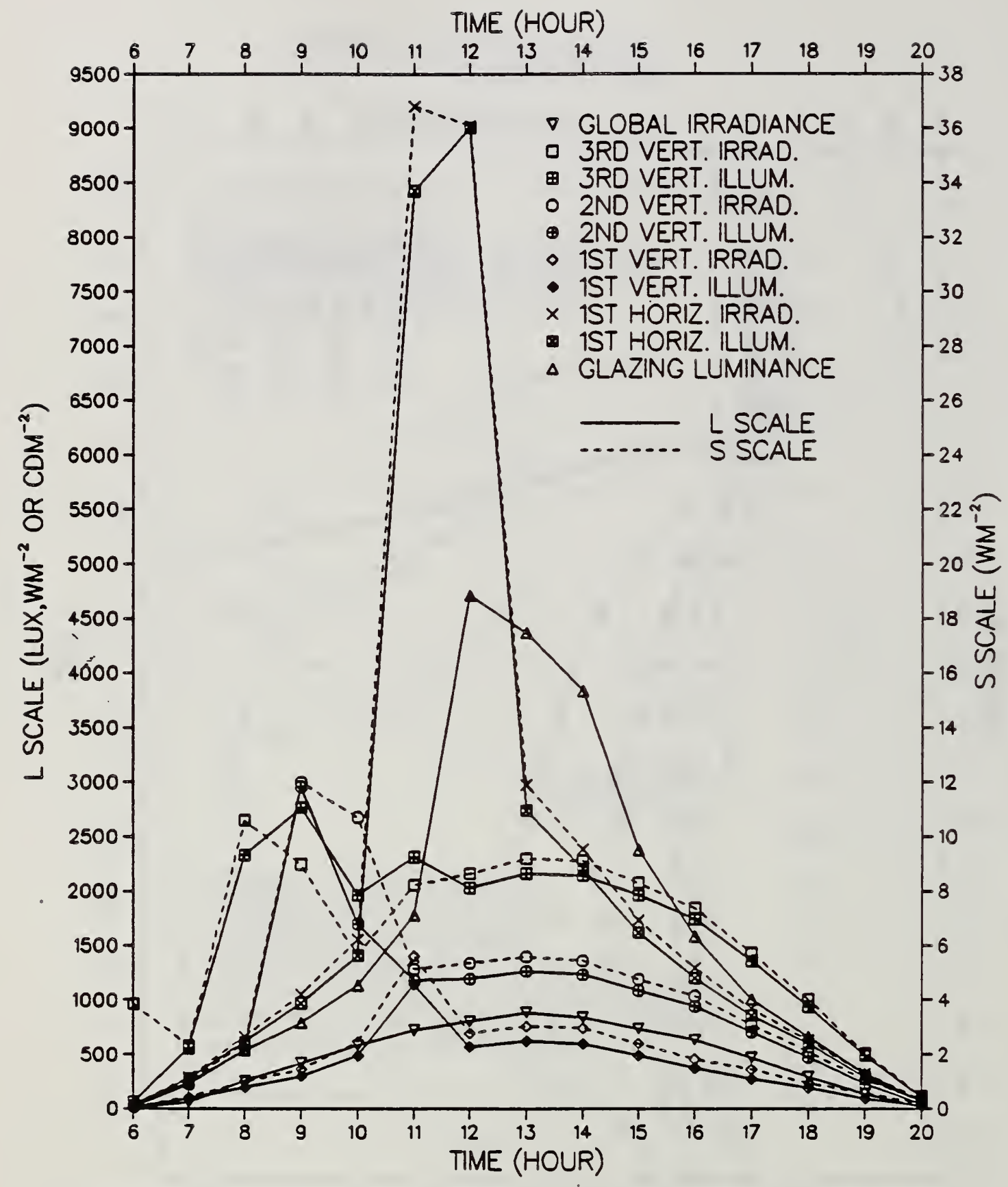

Figure 4. Hourly irradiance and illuminance levels in building D (AT\&T Long Lines) 


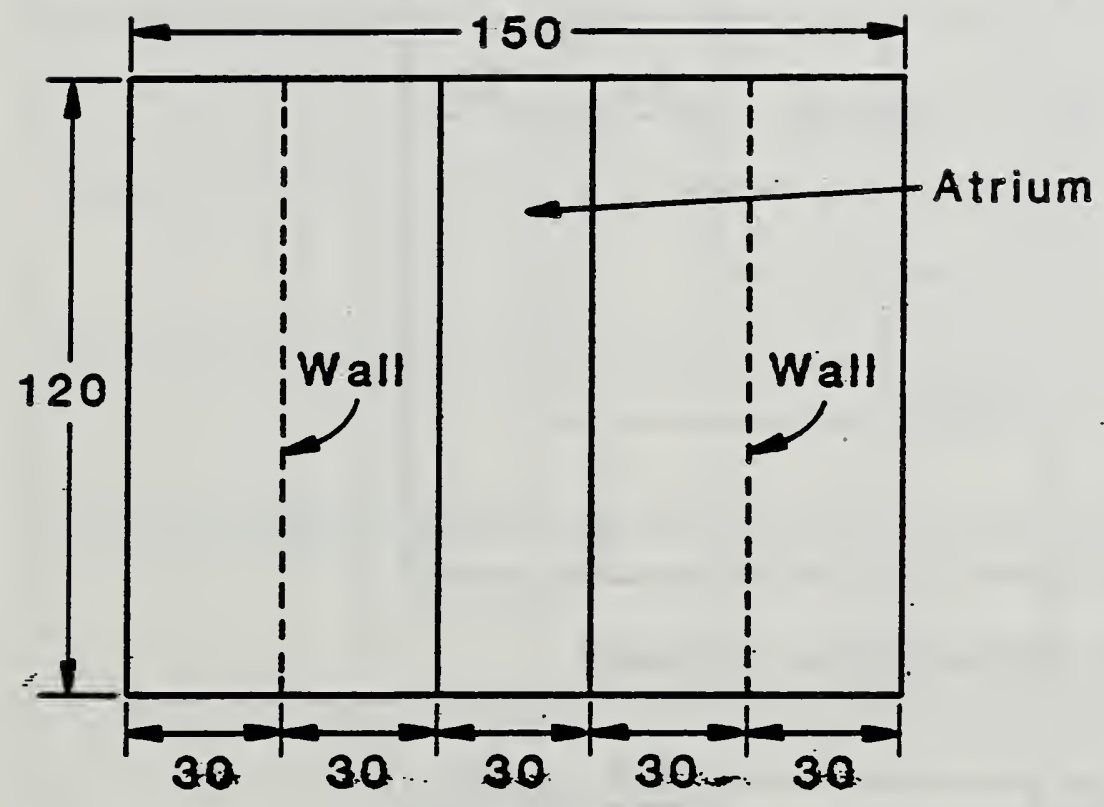

All dimensions in feet

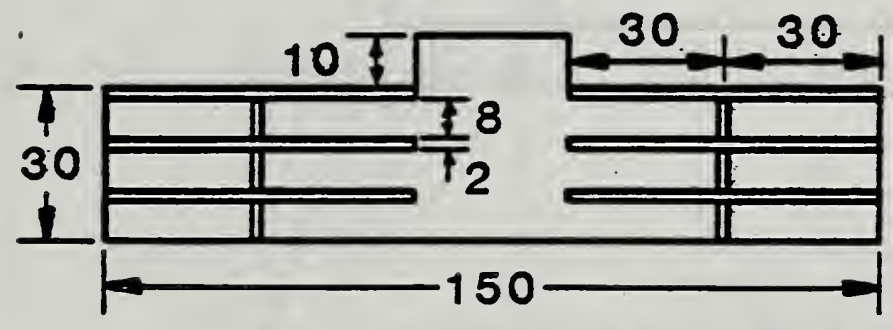

Figure 5. Linear atrium building 


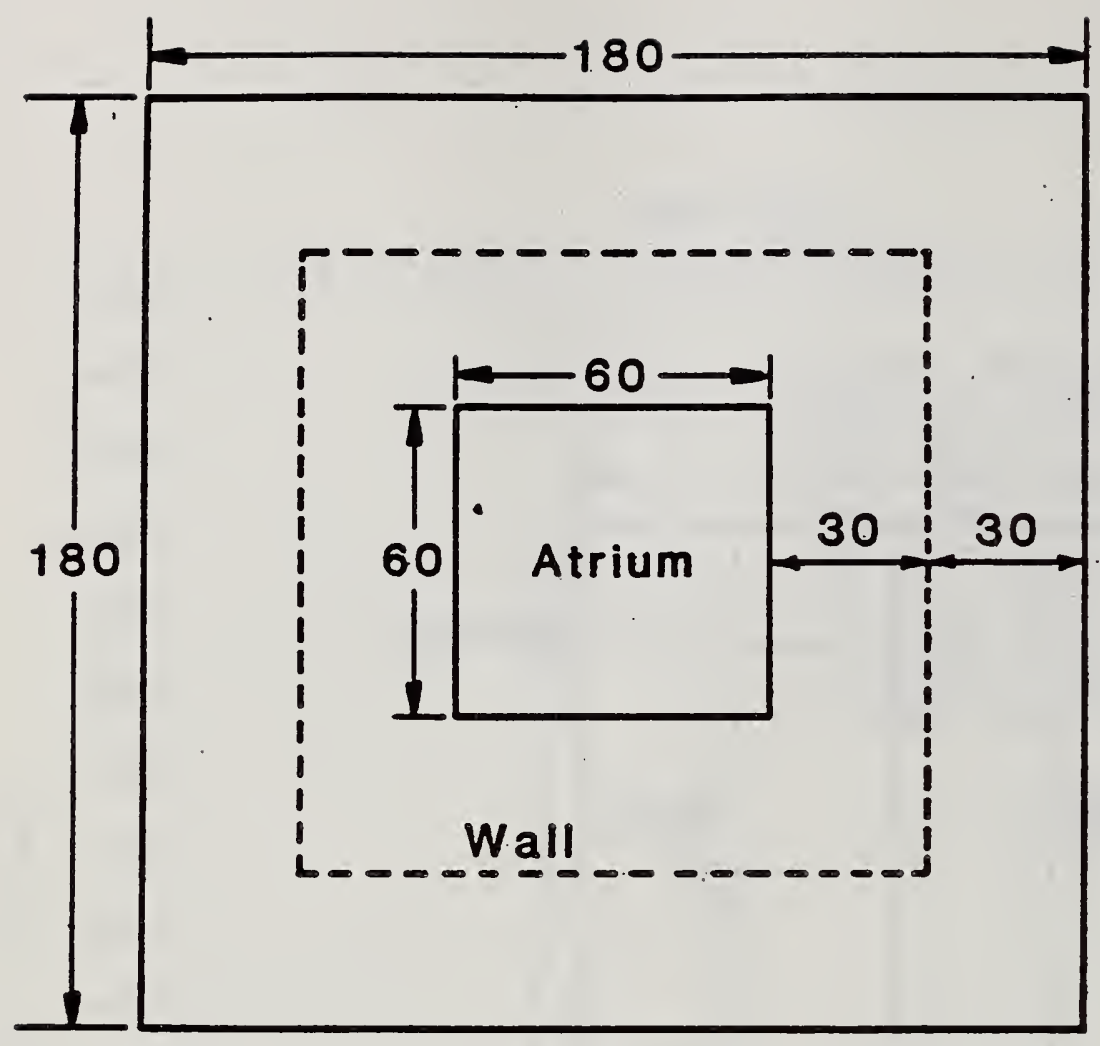

All dimensions in feet

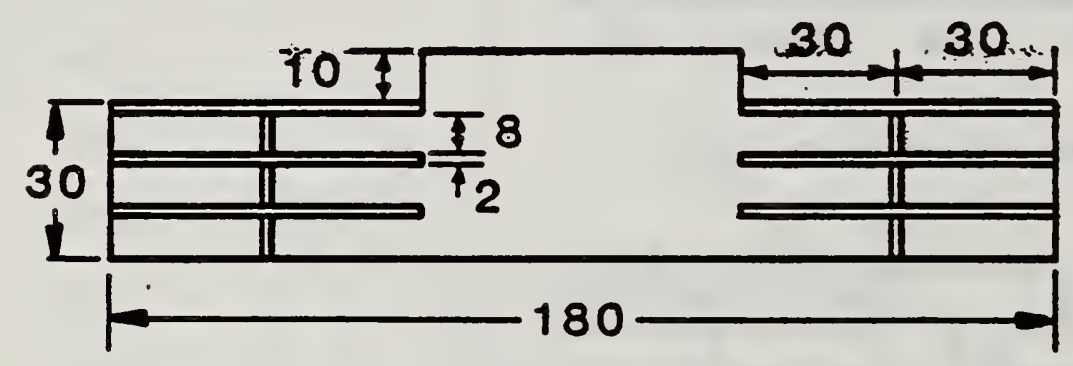

Figure $6 . \quad$ Square atrium building 


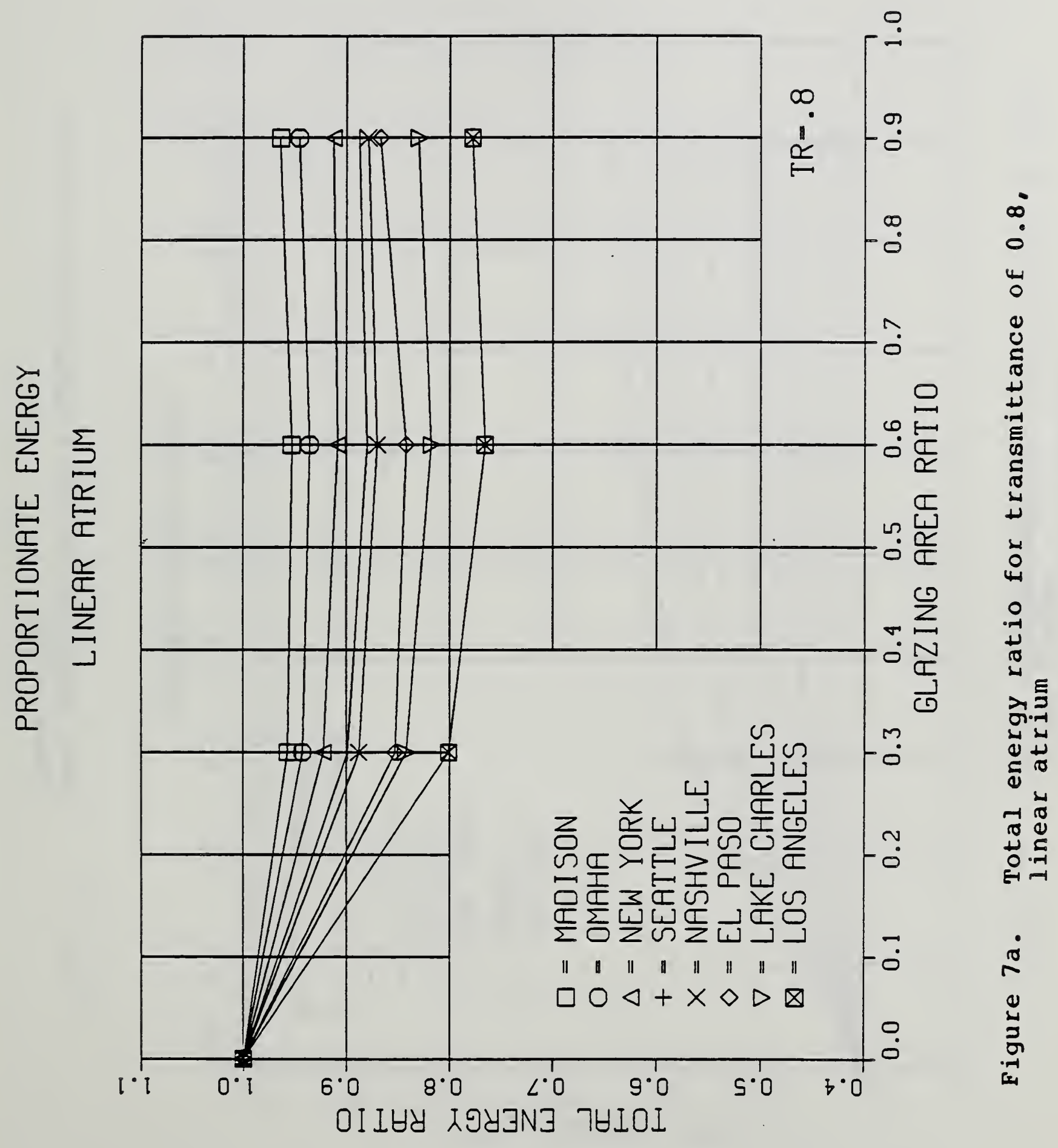




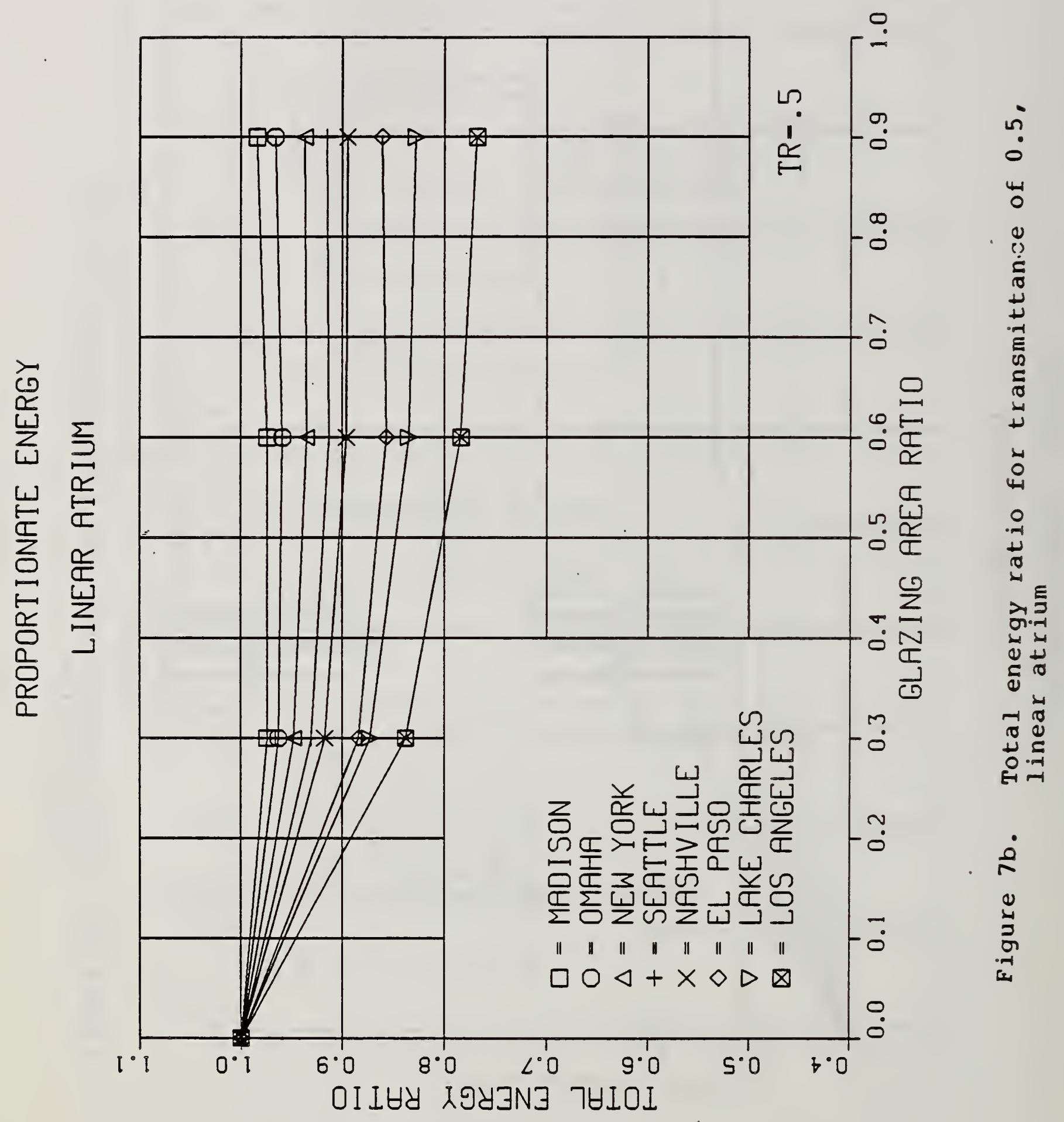




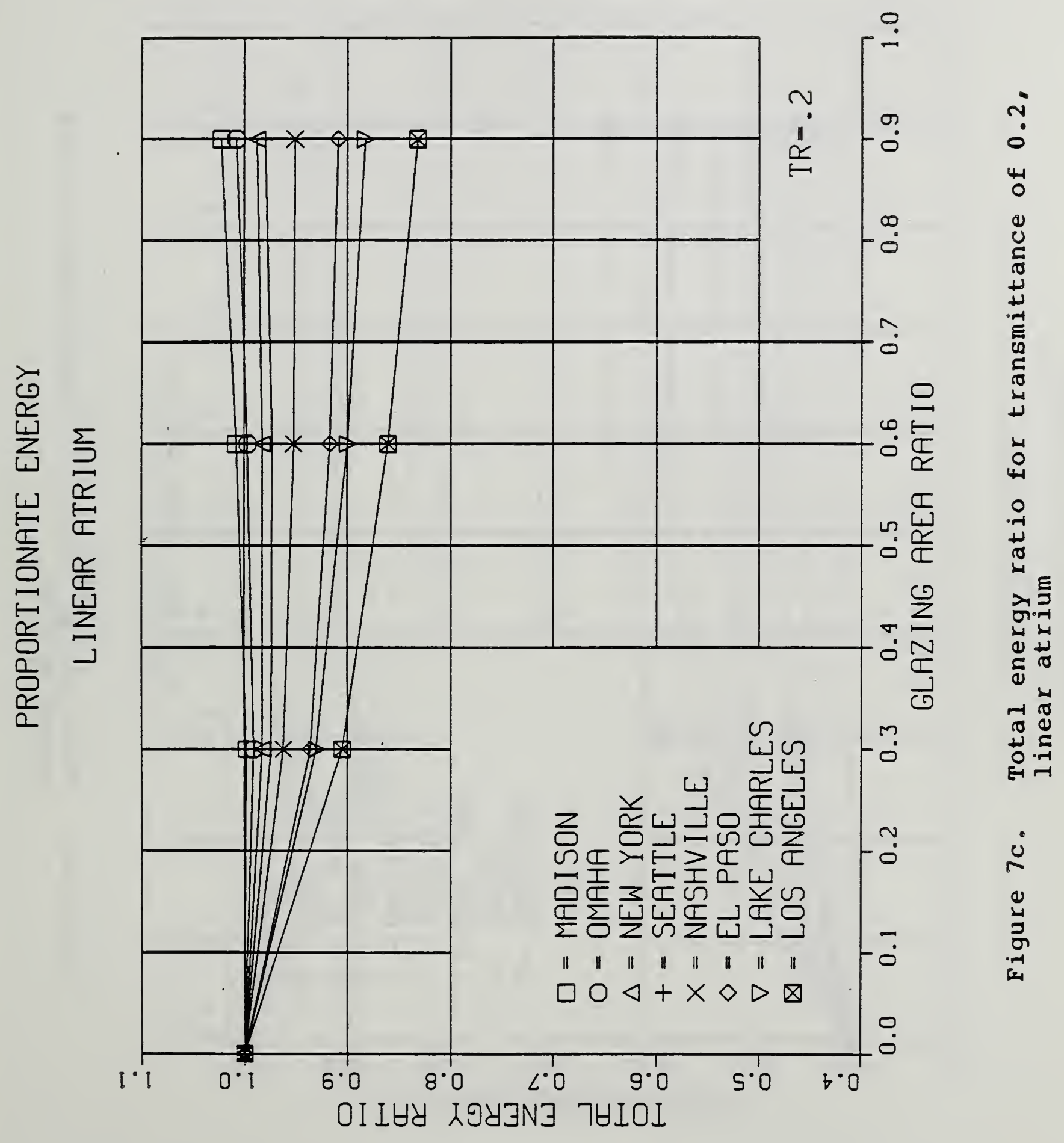




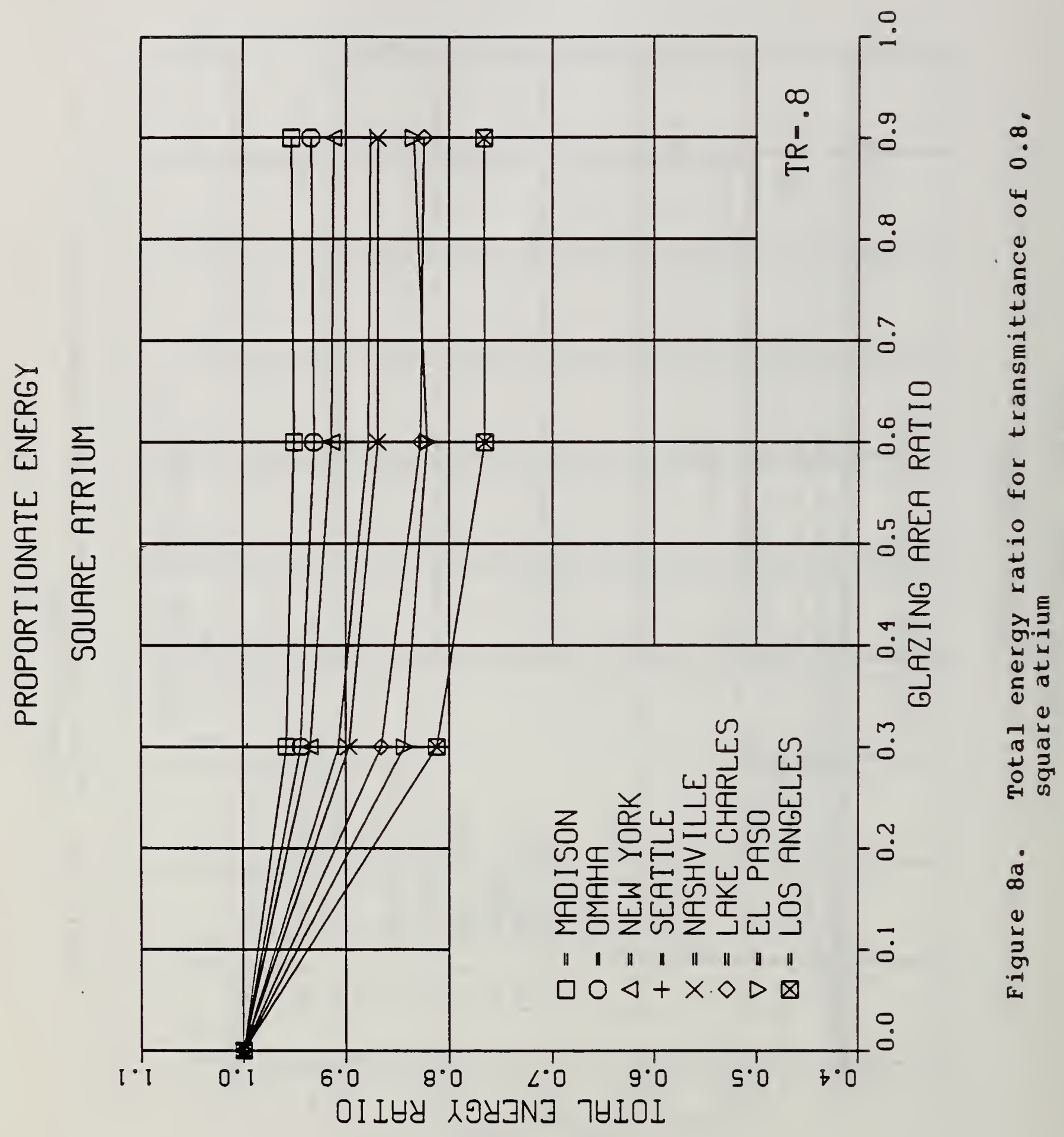




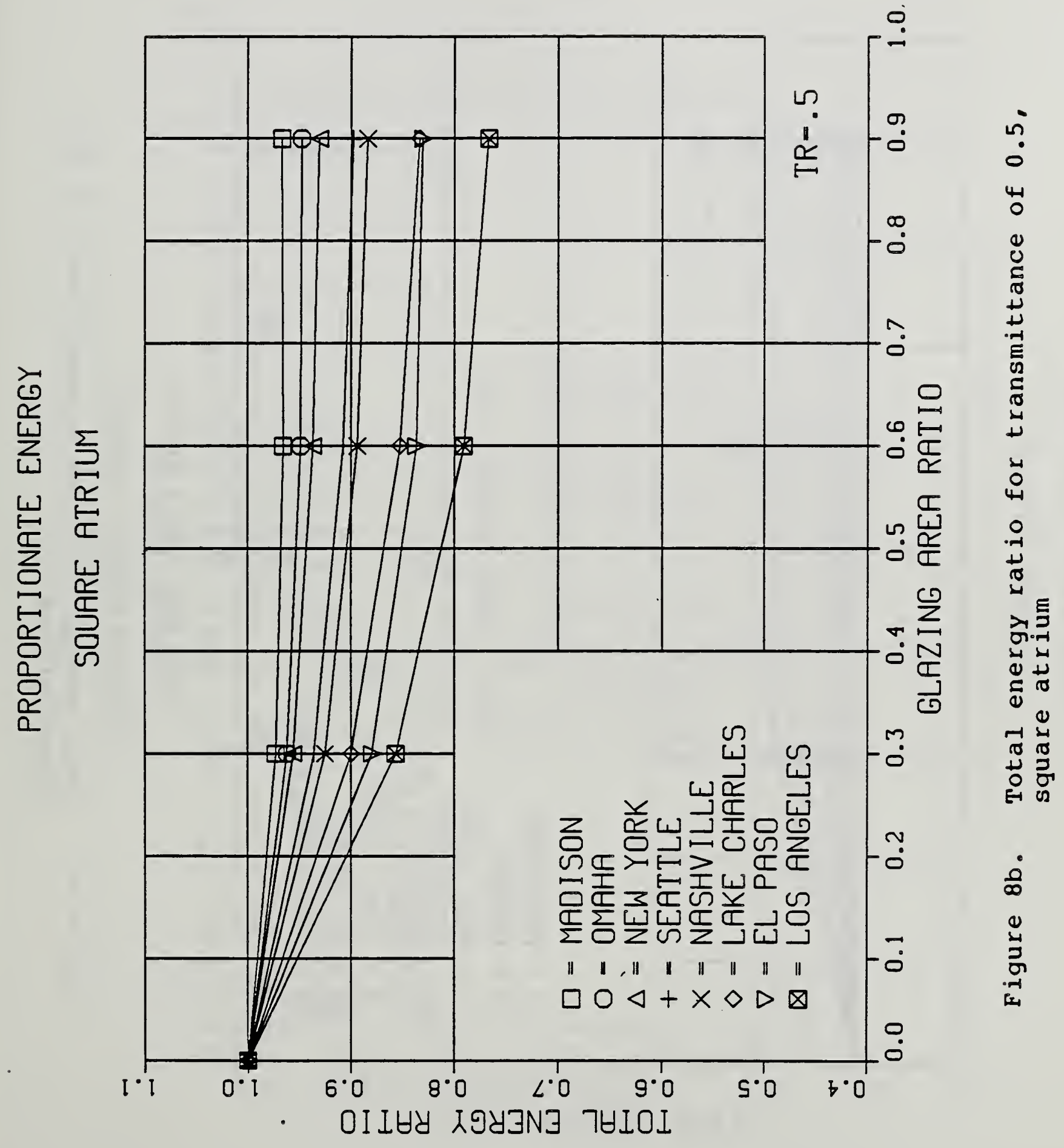




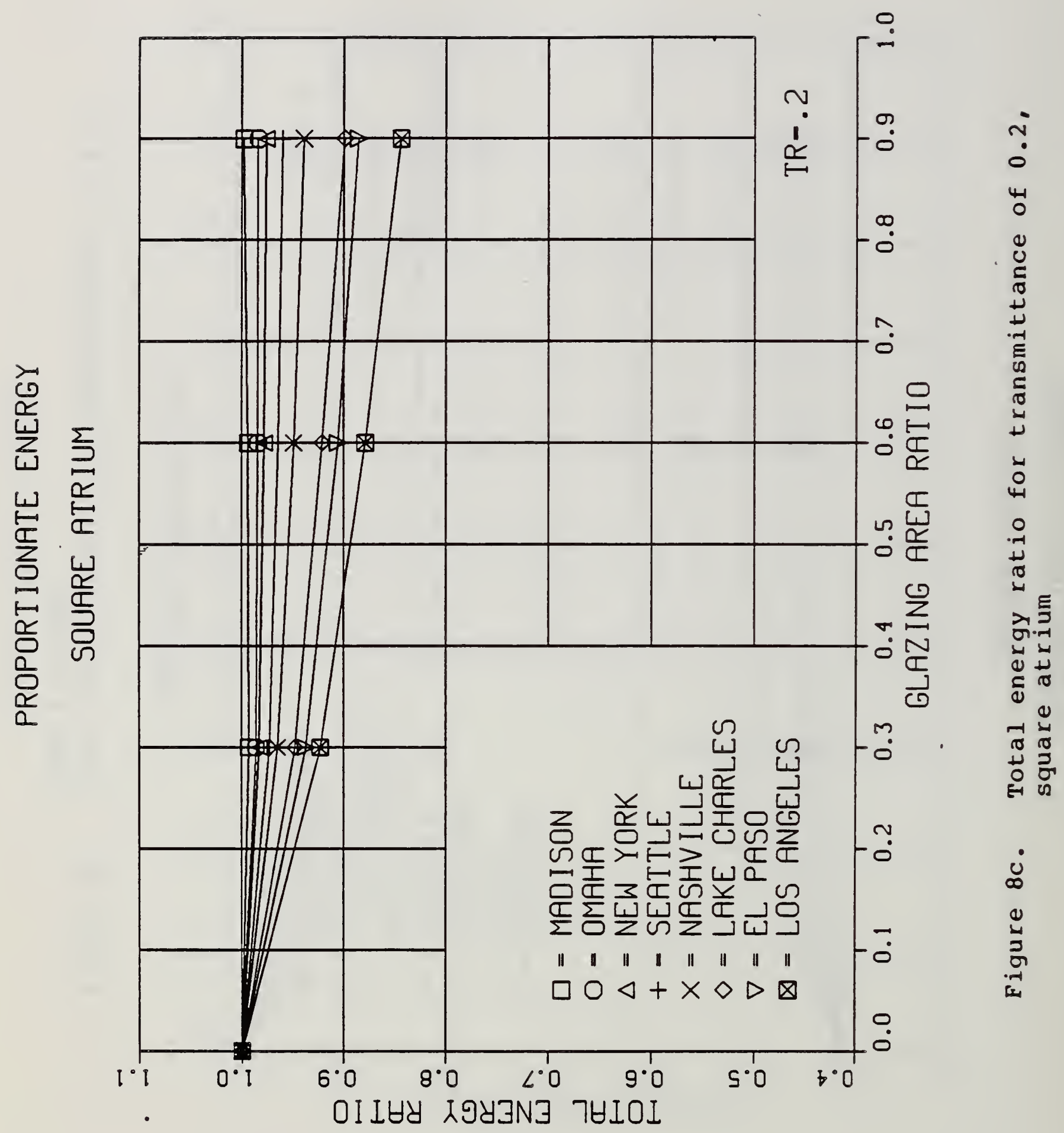




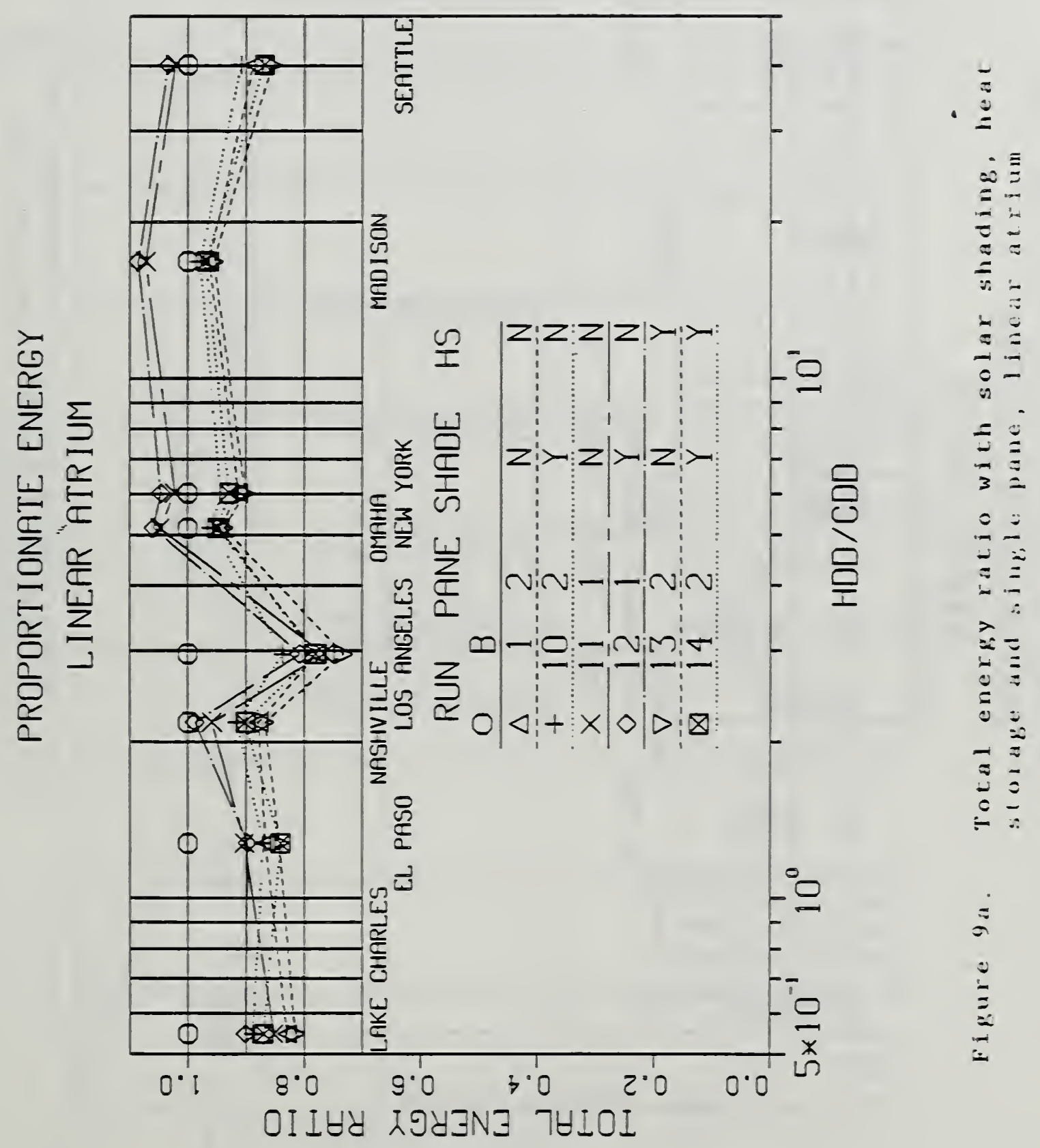




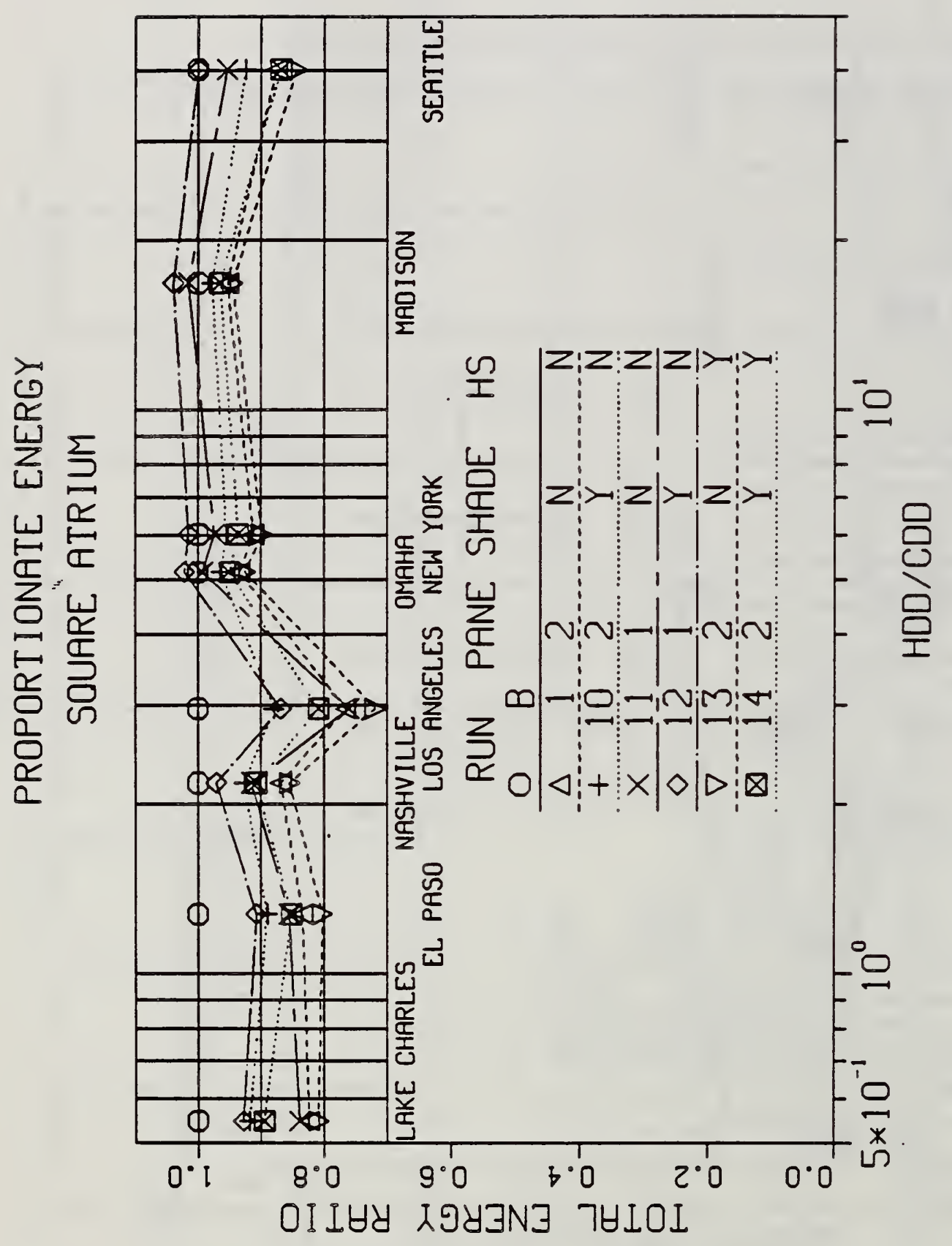

$\stackrel{\square}{ \pm}$

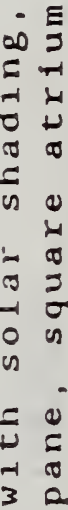

01

$\because 5$

in

ते

-

ข

(1) 1

$\begin{array}{cc} & \infty \\ -1 & 1 \\ 0 & 0 \\ -1 & 0 \\ 0 & 0 \\ = & 0\end{array}$

$\doteqdot$

0
$\vdots$
$=0$
$=1$ 


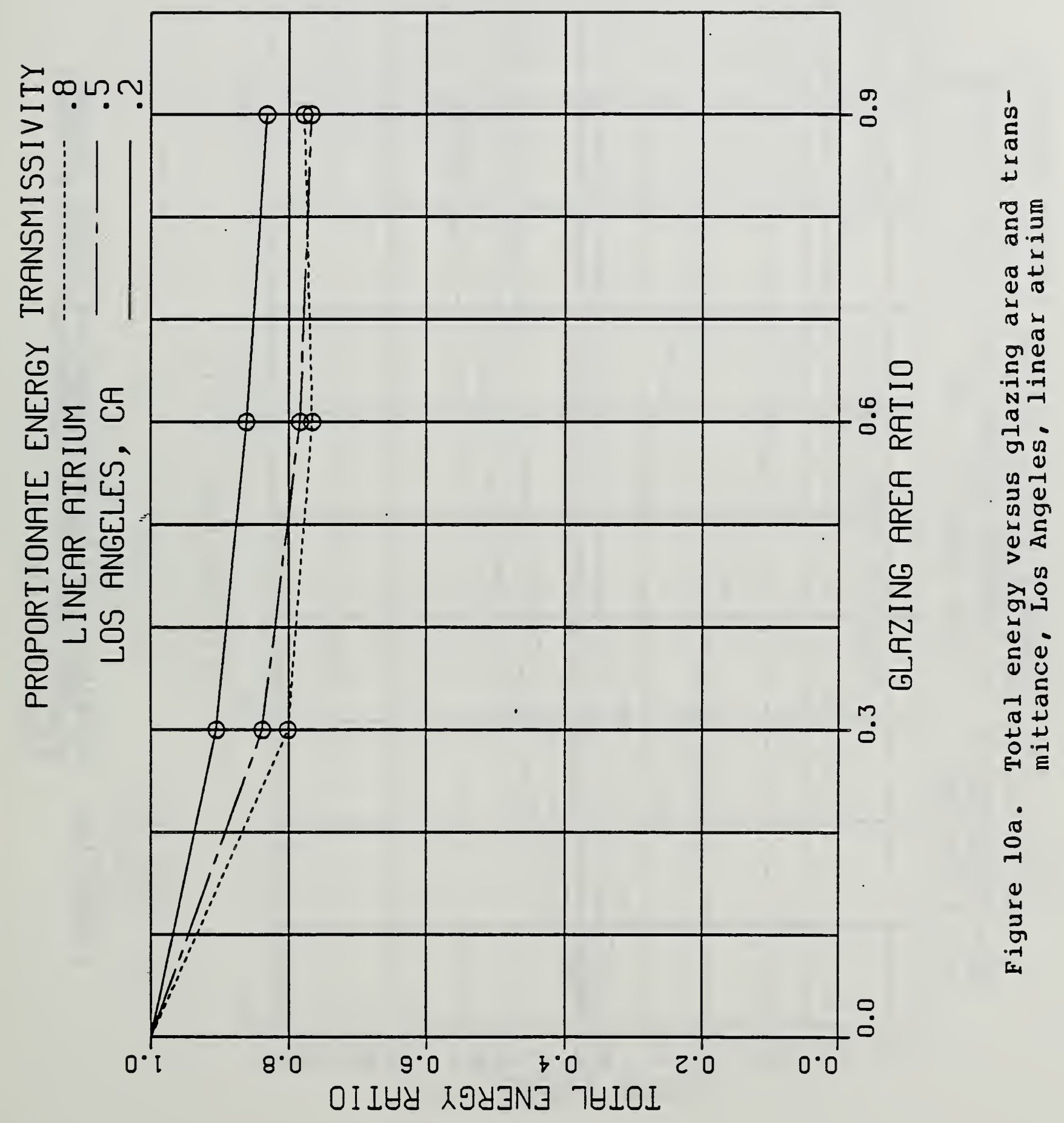




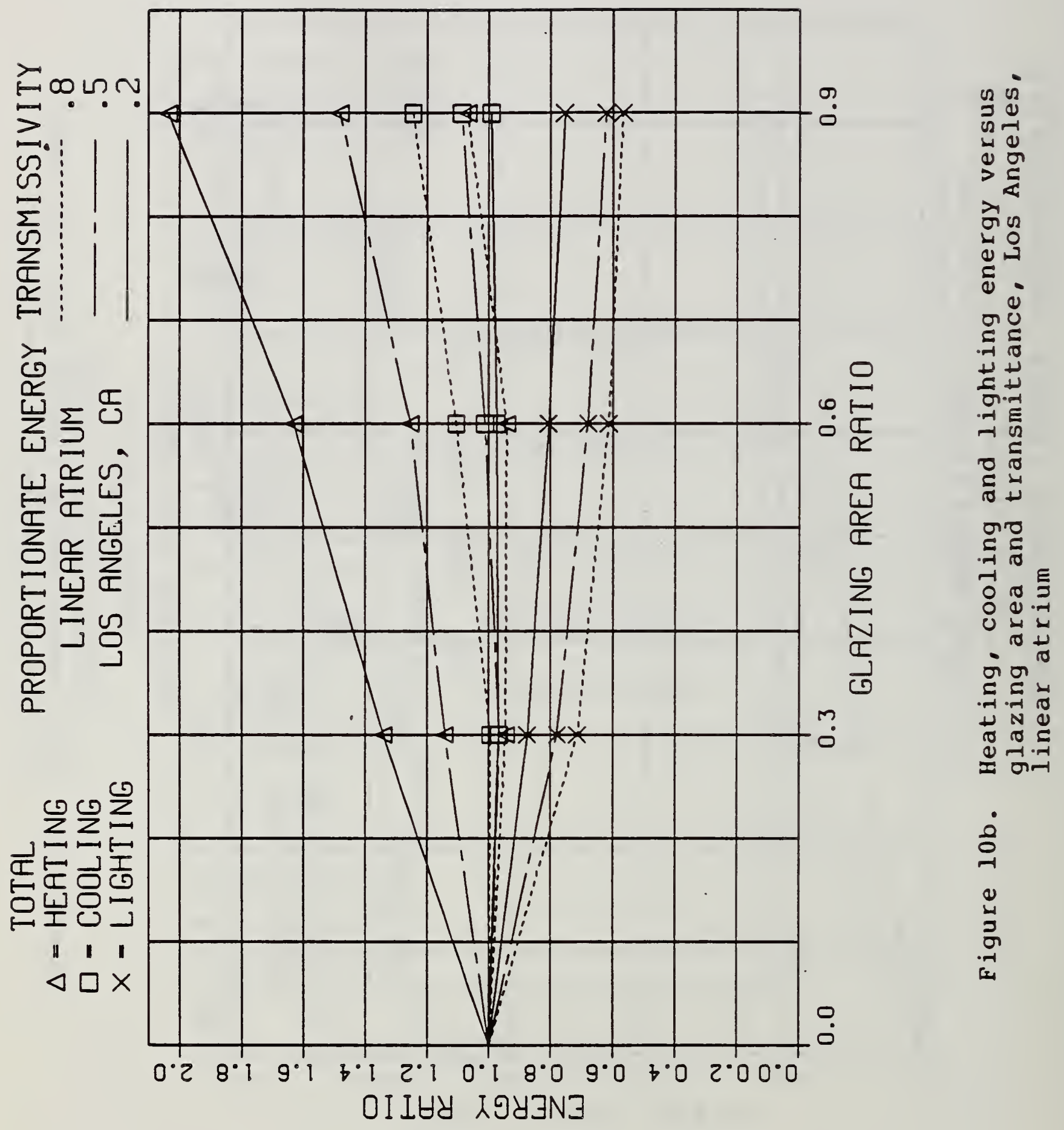




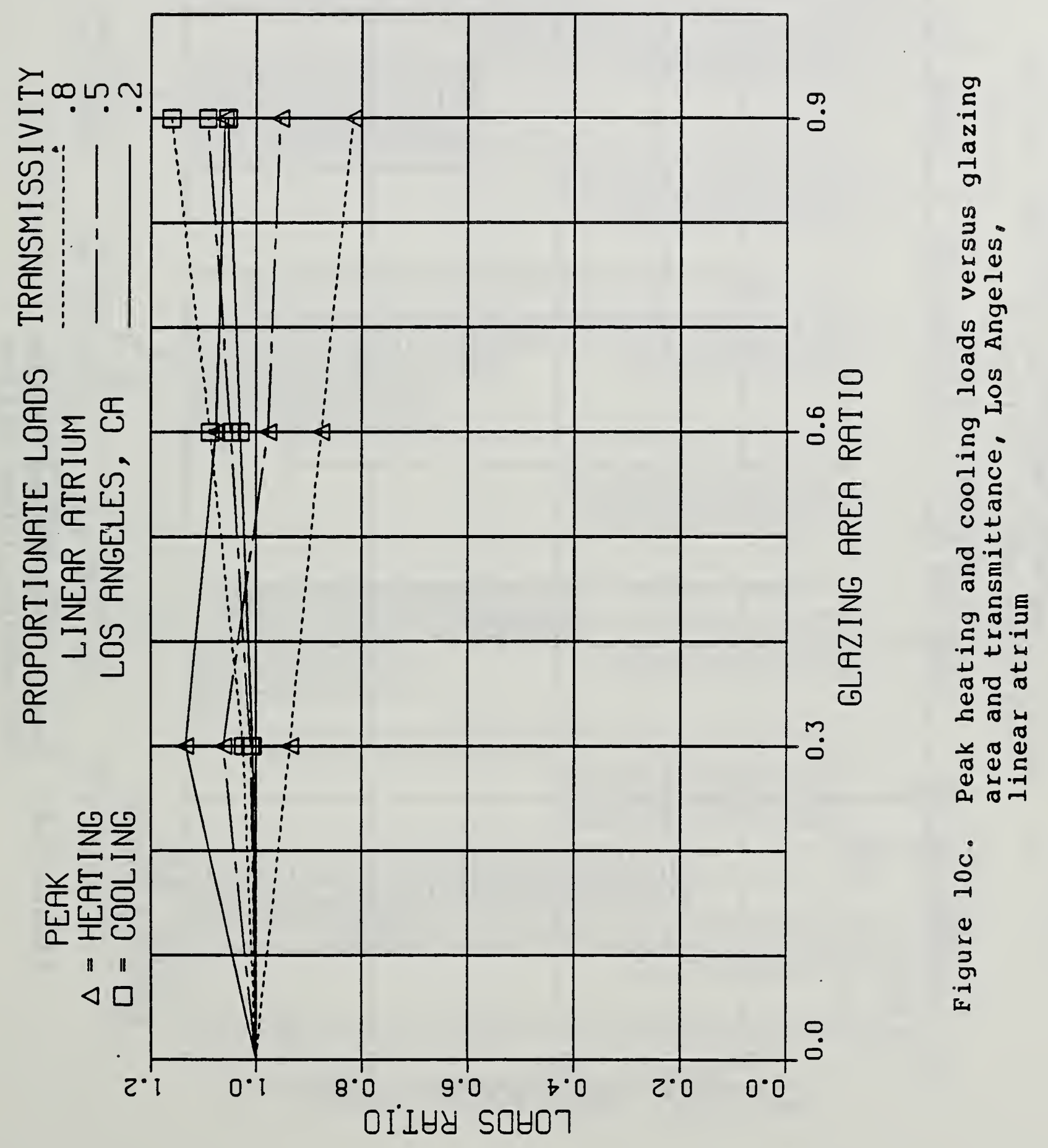




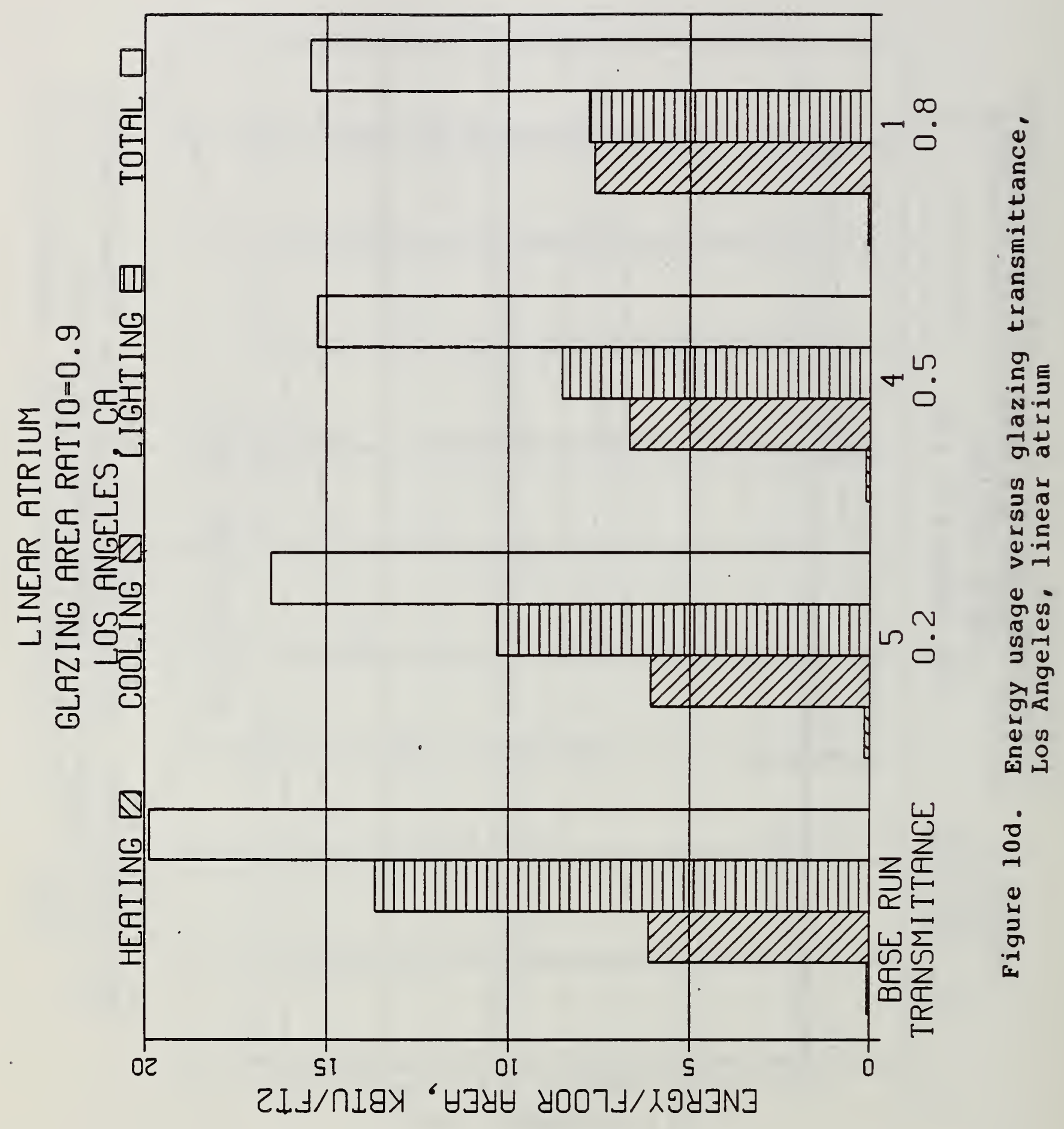




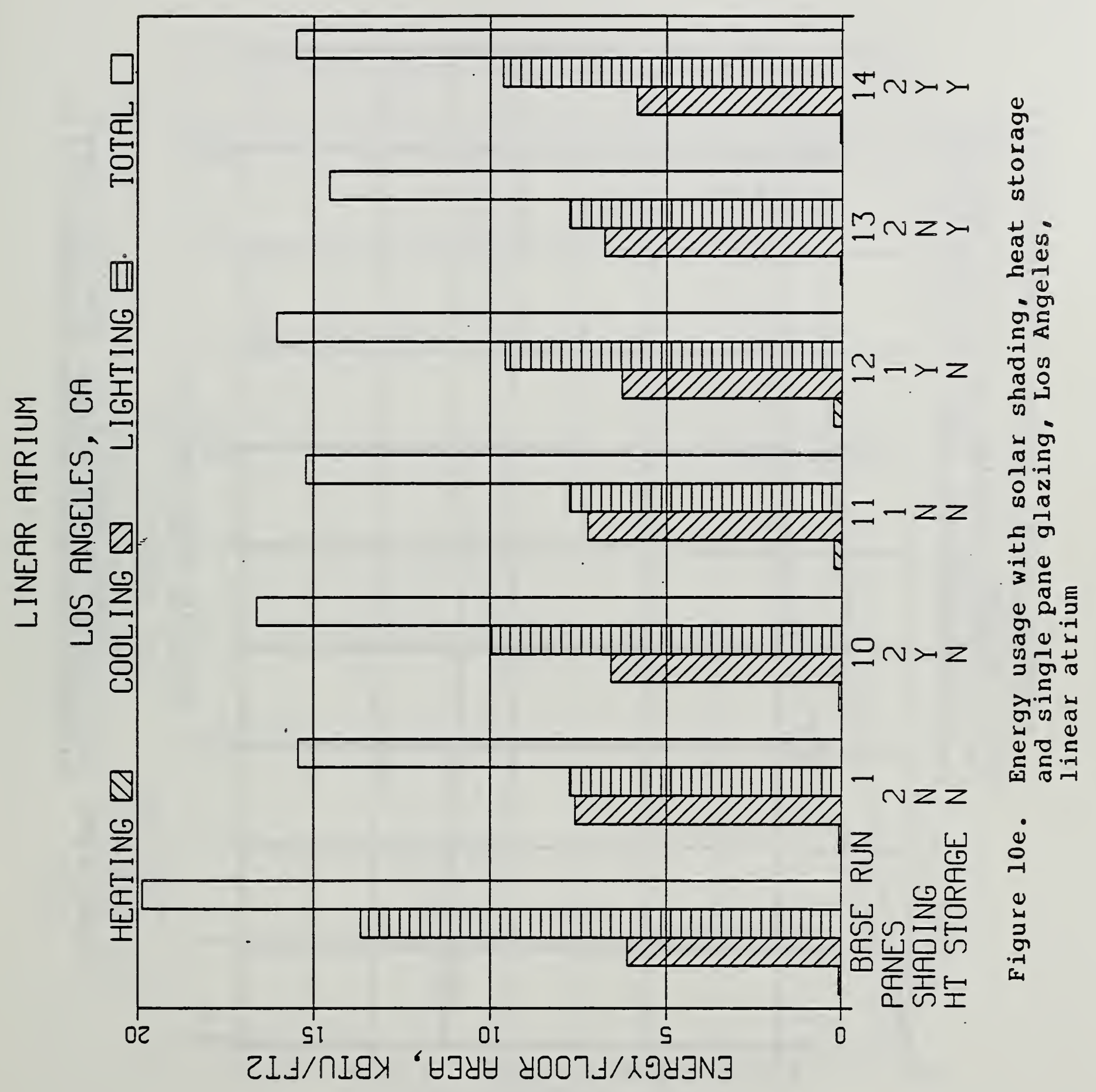




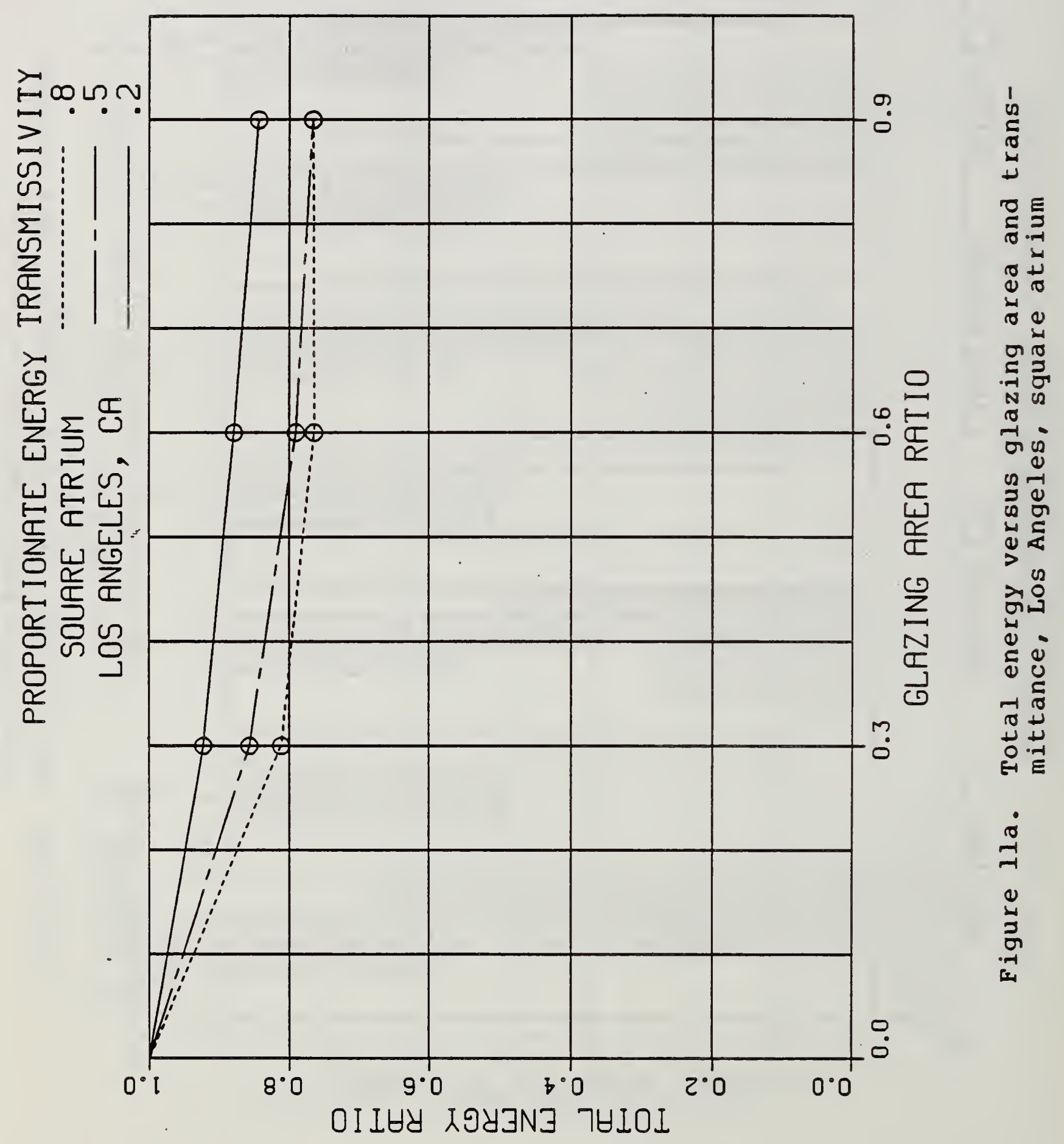




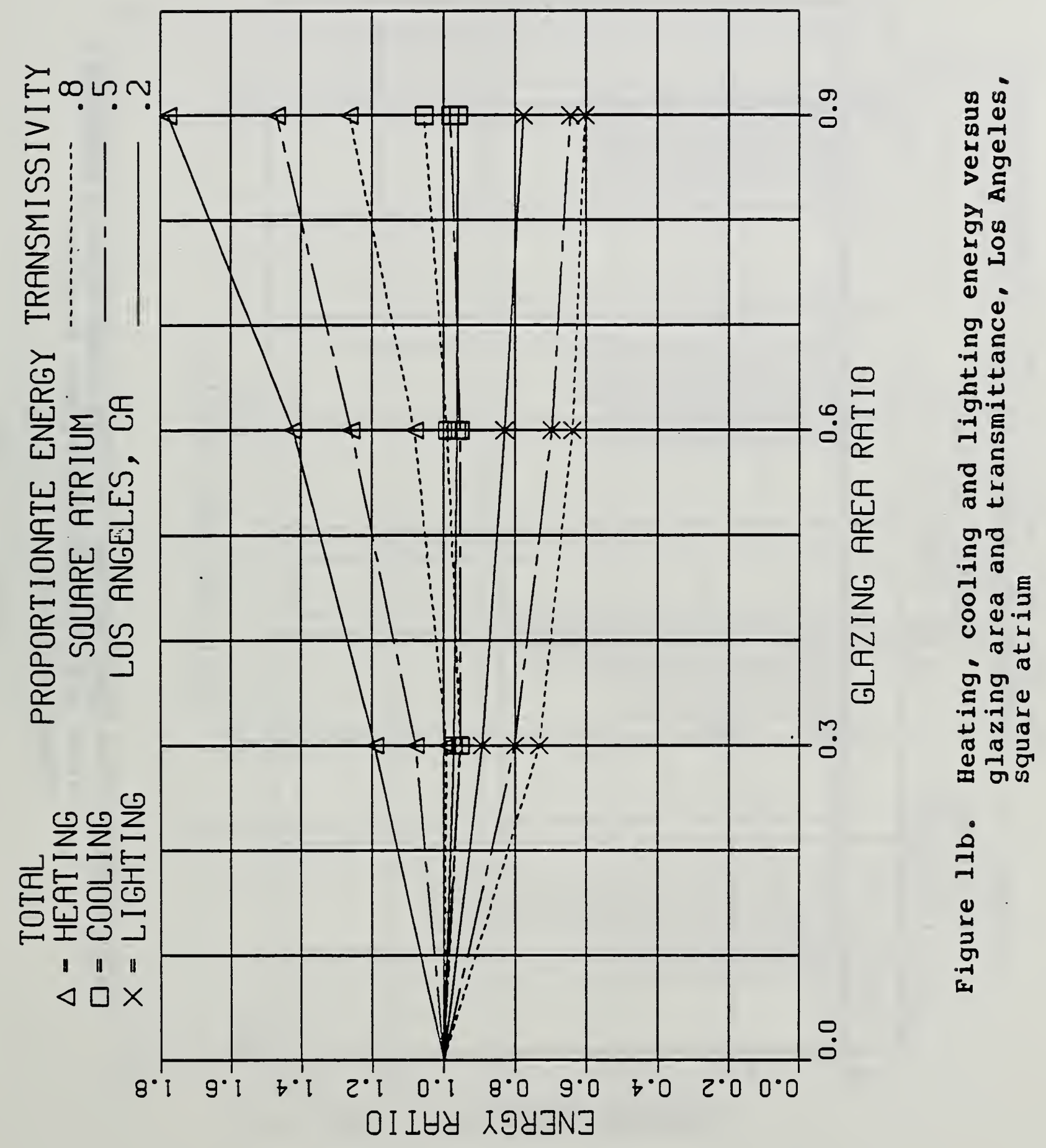




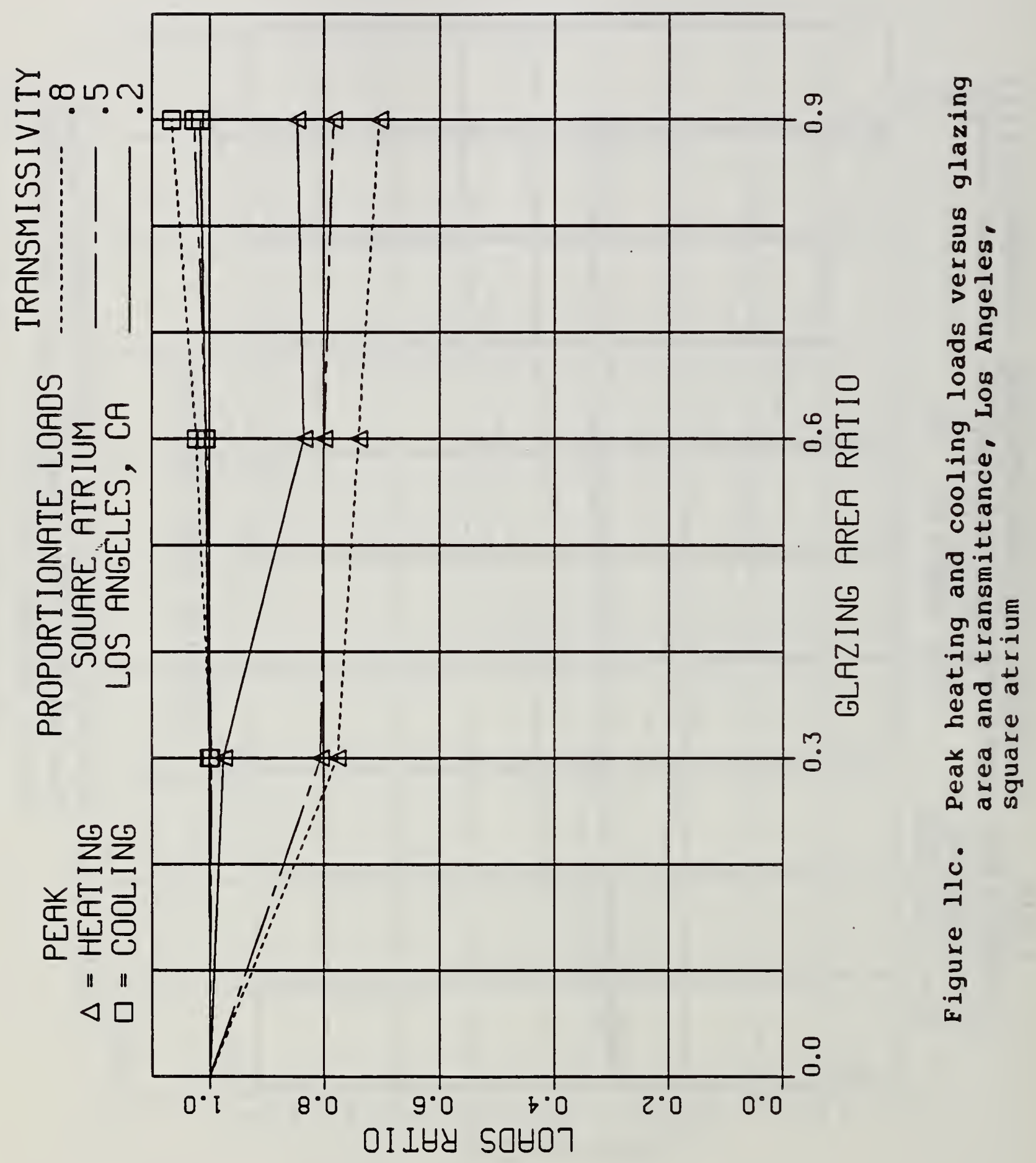




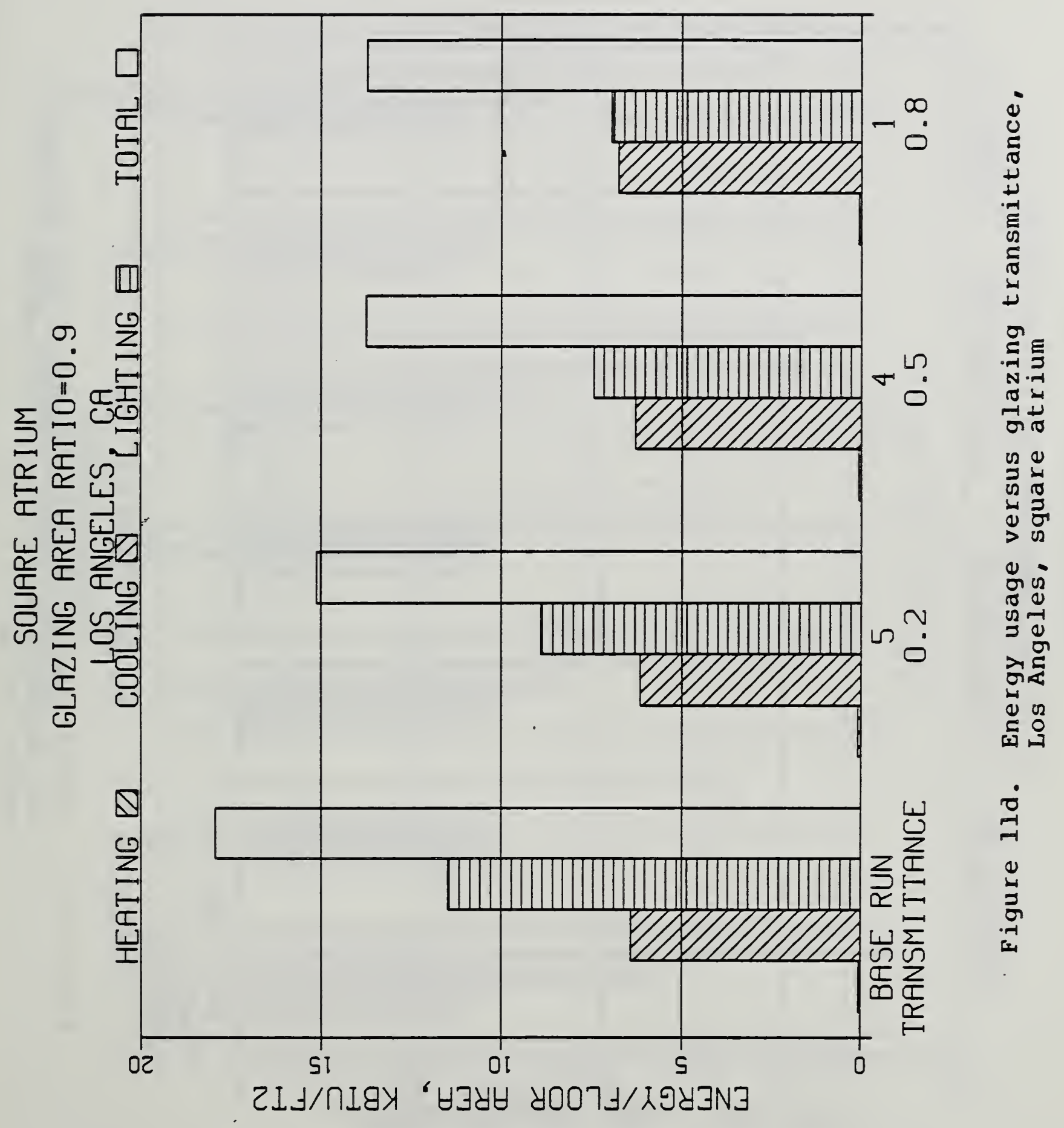




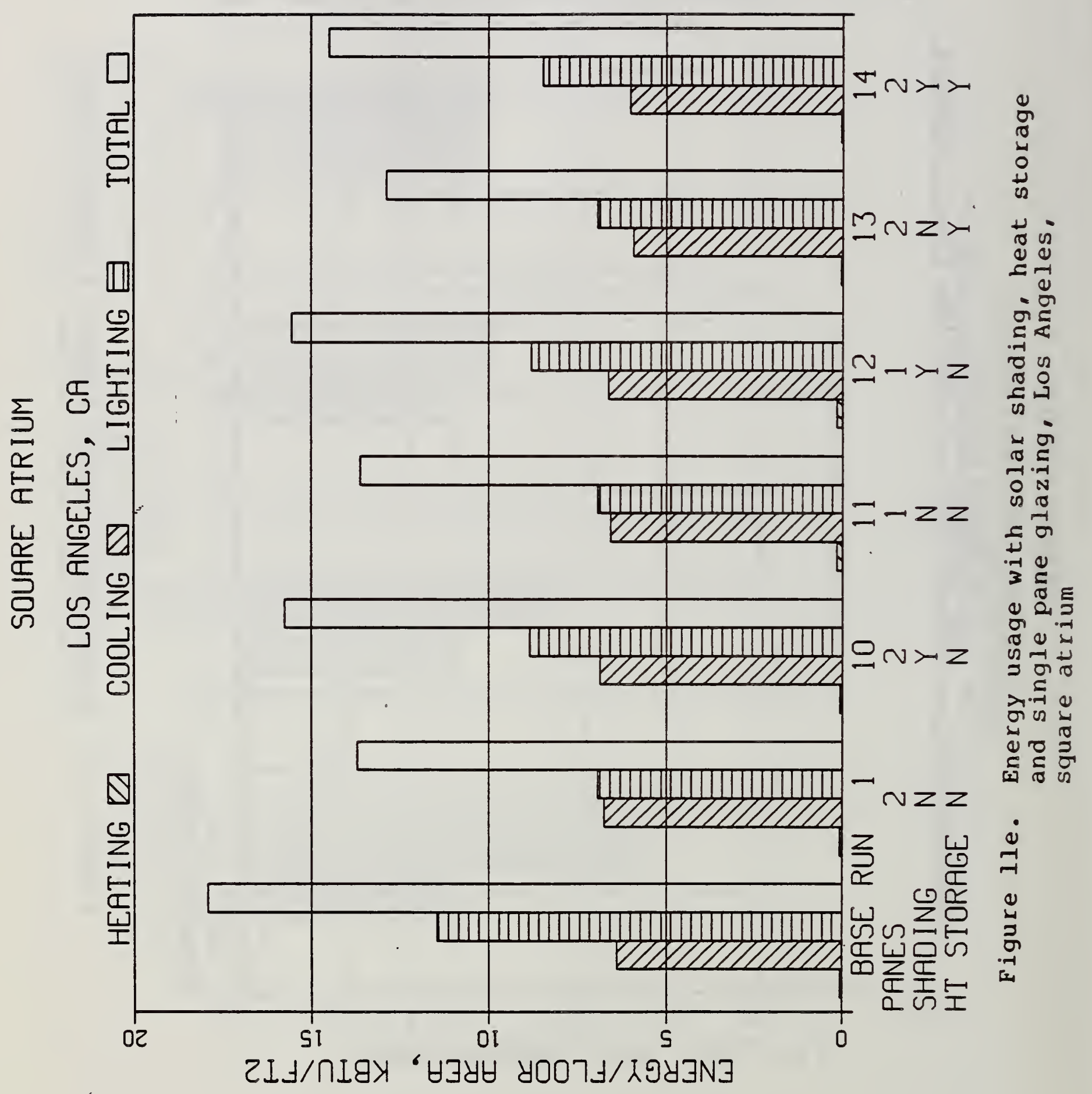




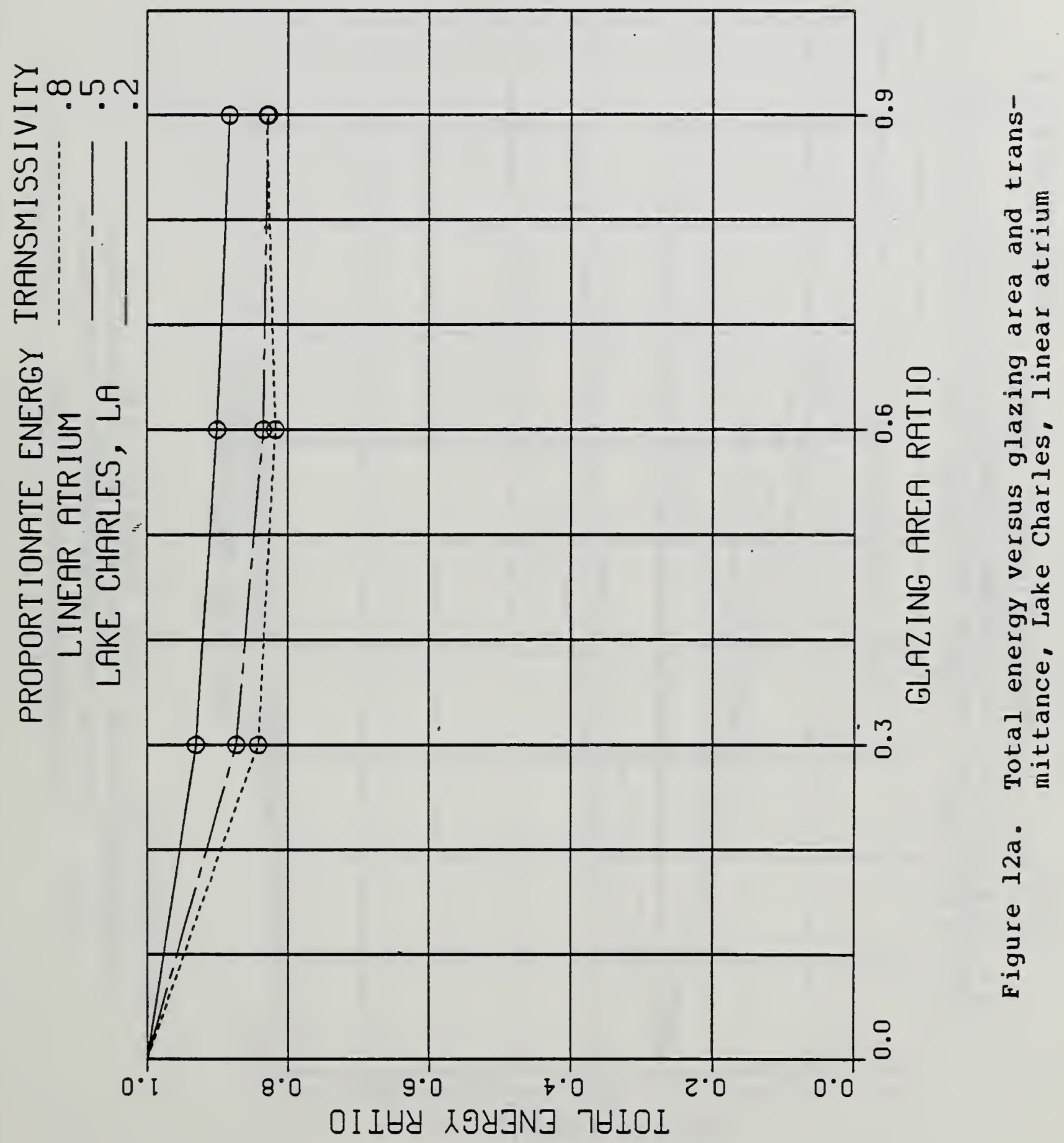




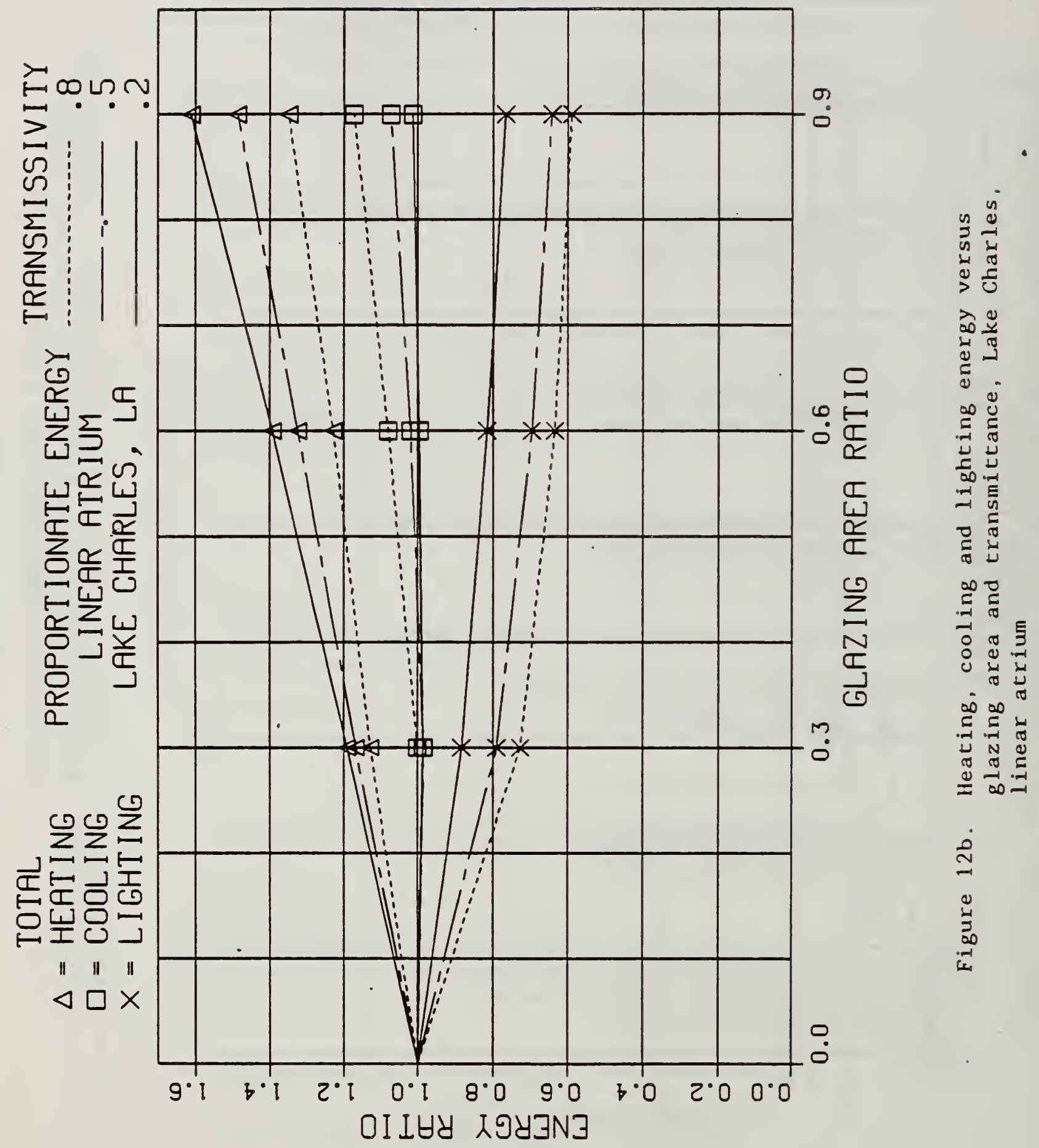




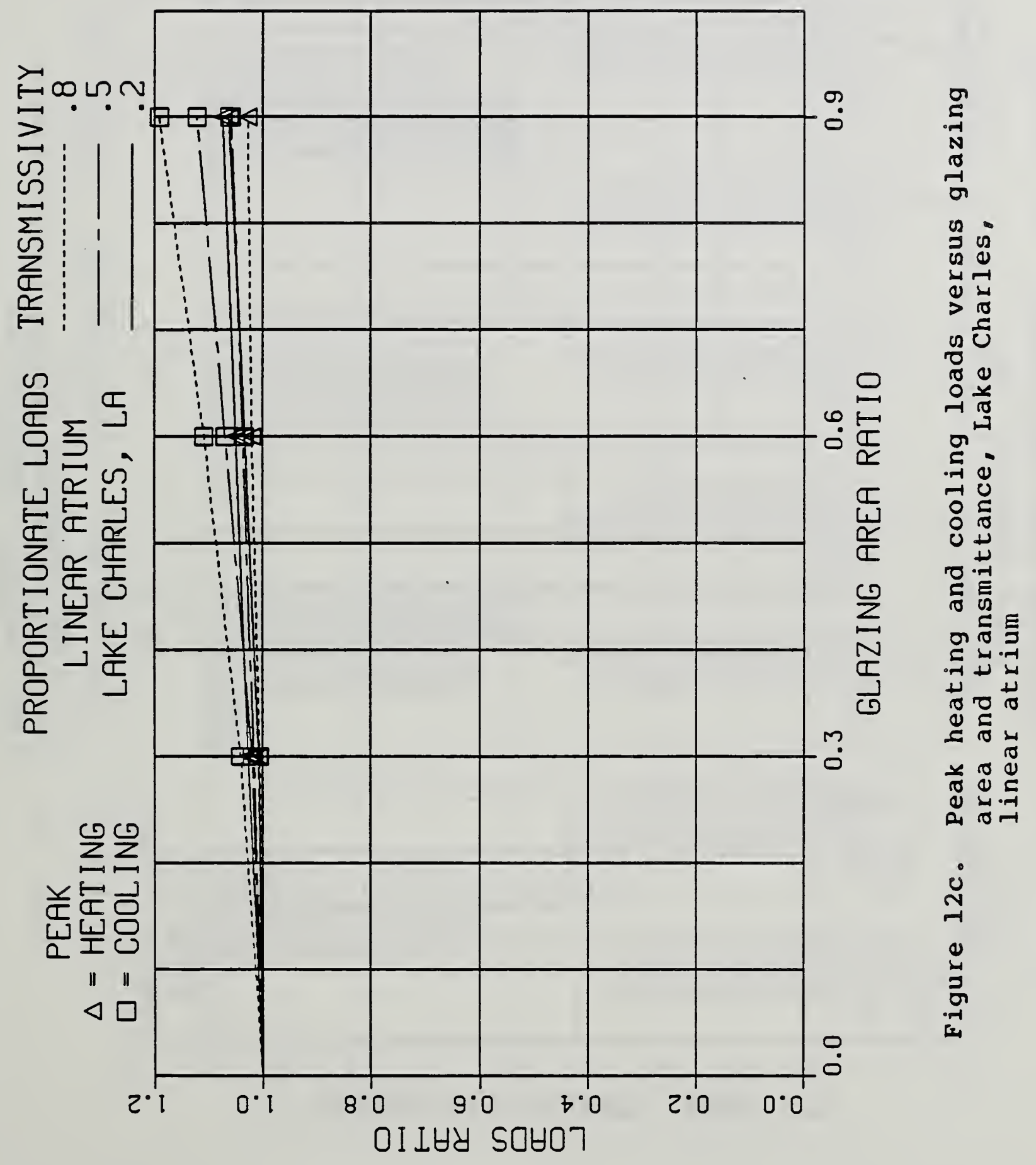




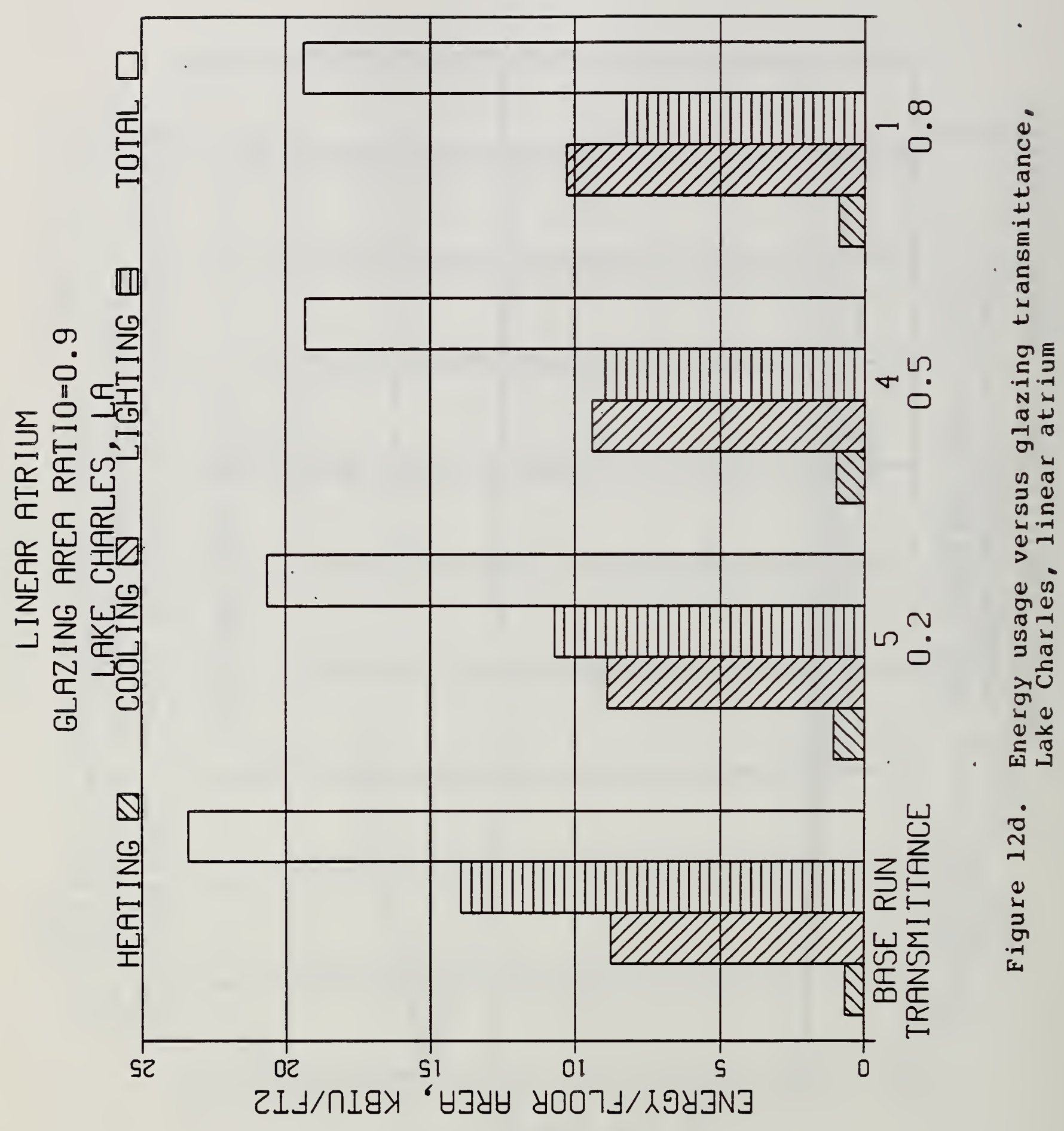




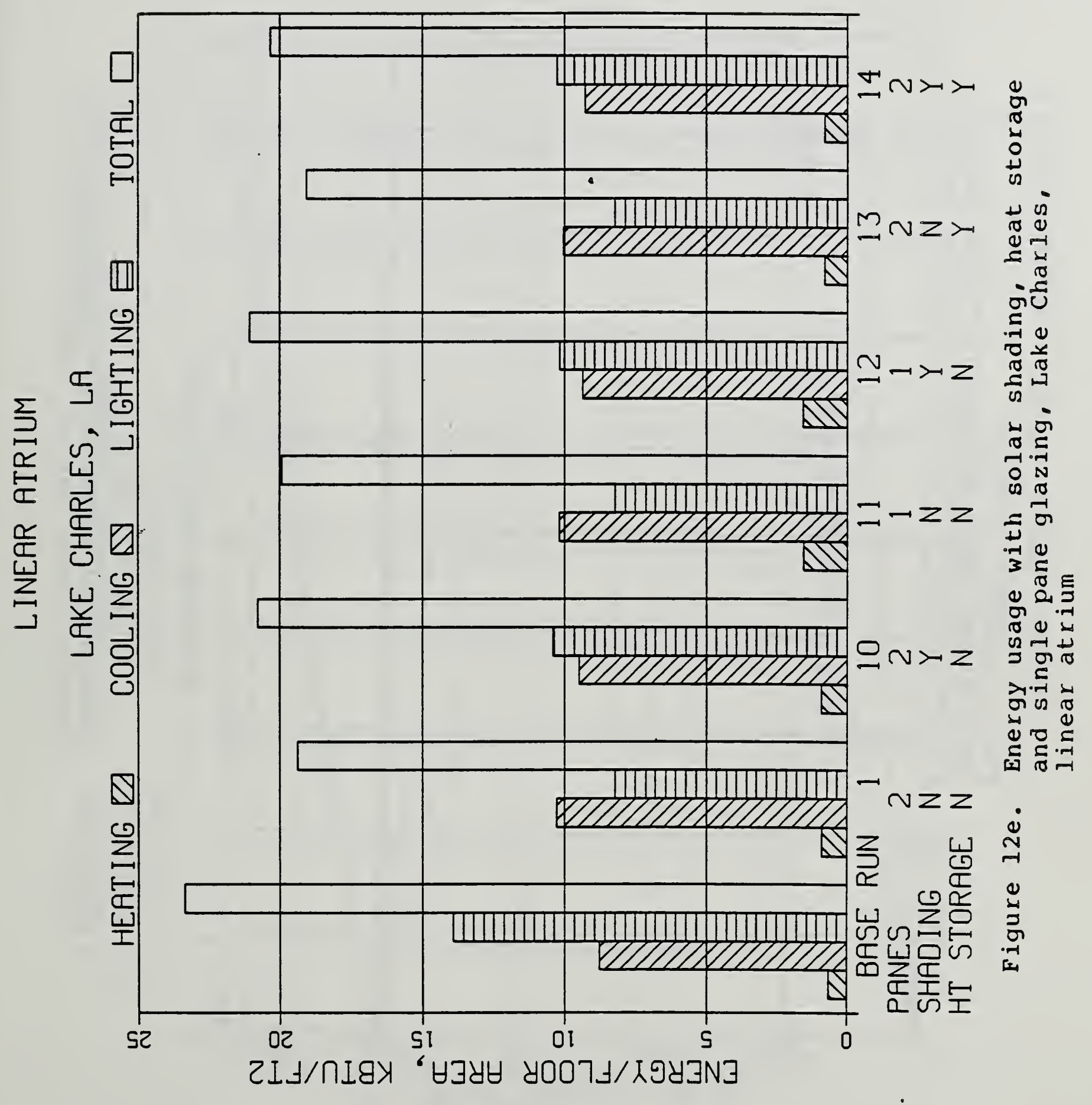




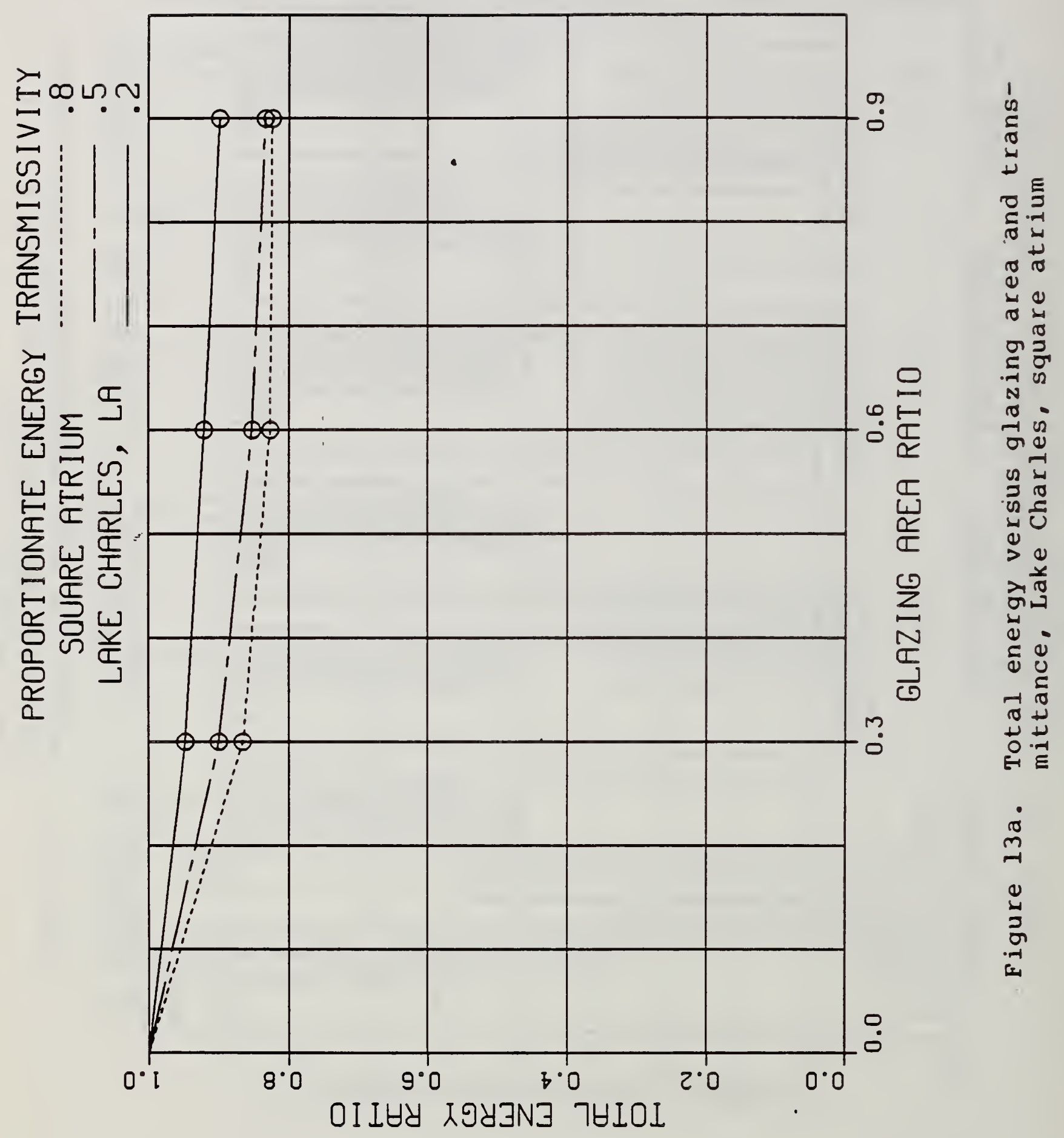




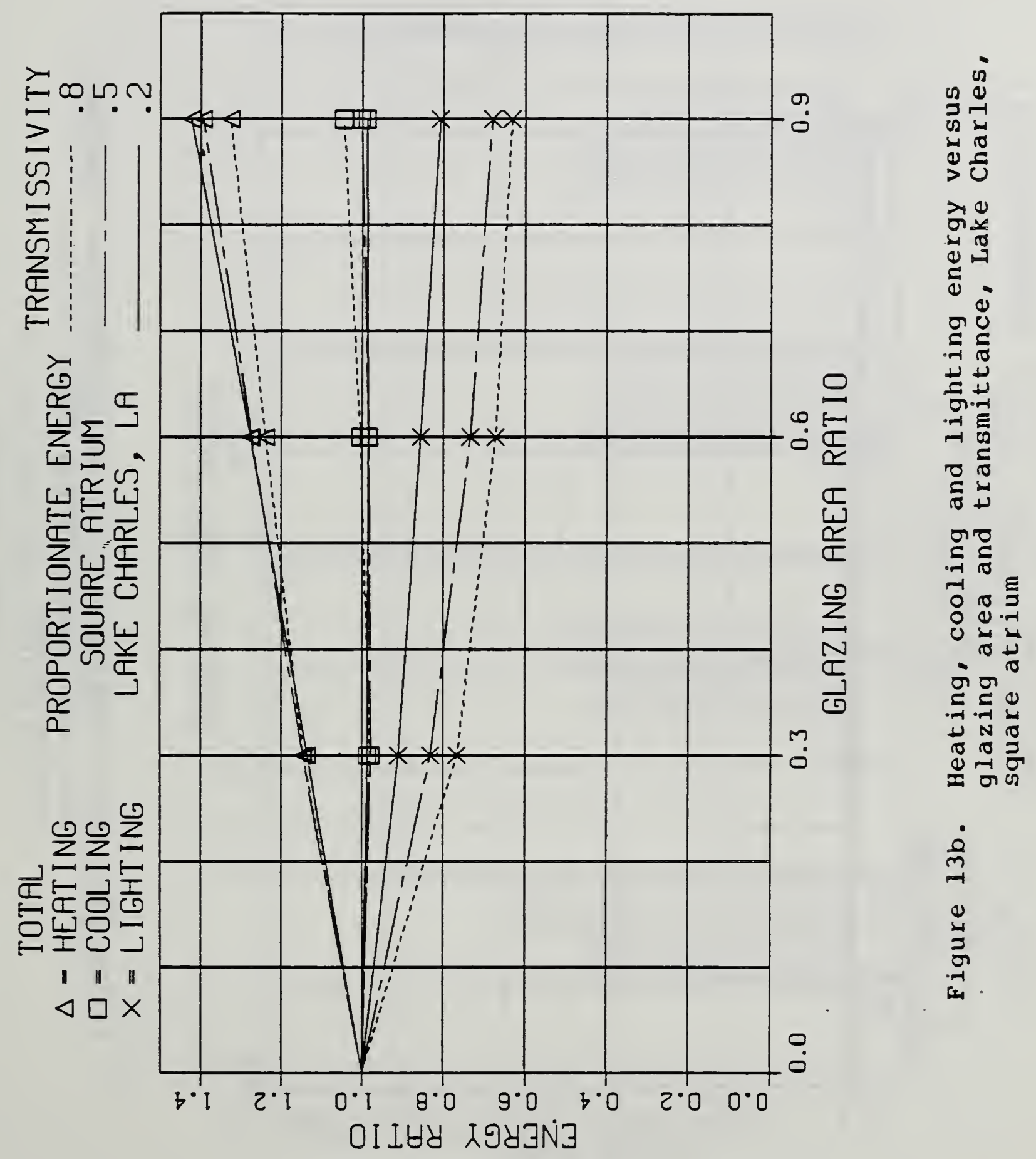




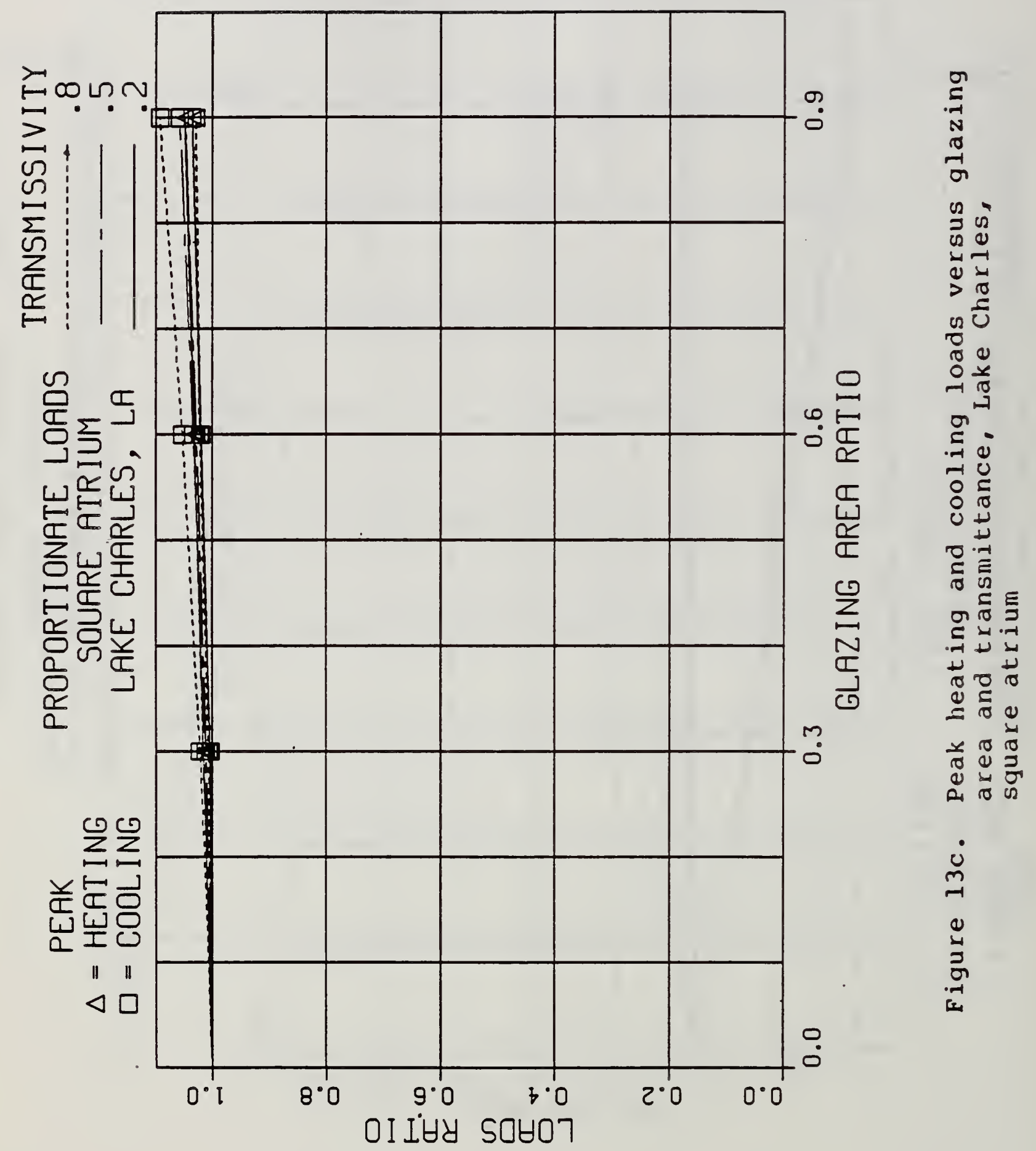




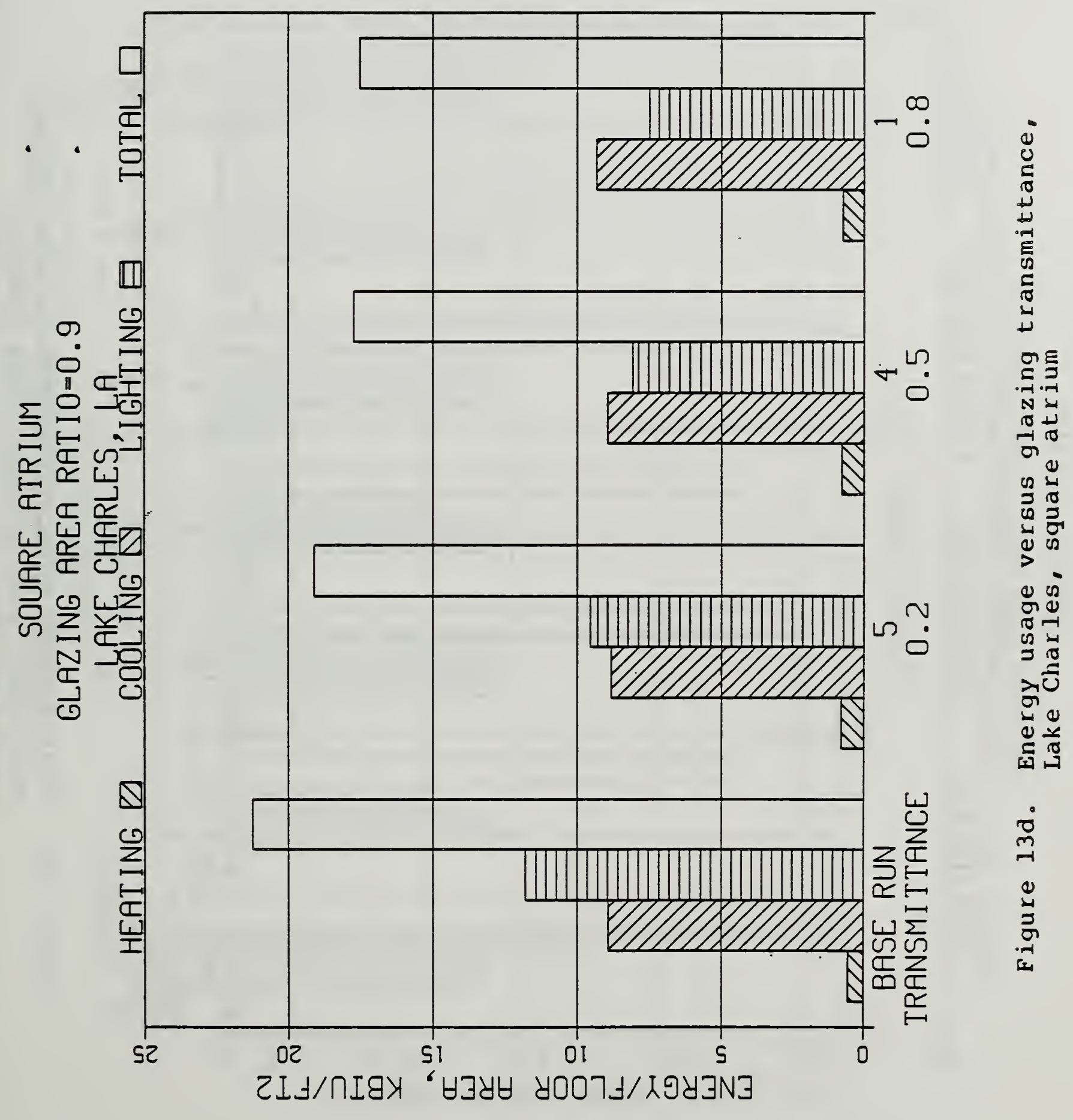




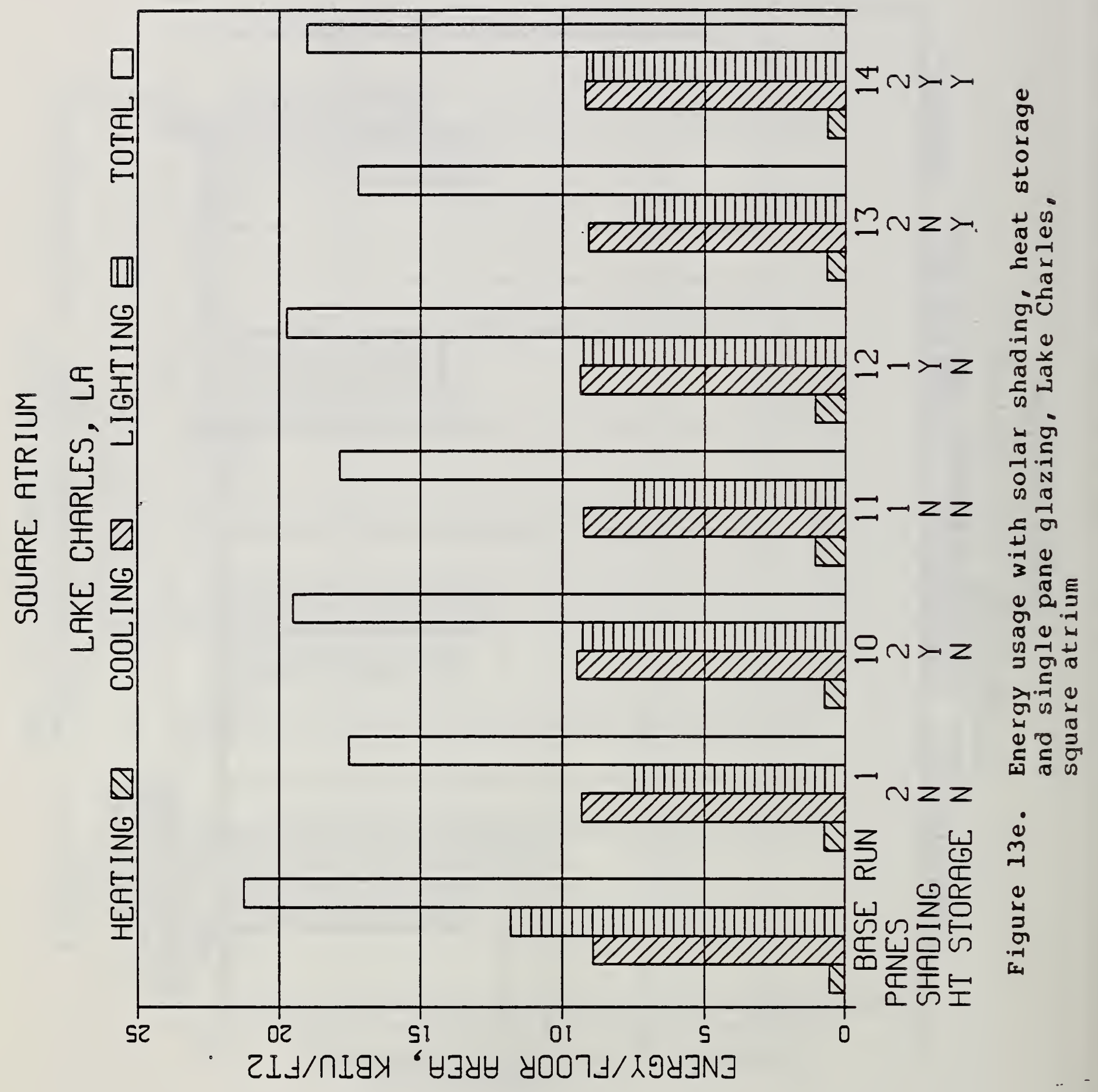




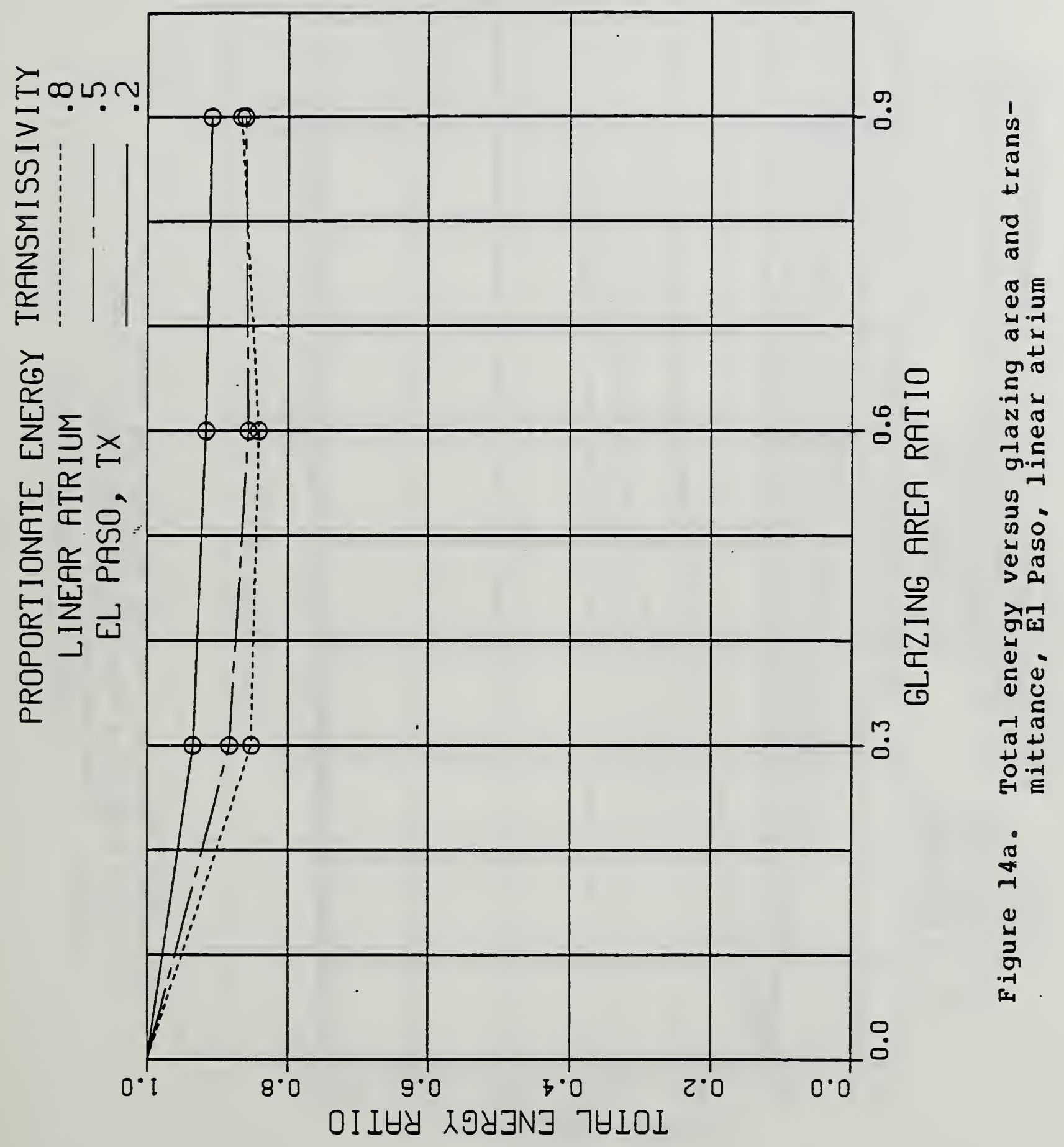




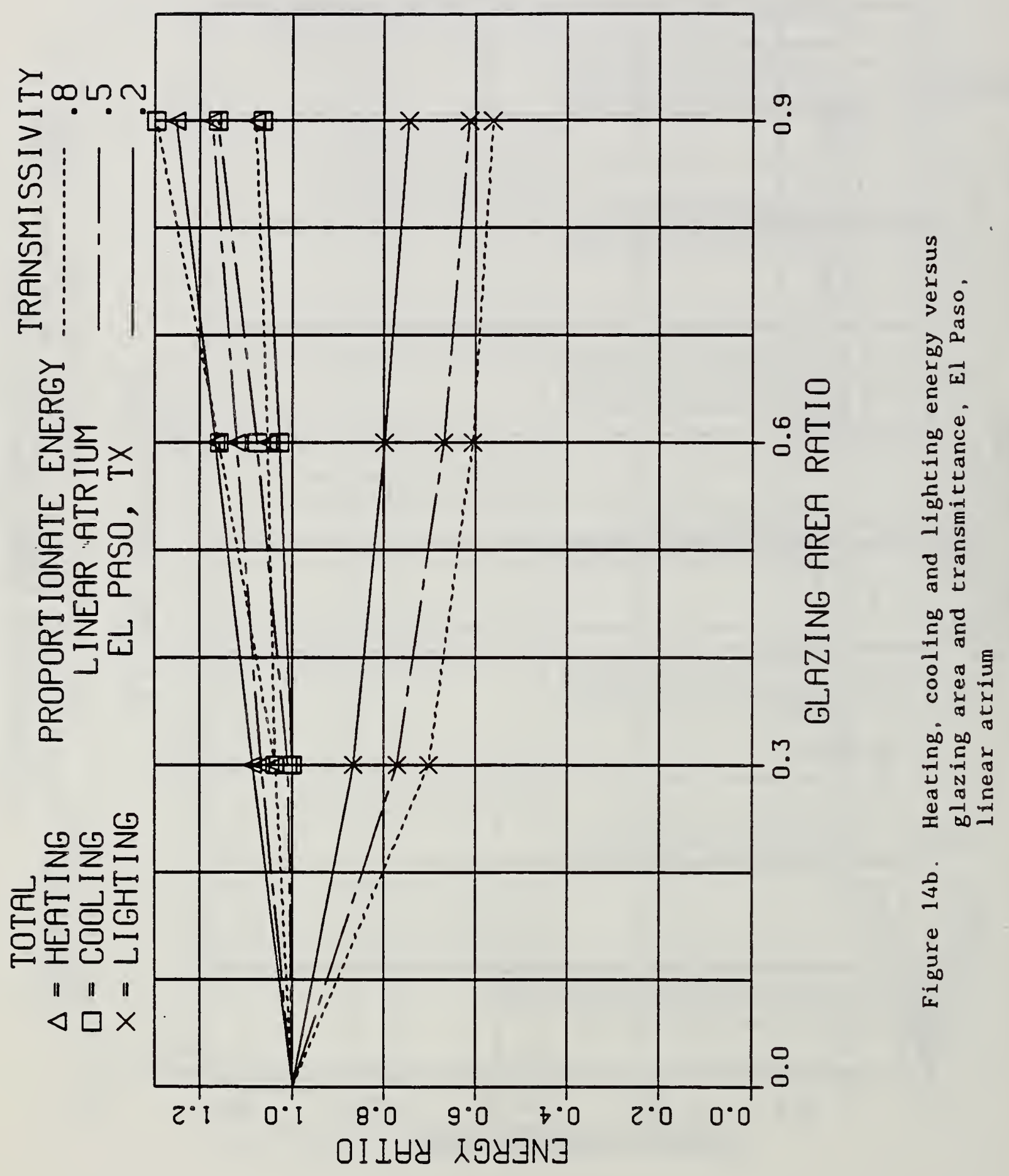




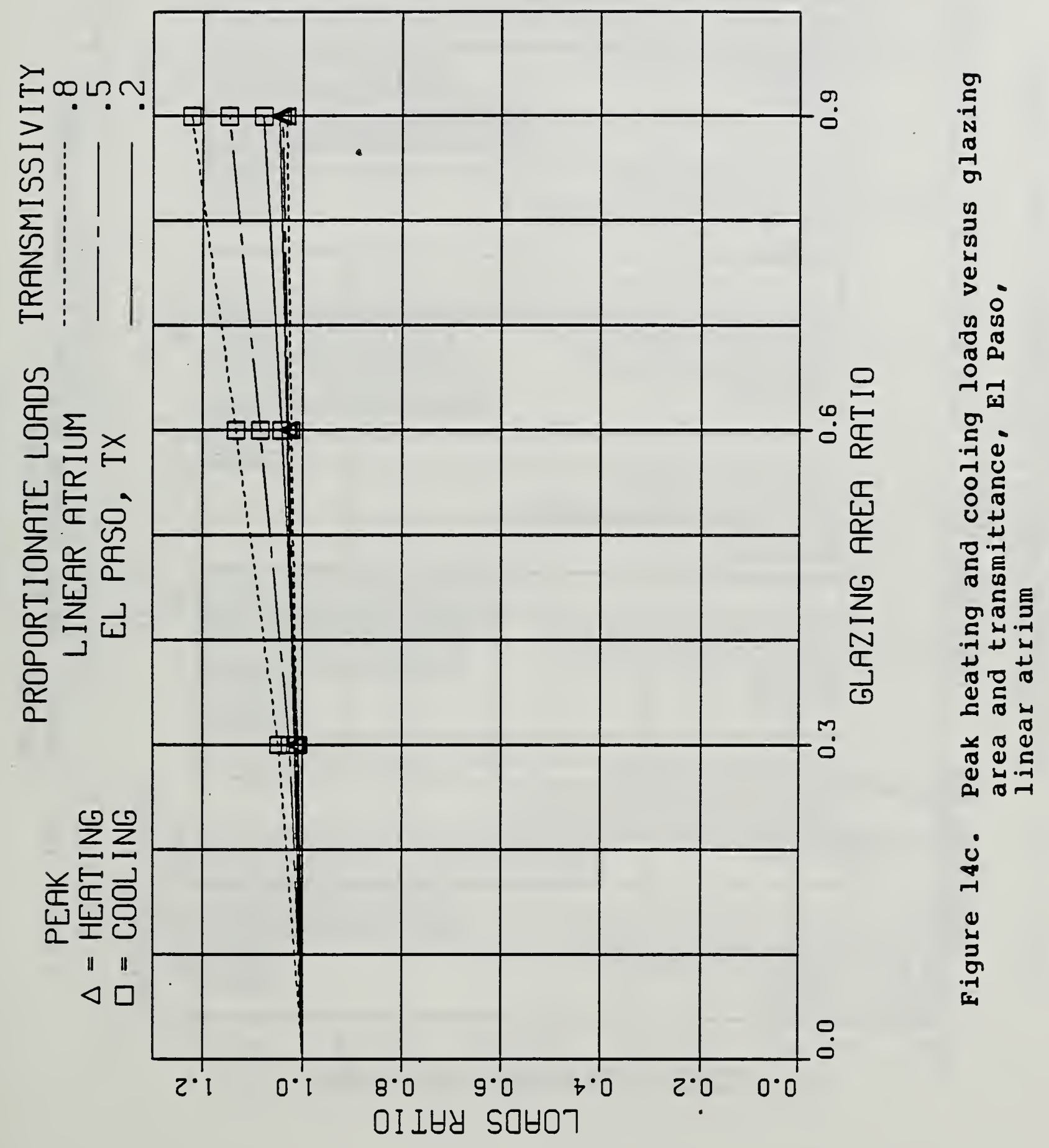




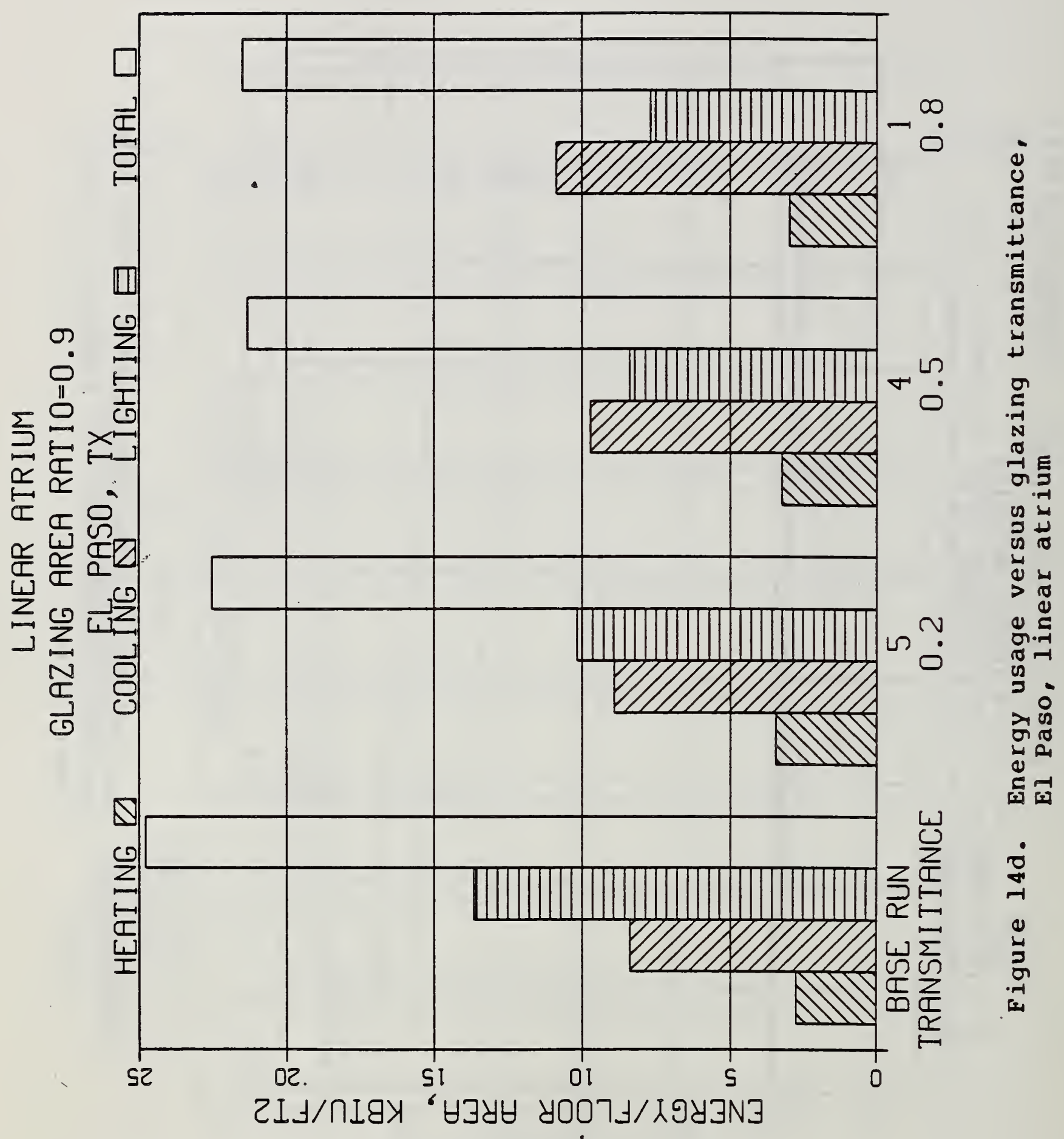




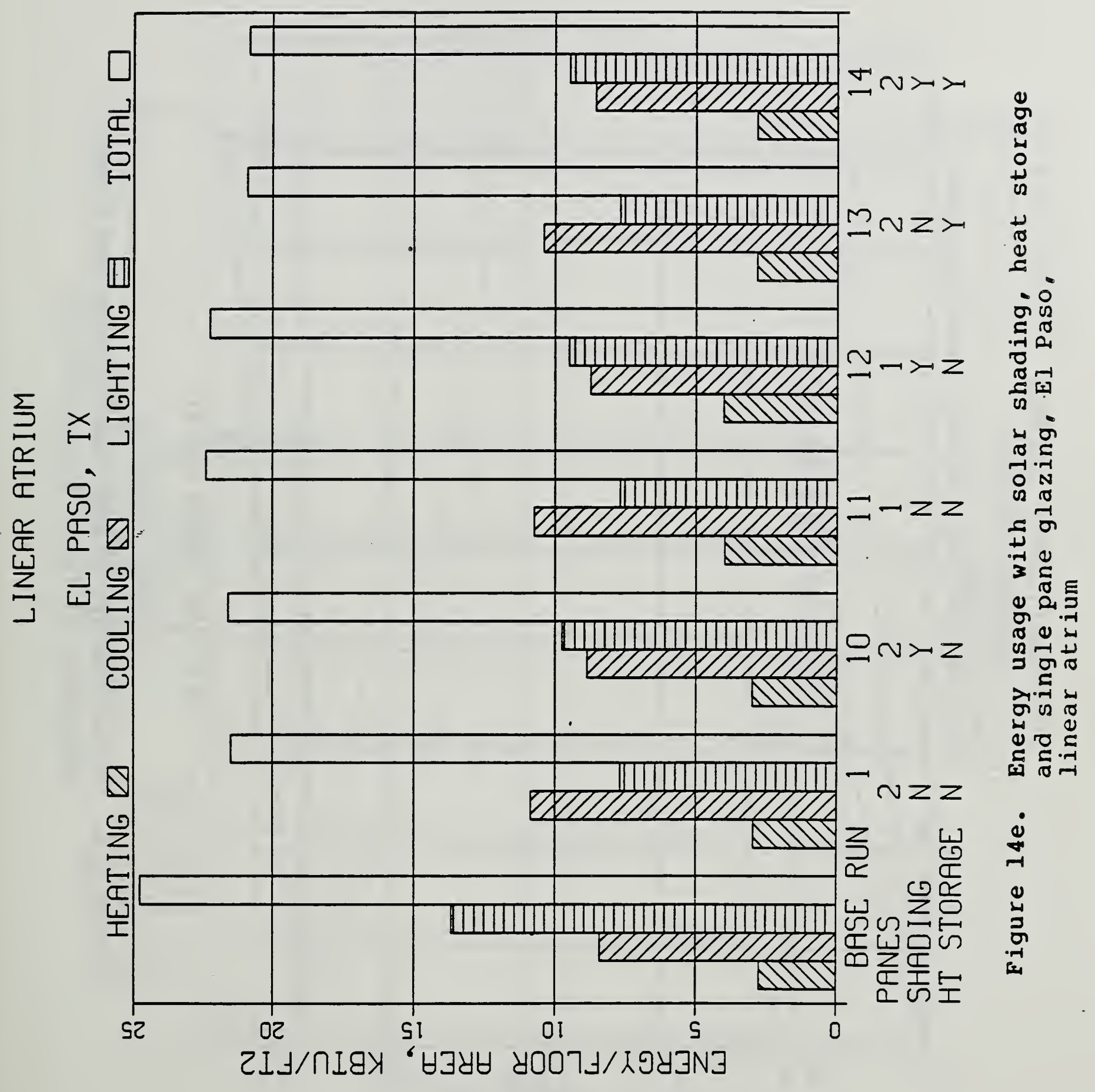




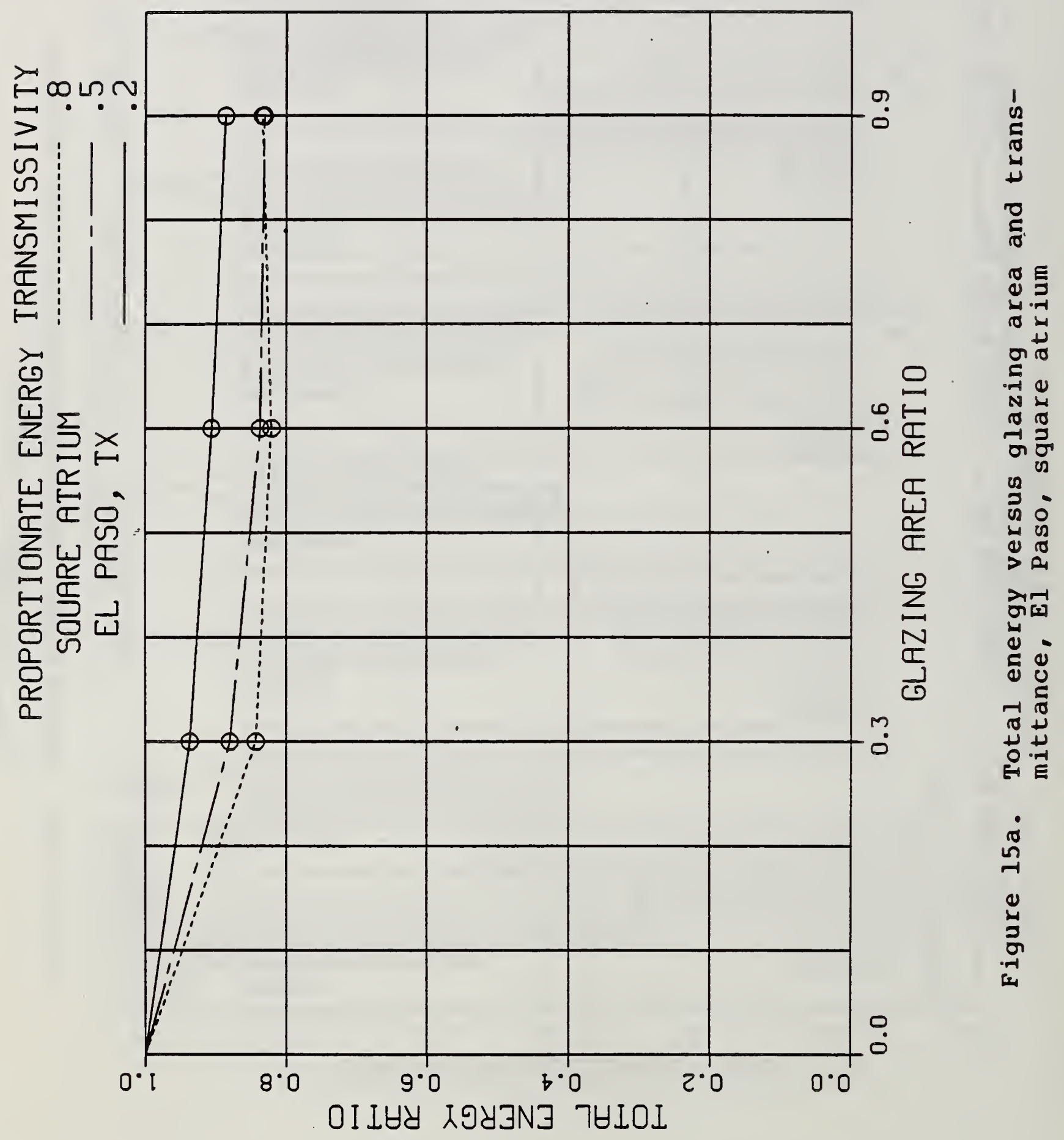




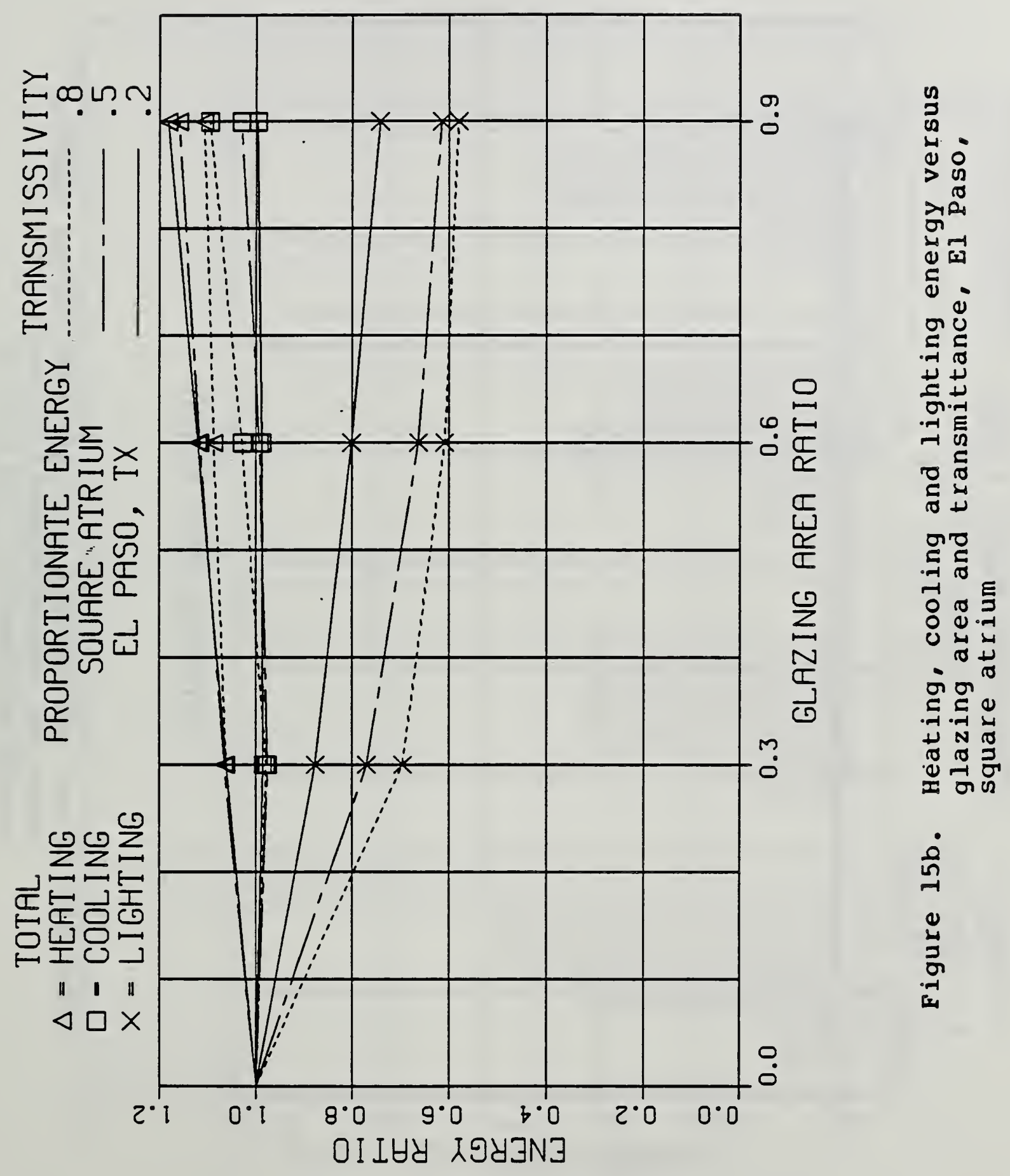




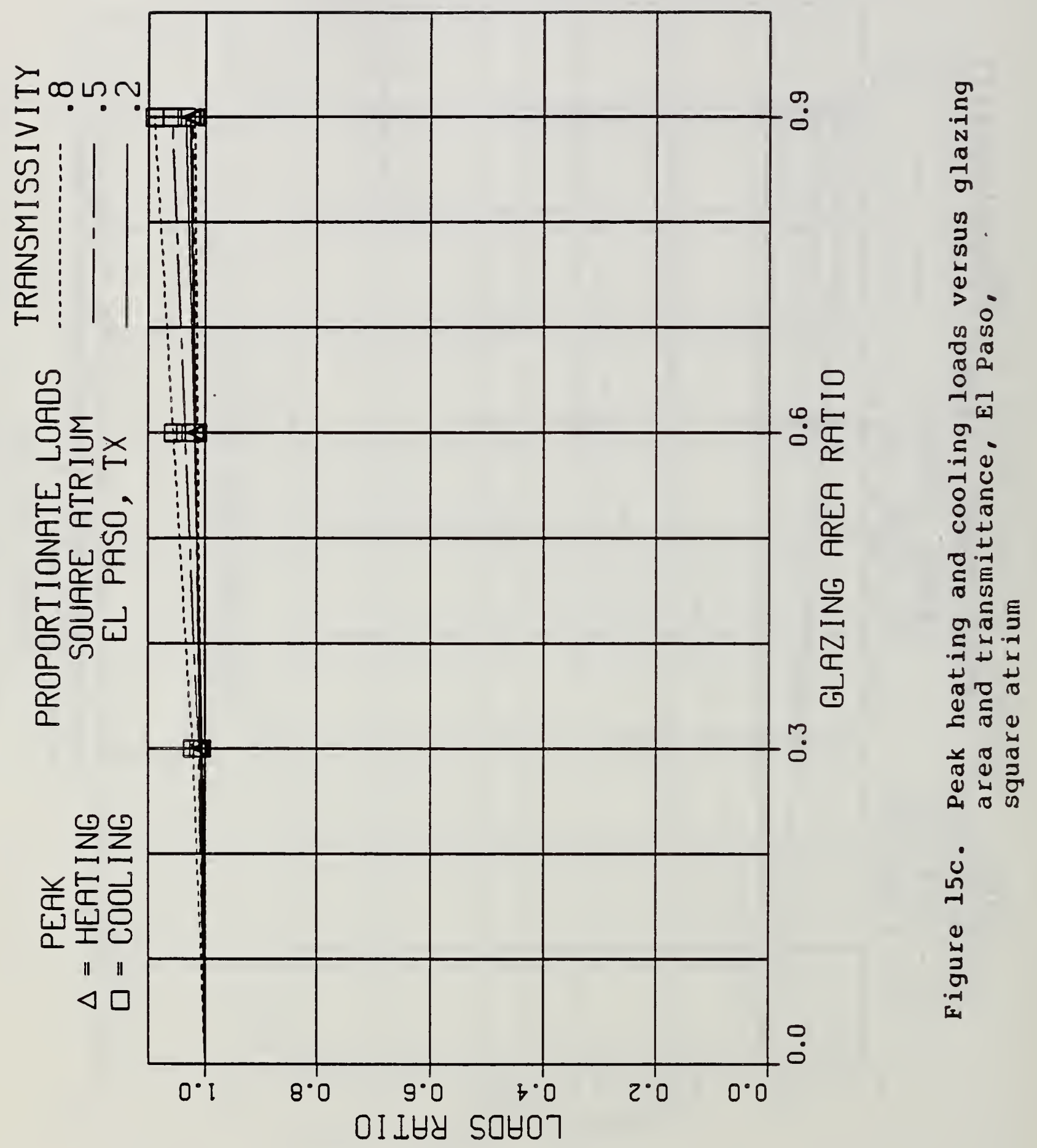




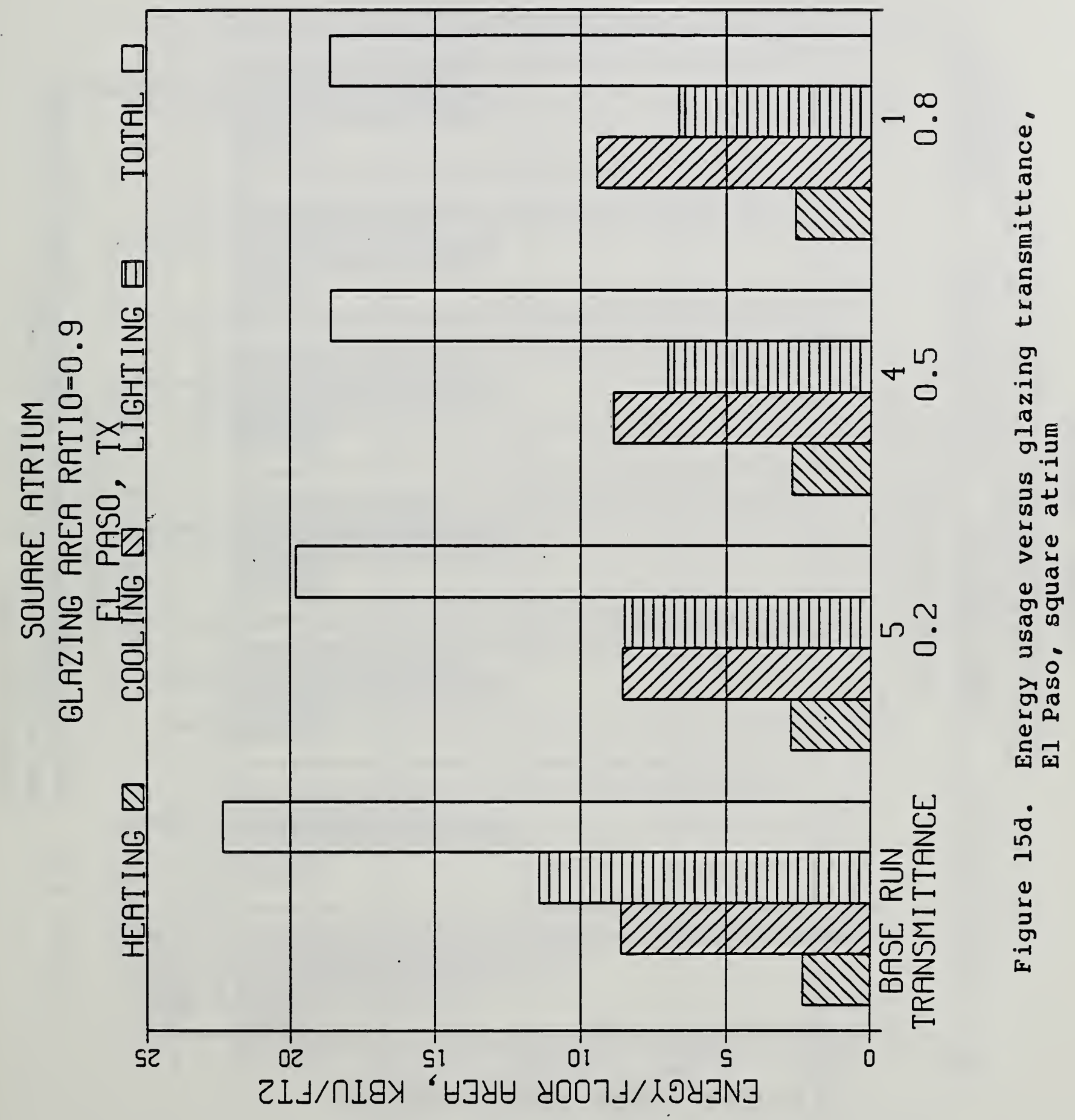




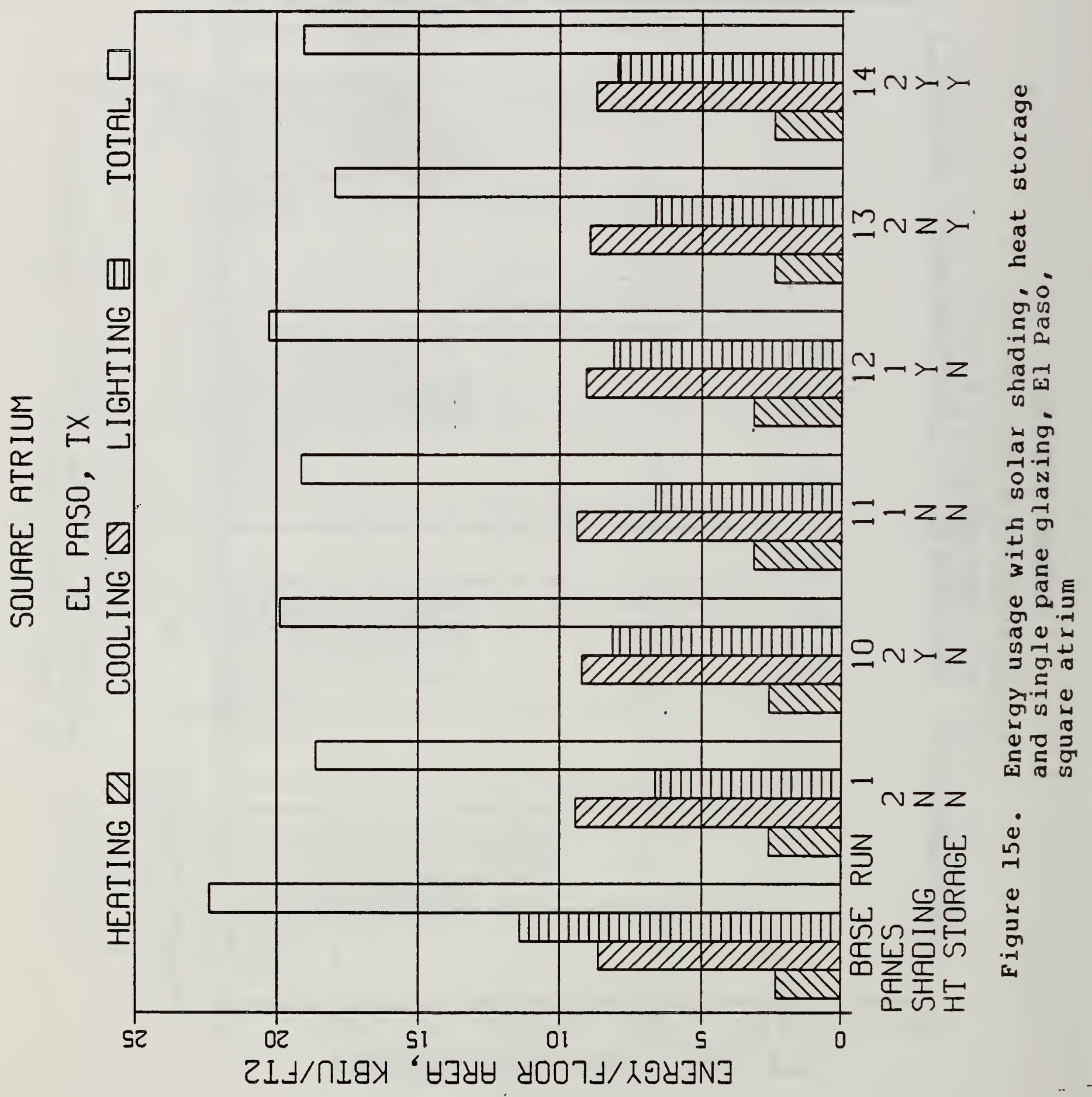




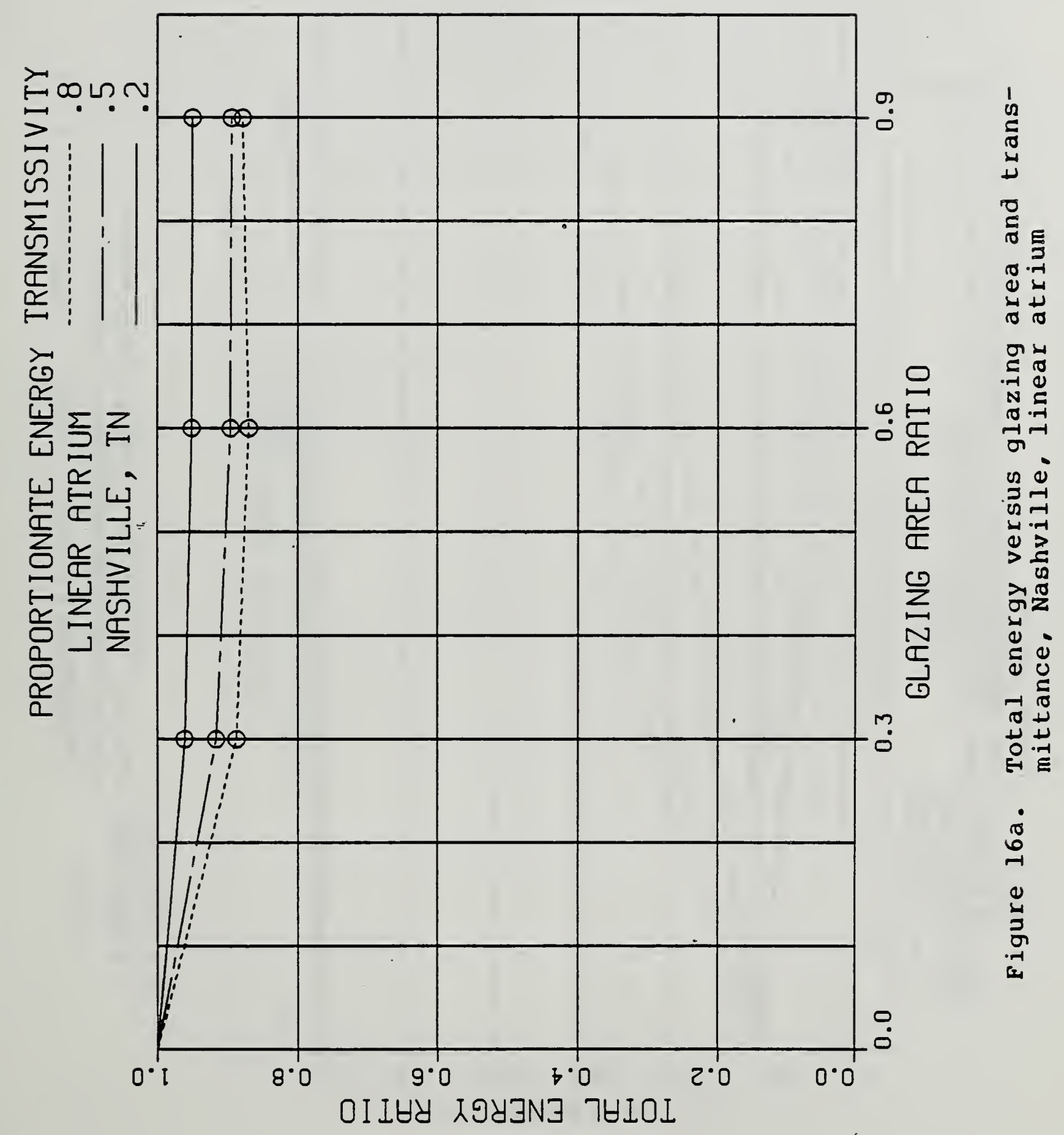




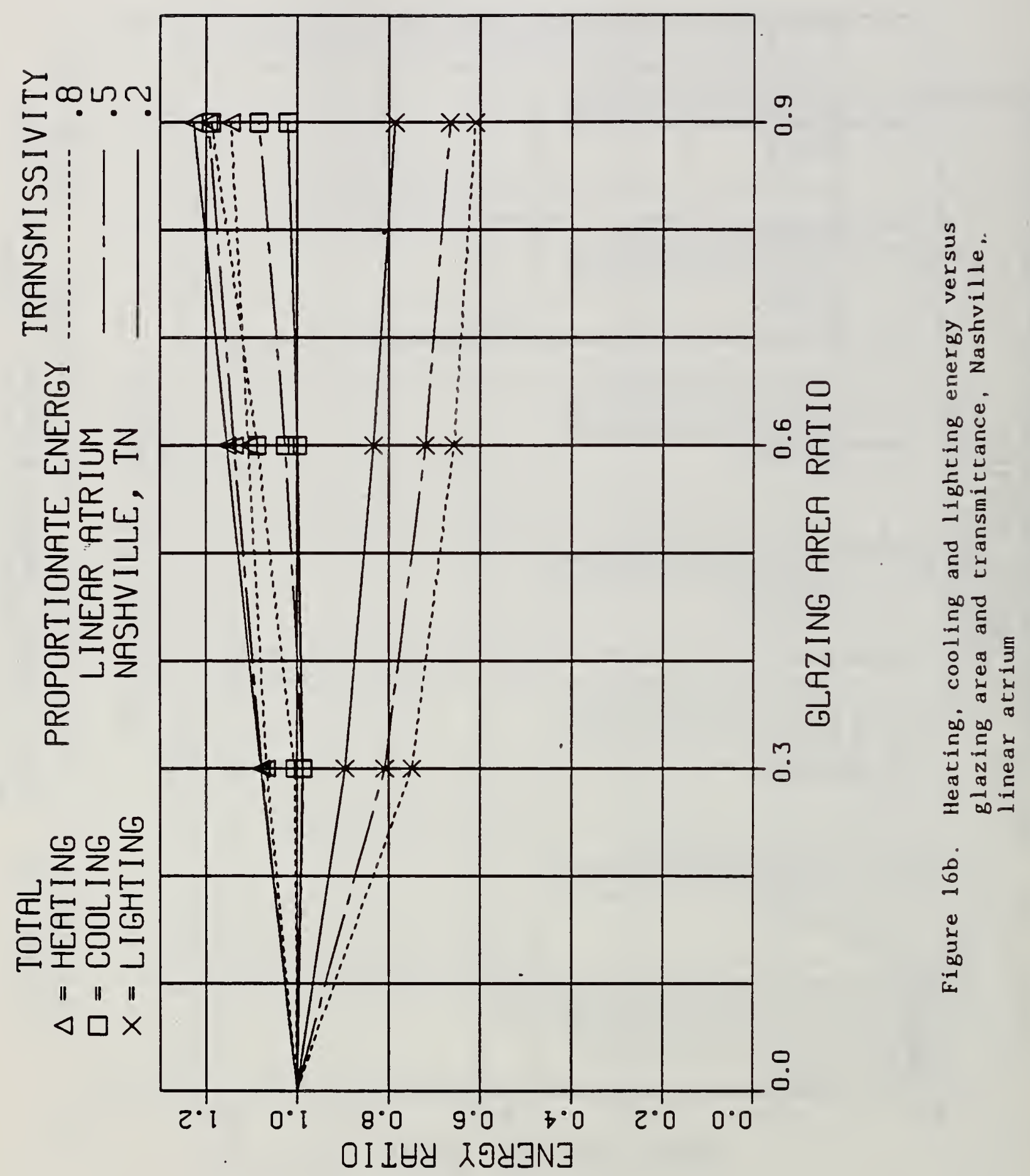




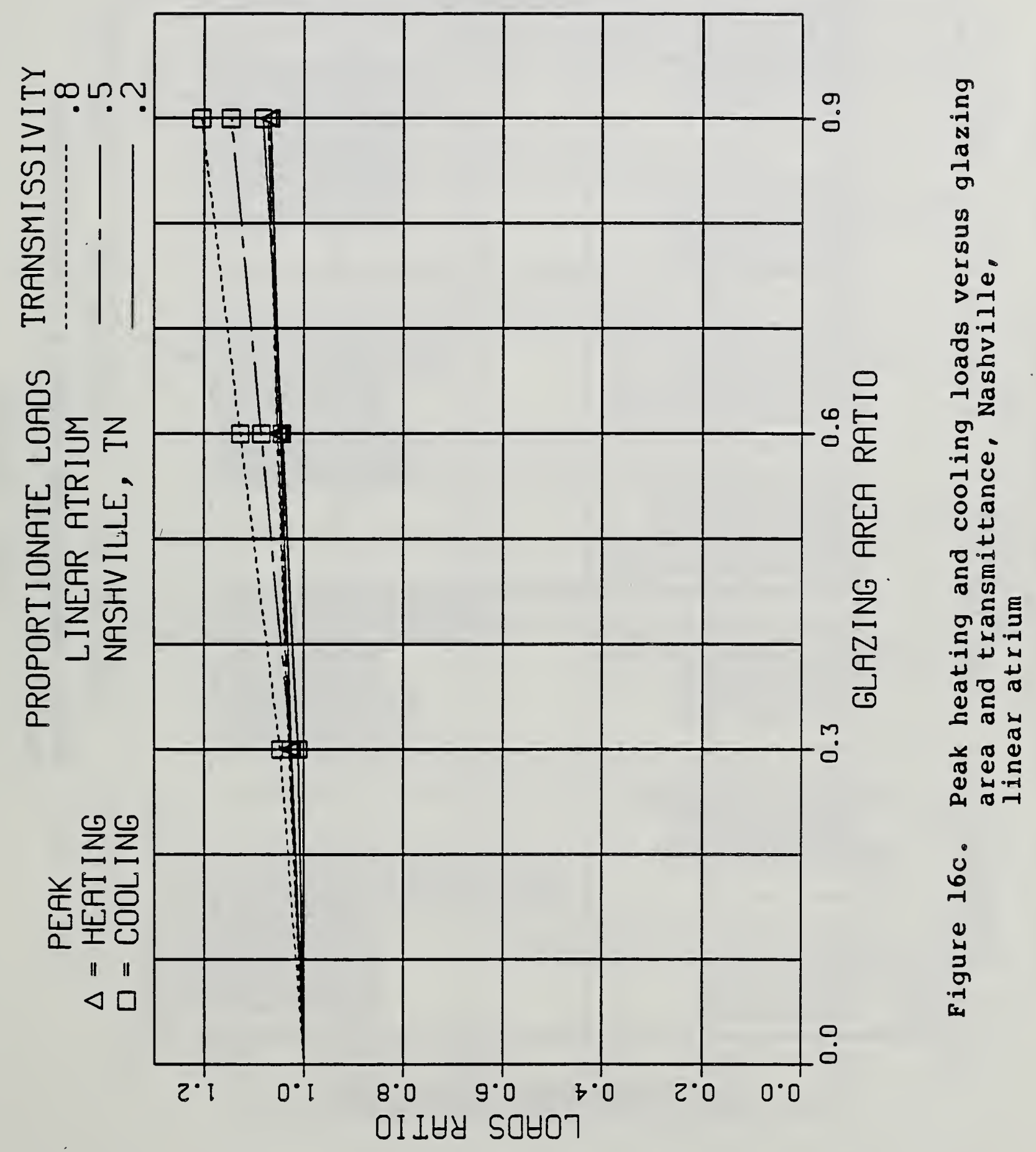




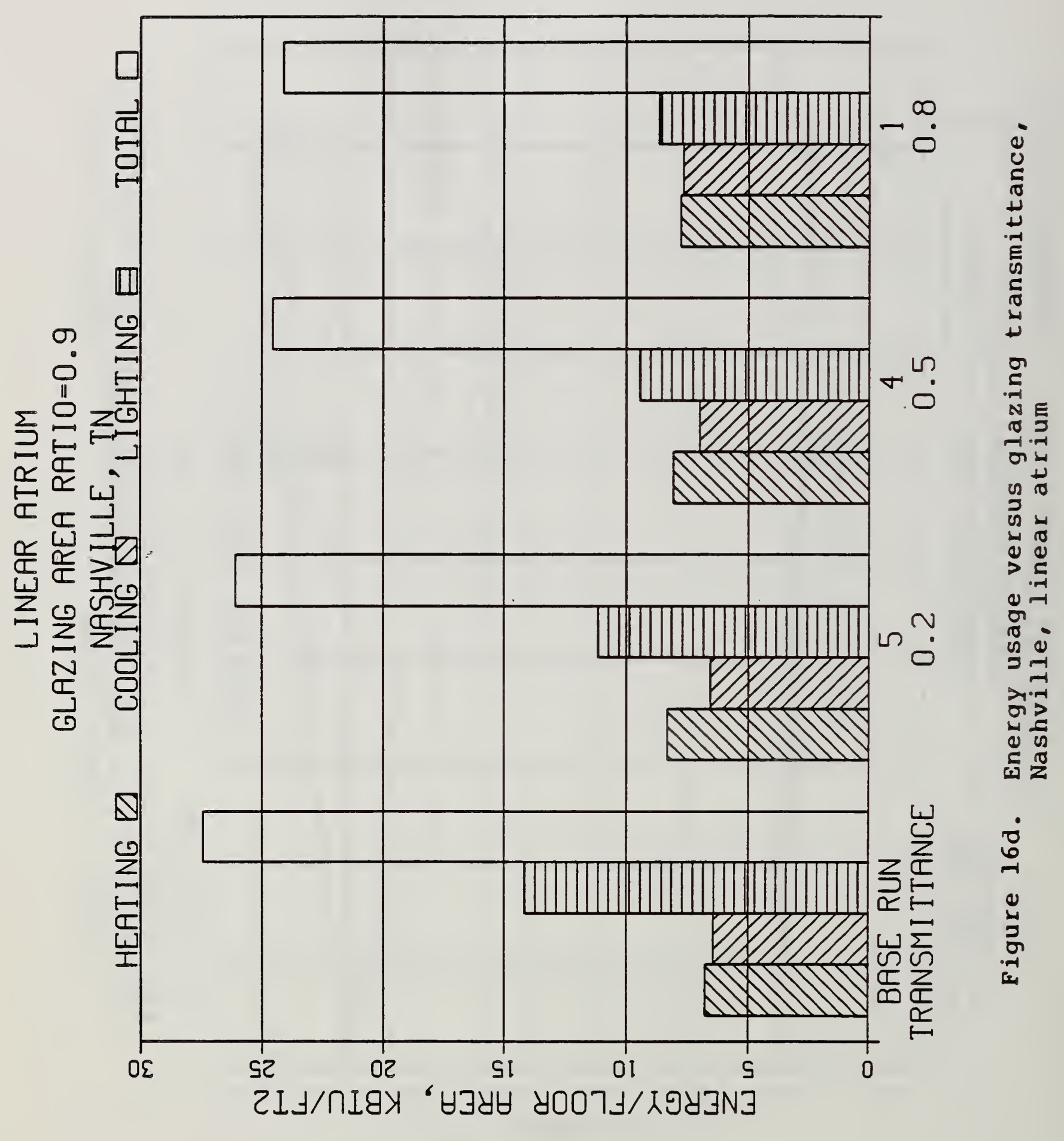




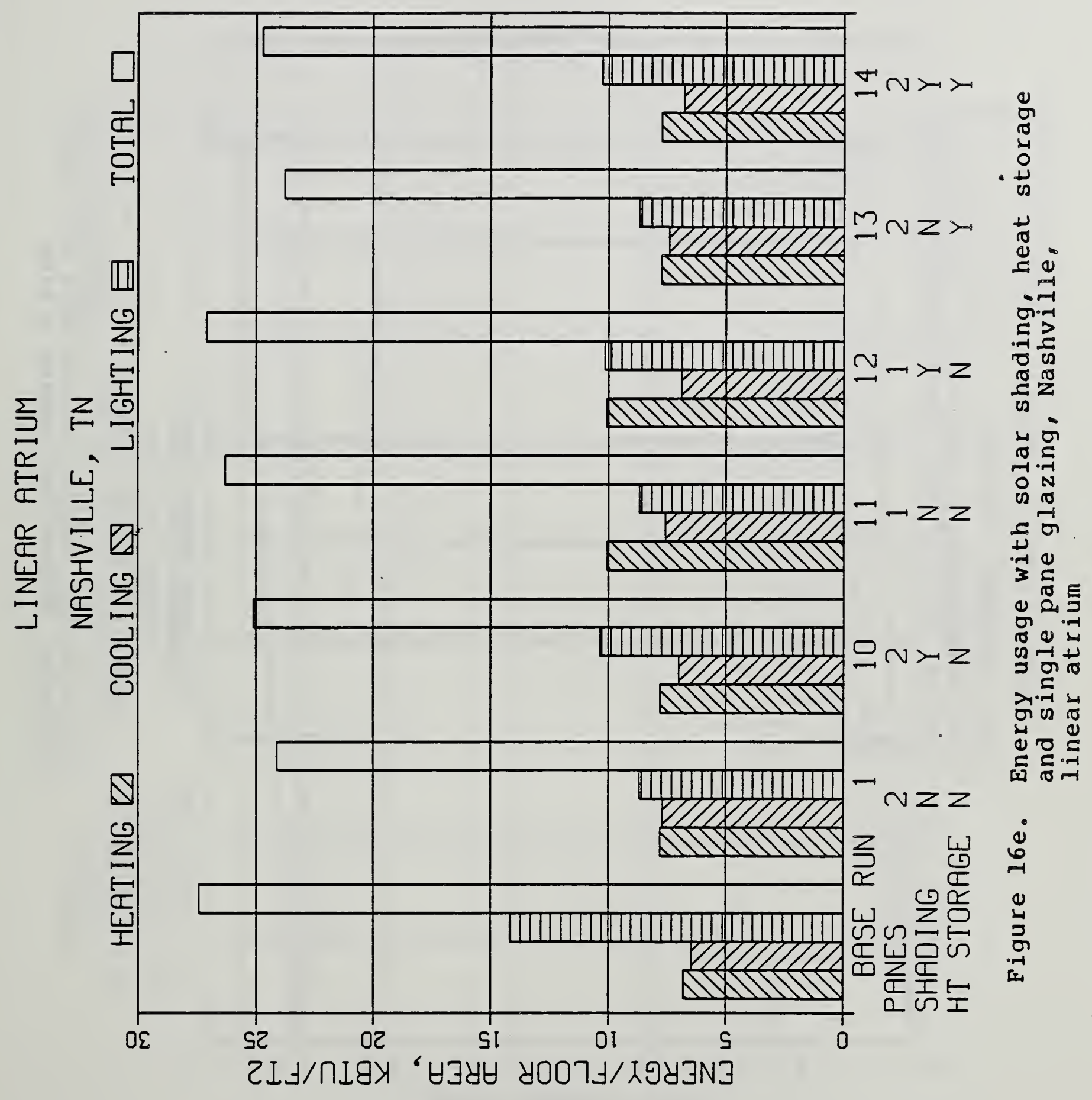




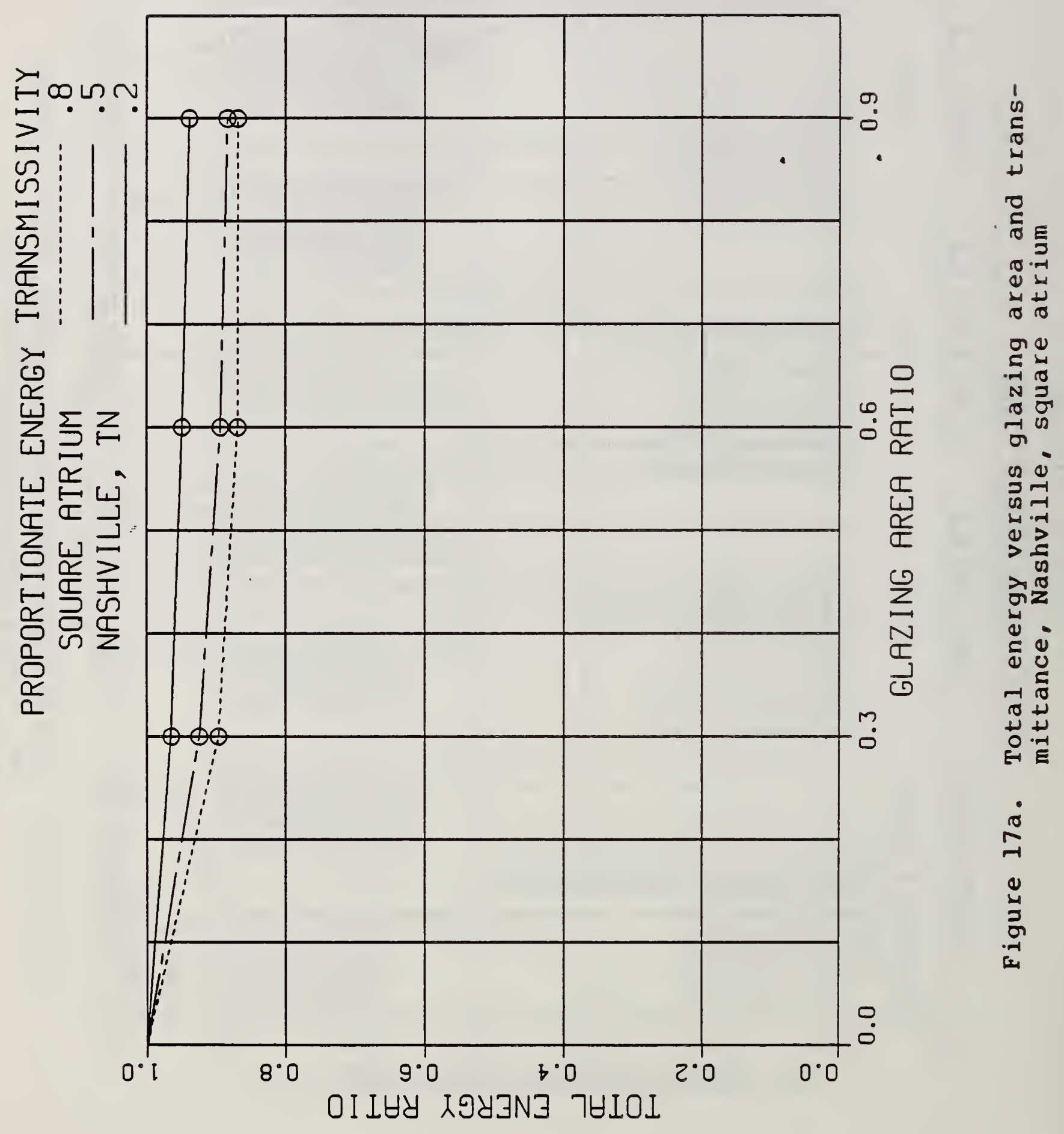




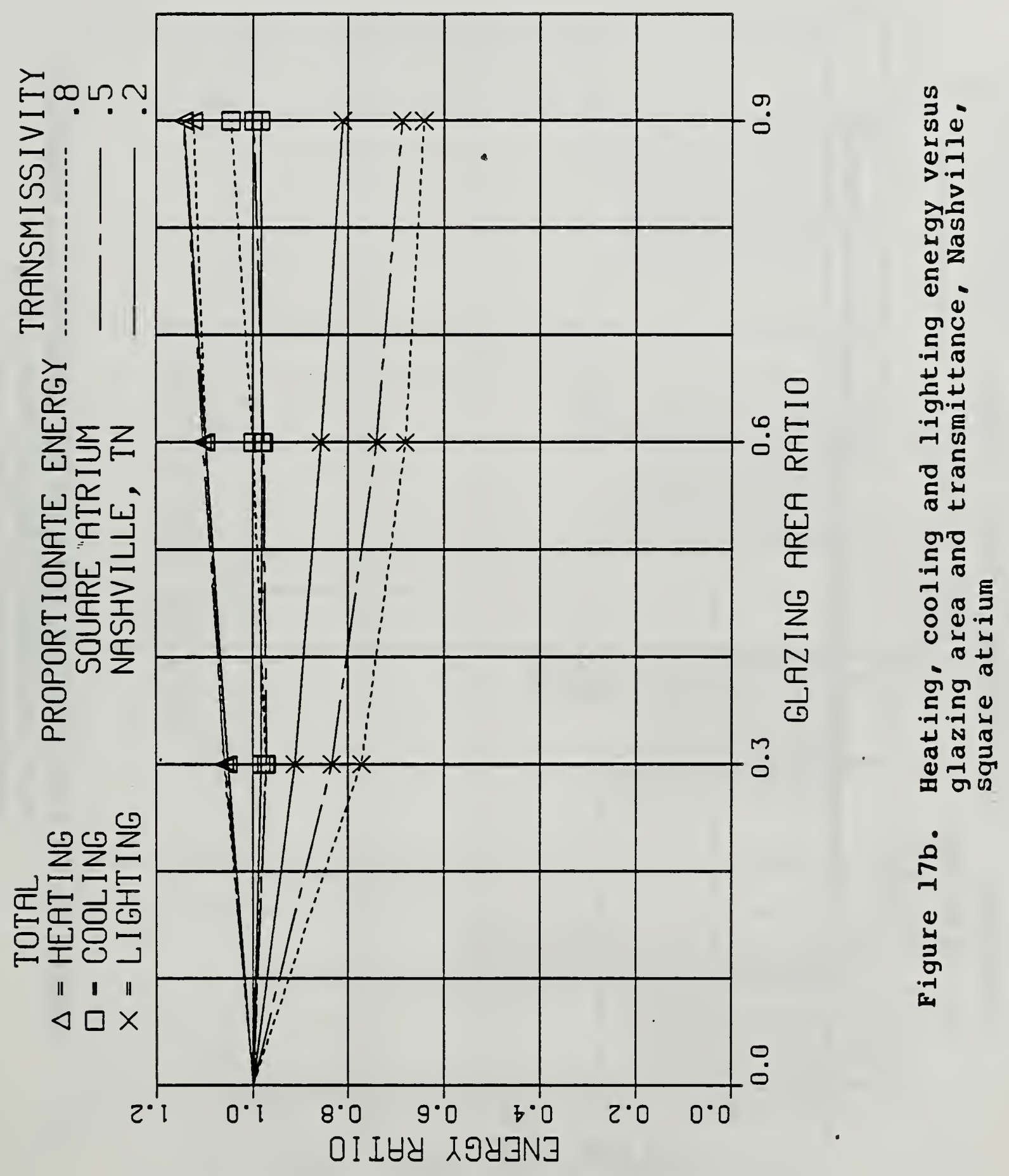




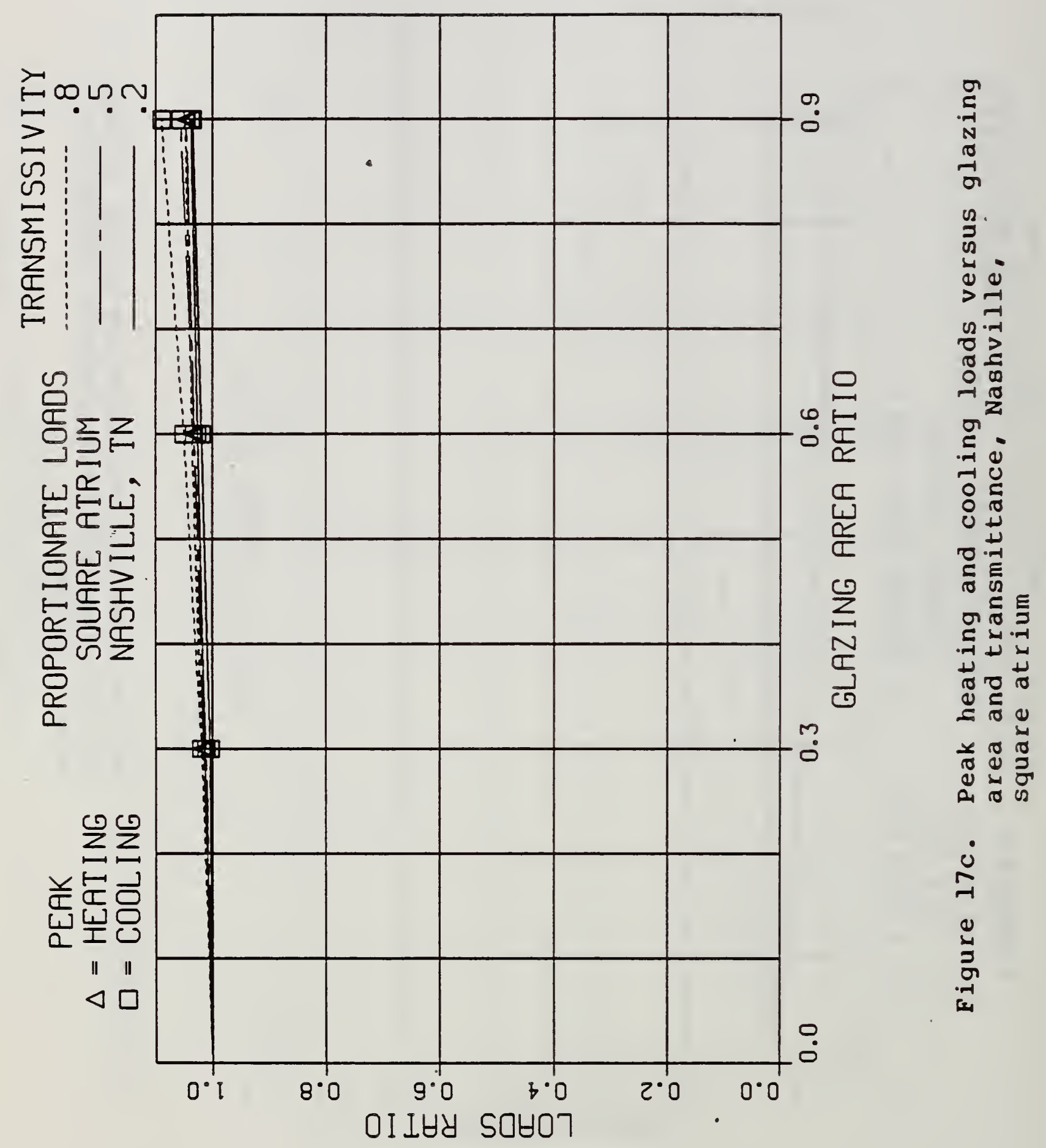




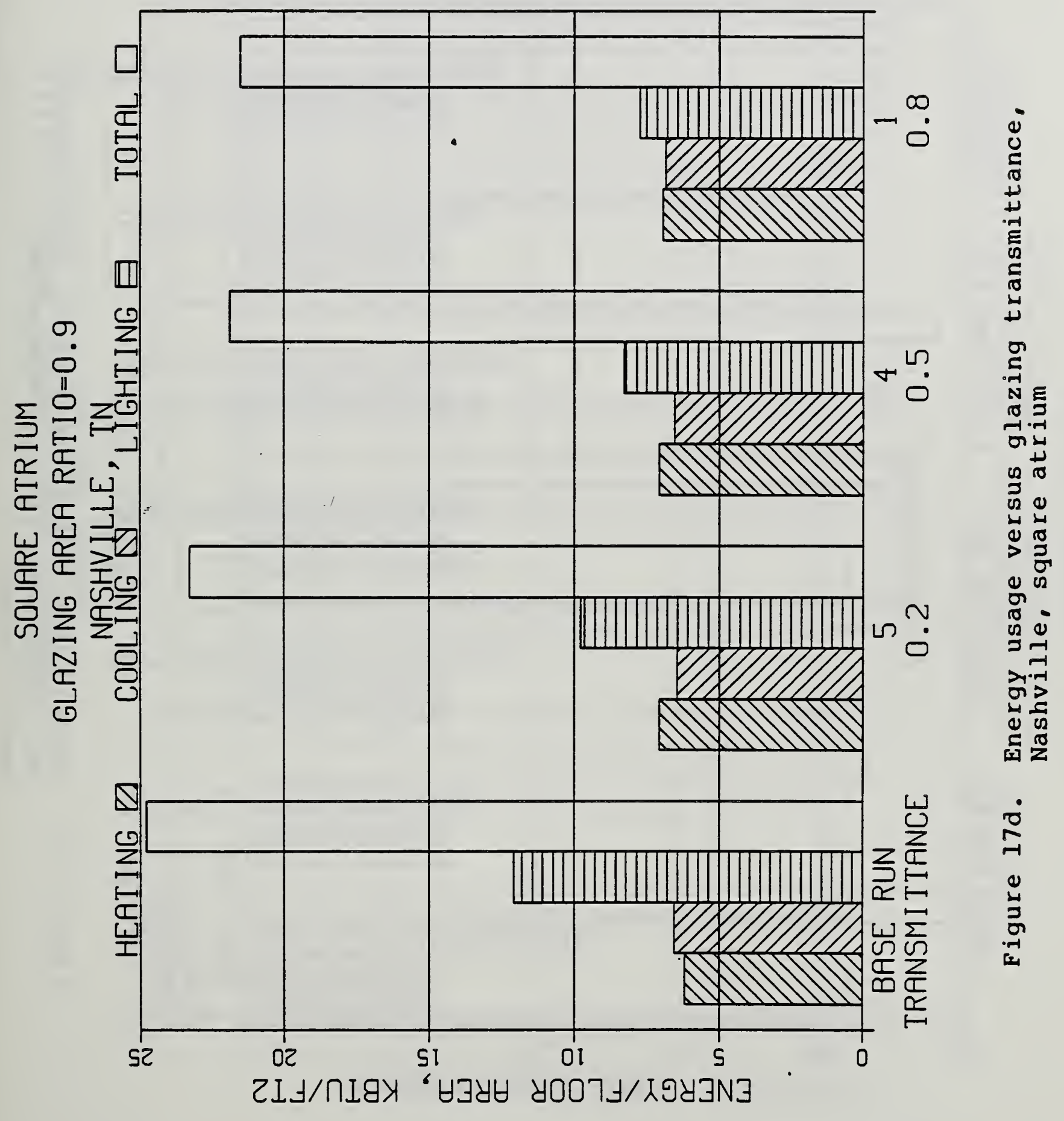




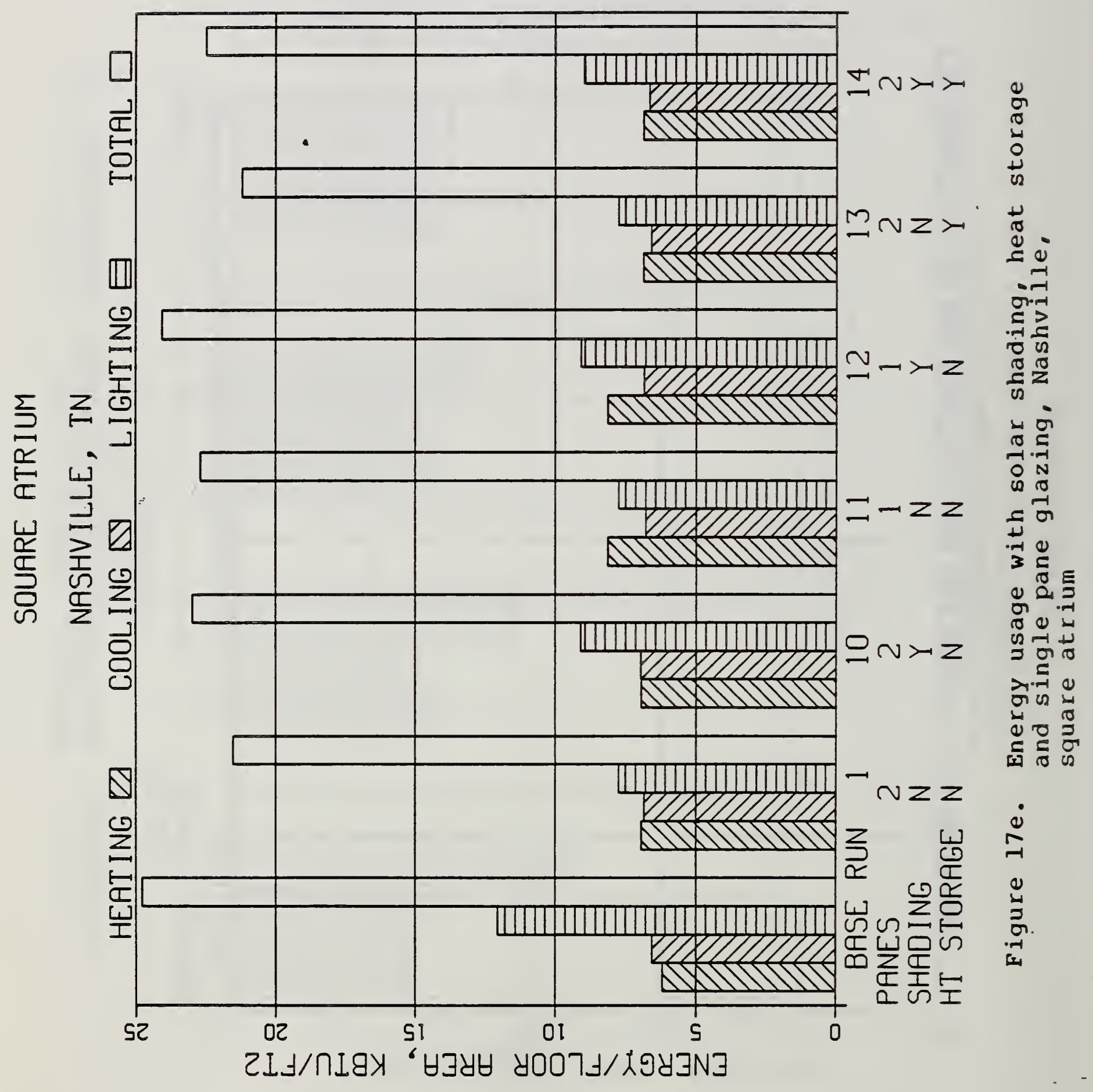




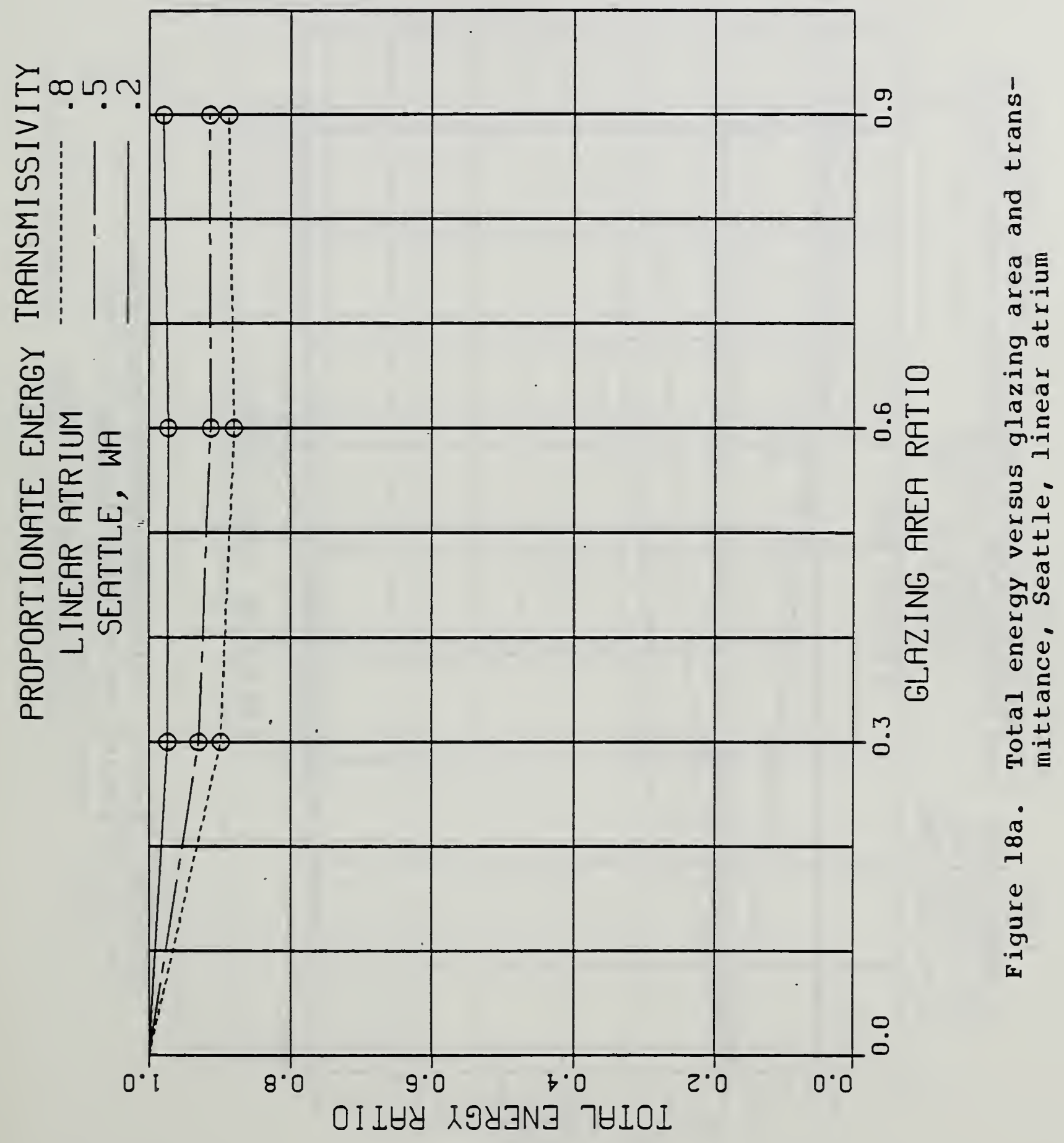




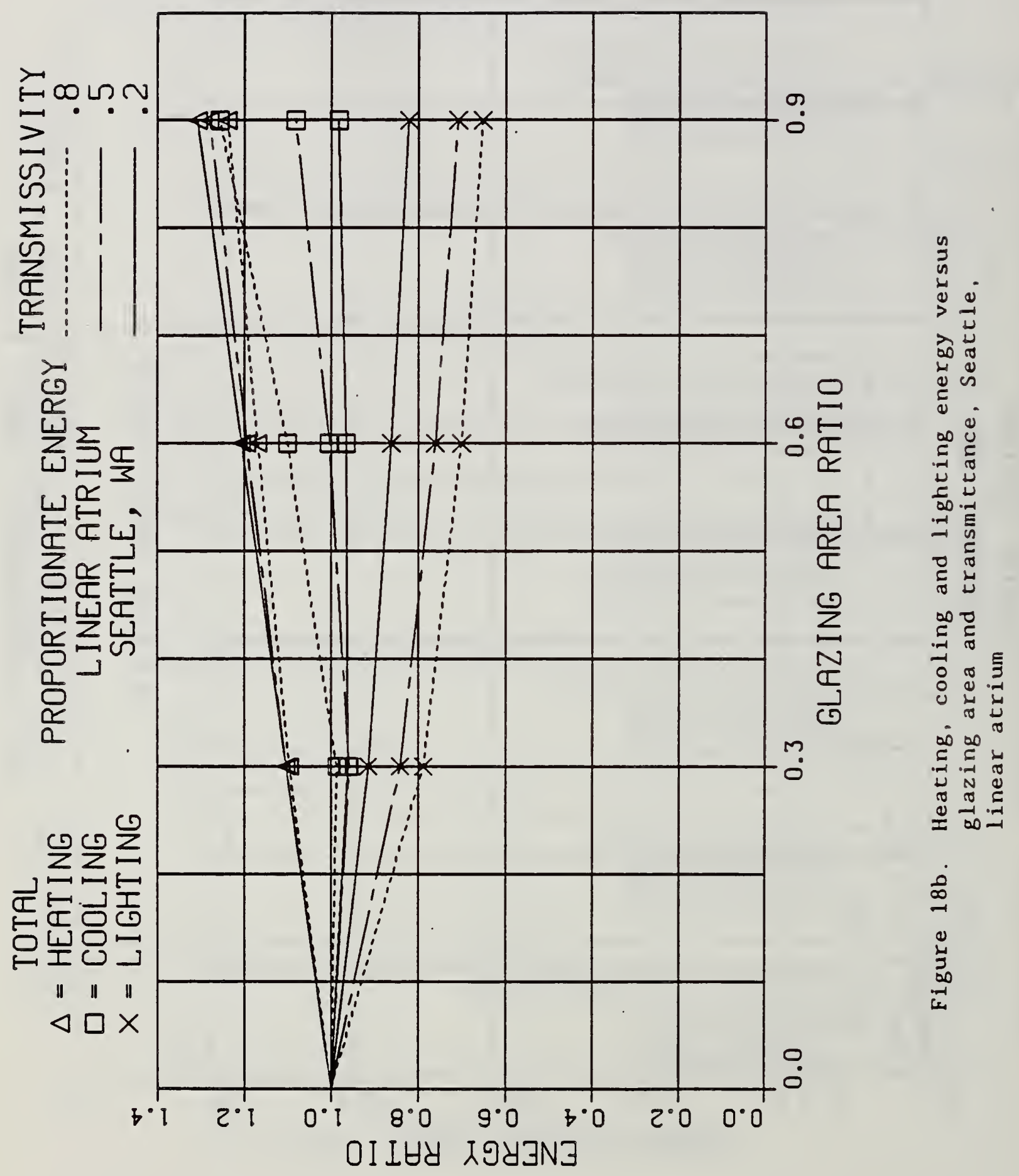




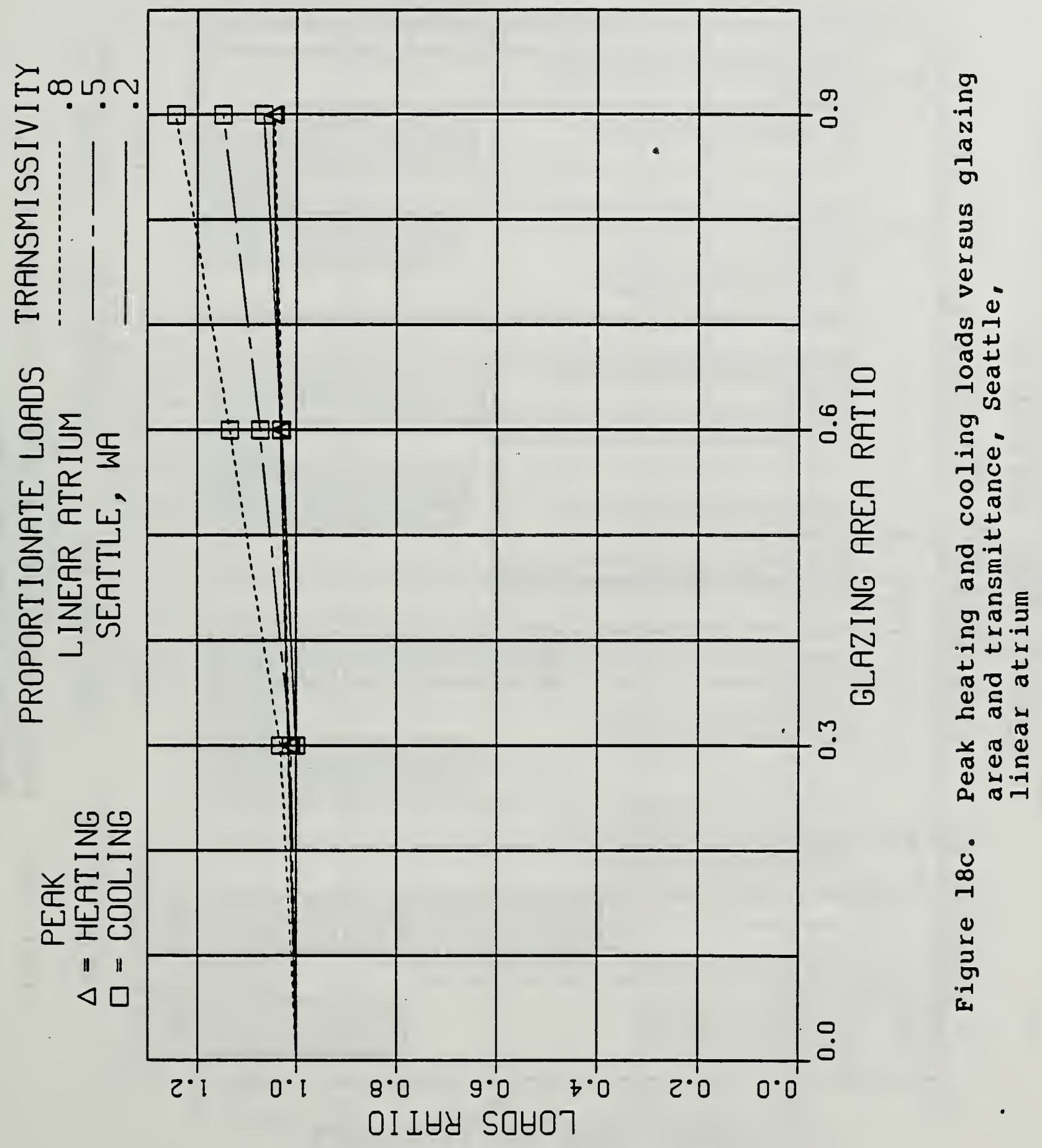




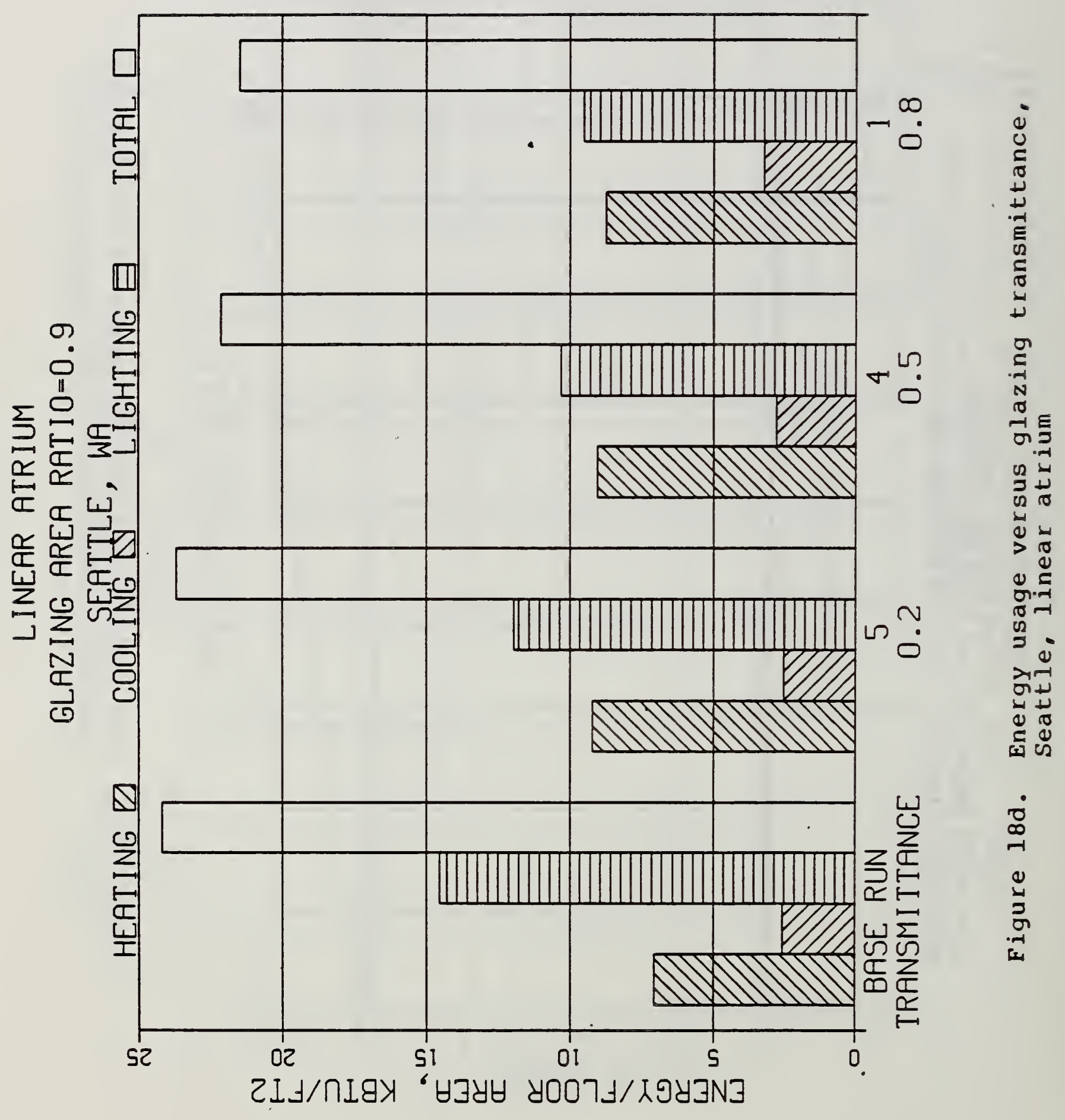




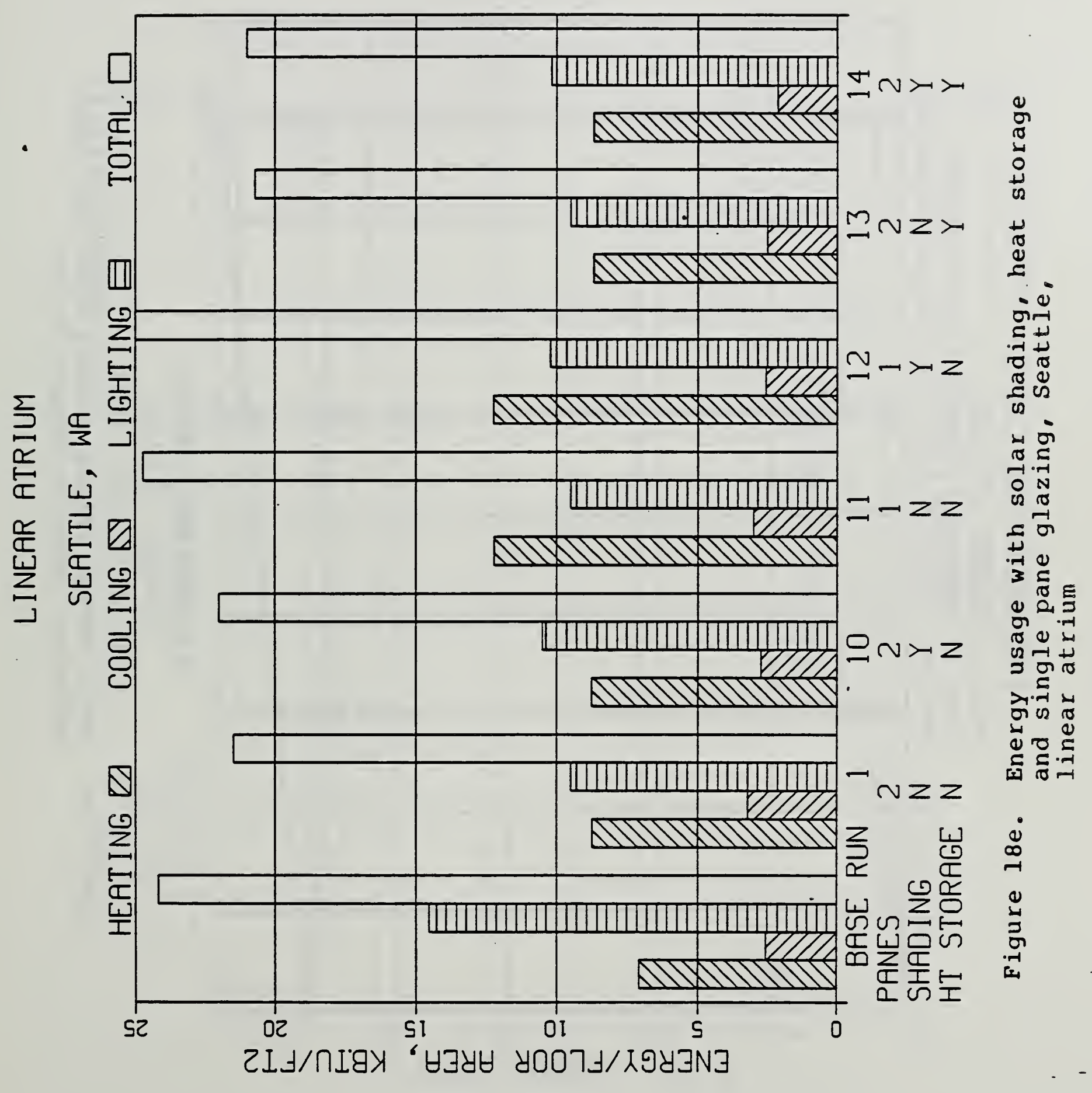




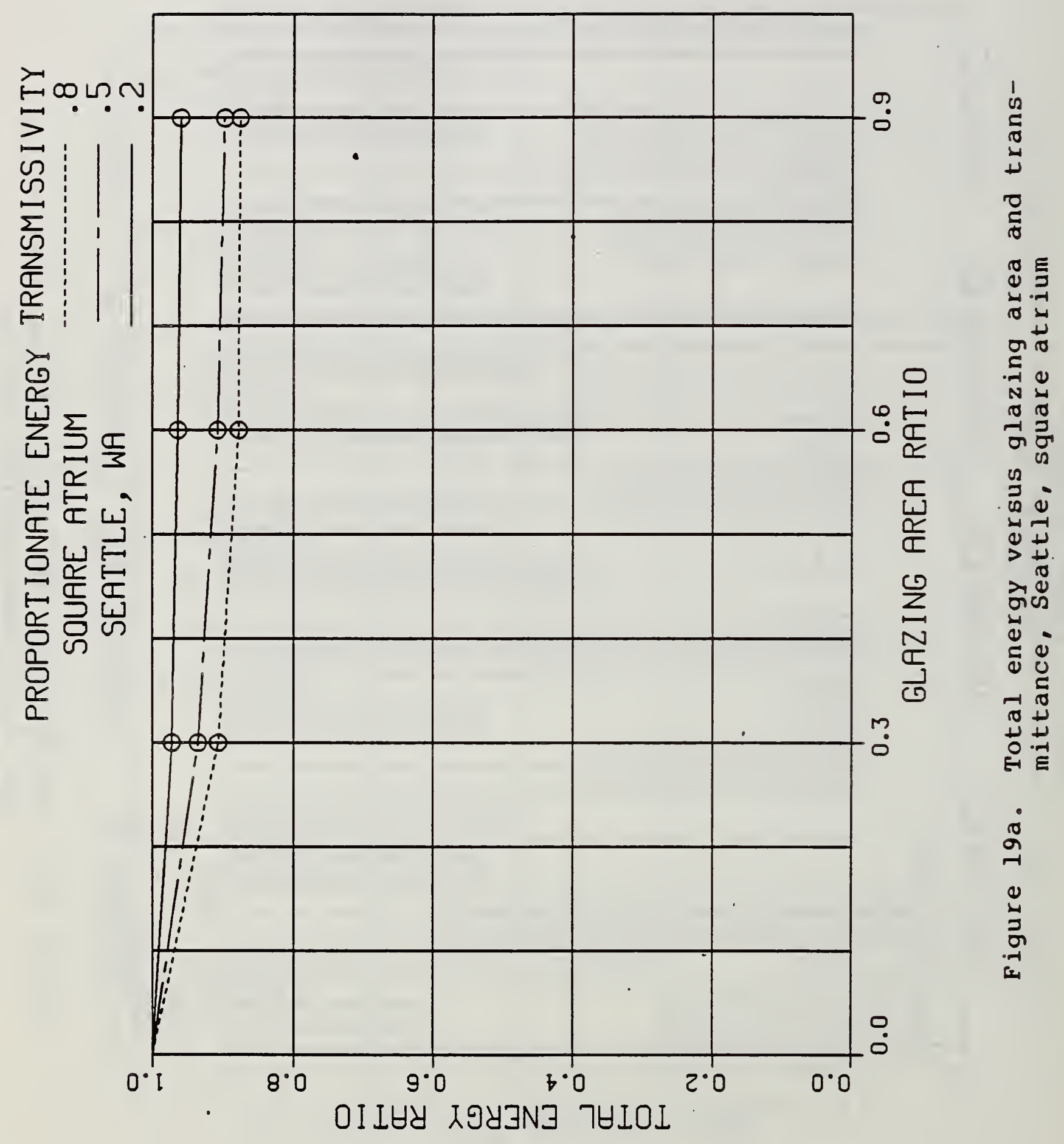




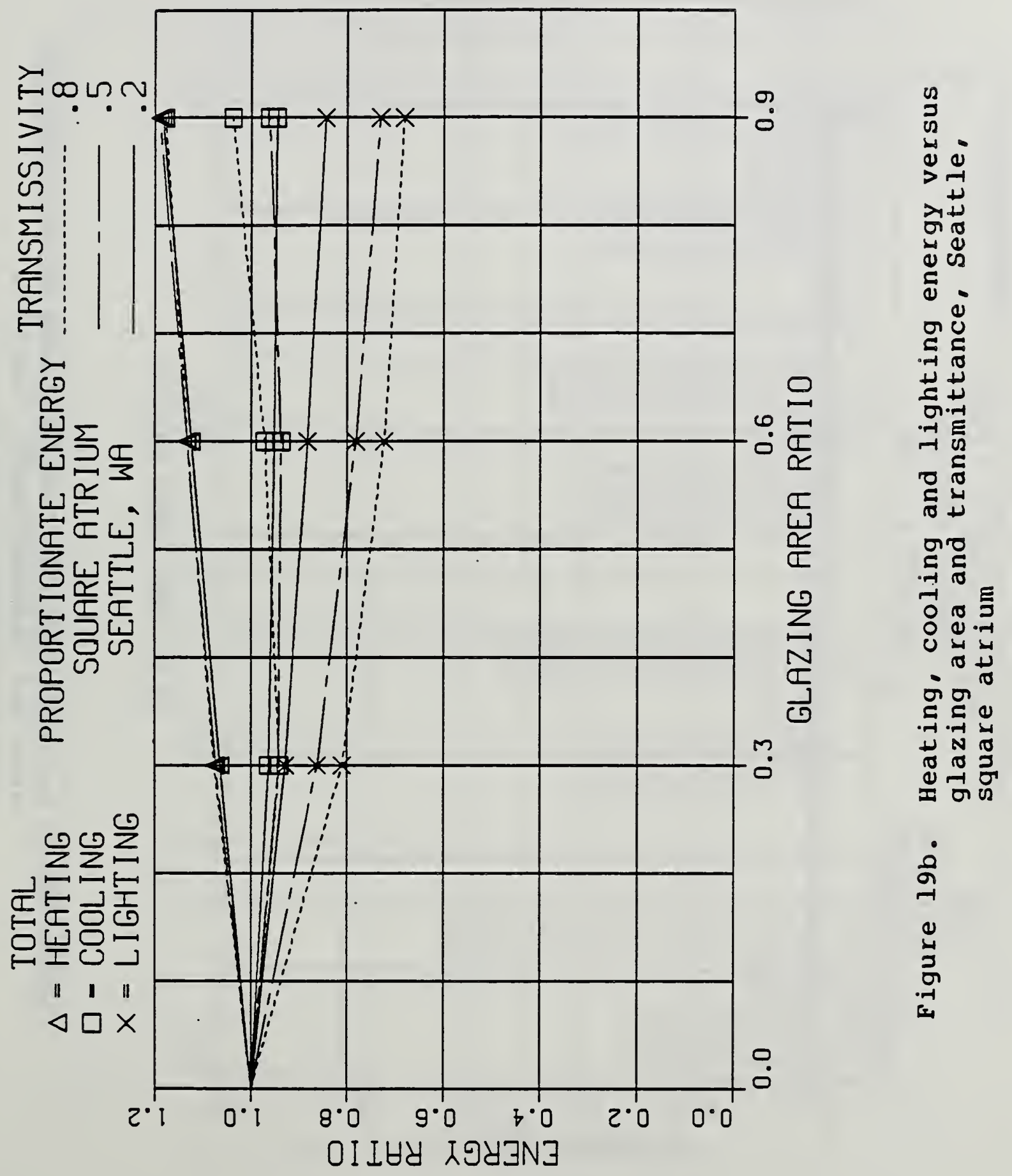




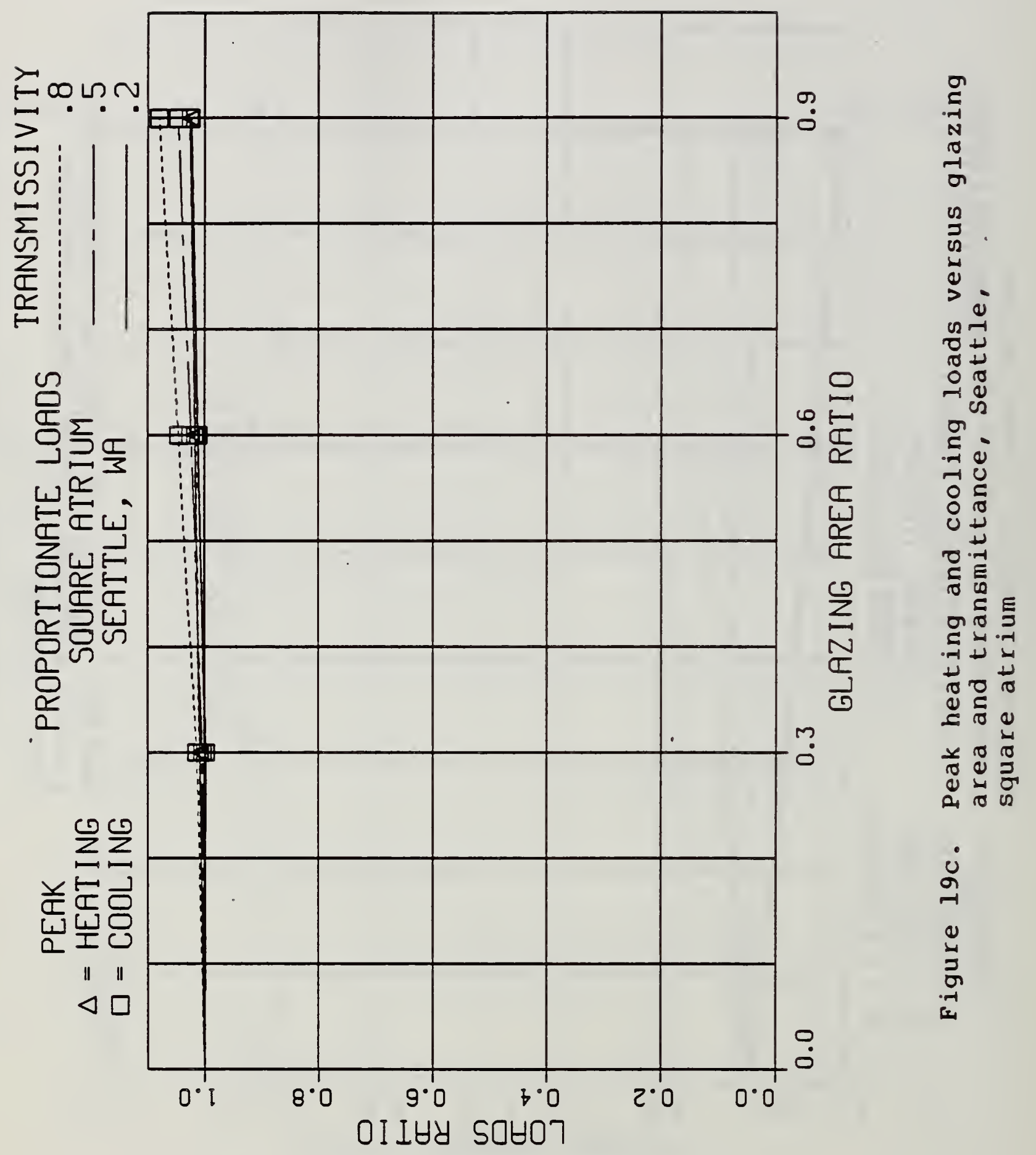




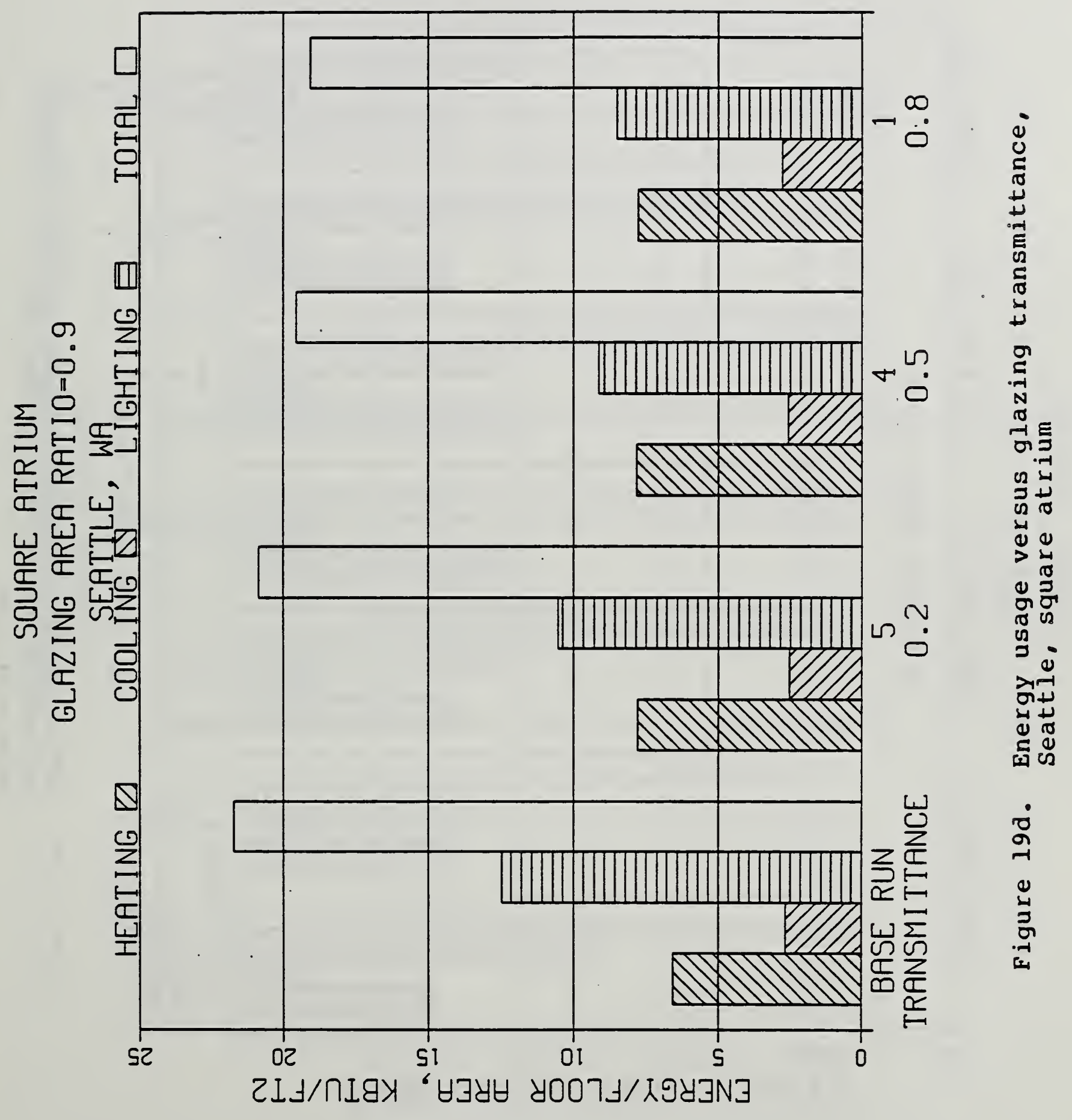




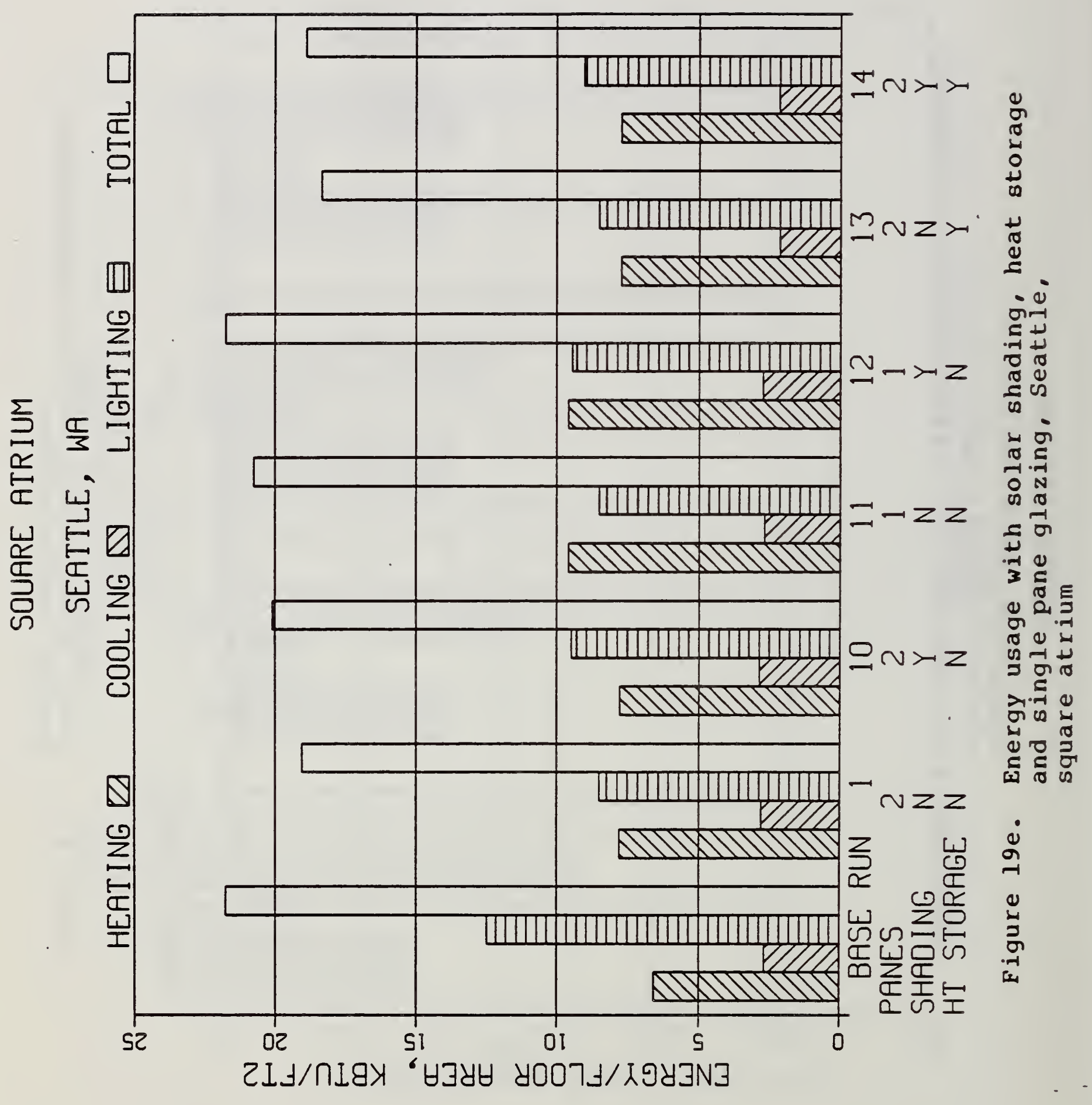




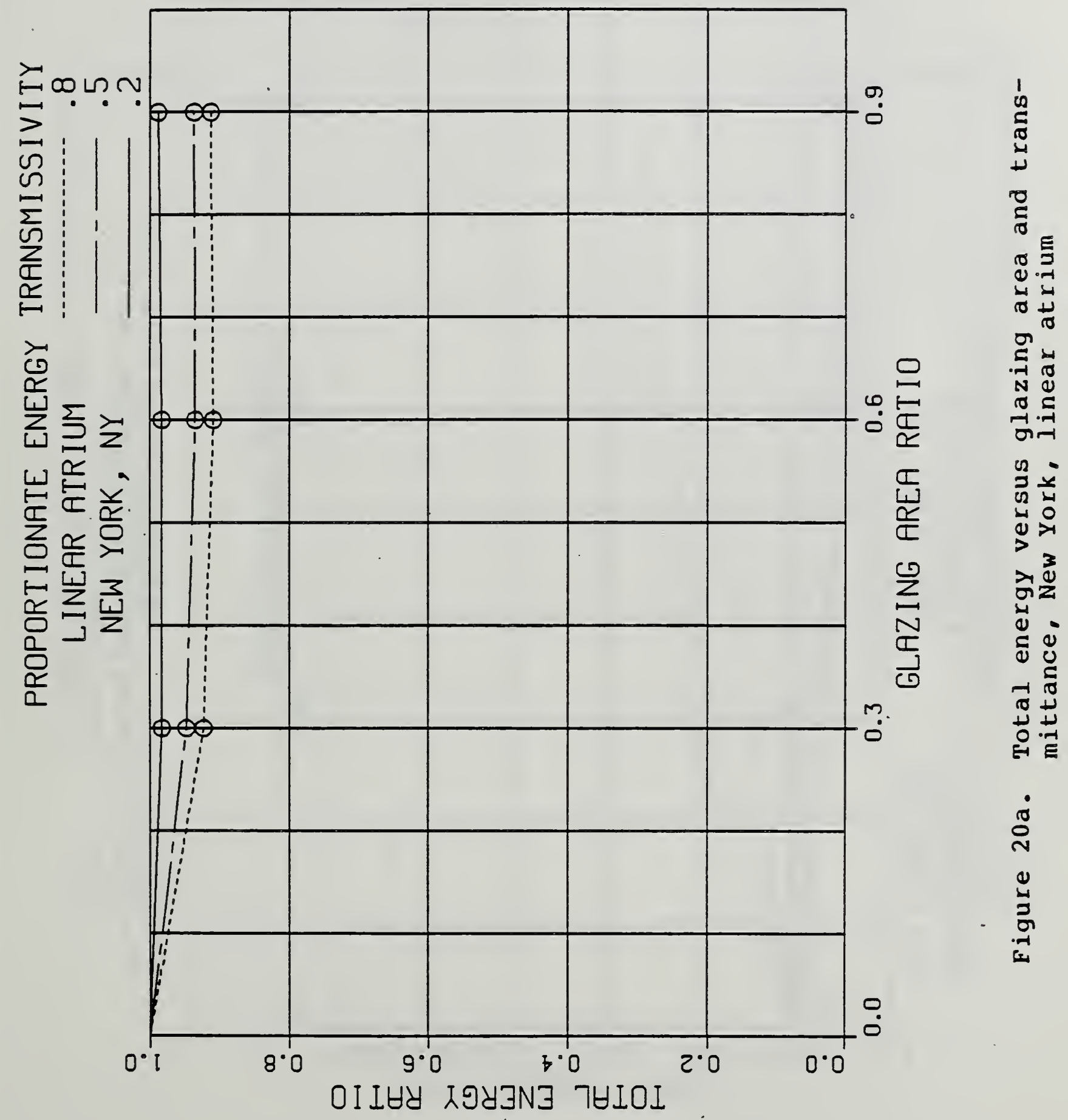




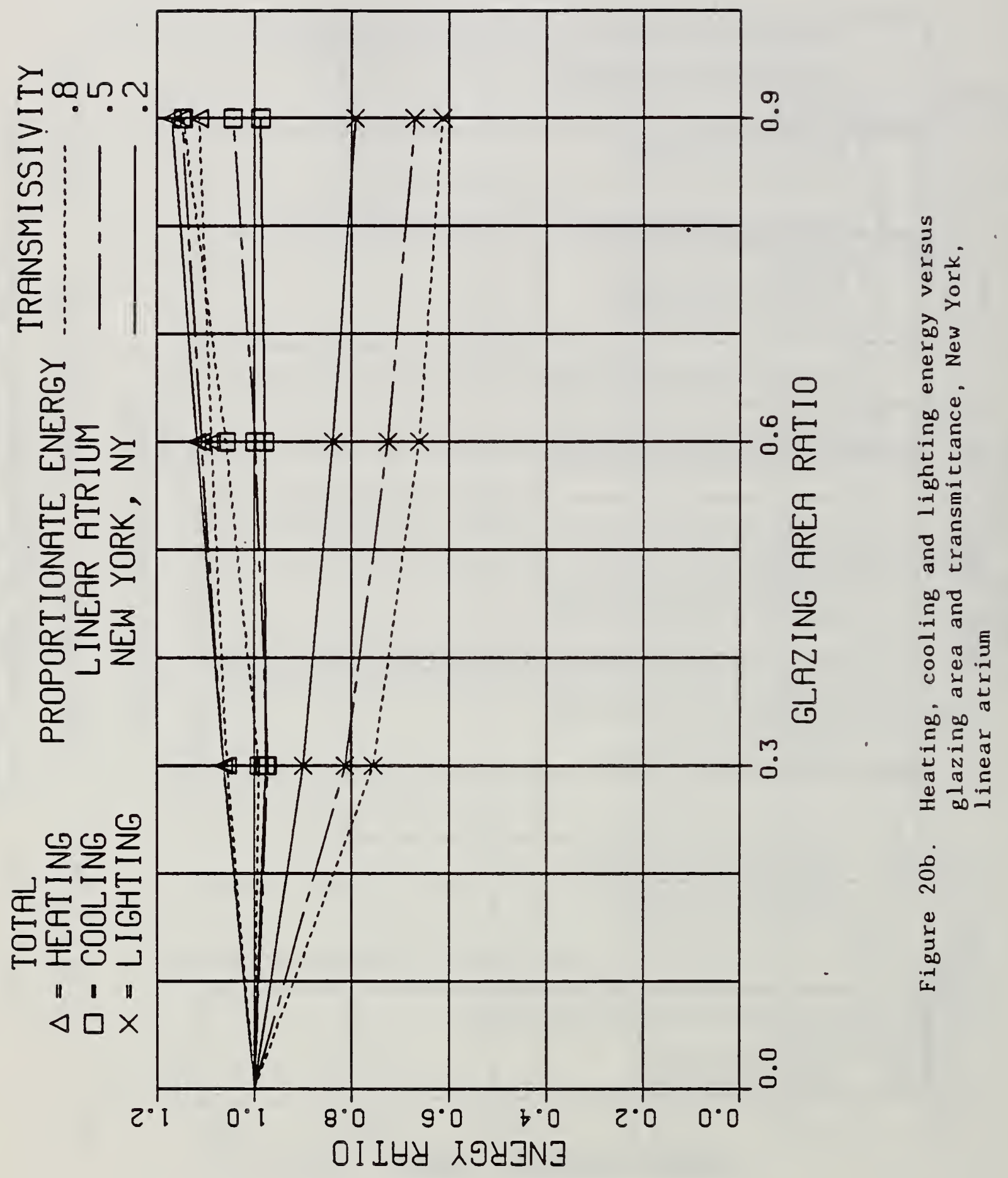




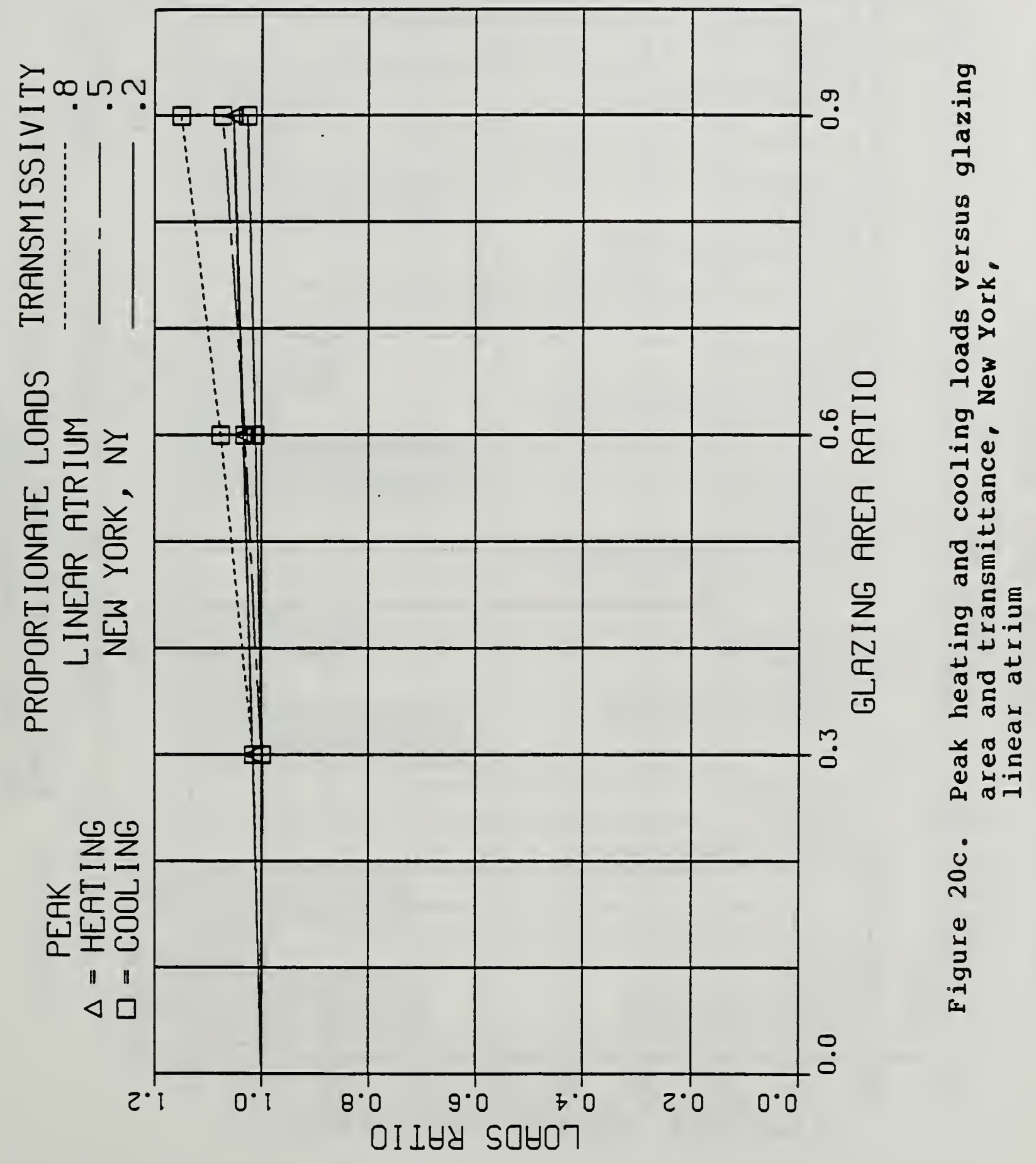




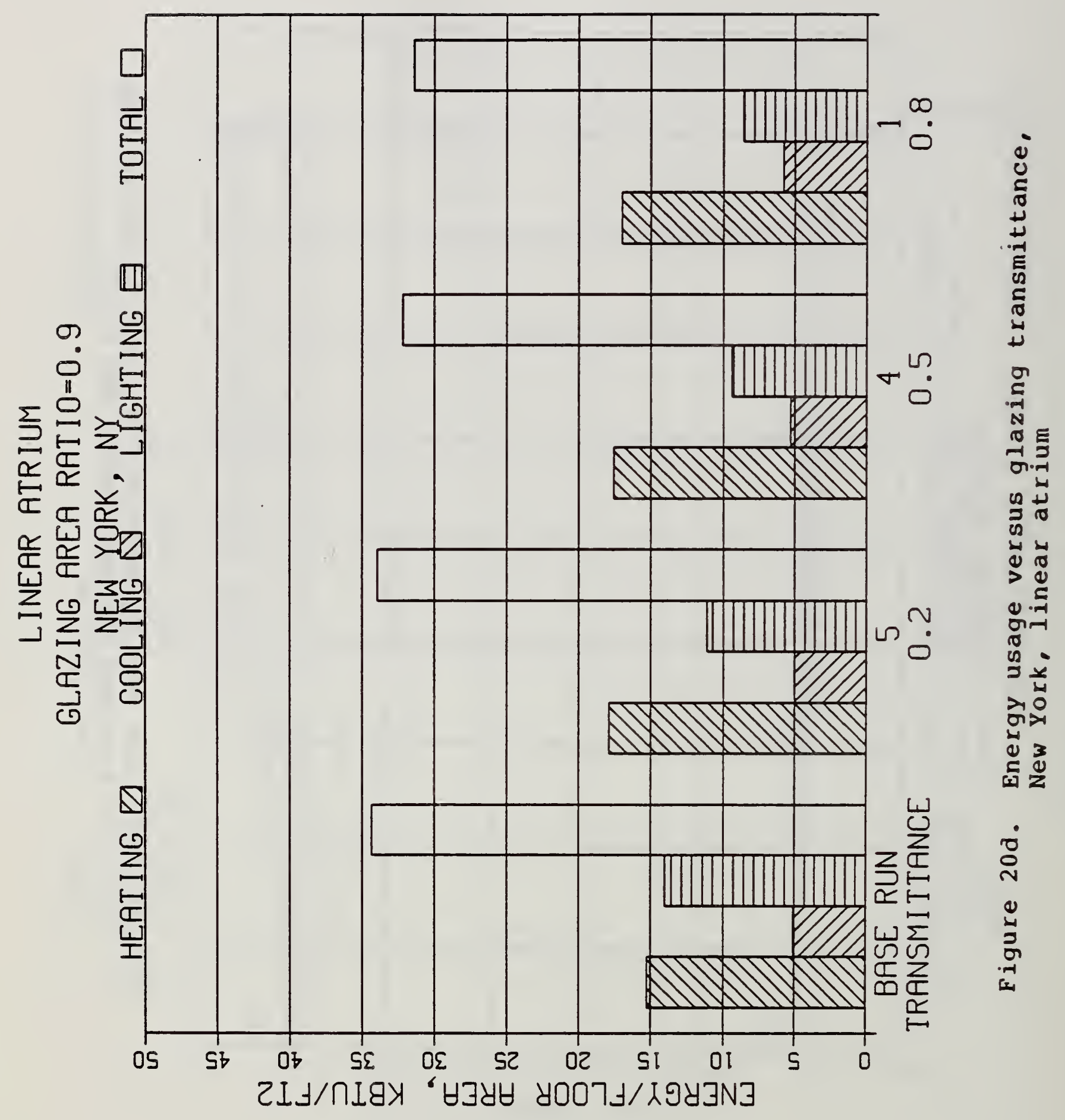




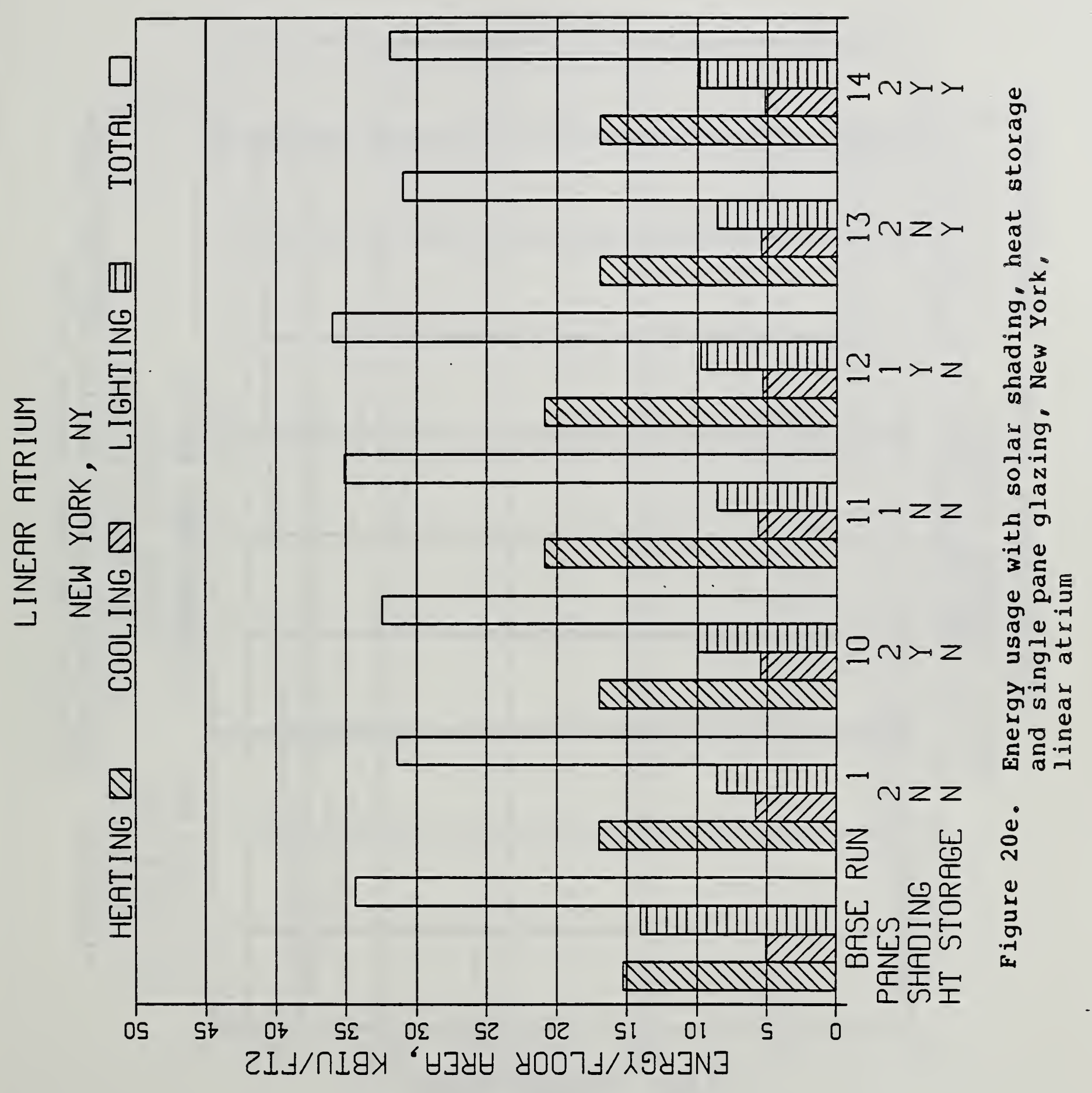




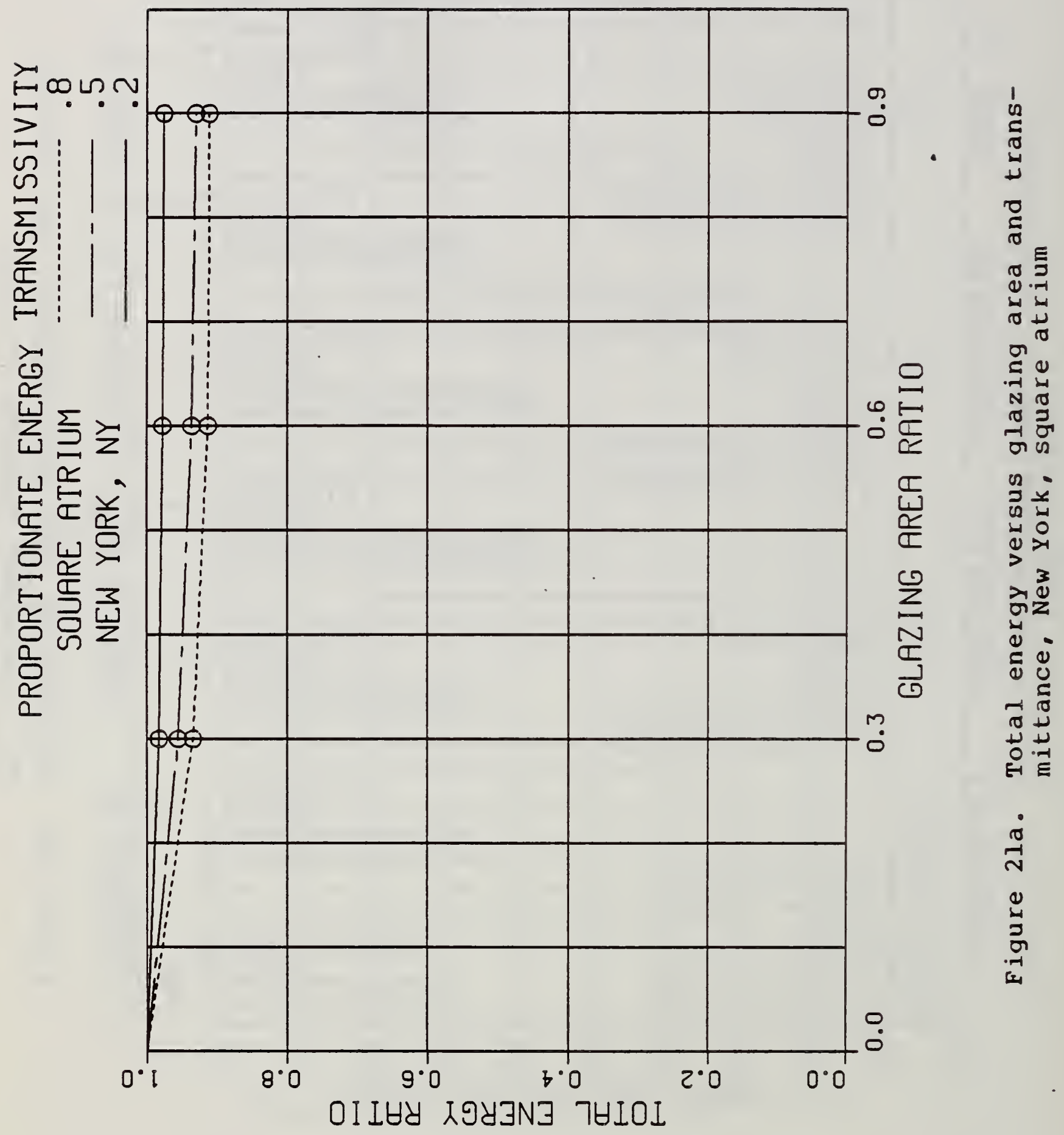




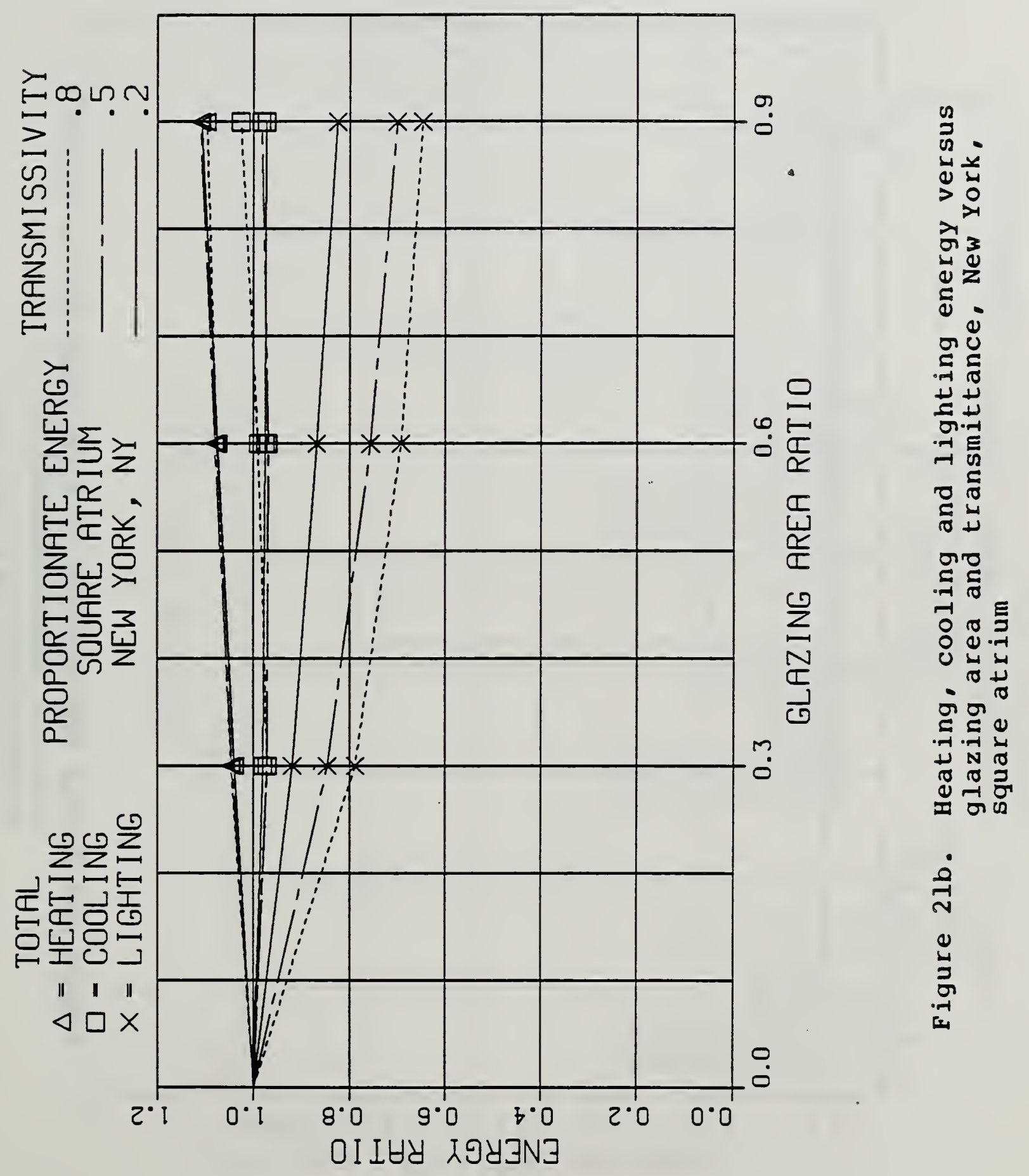




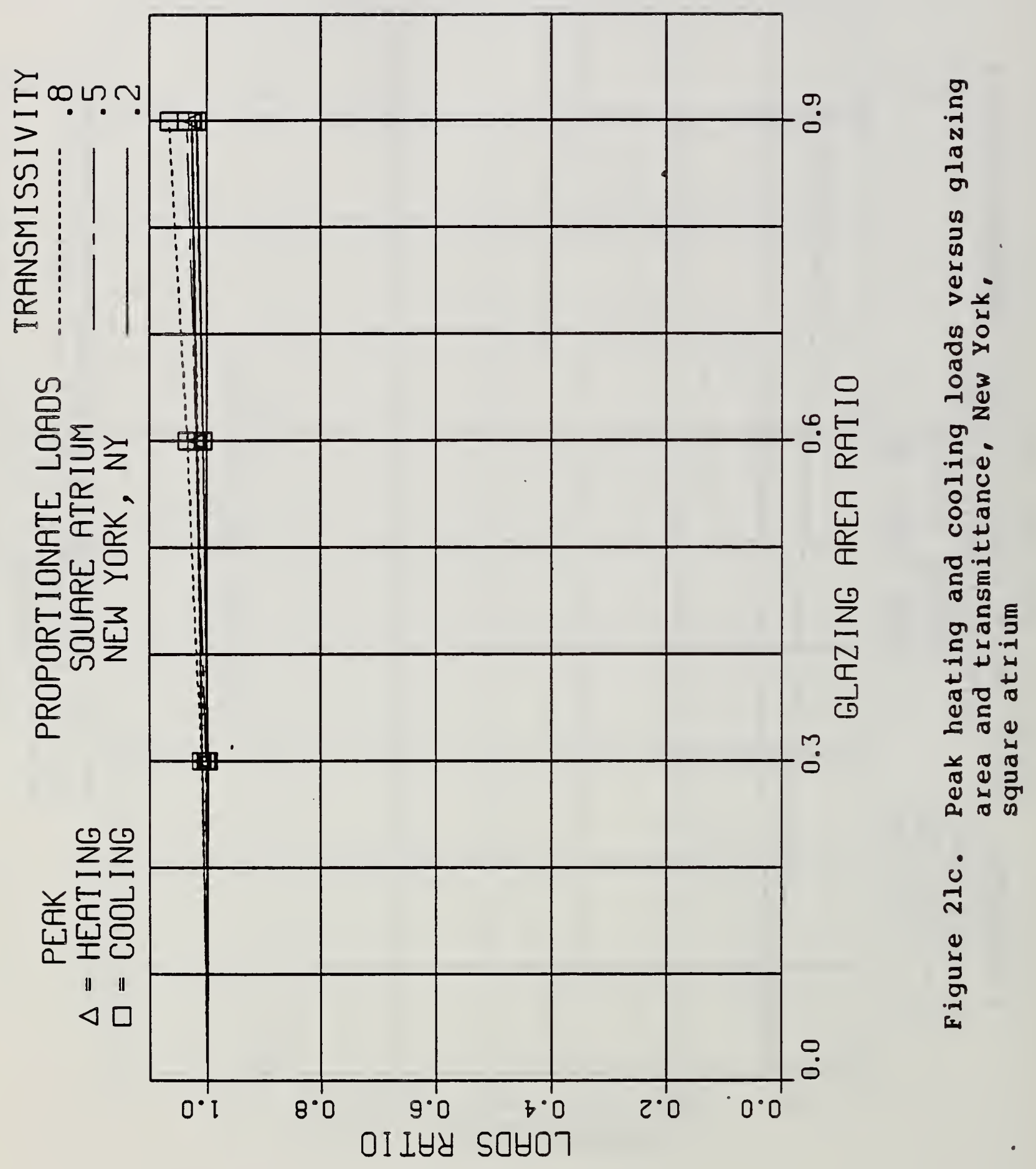




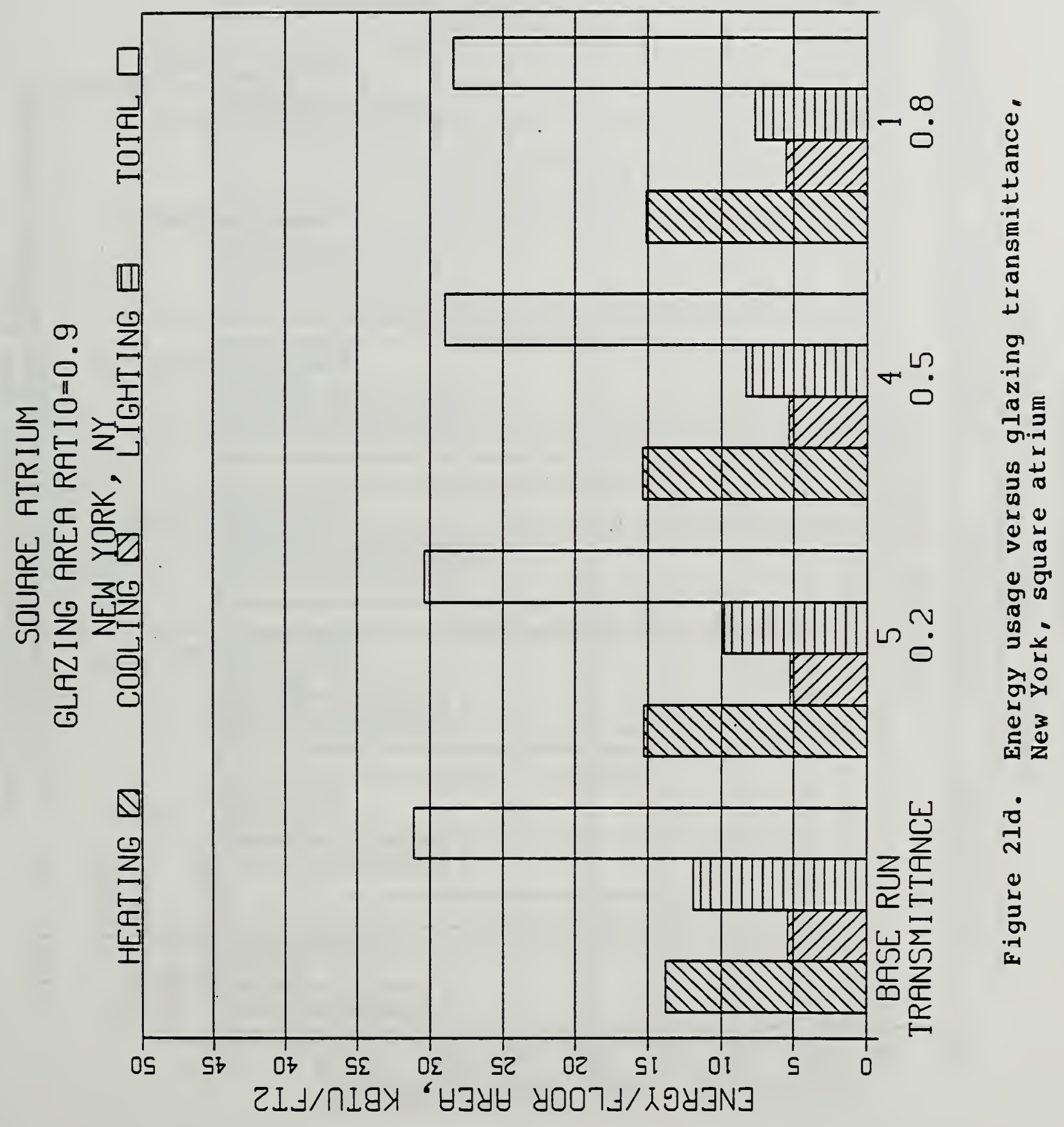




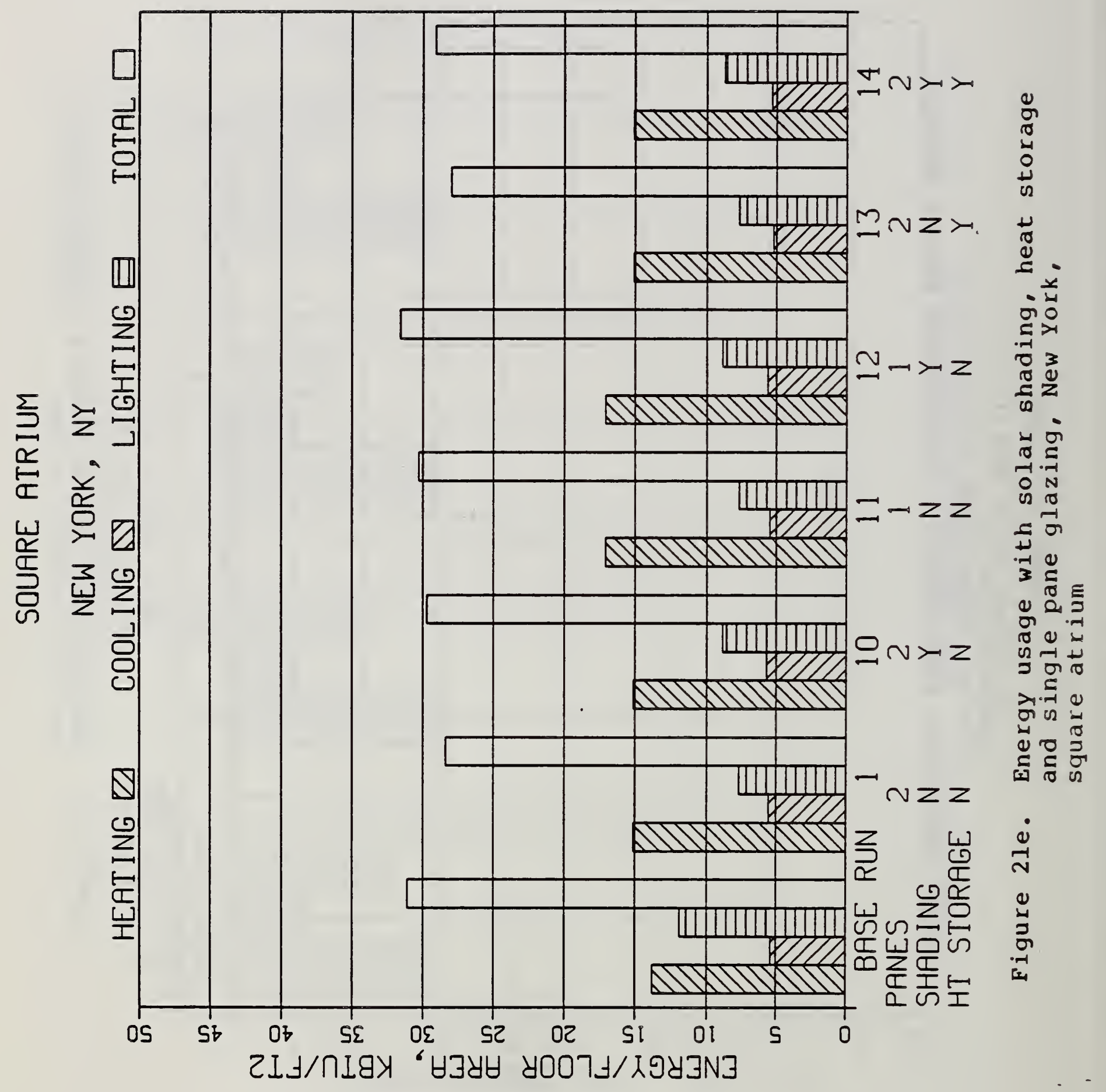




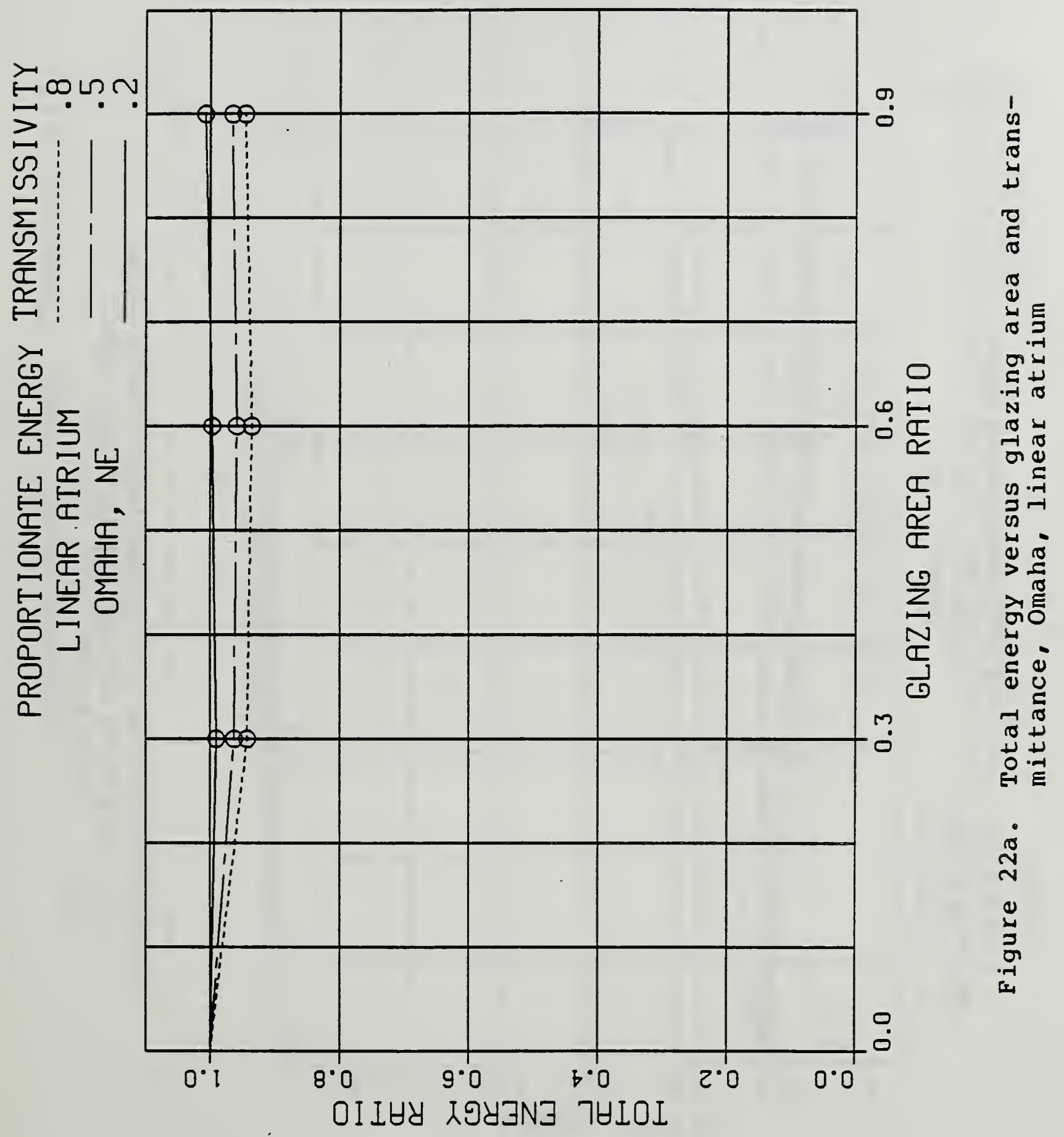




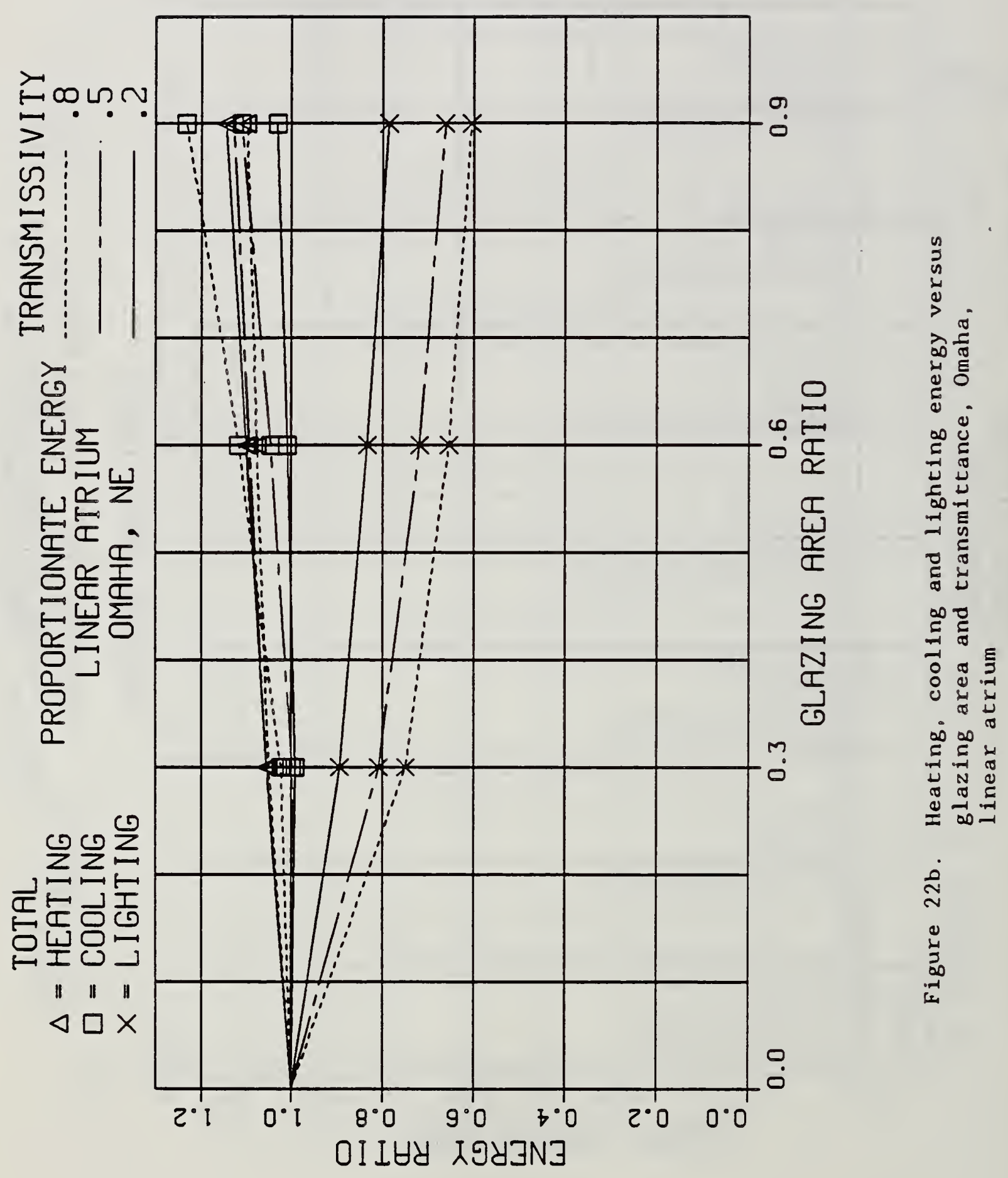




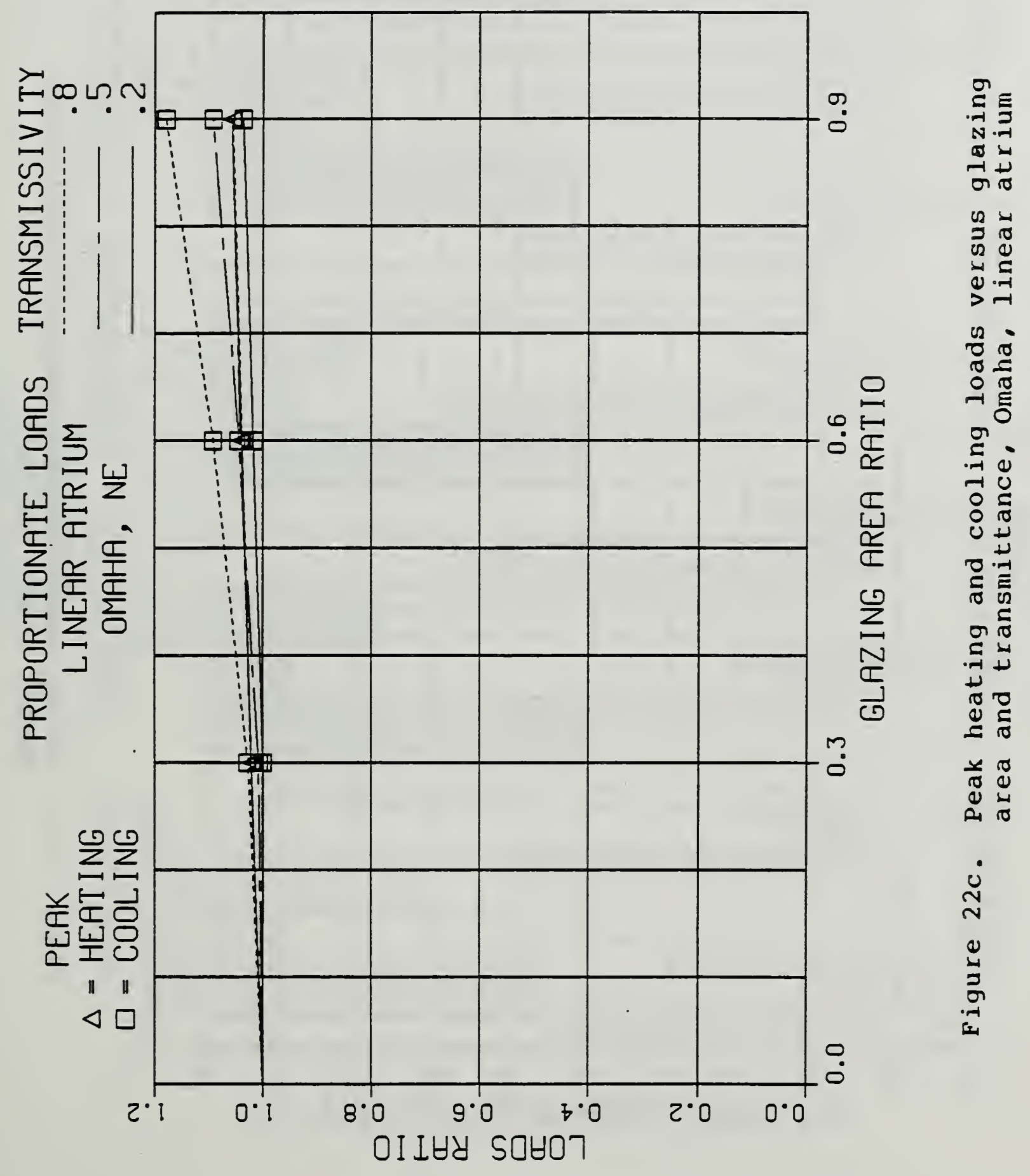




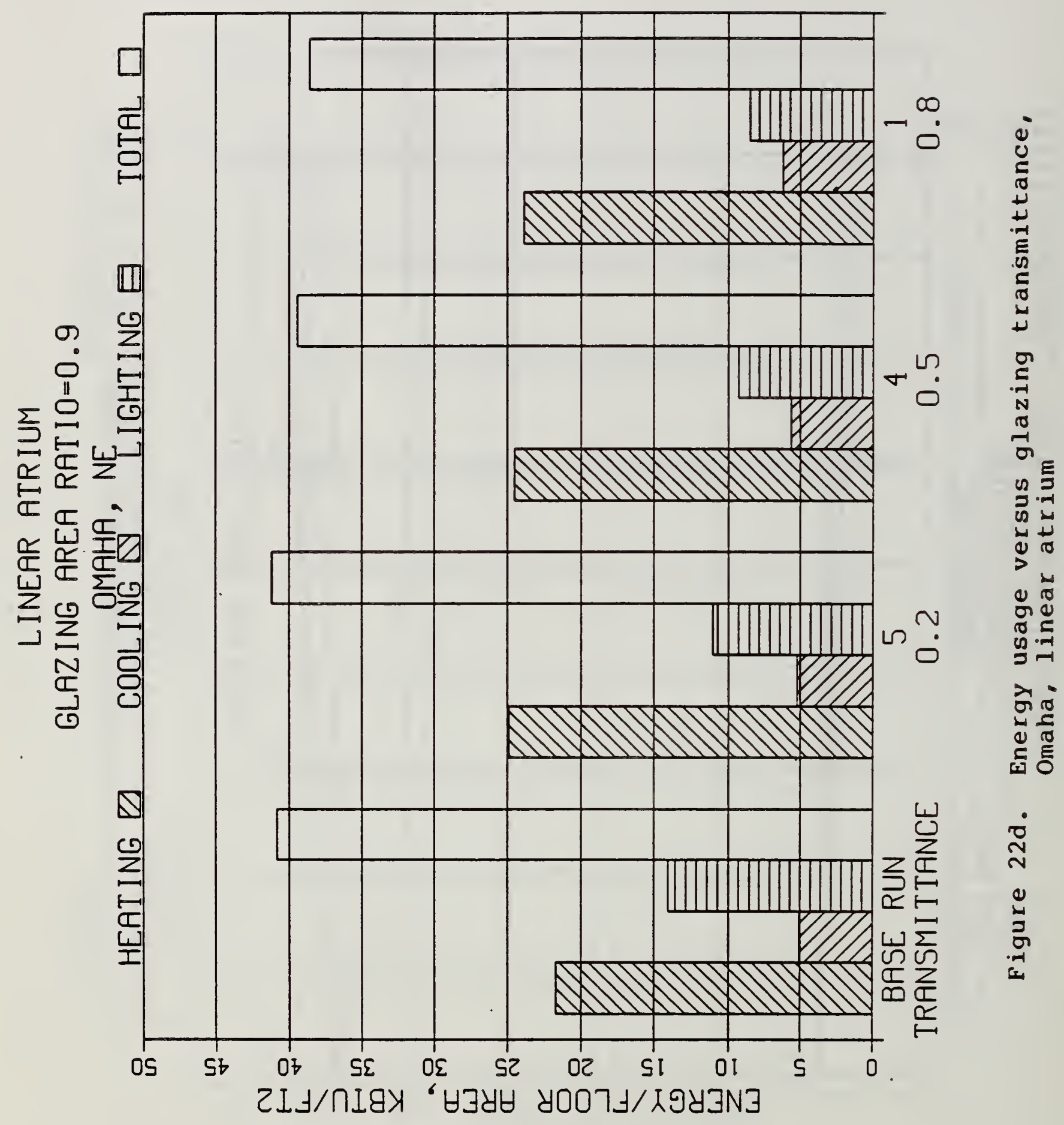




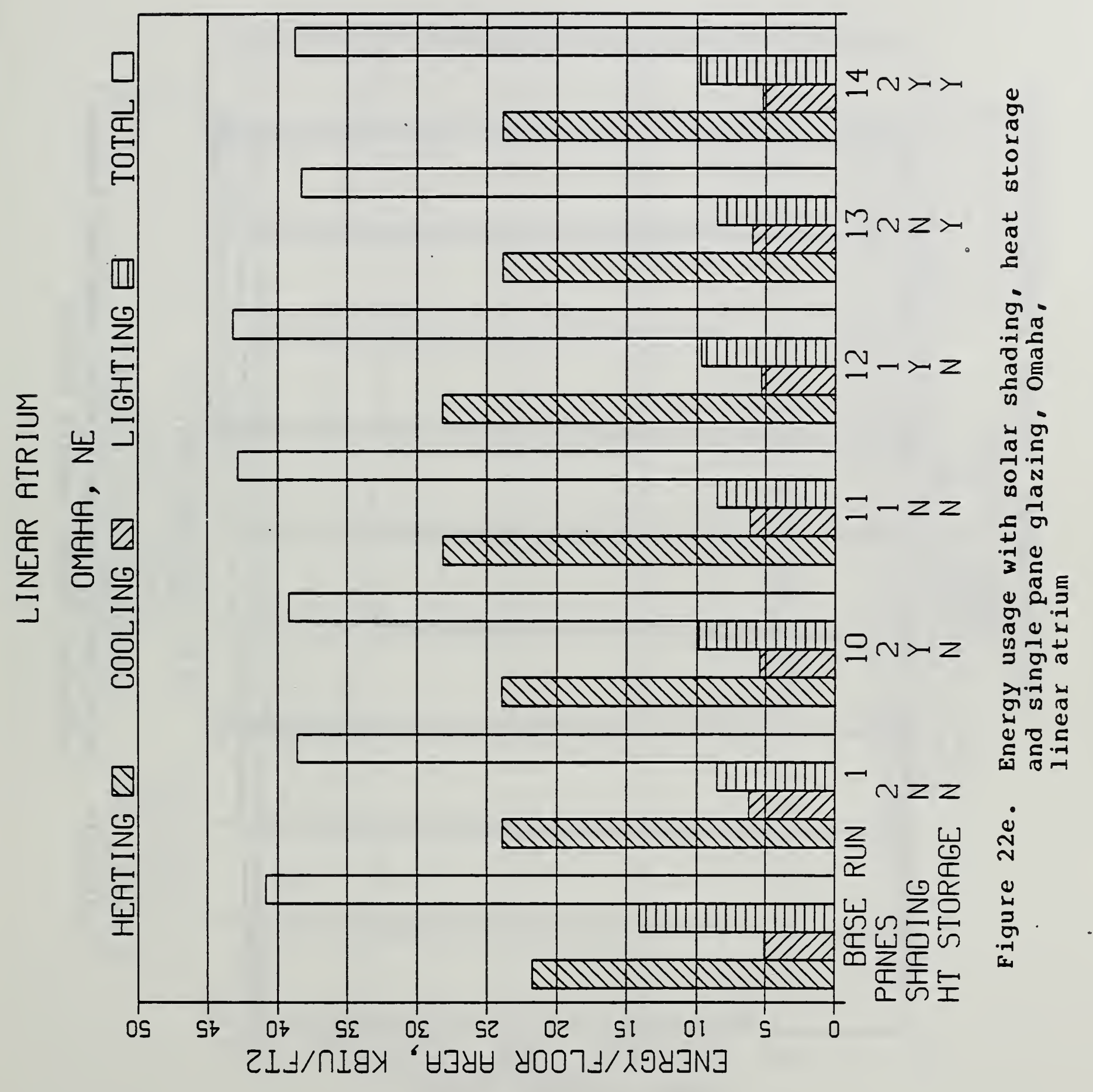




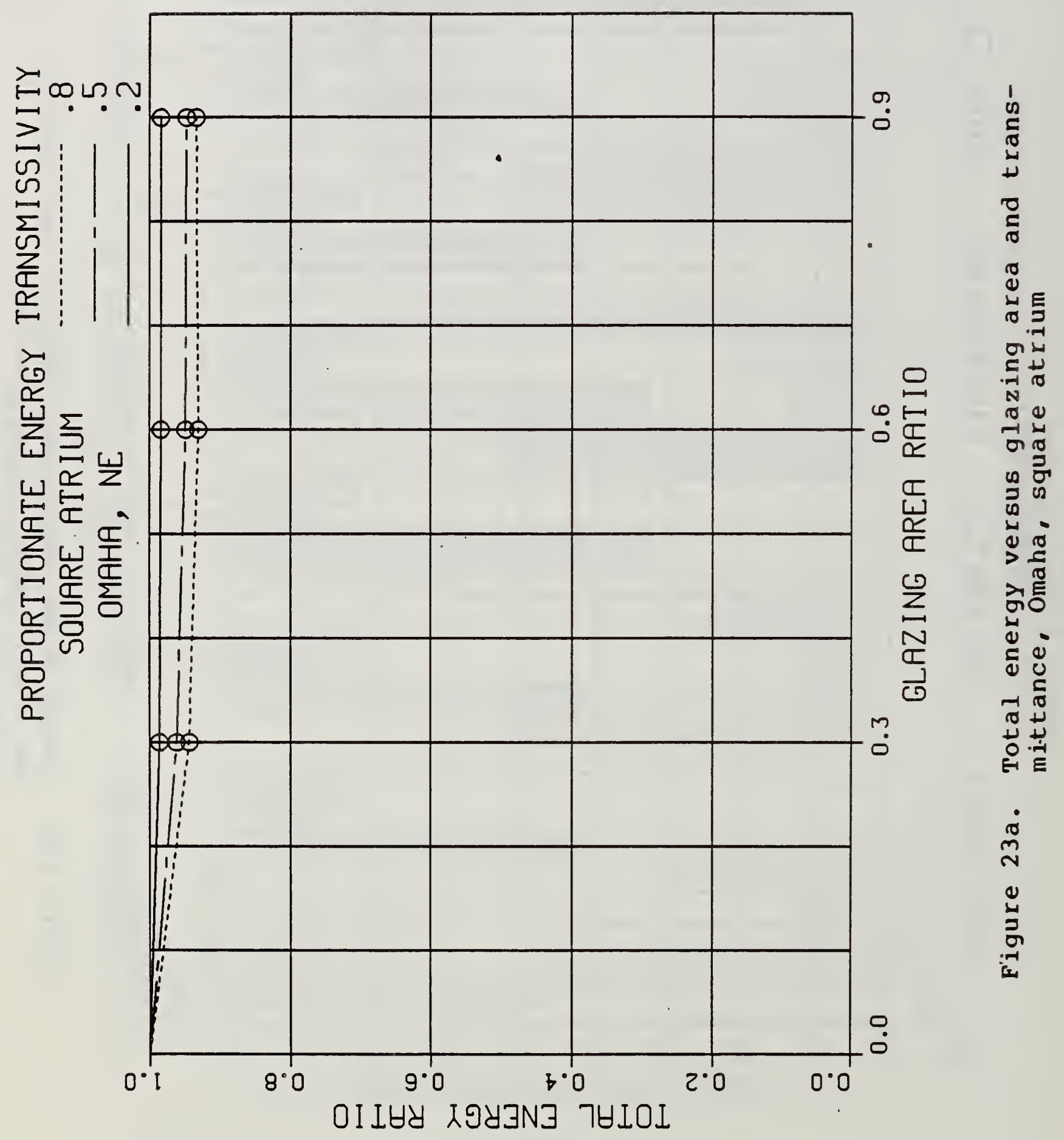




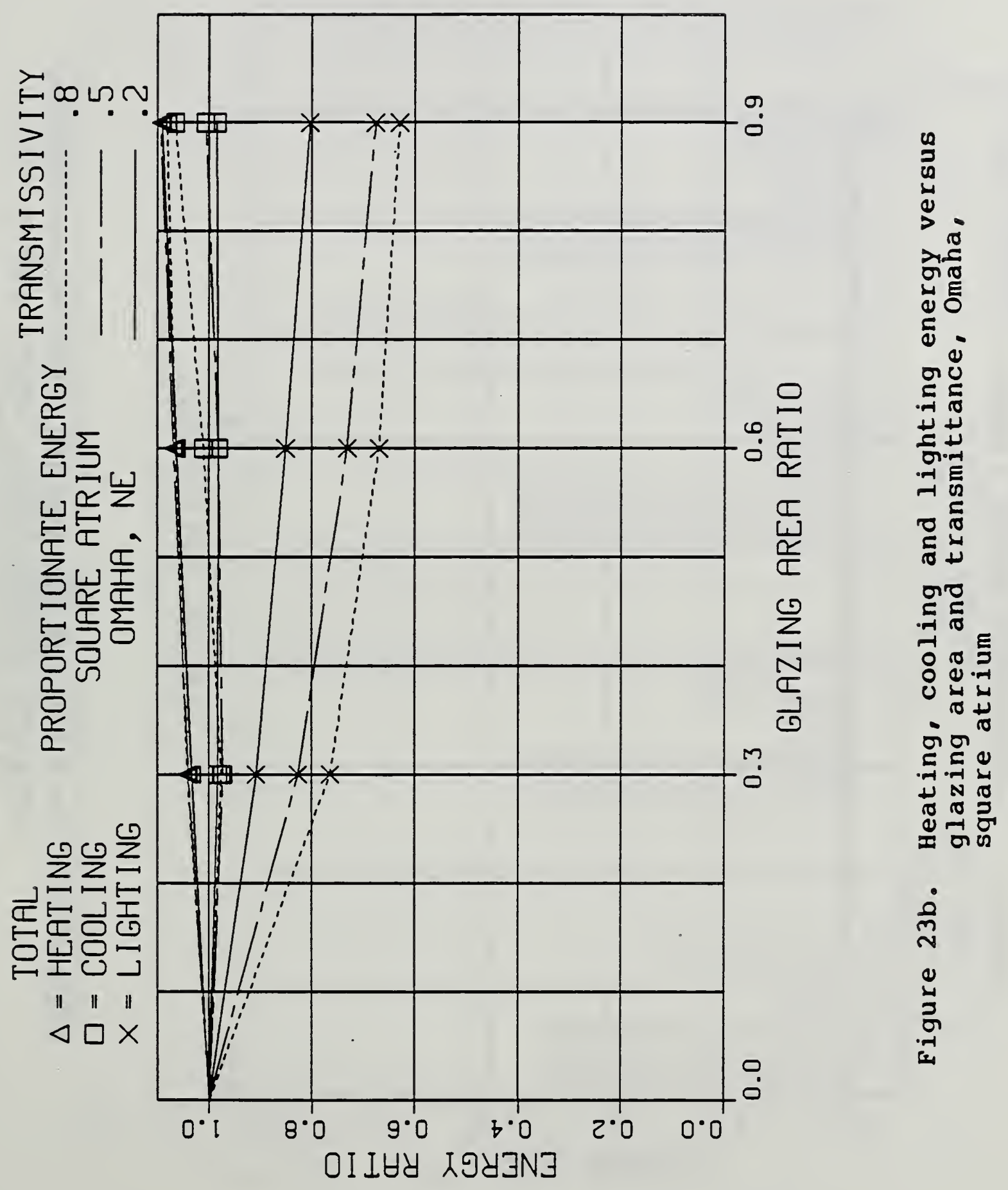




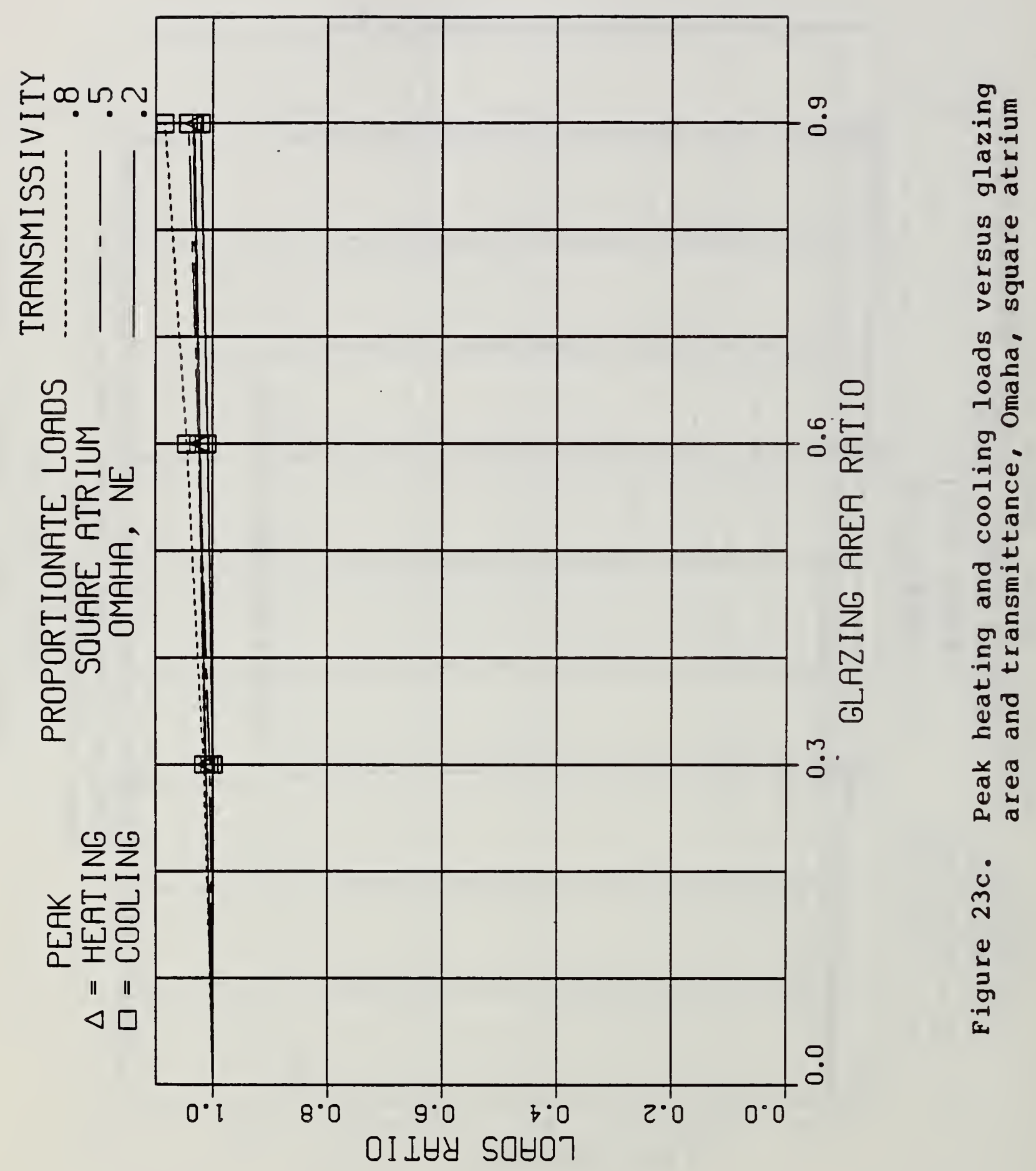




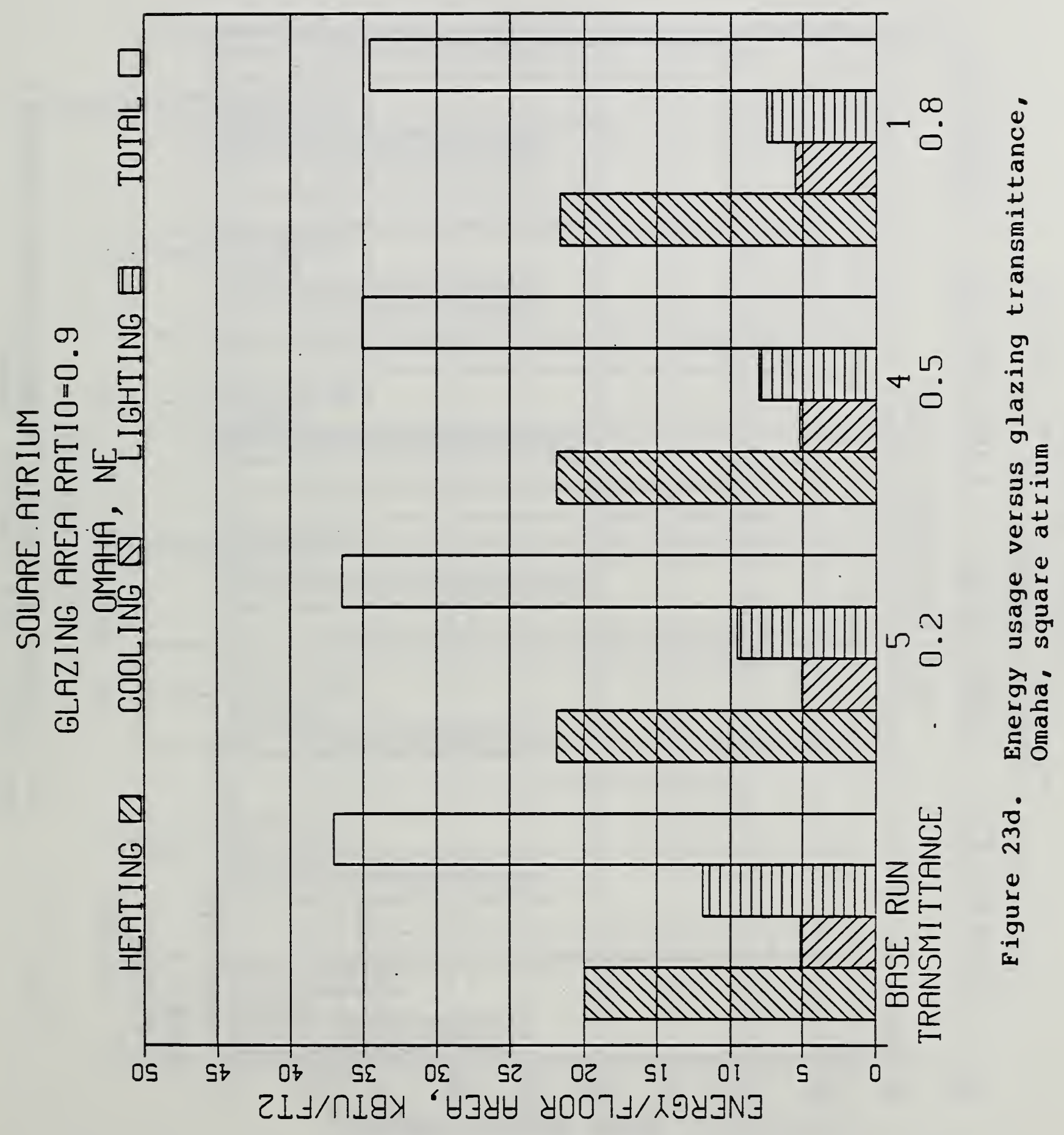




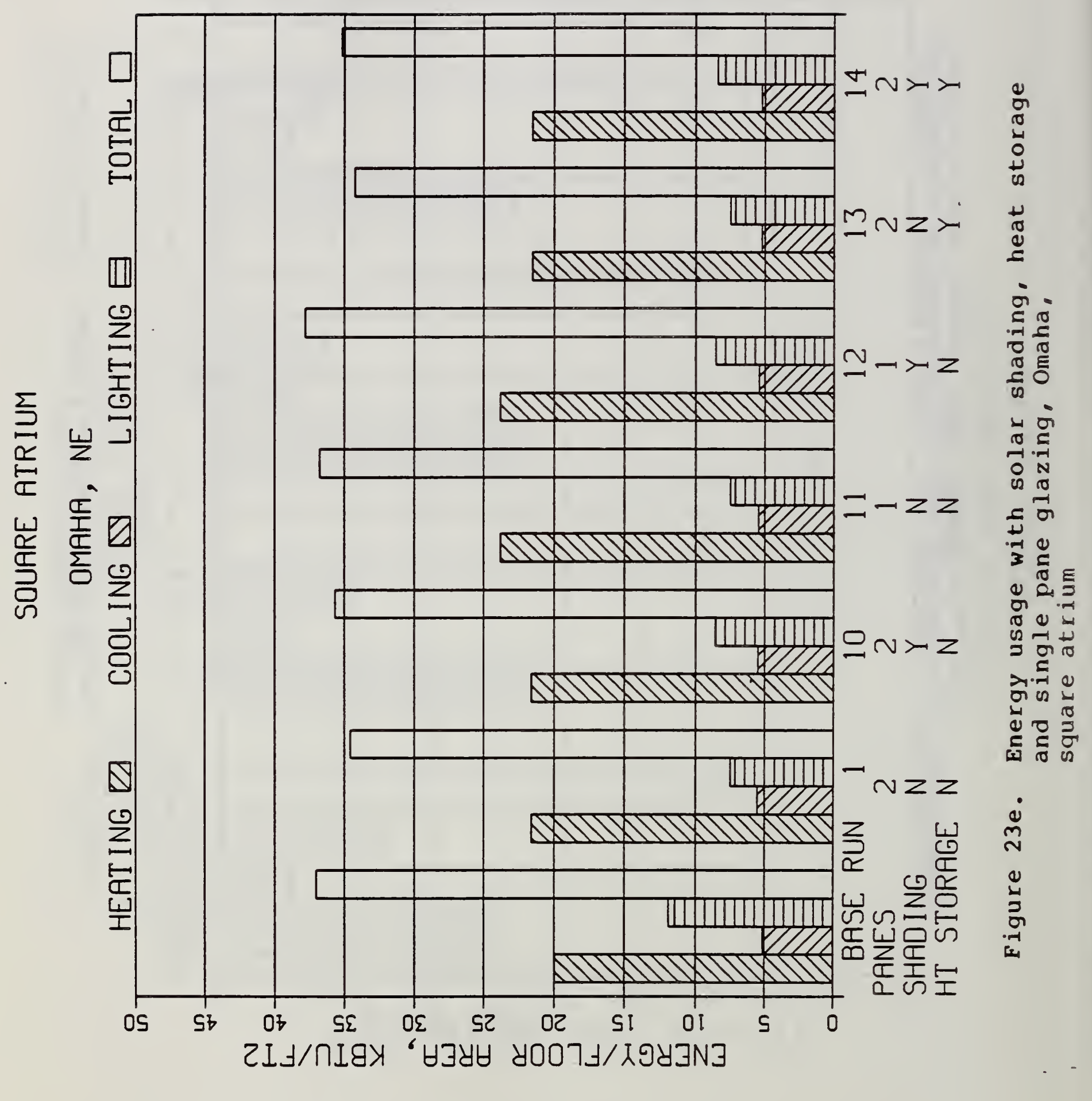




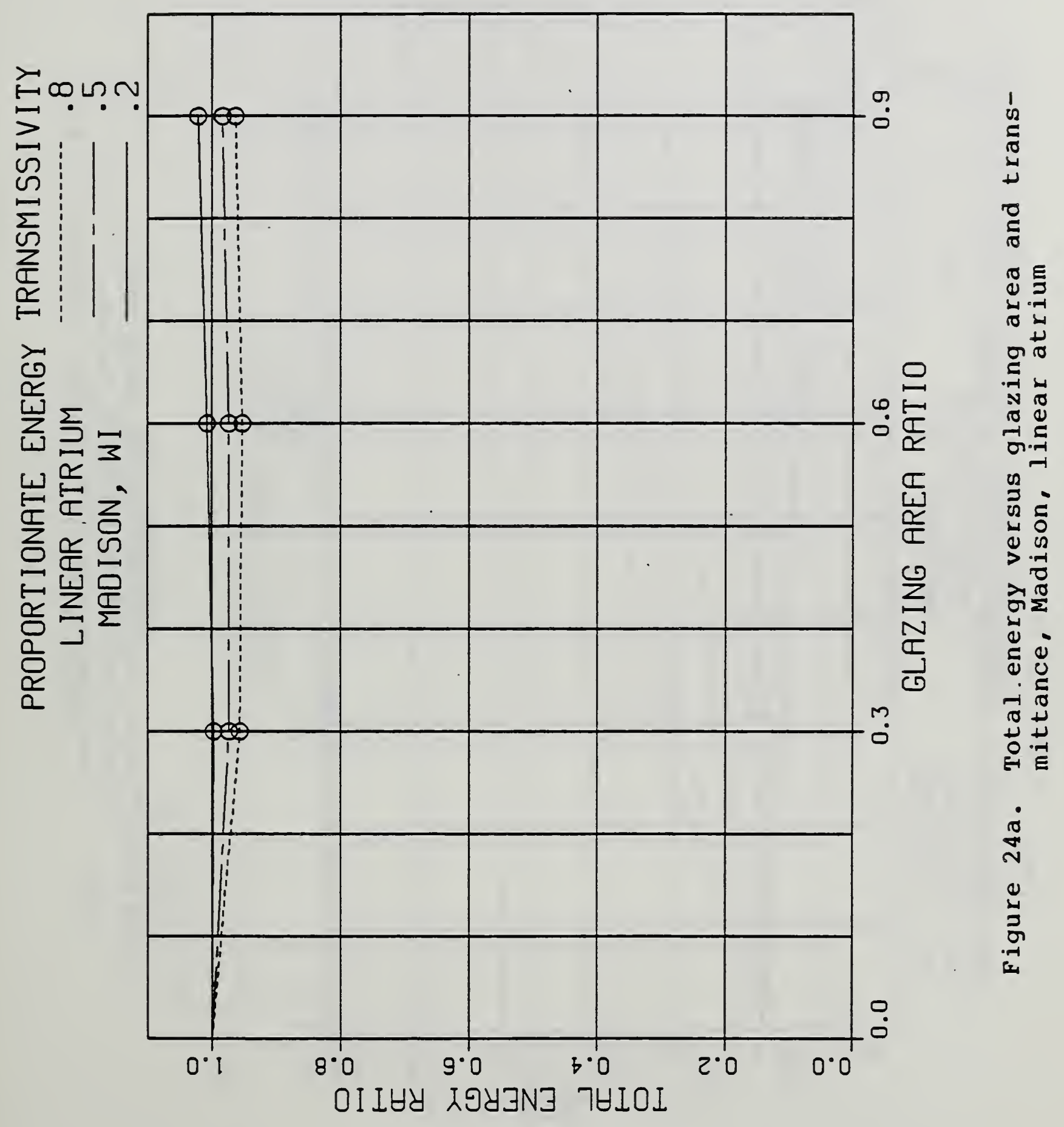




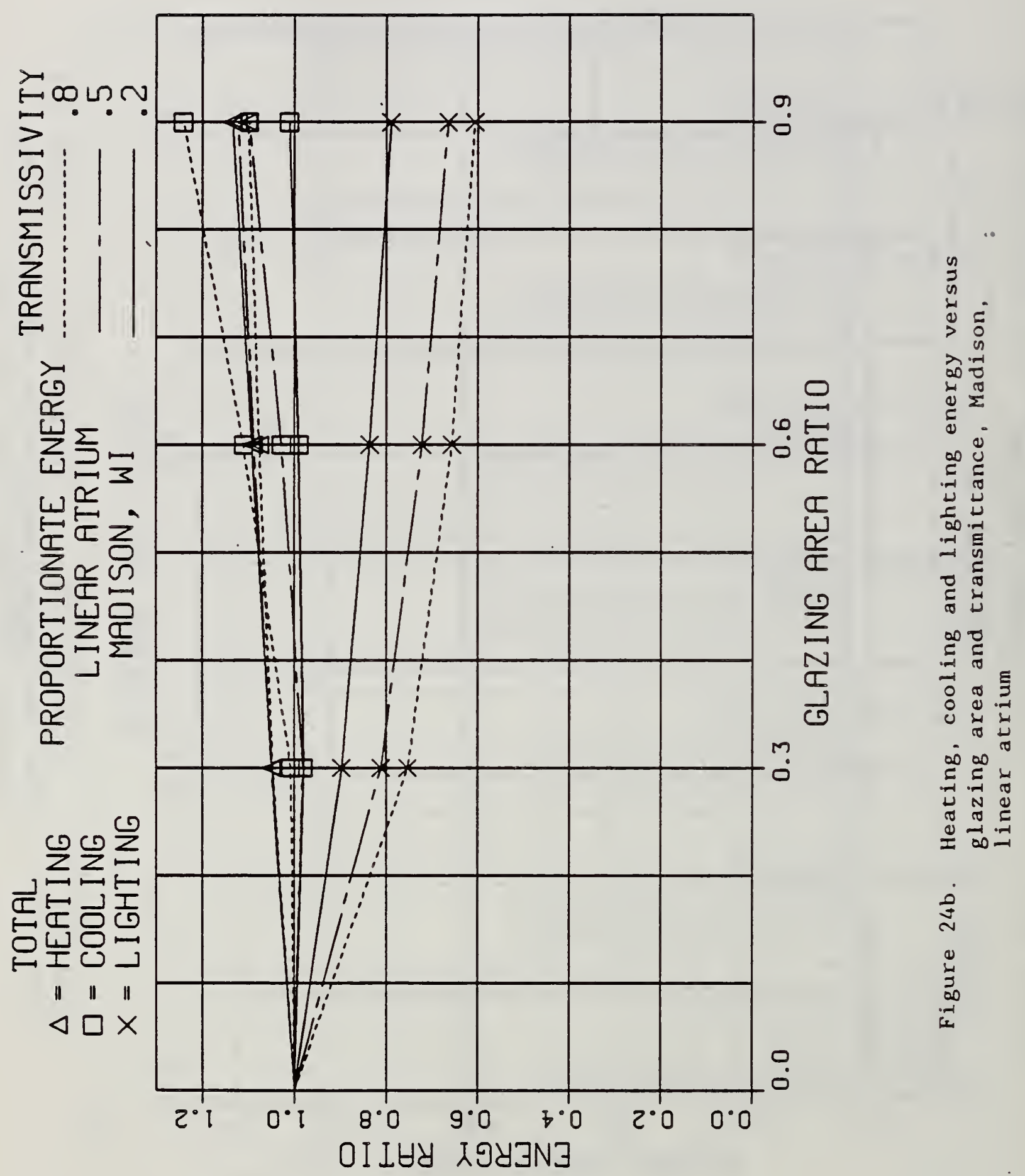




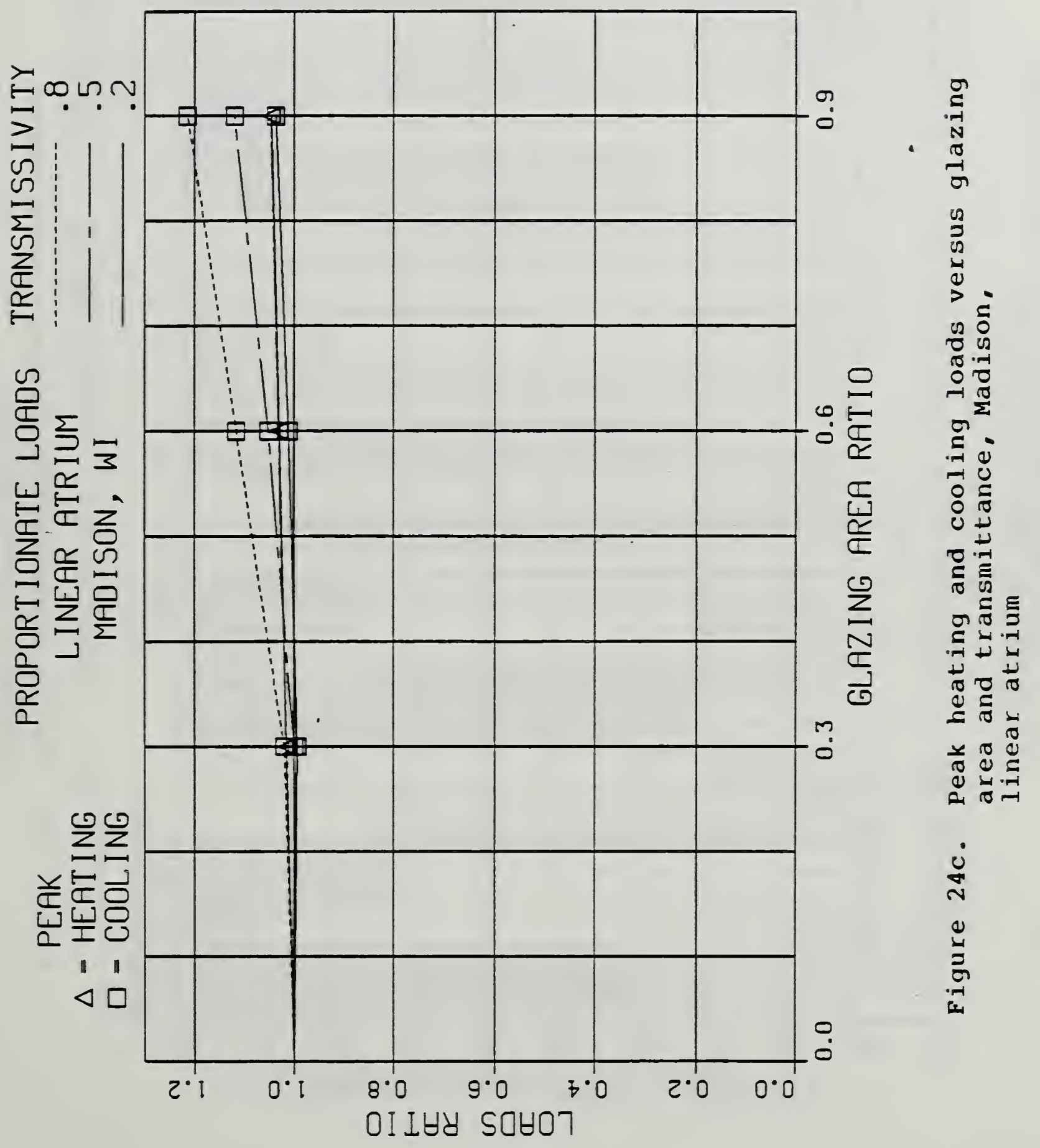




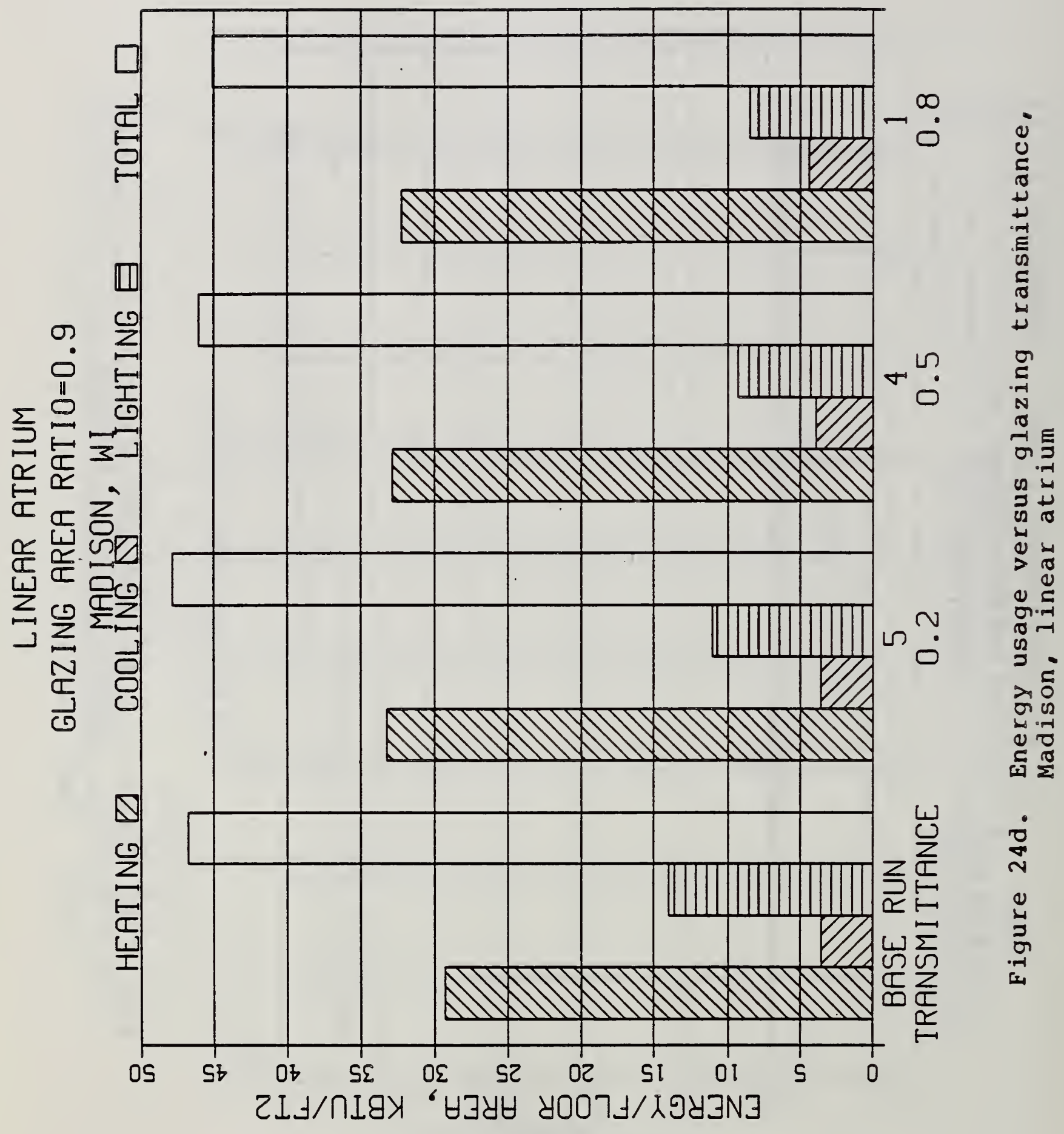




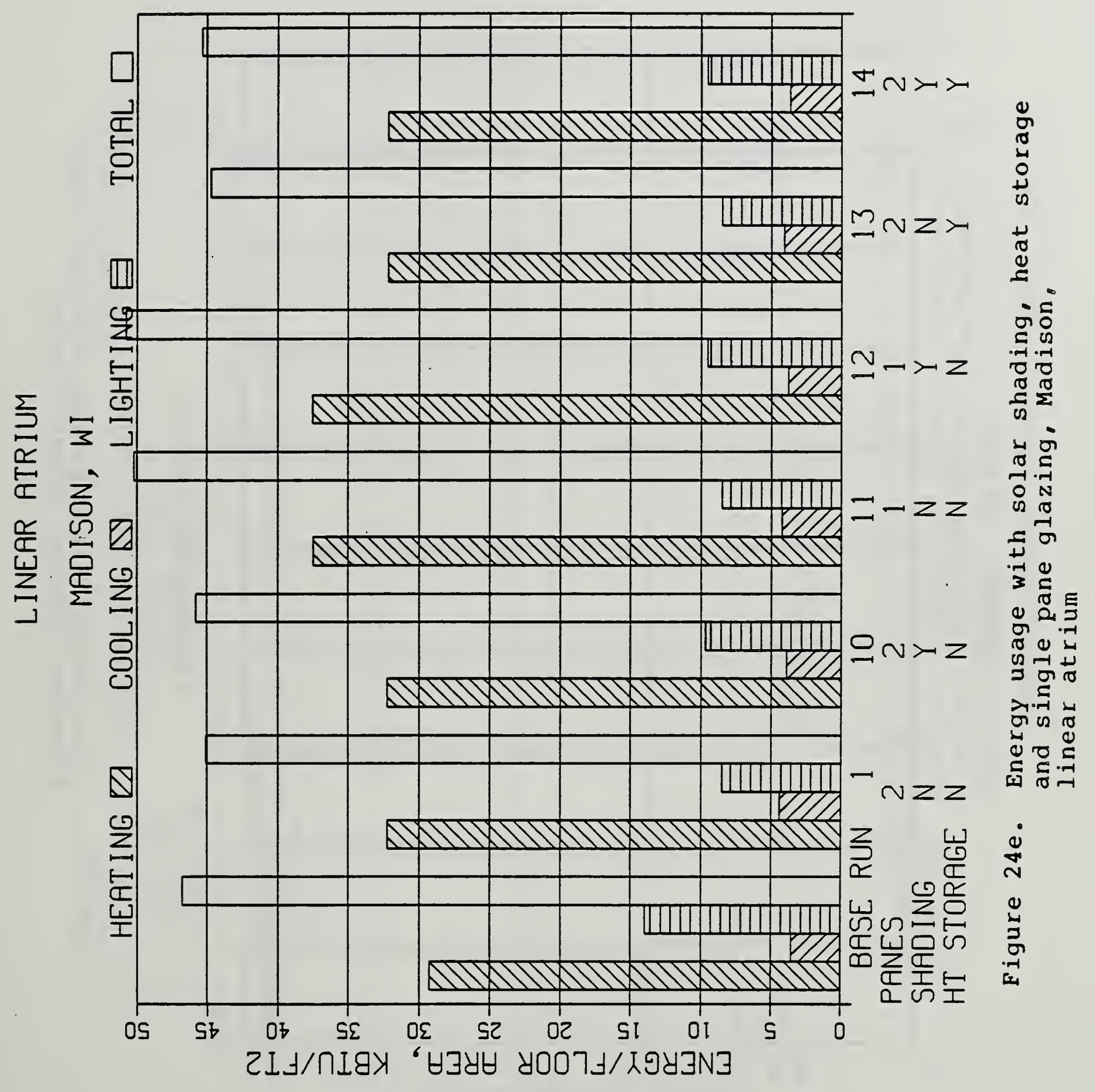




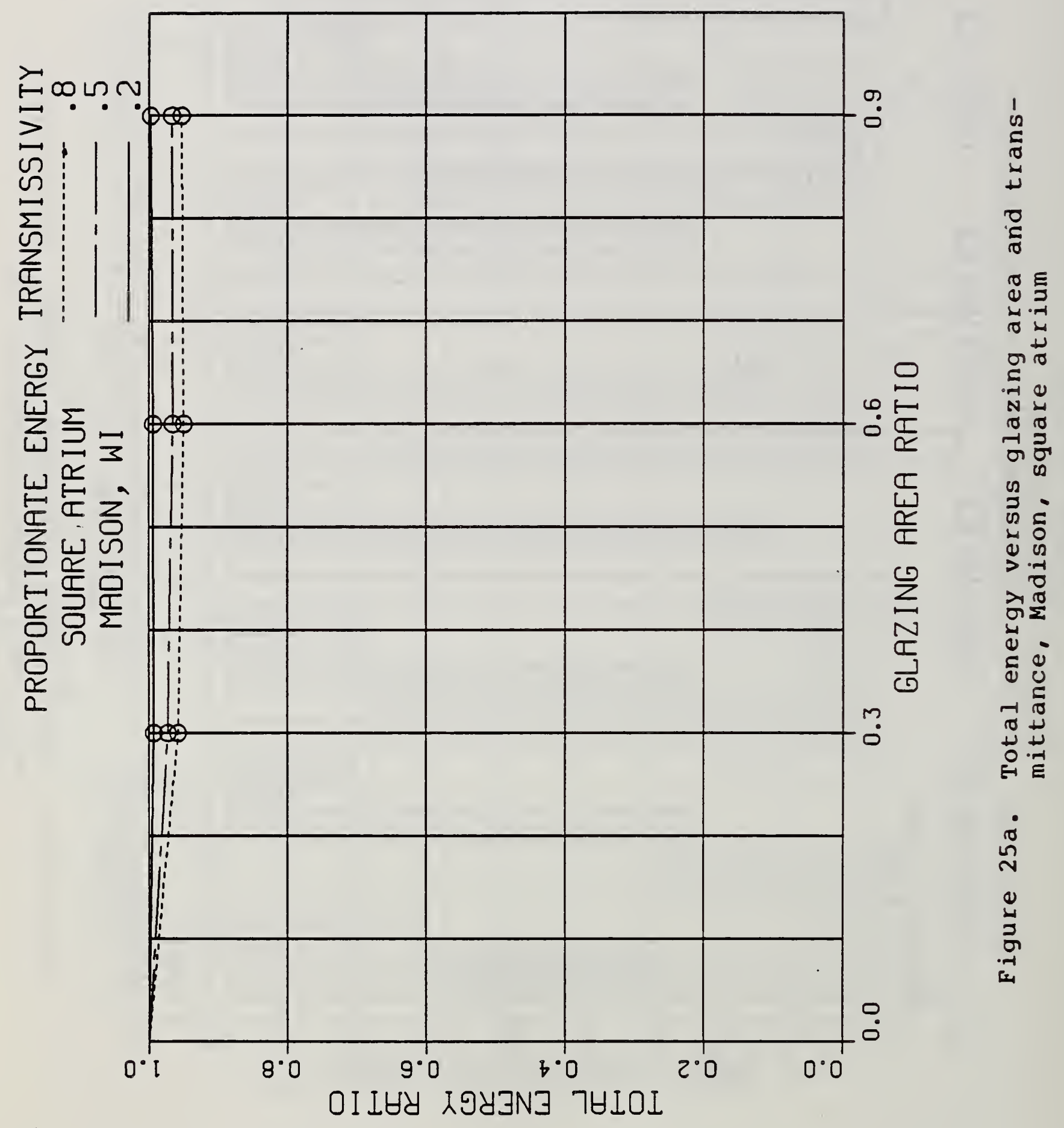




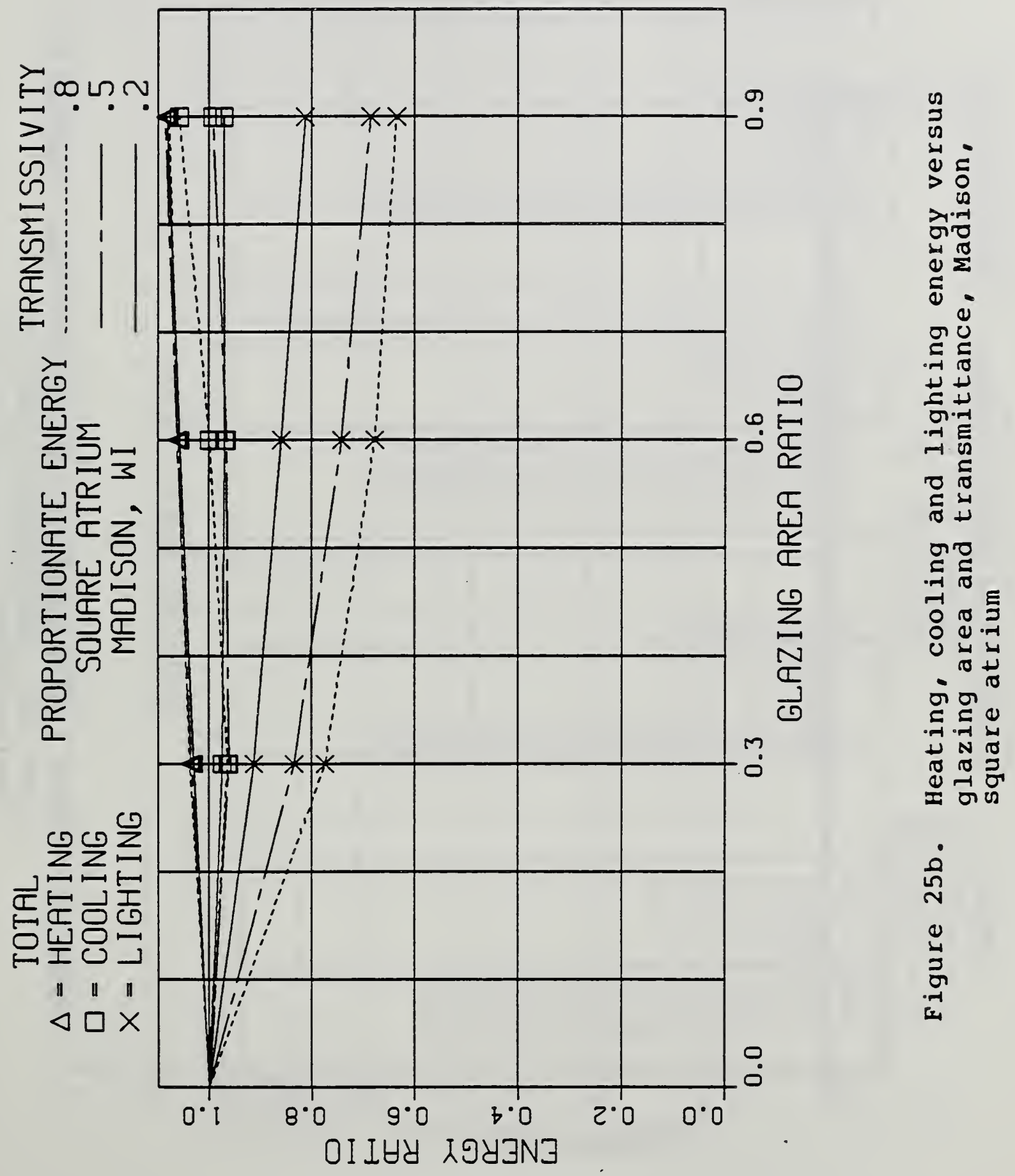




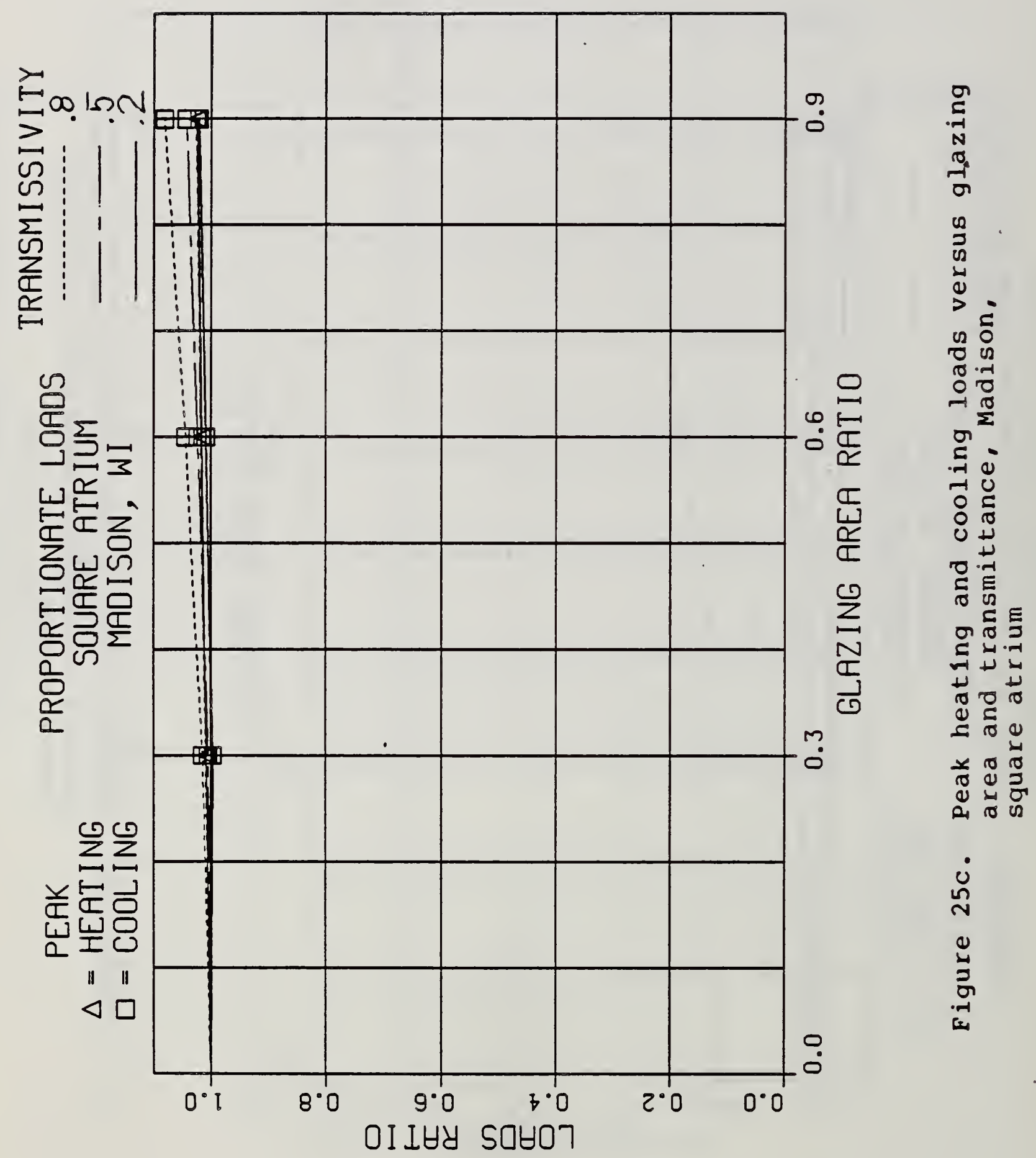




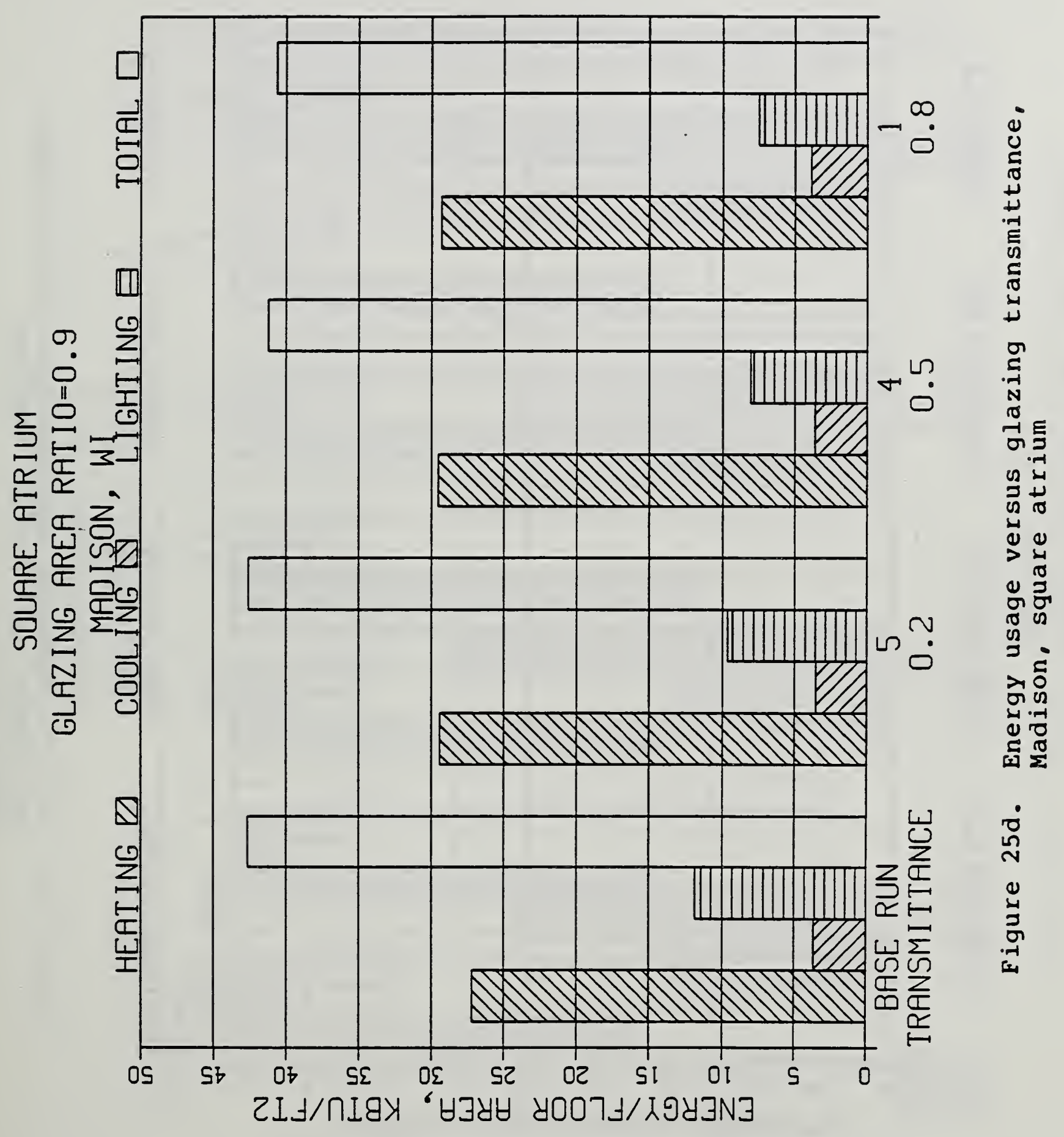




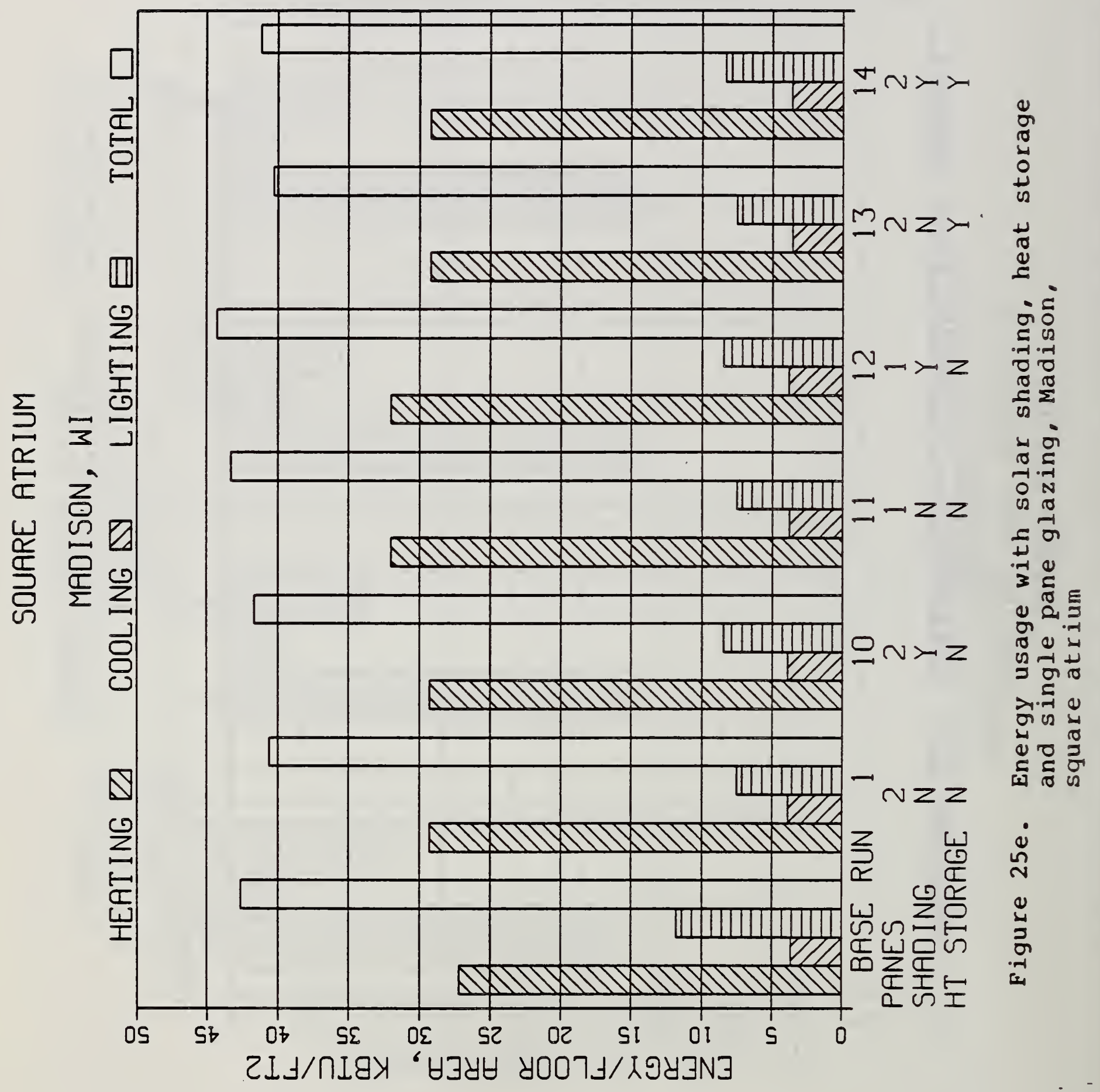




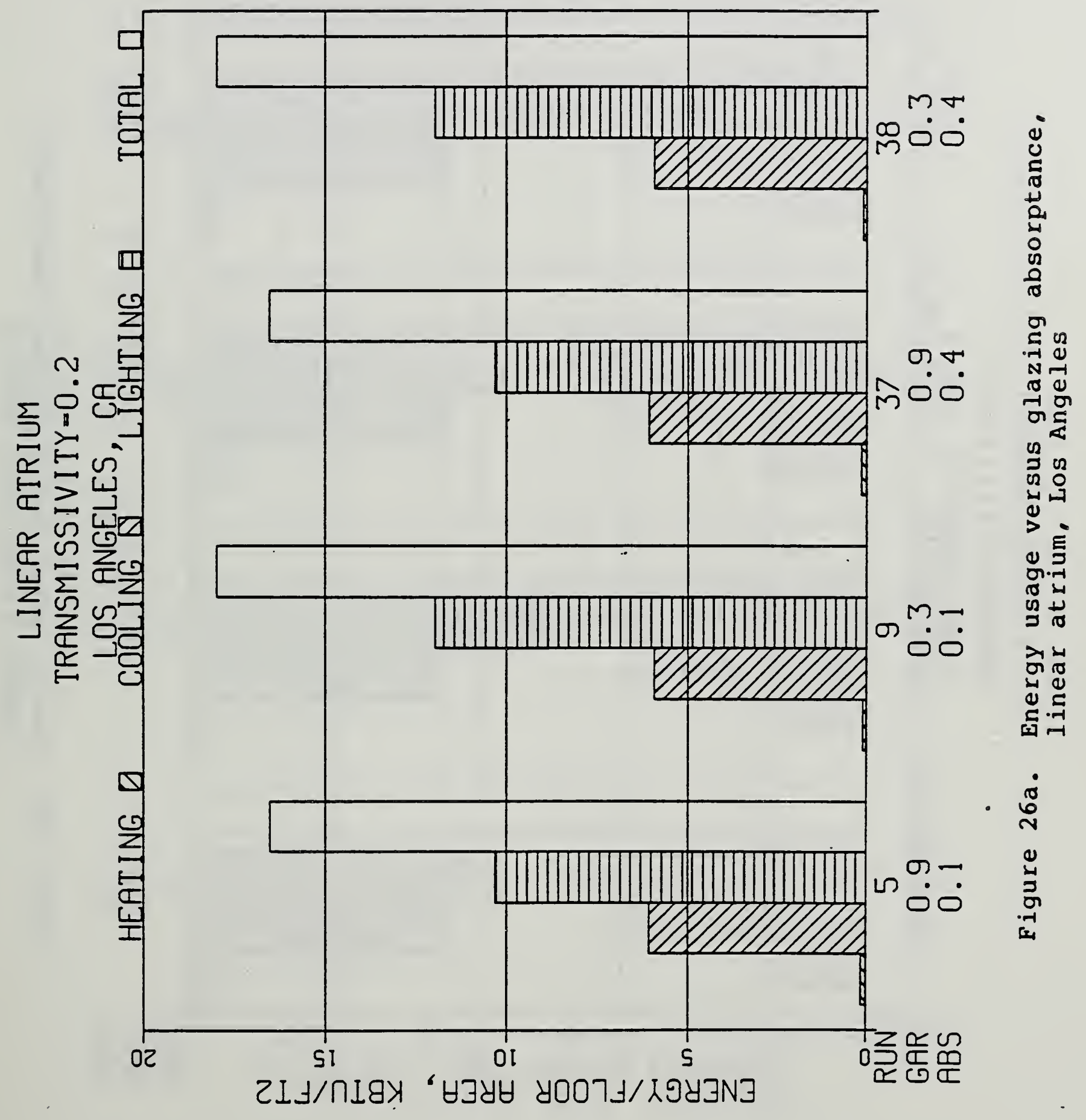




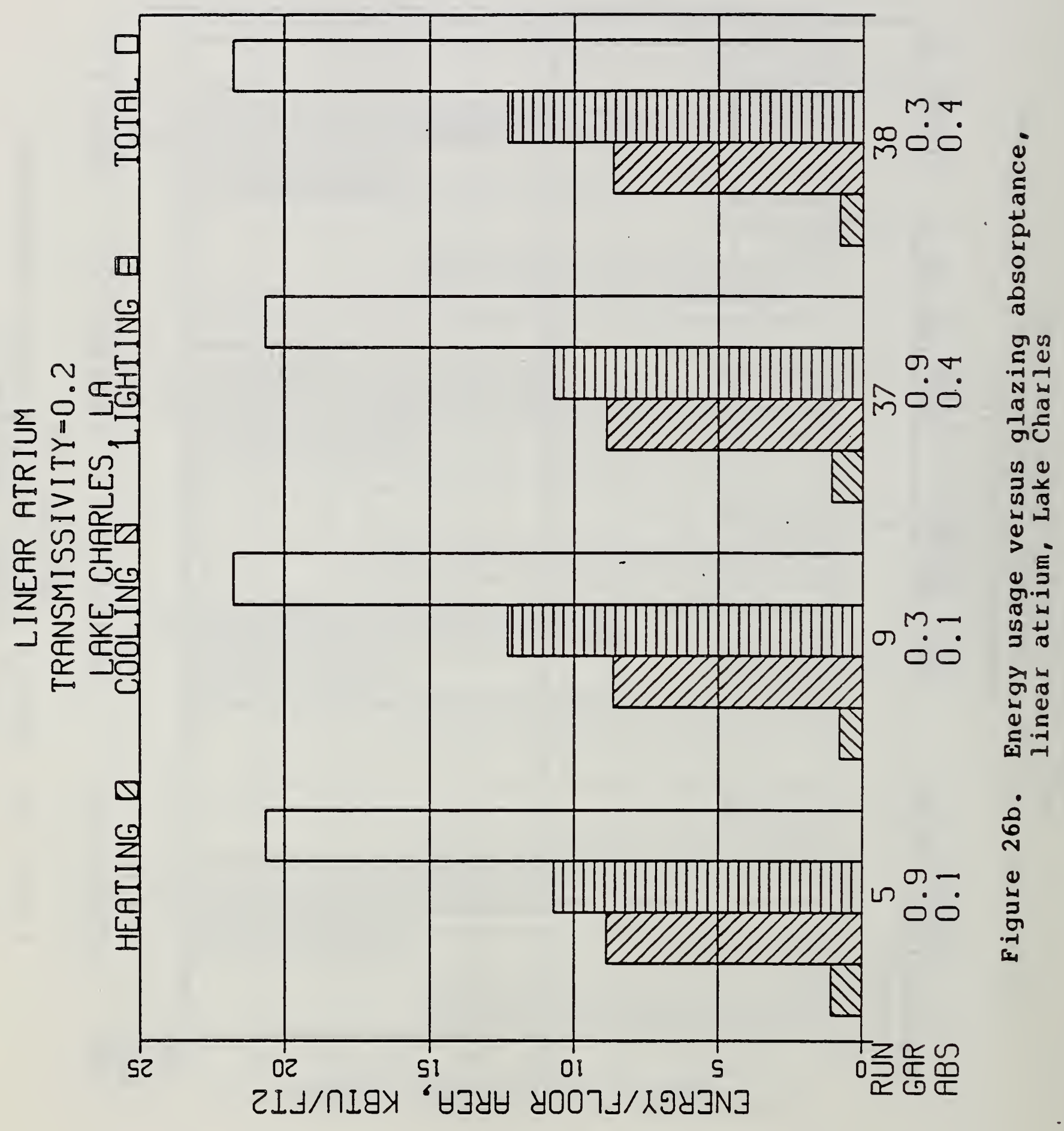




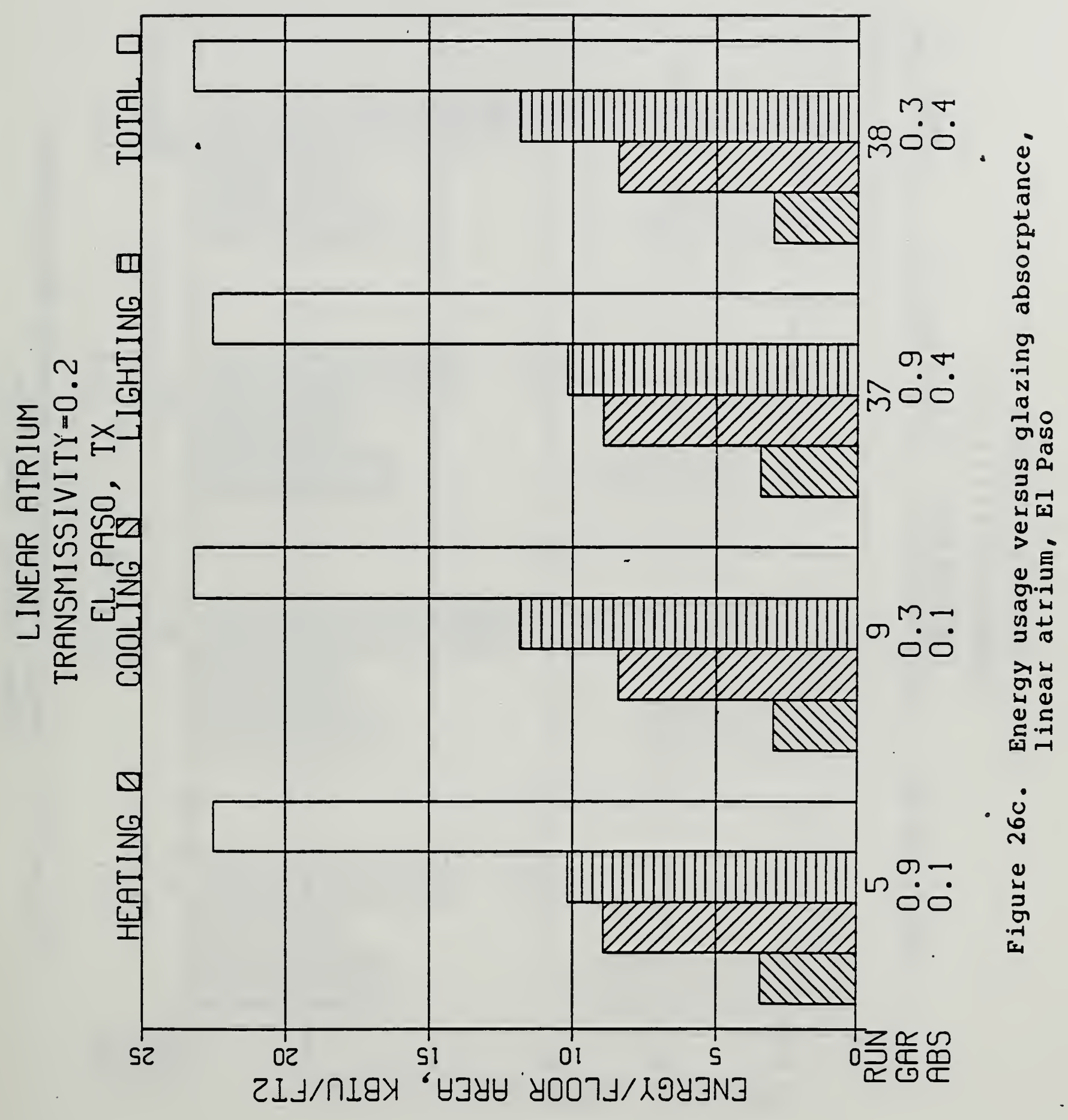




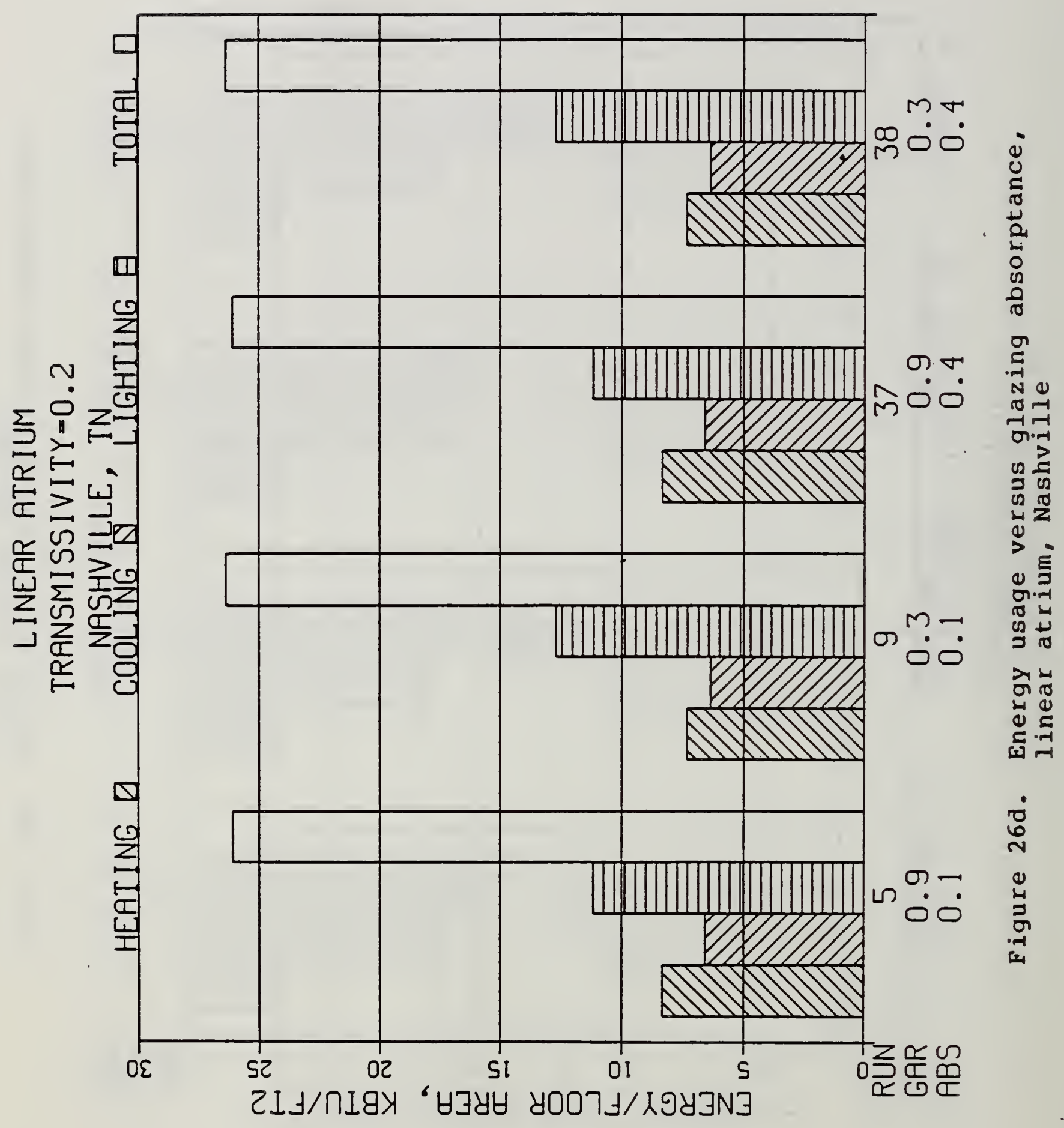




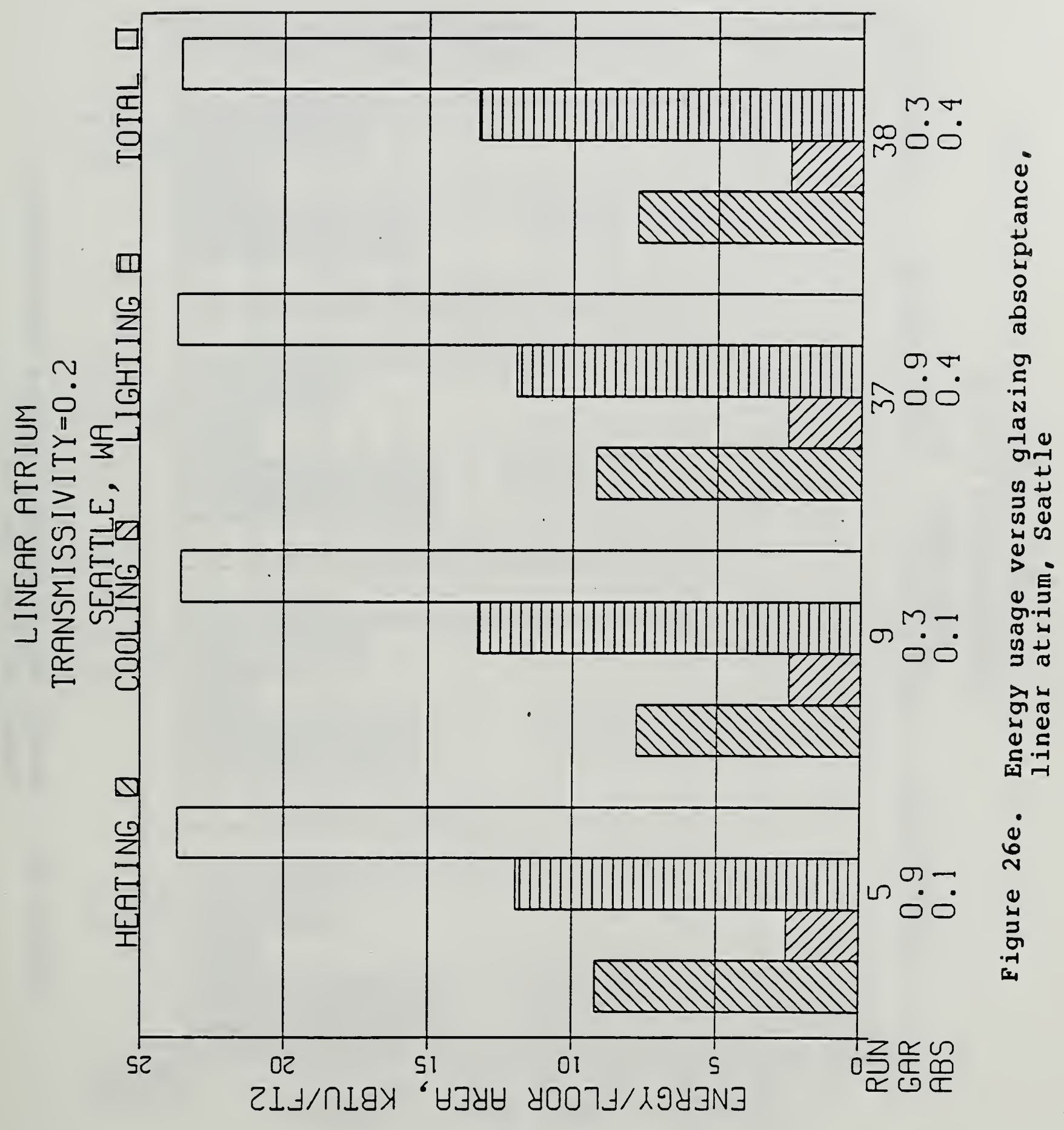




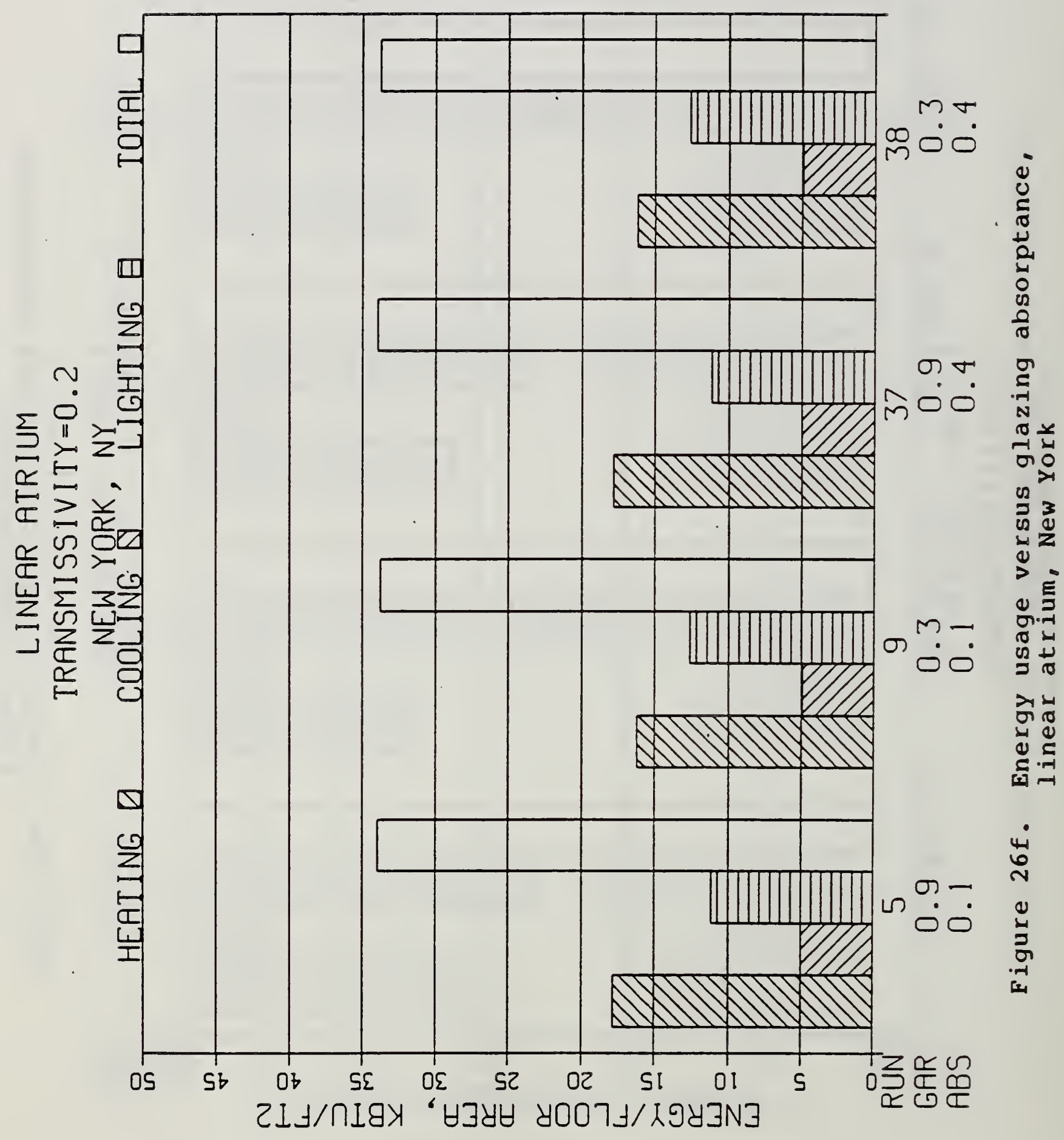




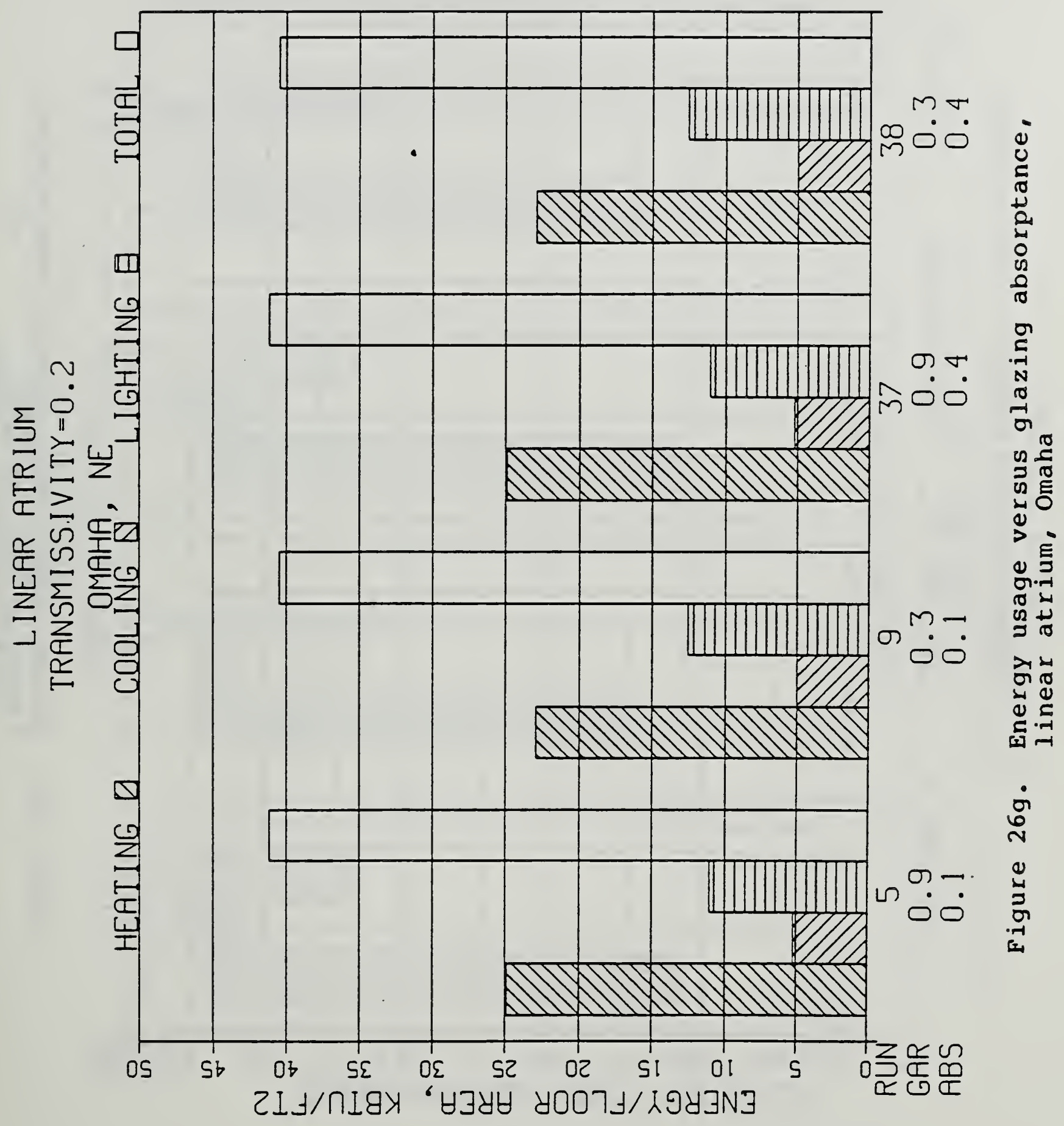




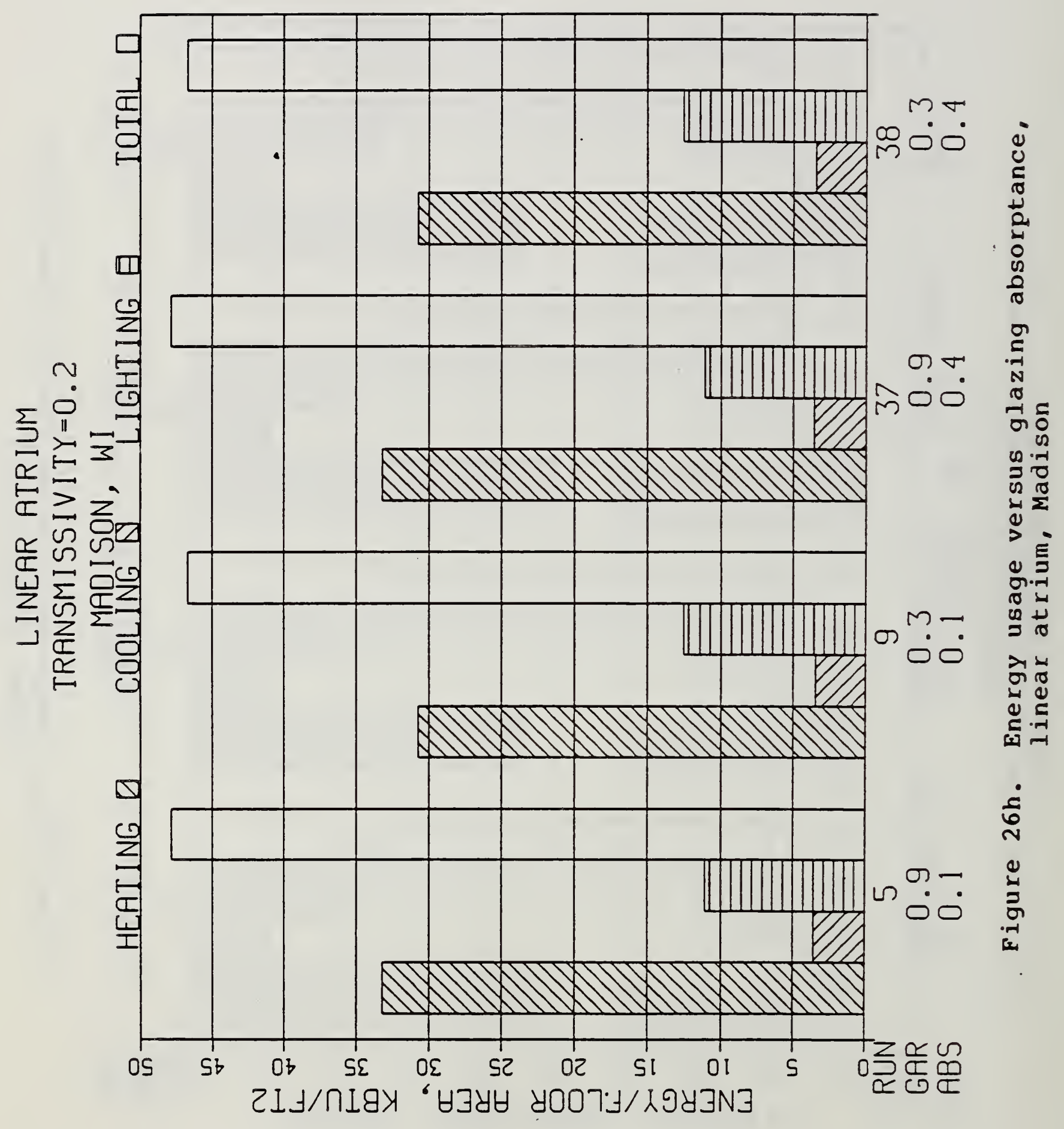




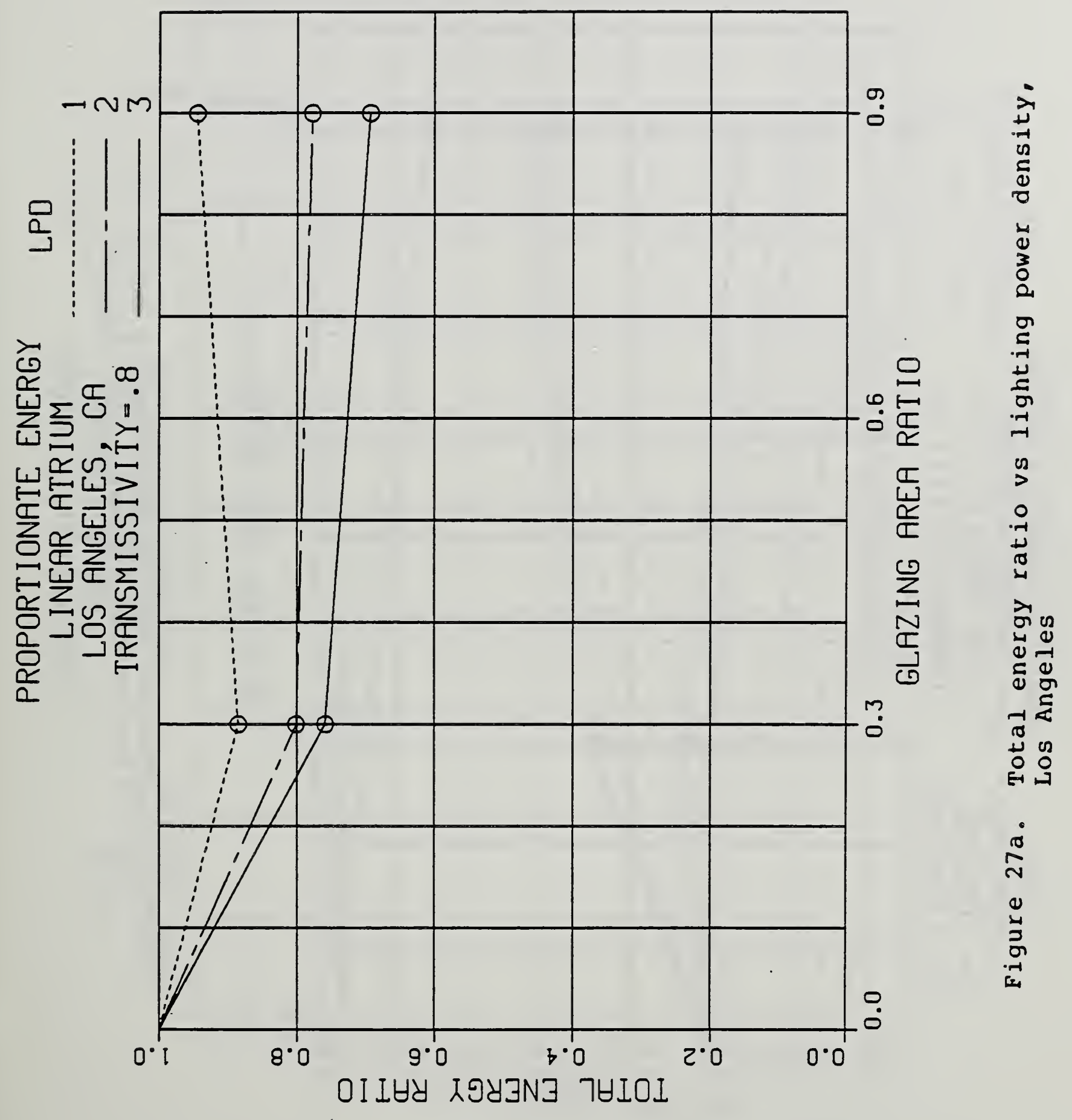




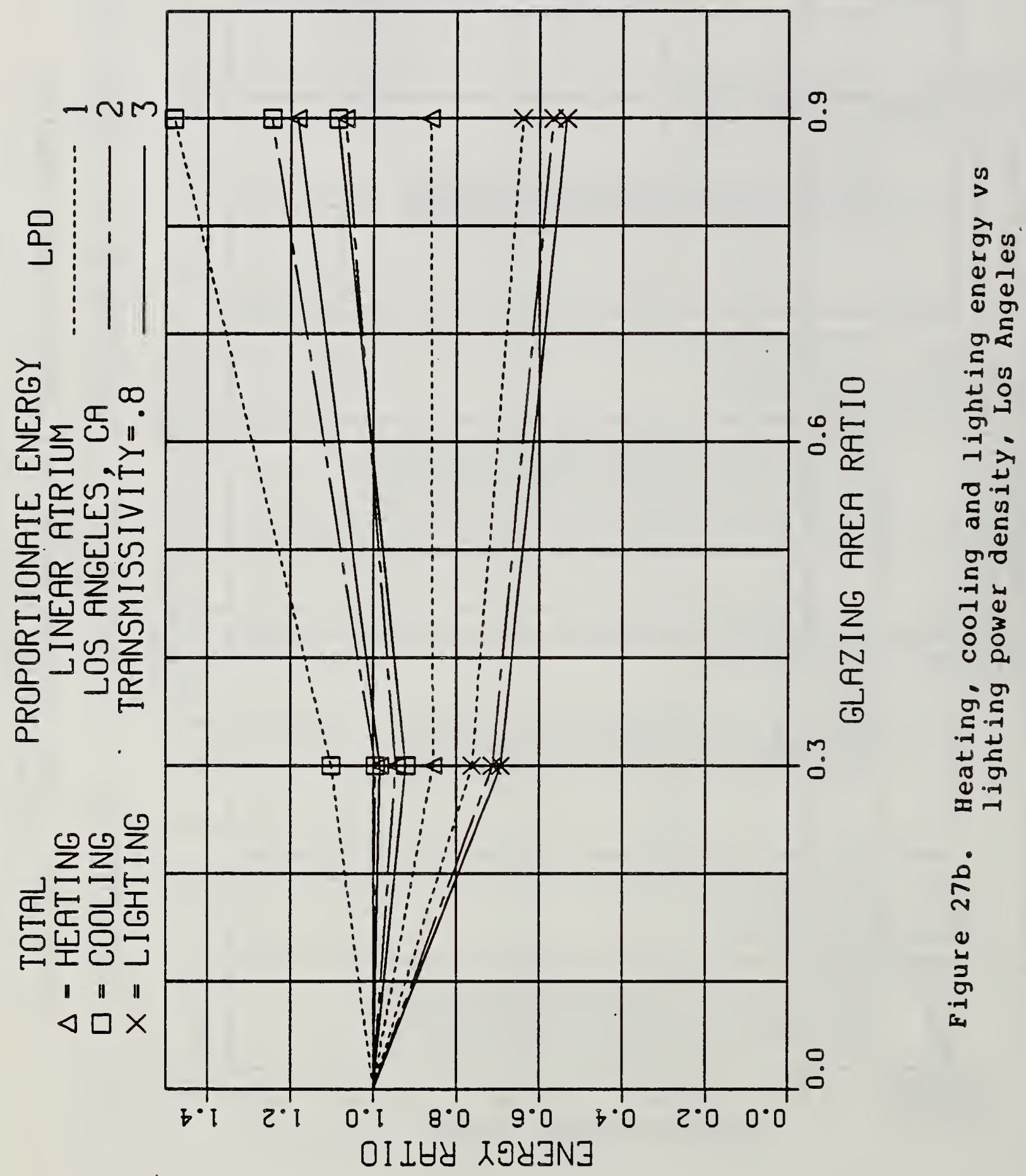




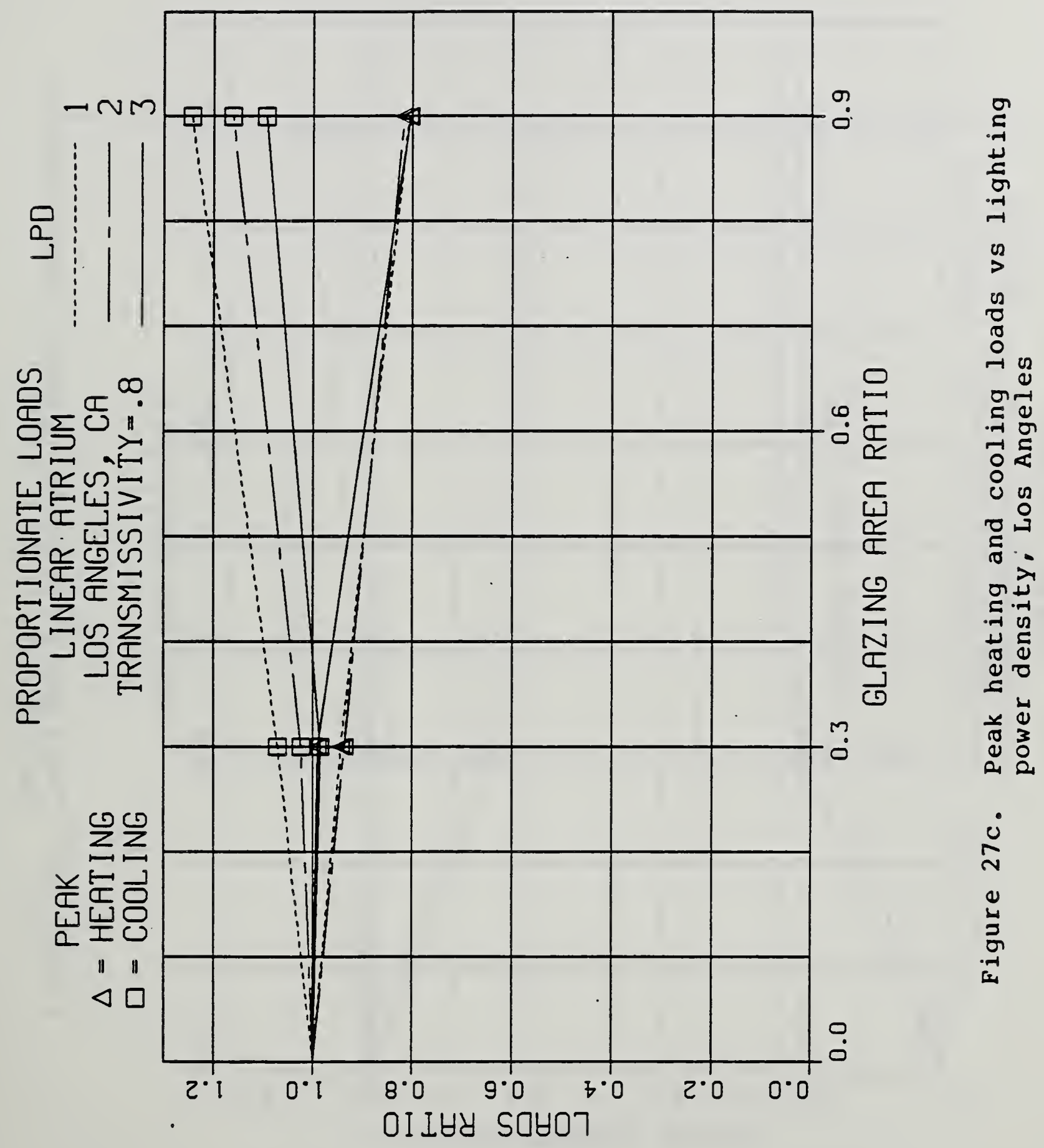




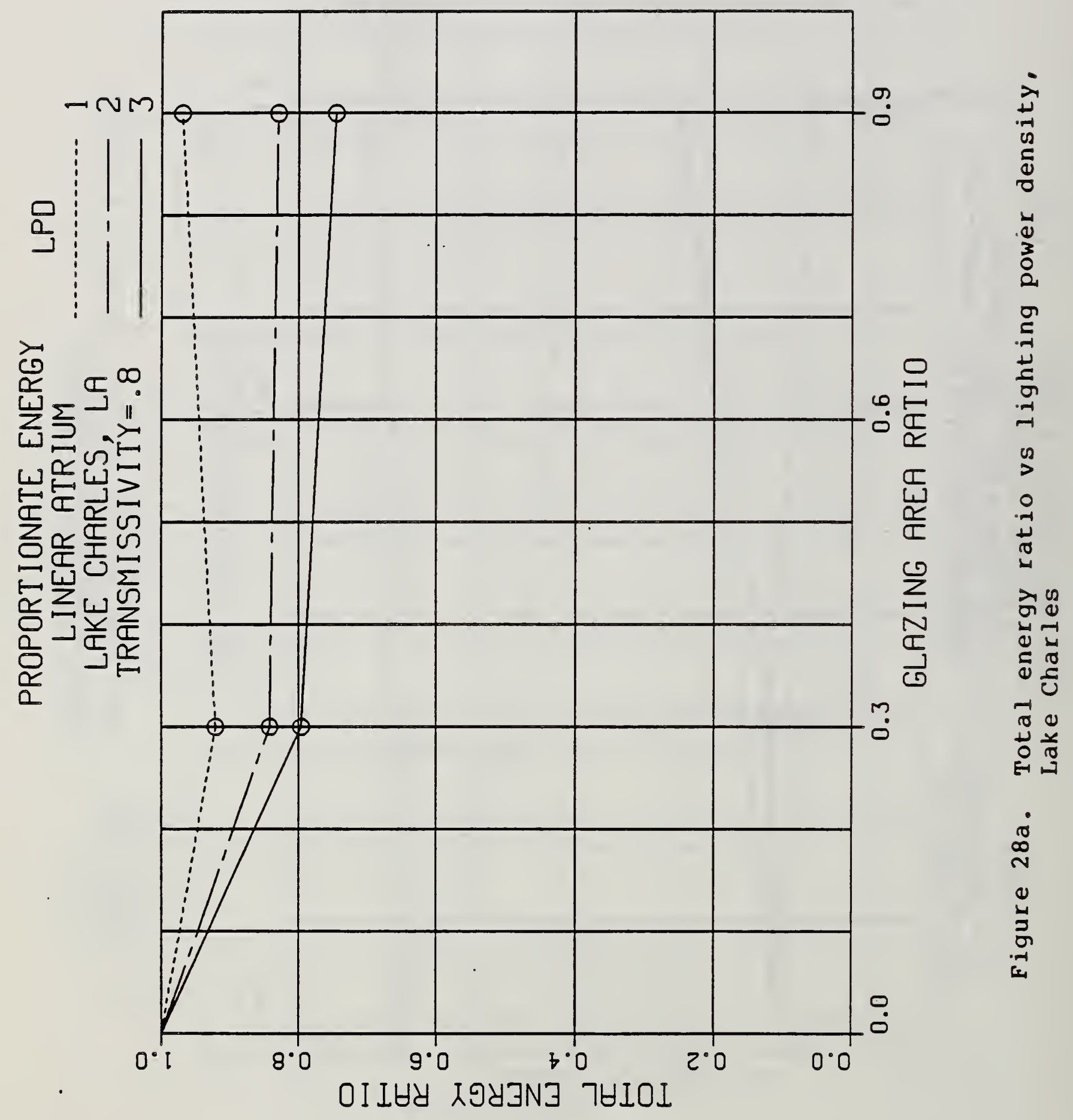




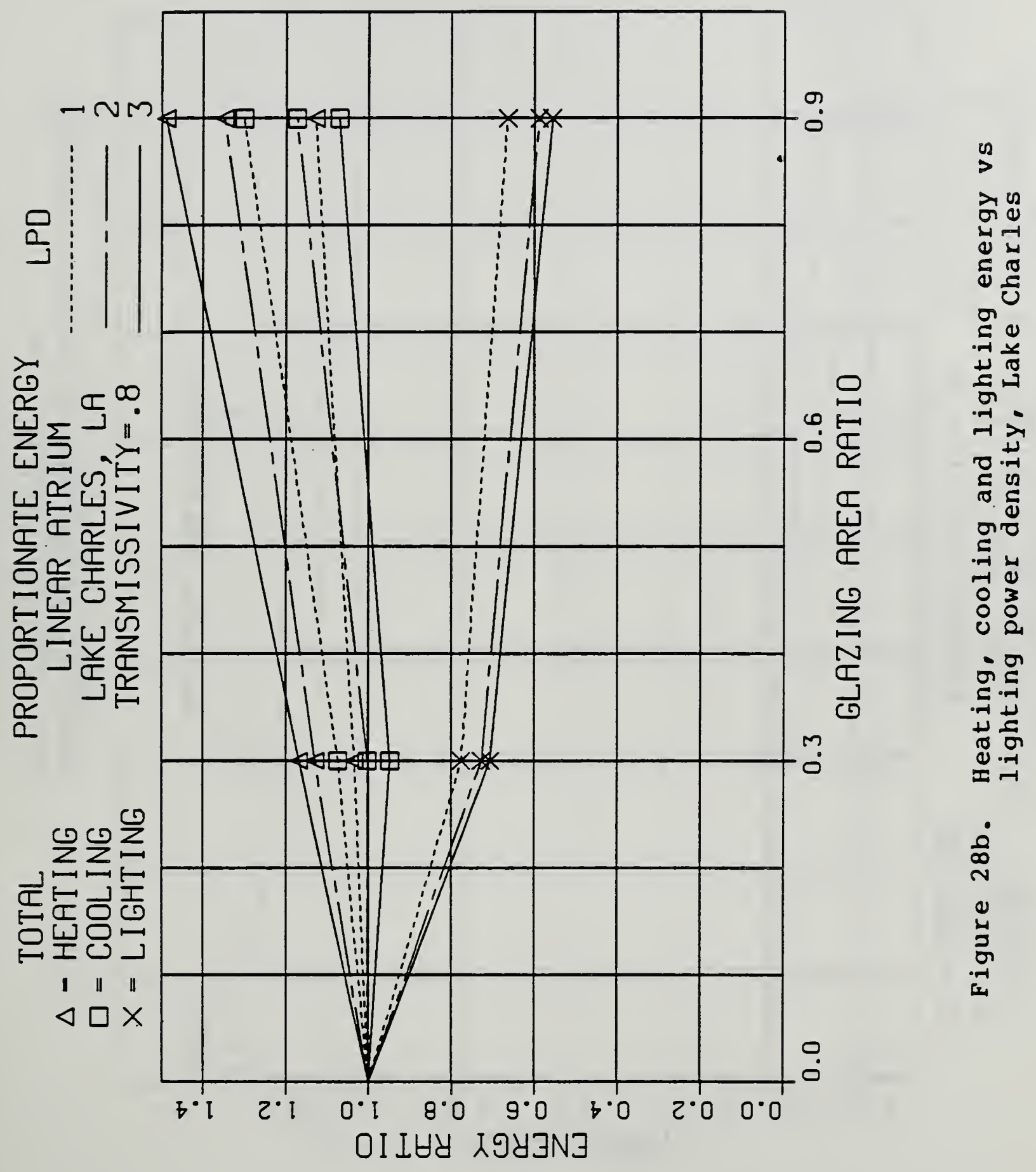




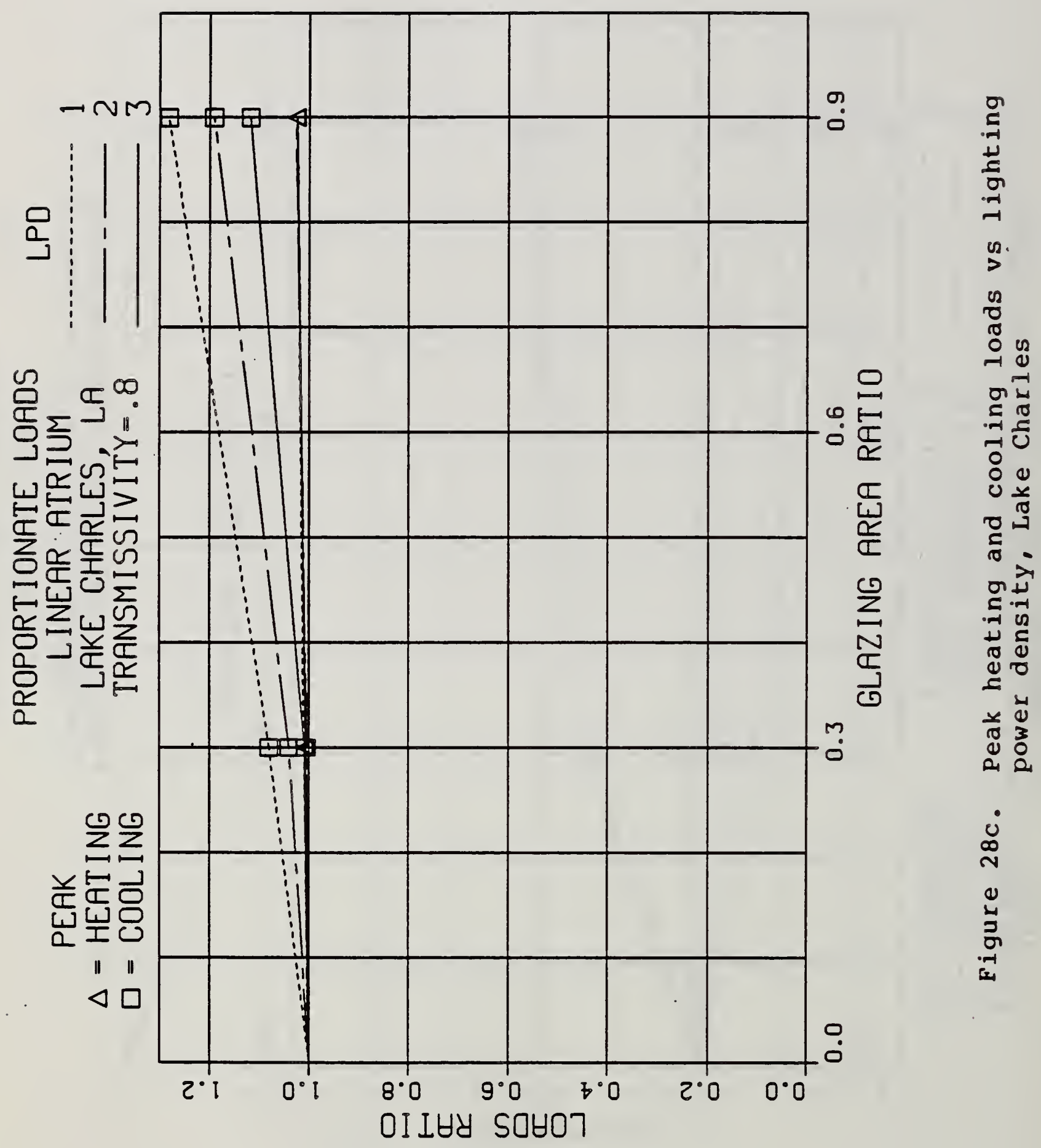




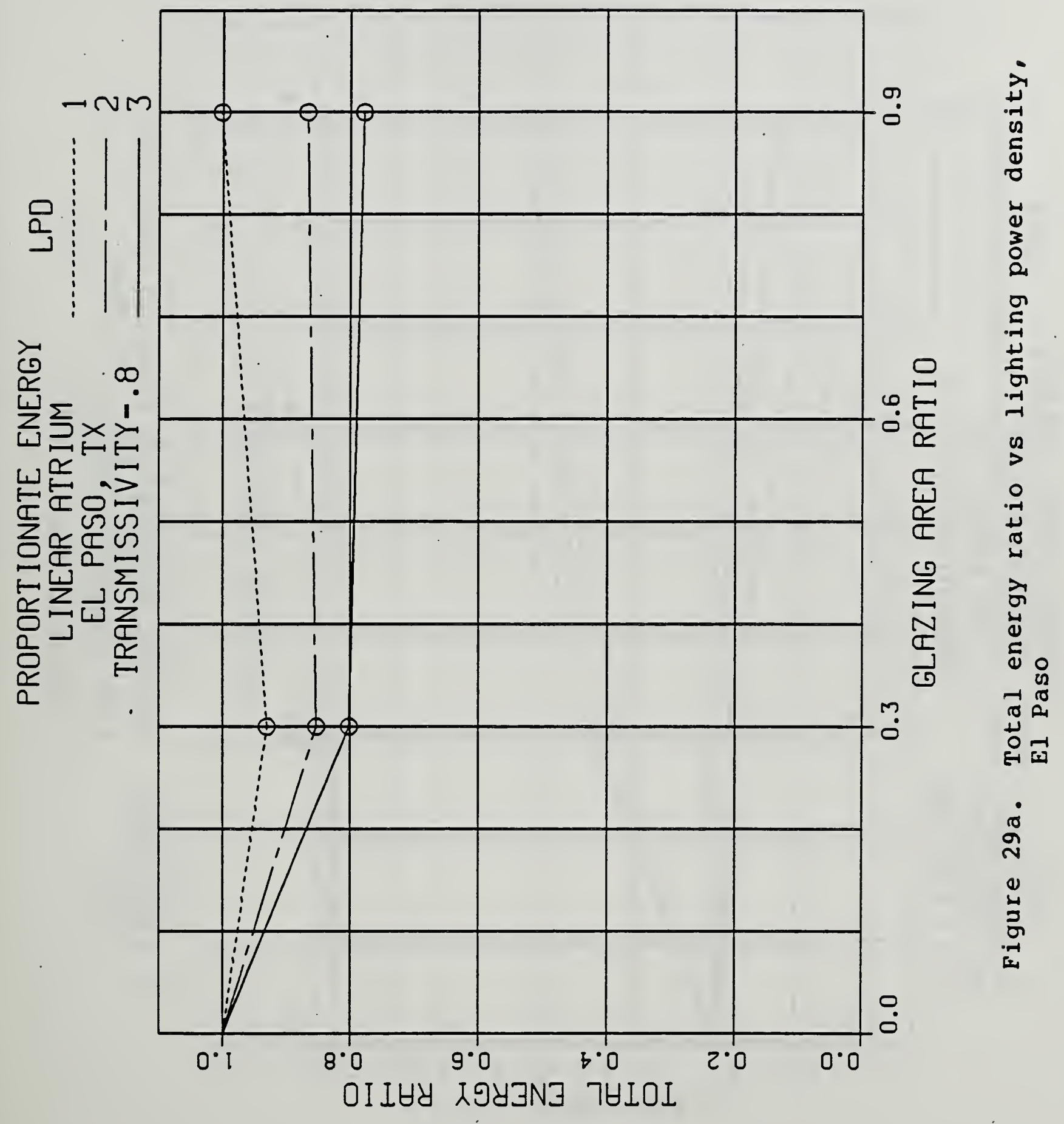




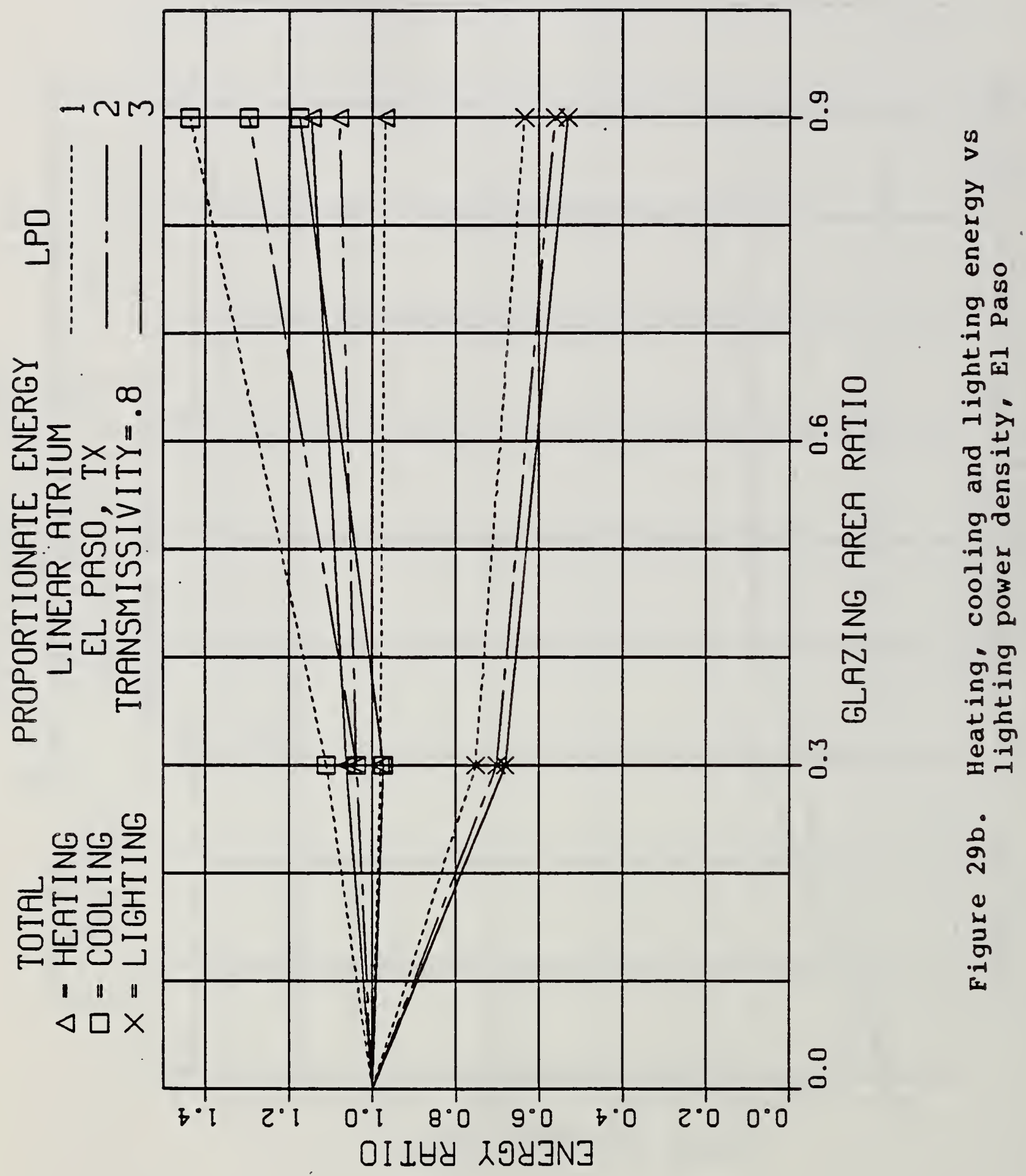




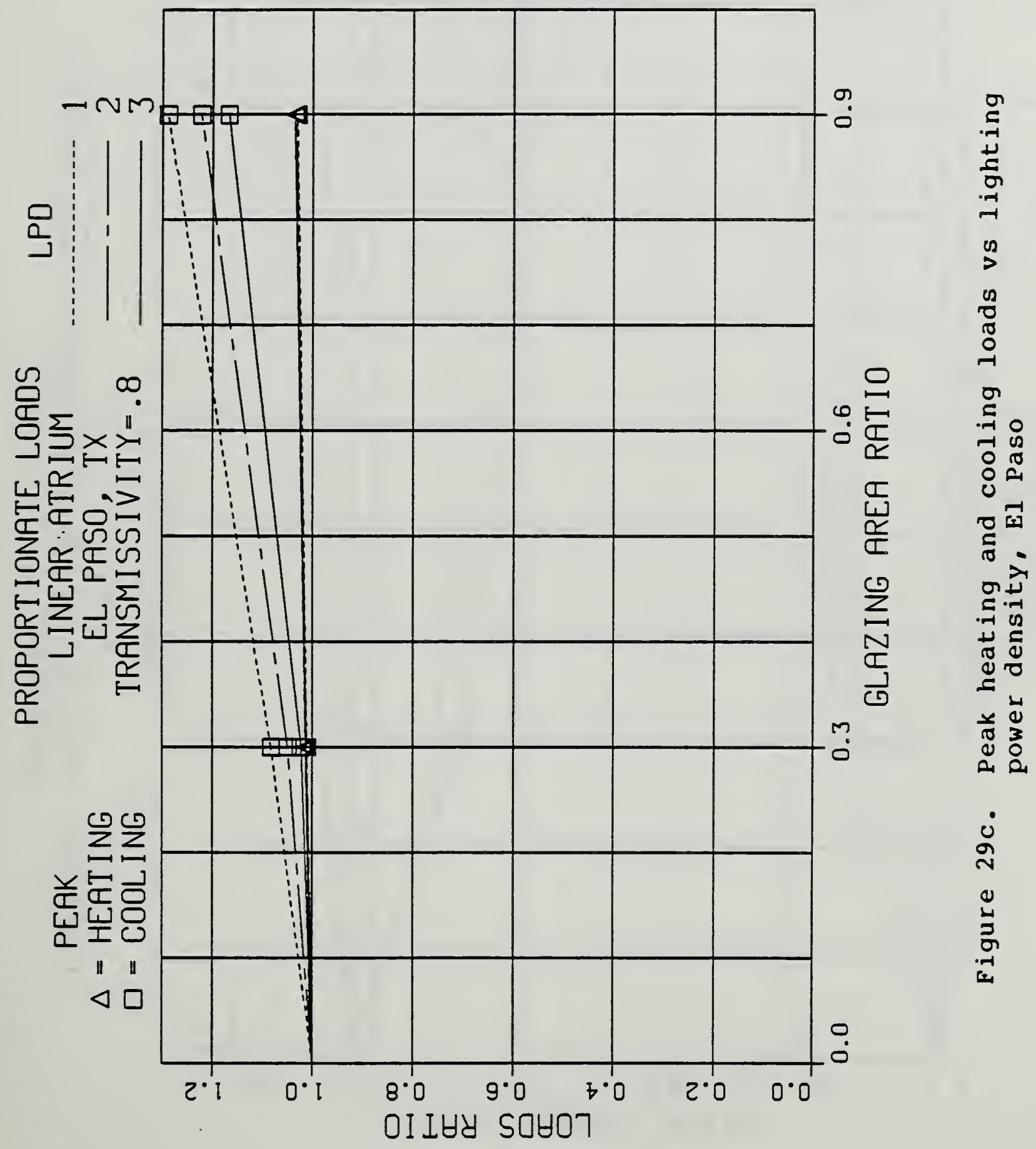




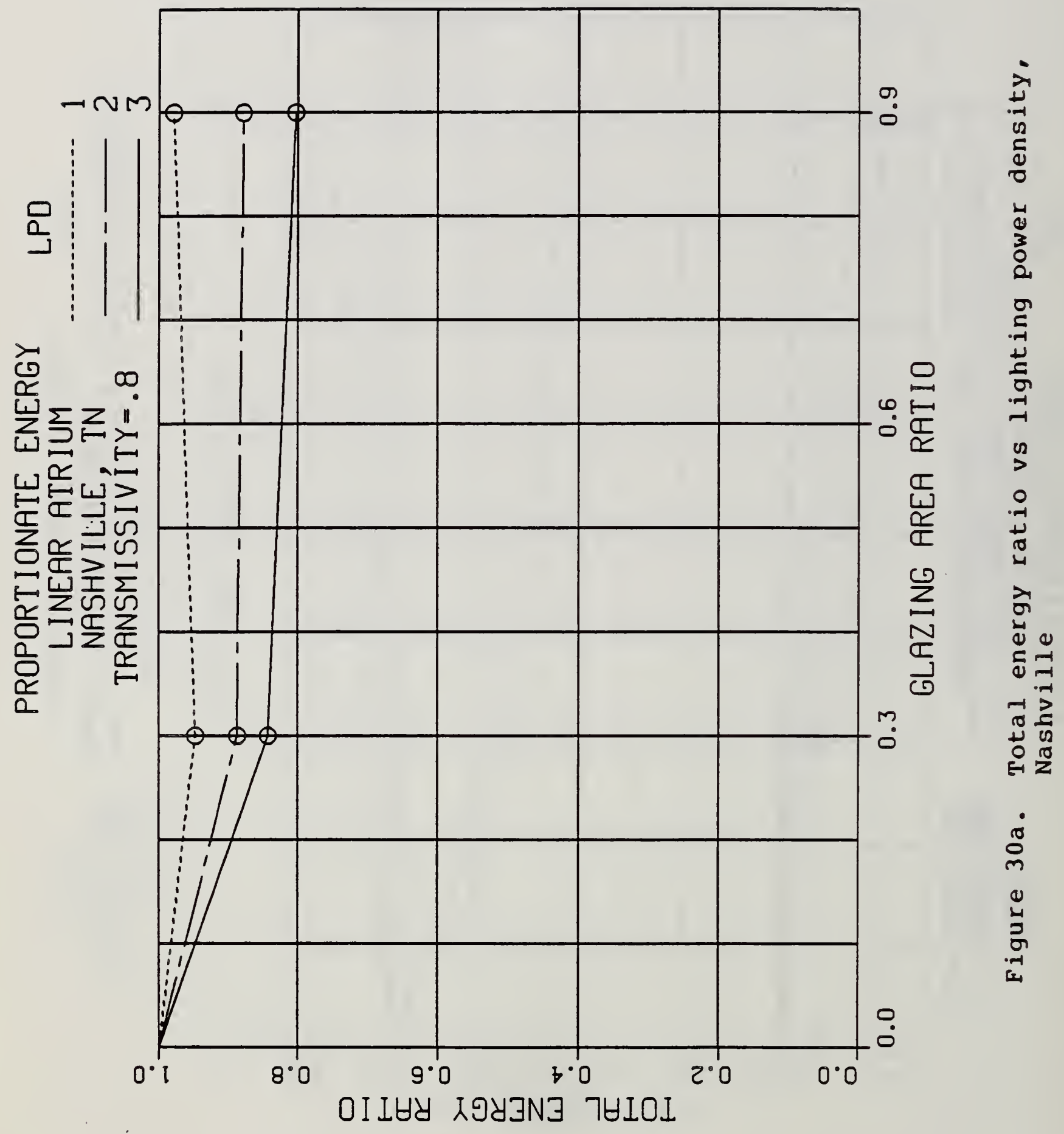




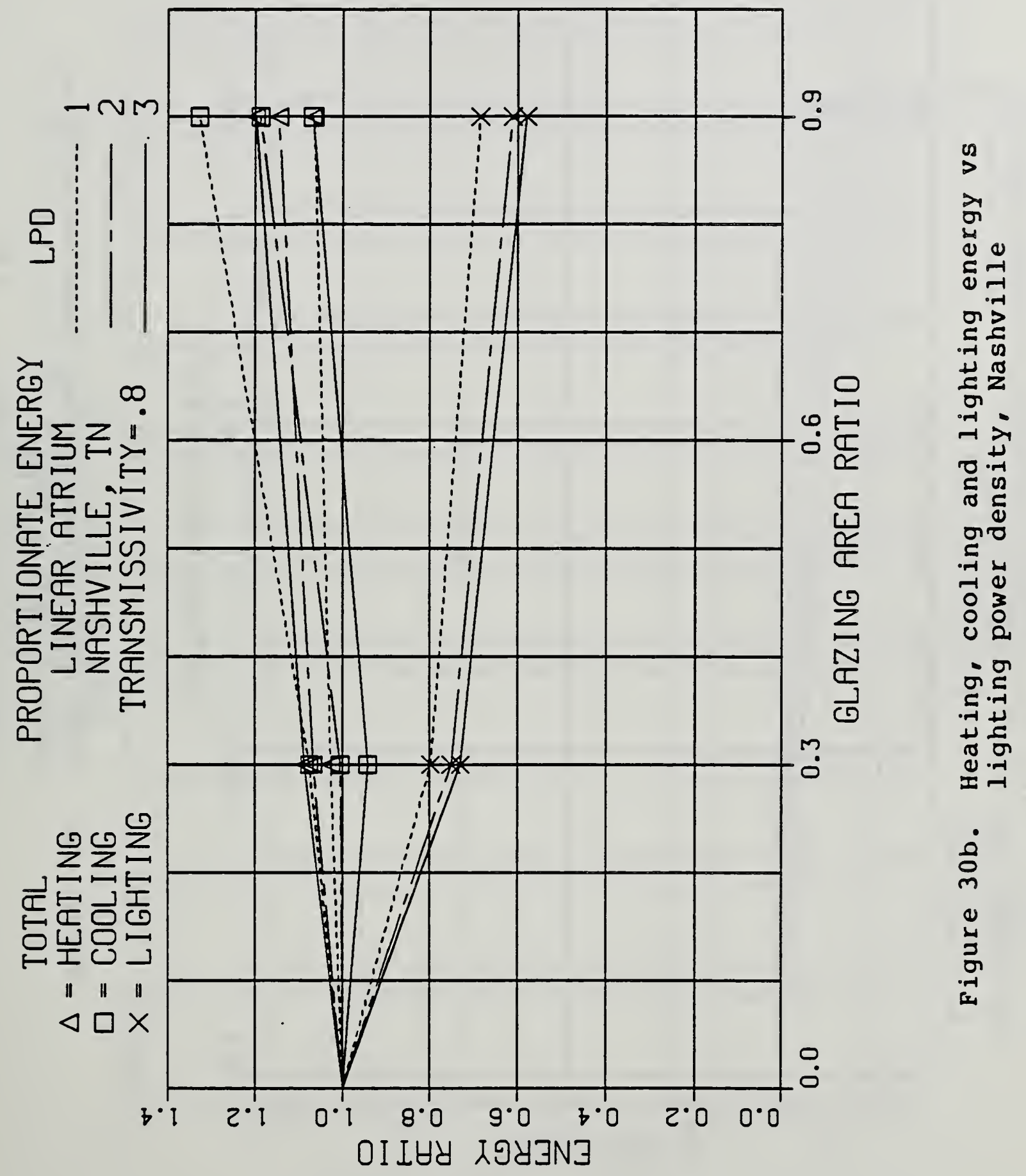




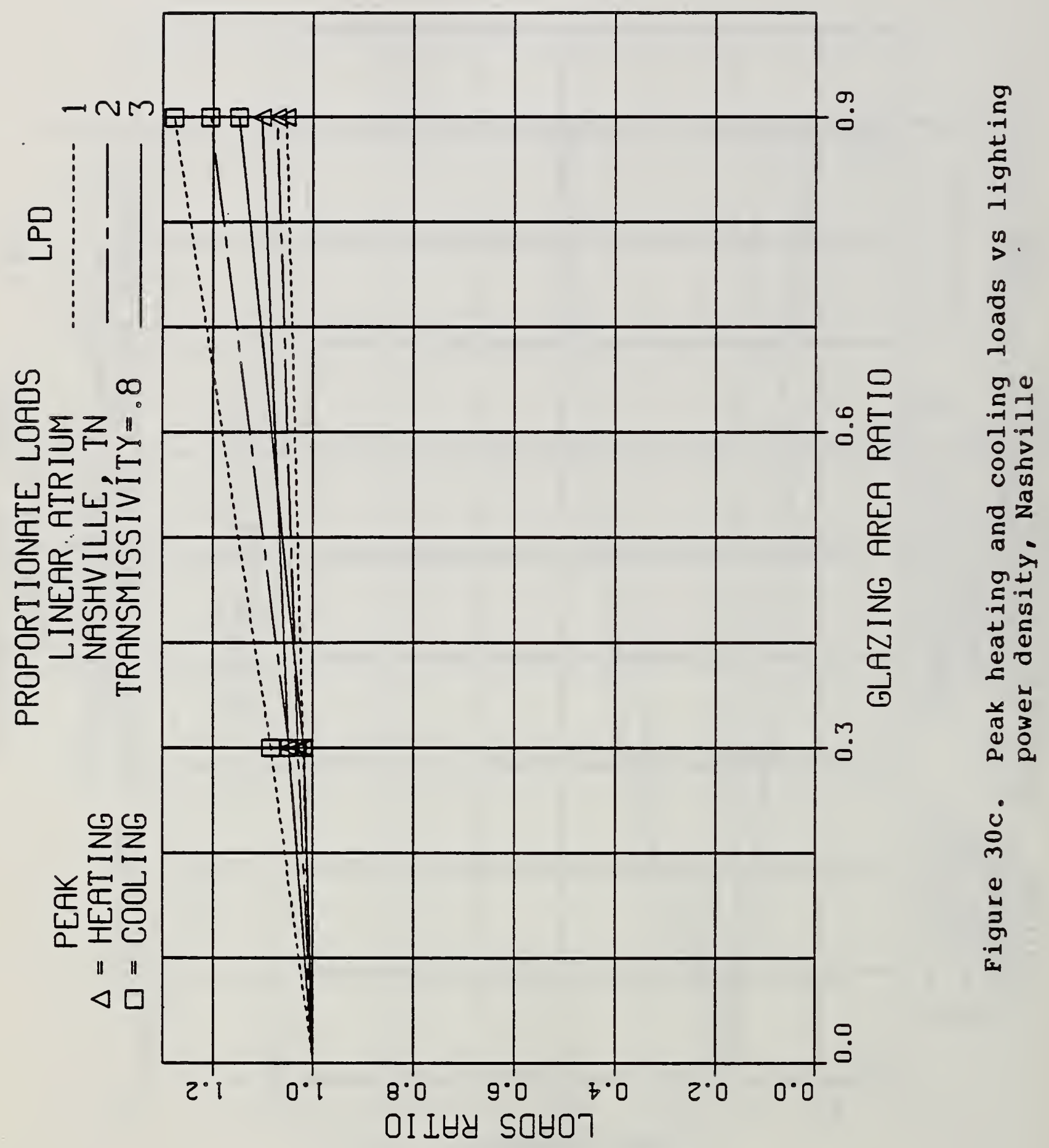




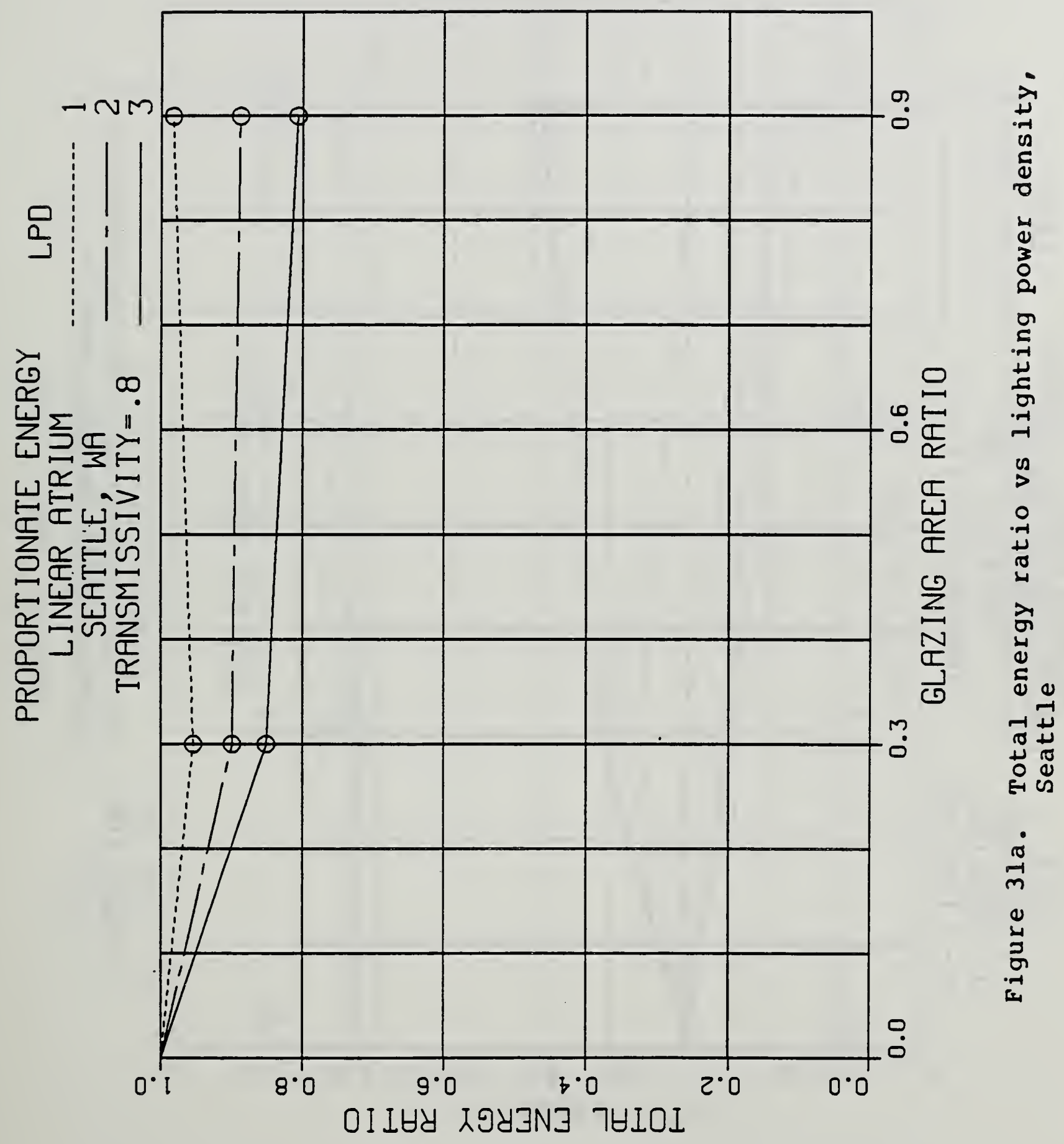




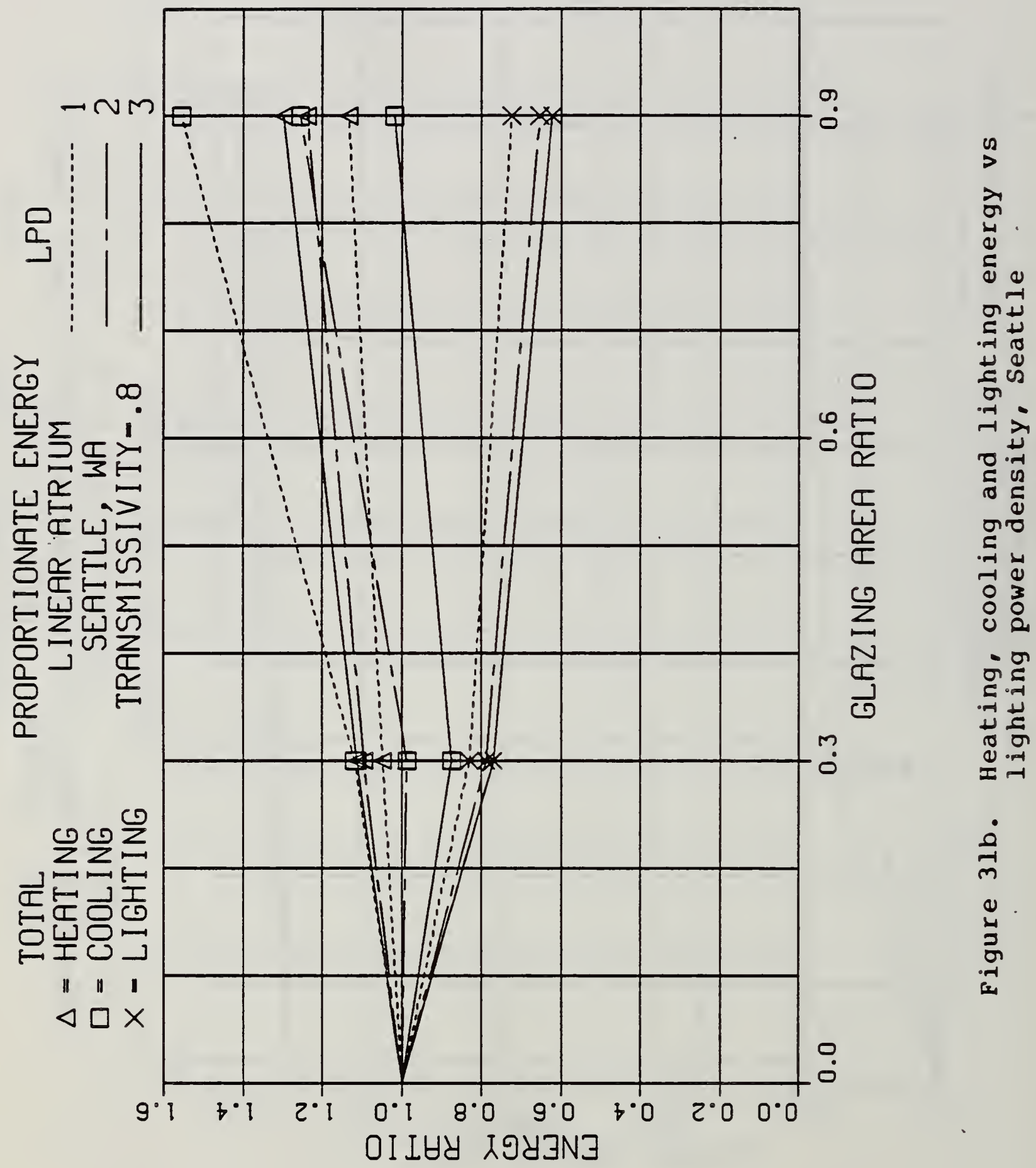




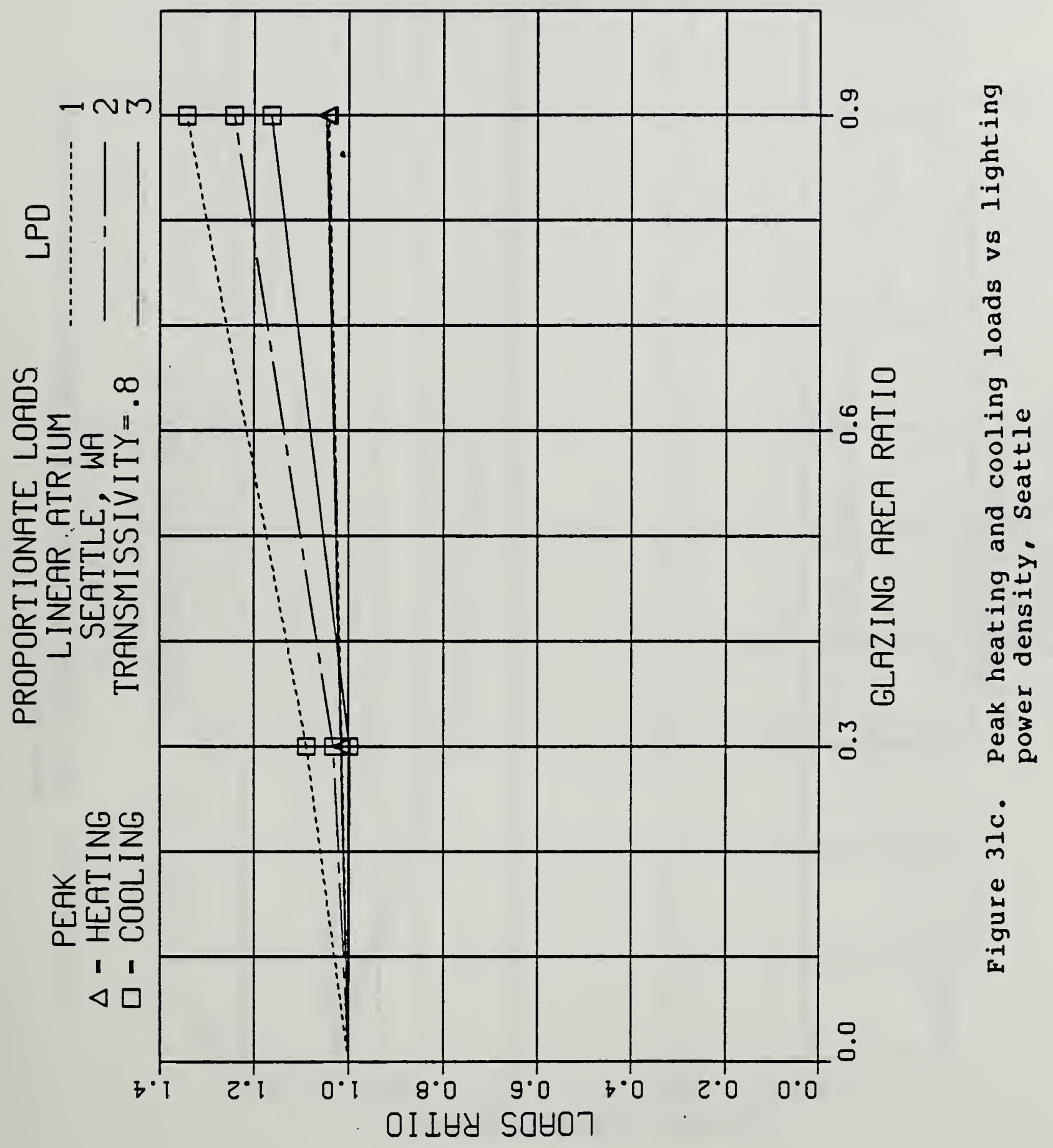




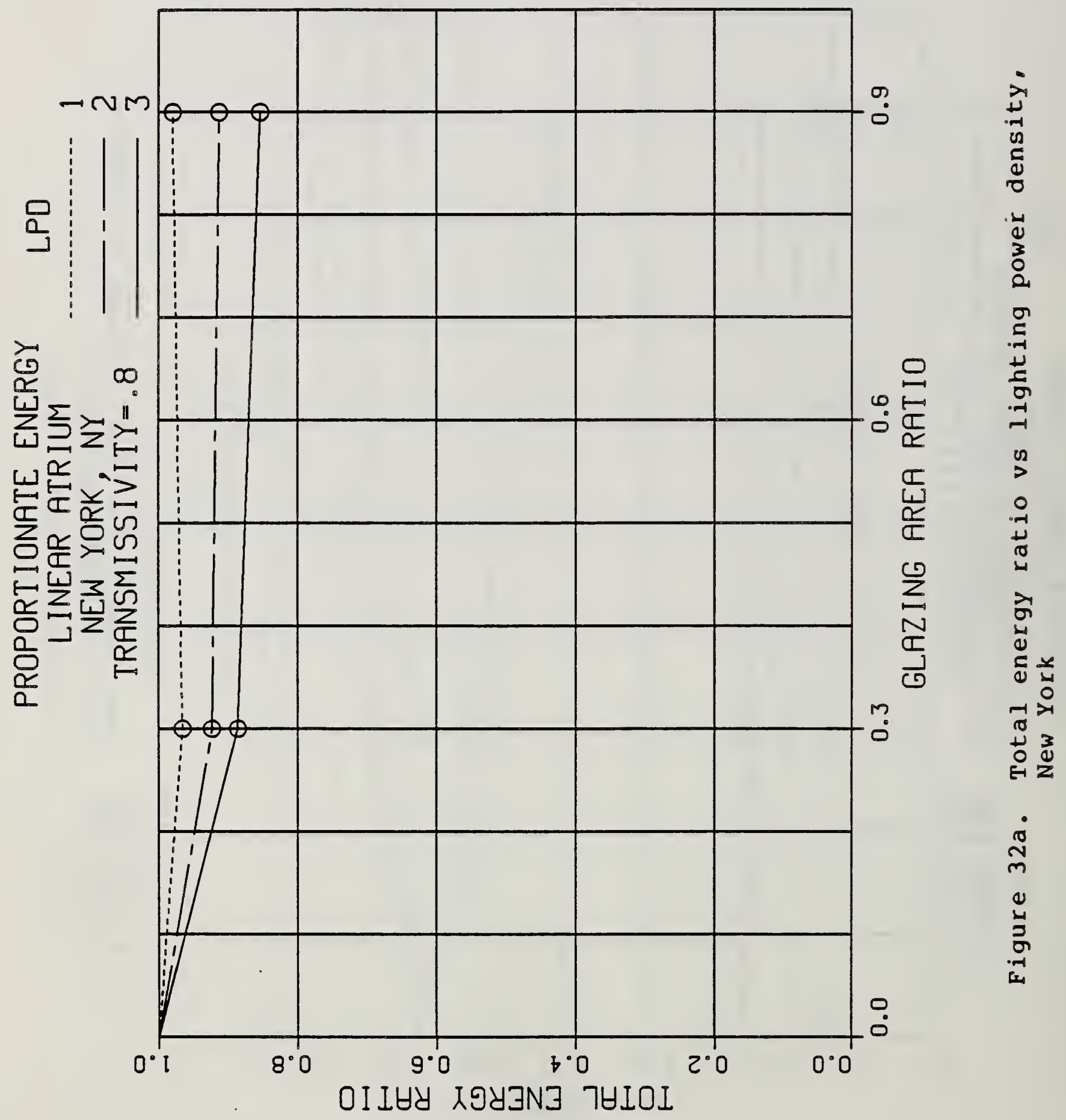




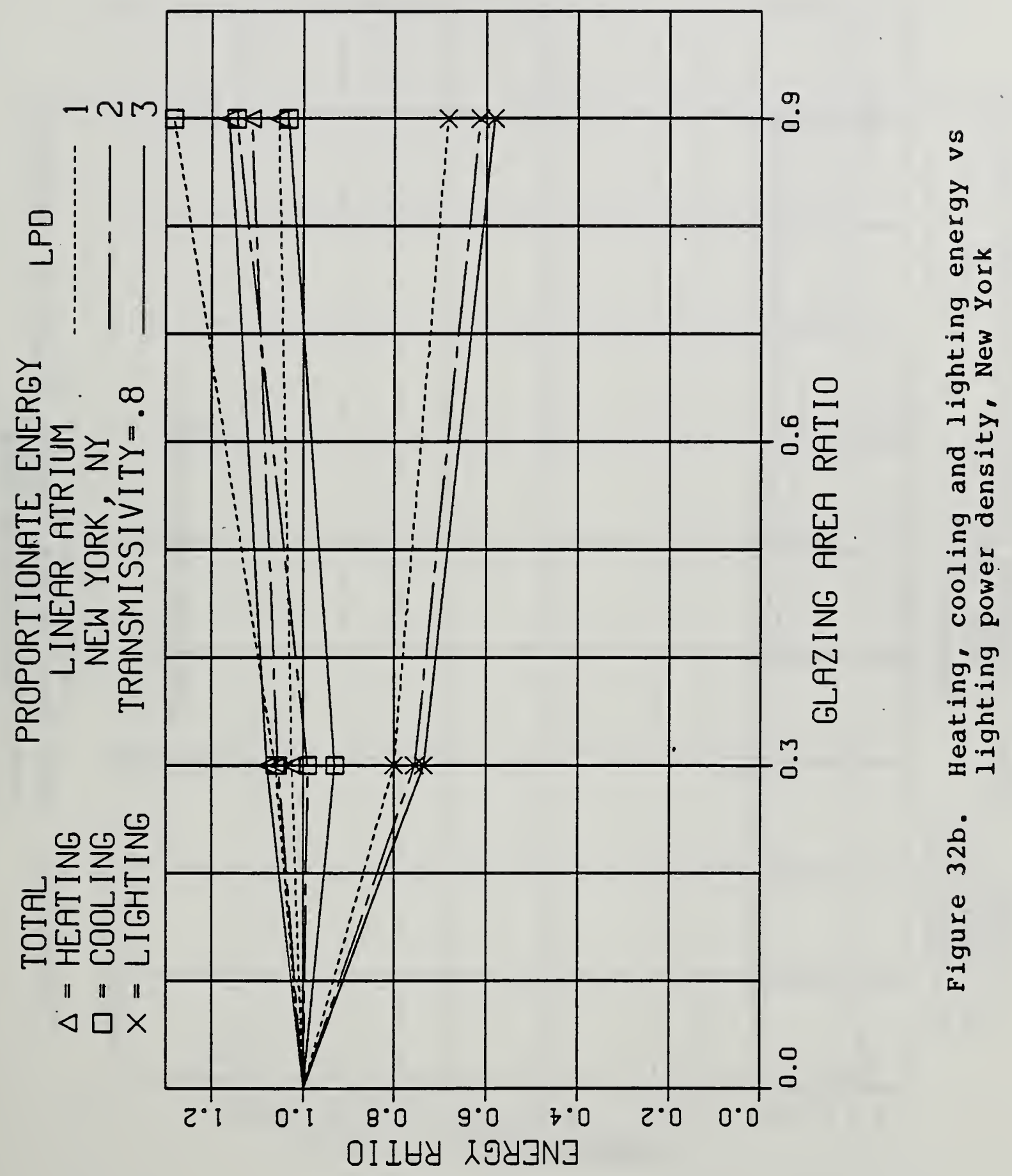




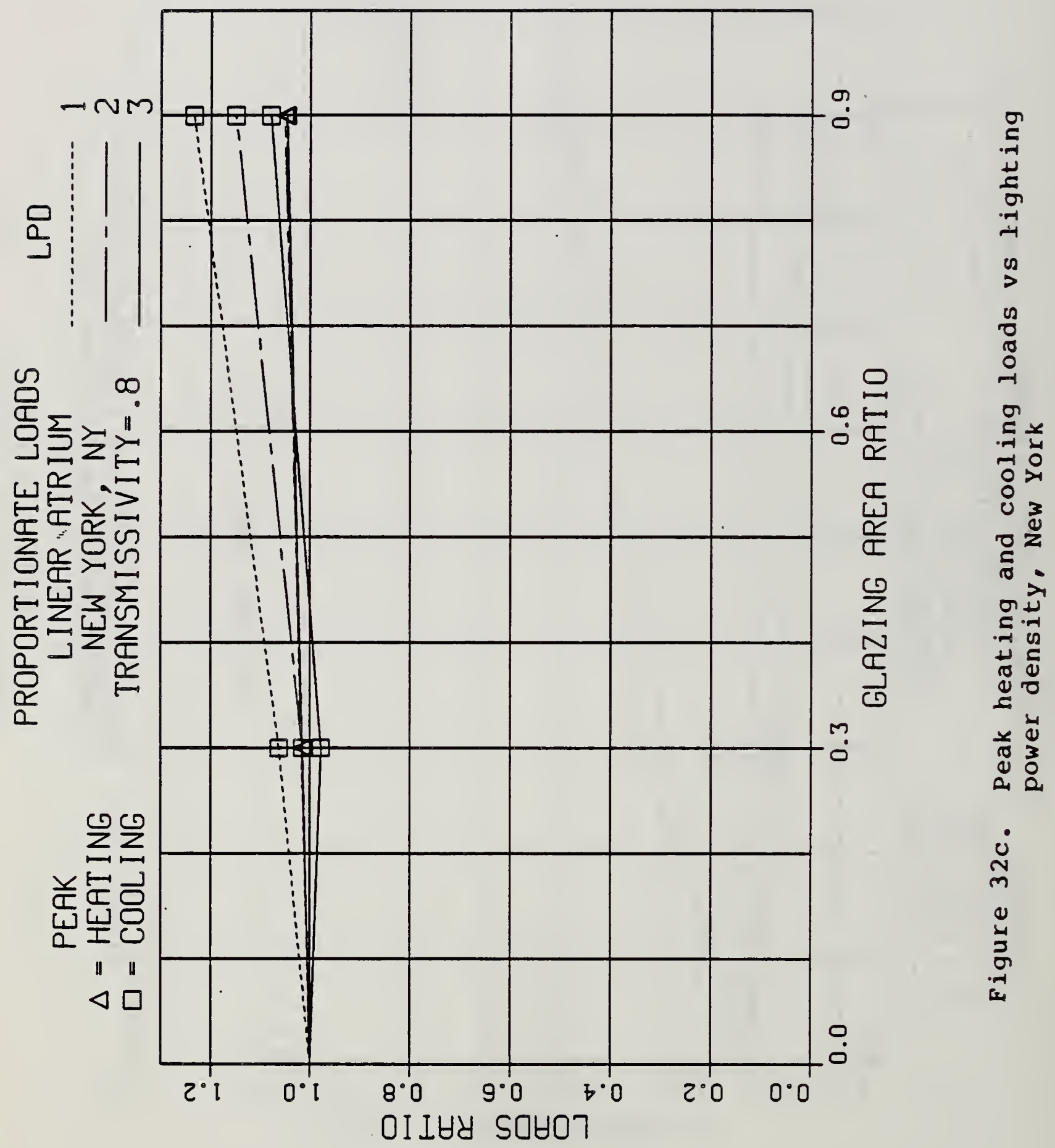




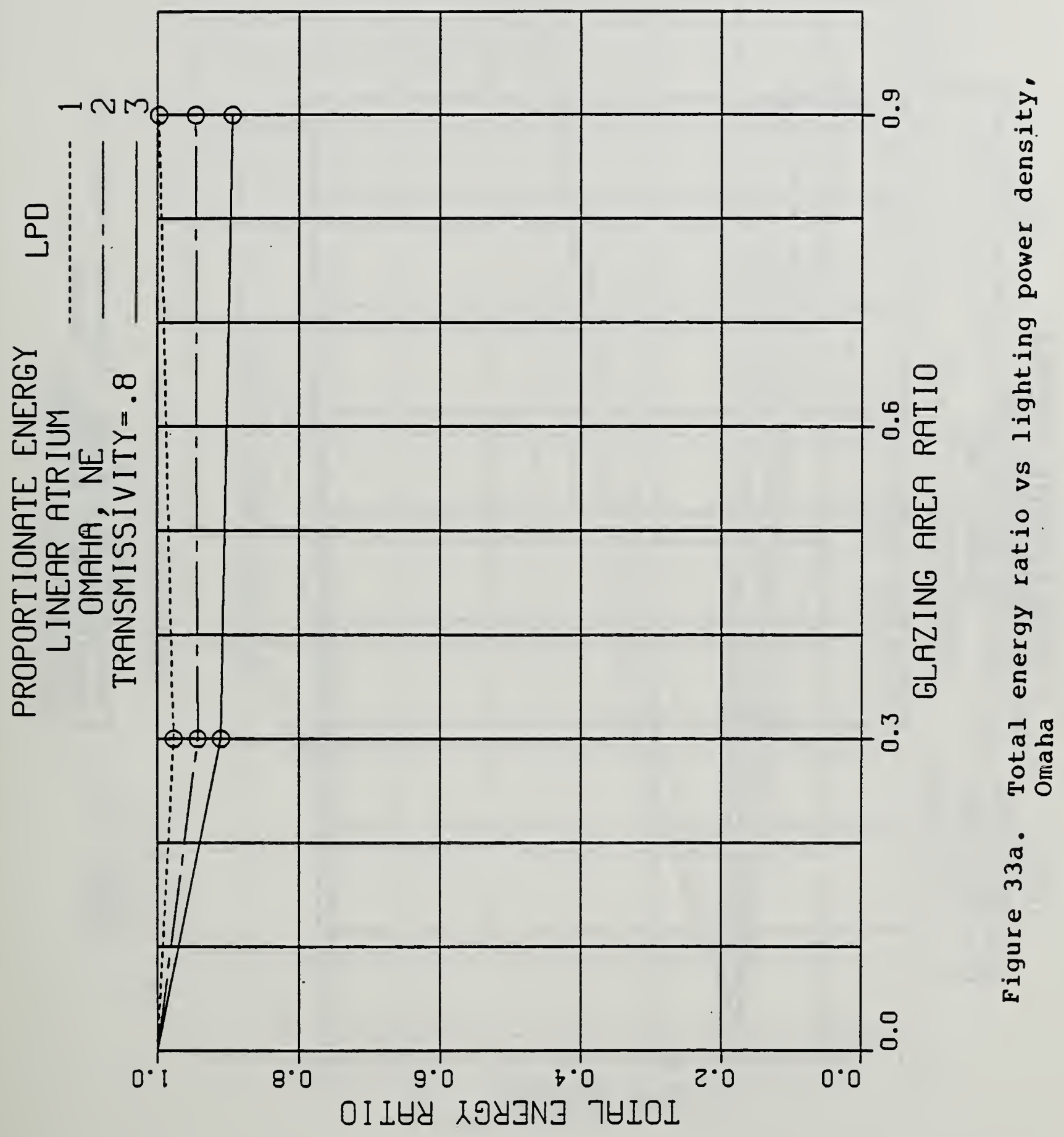




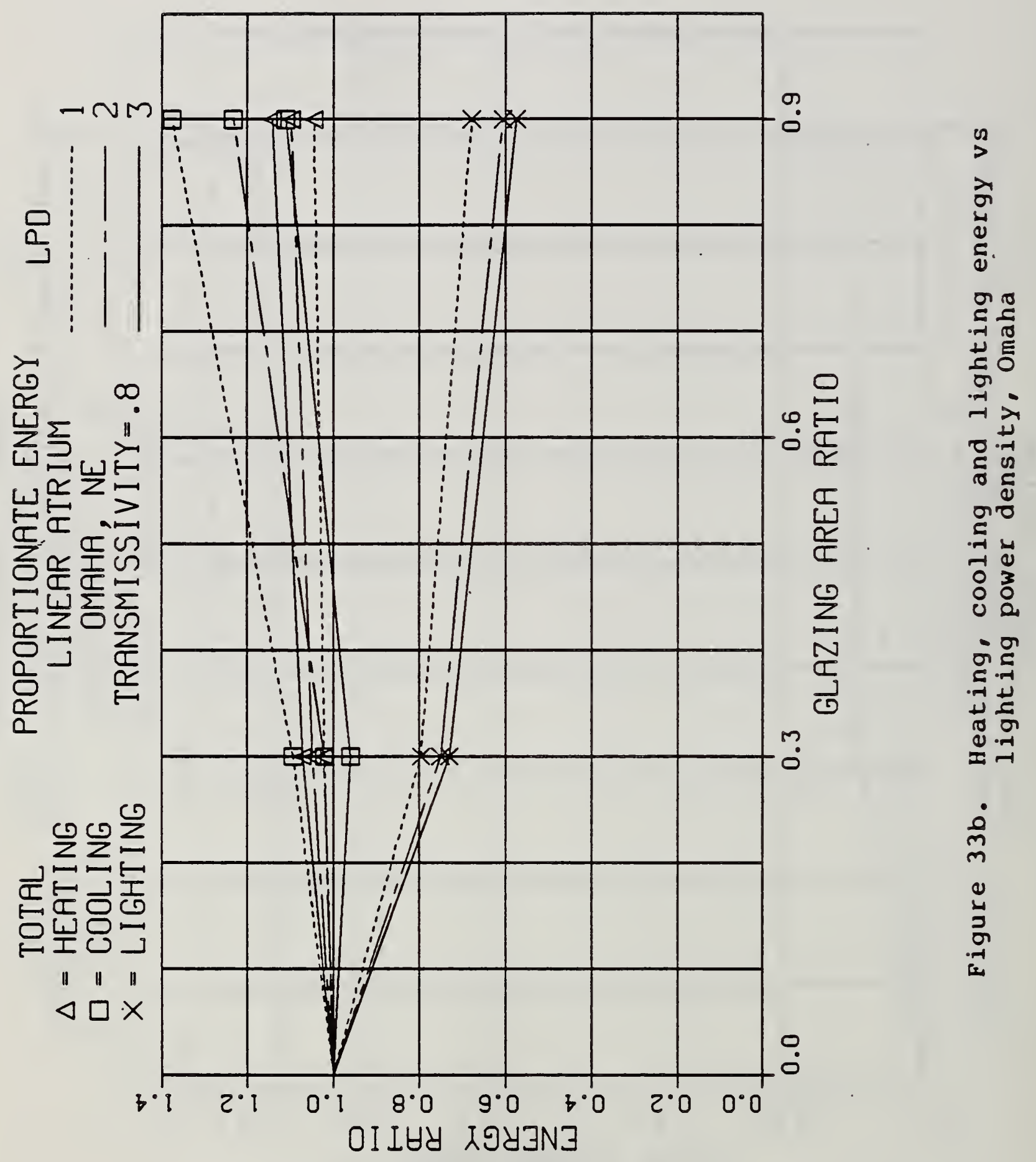




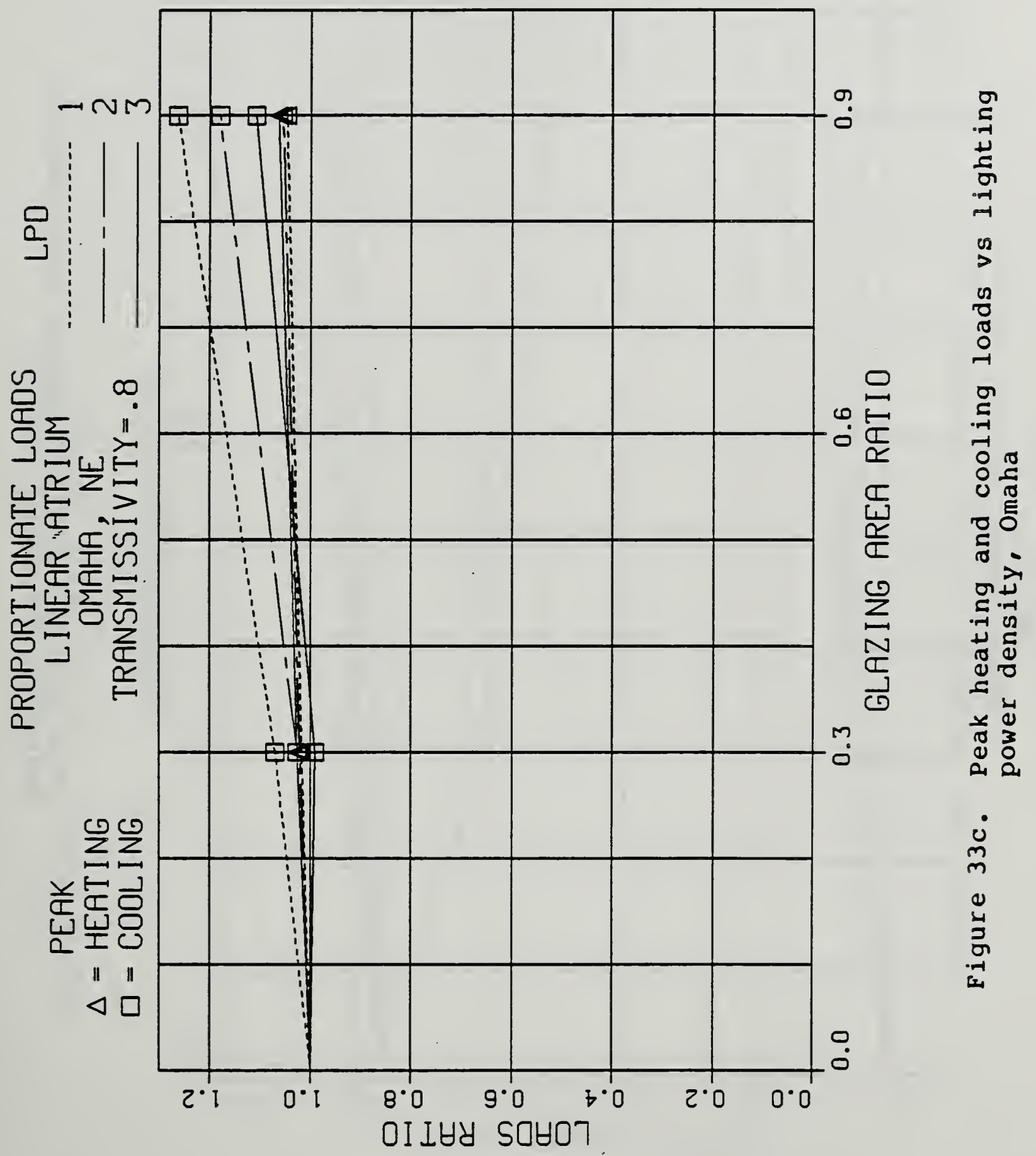




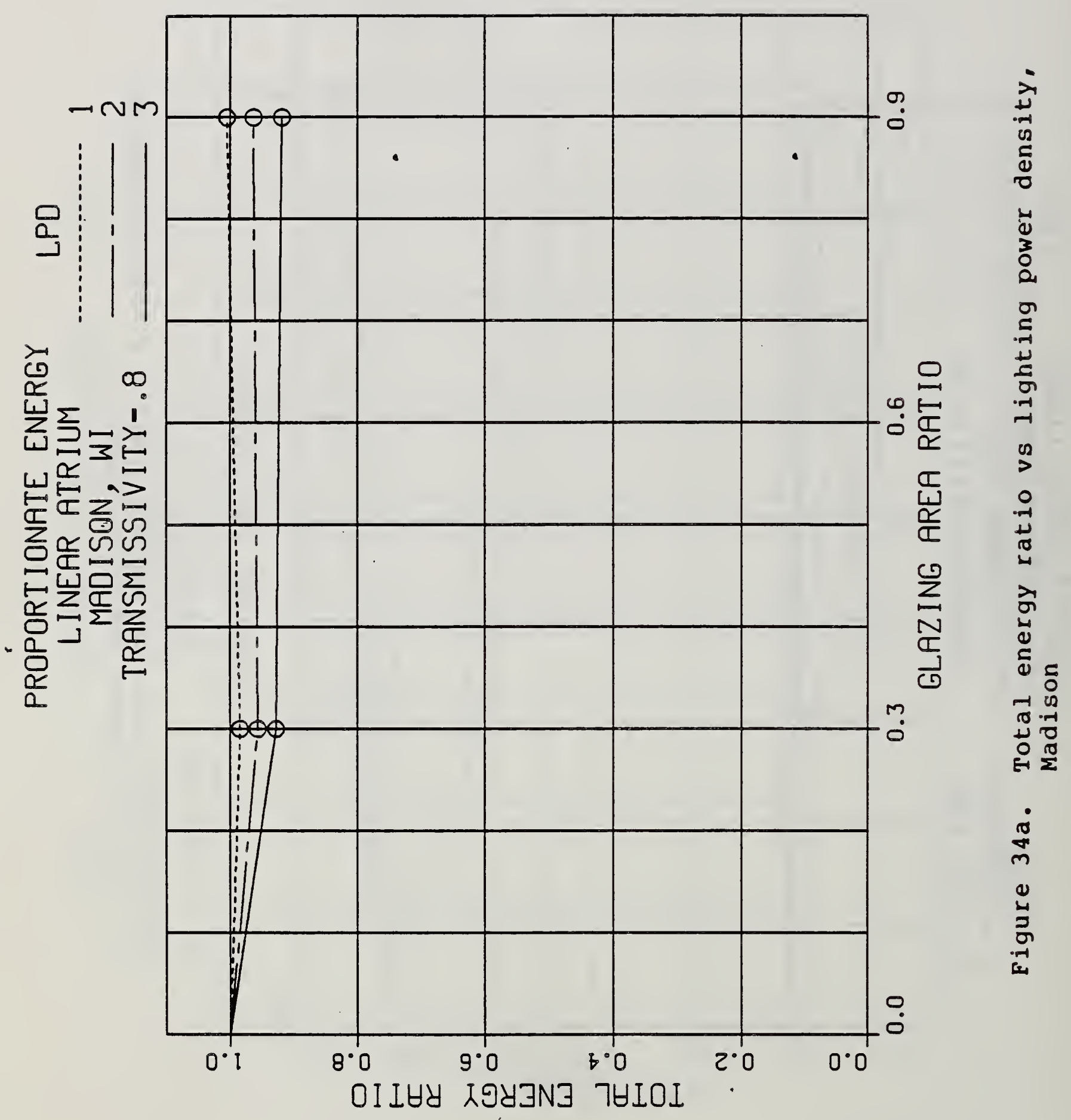




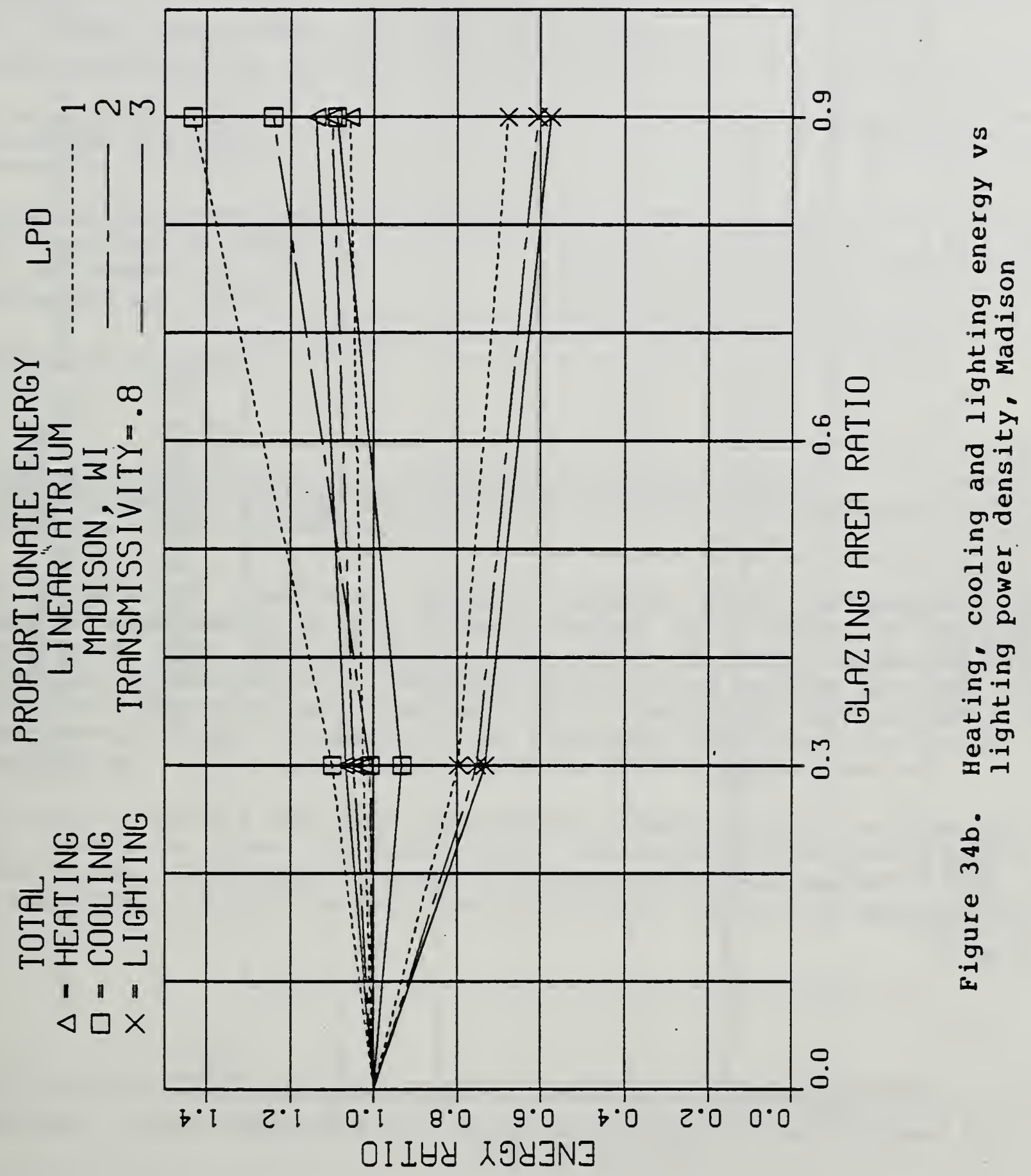




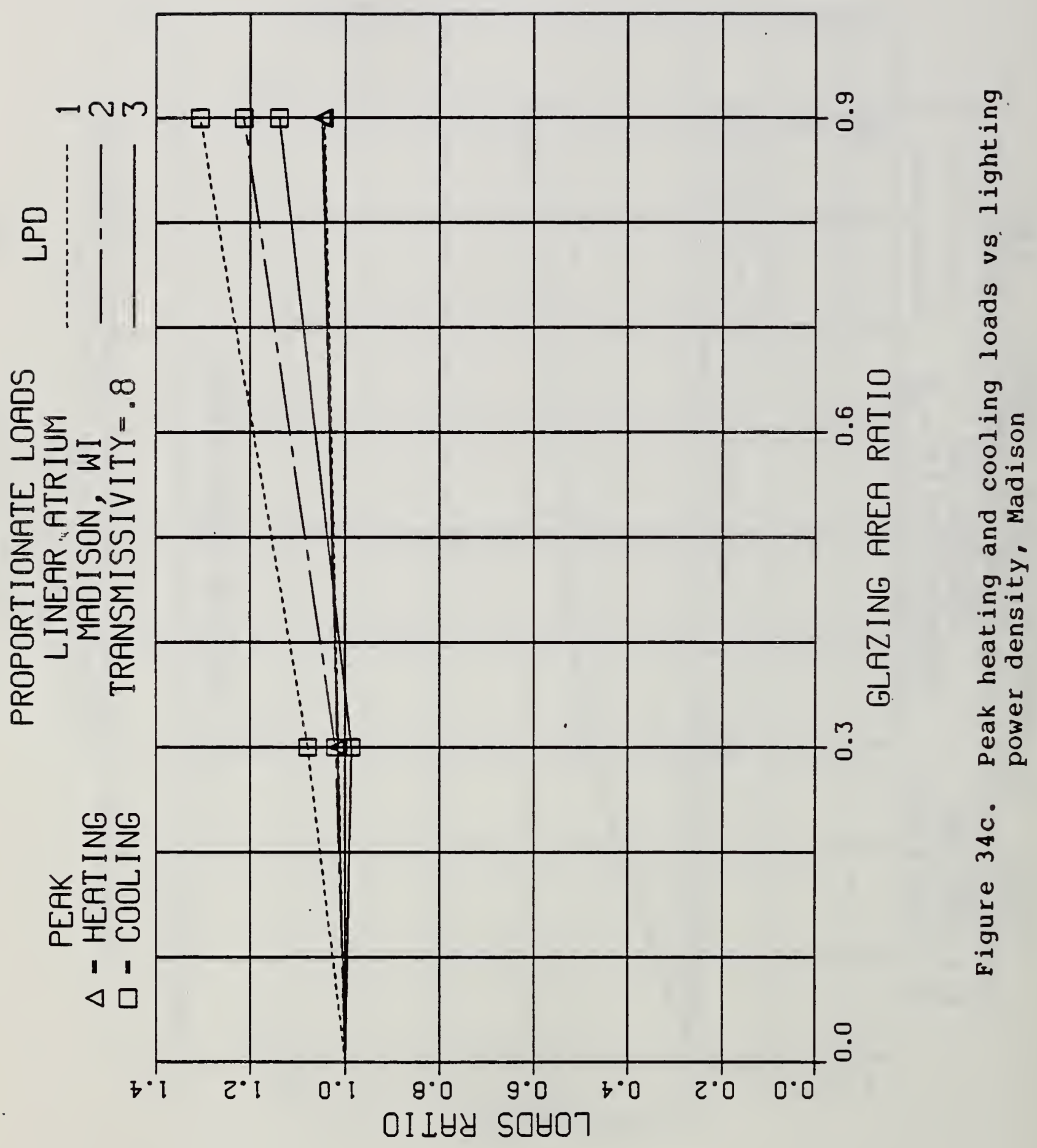




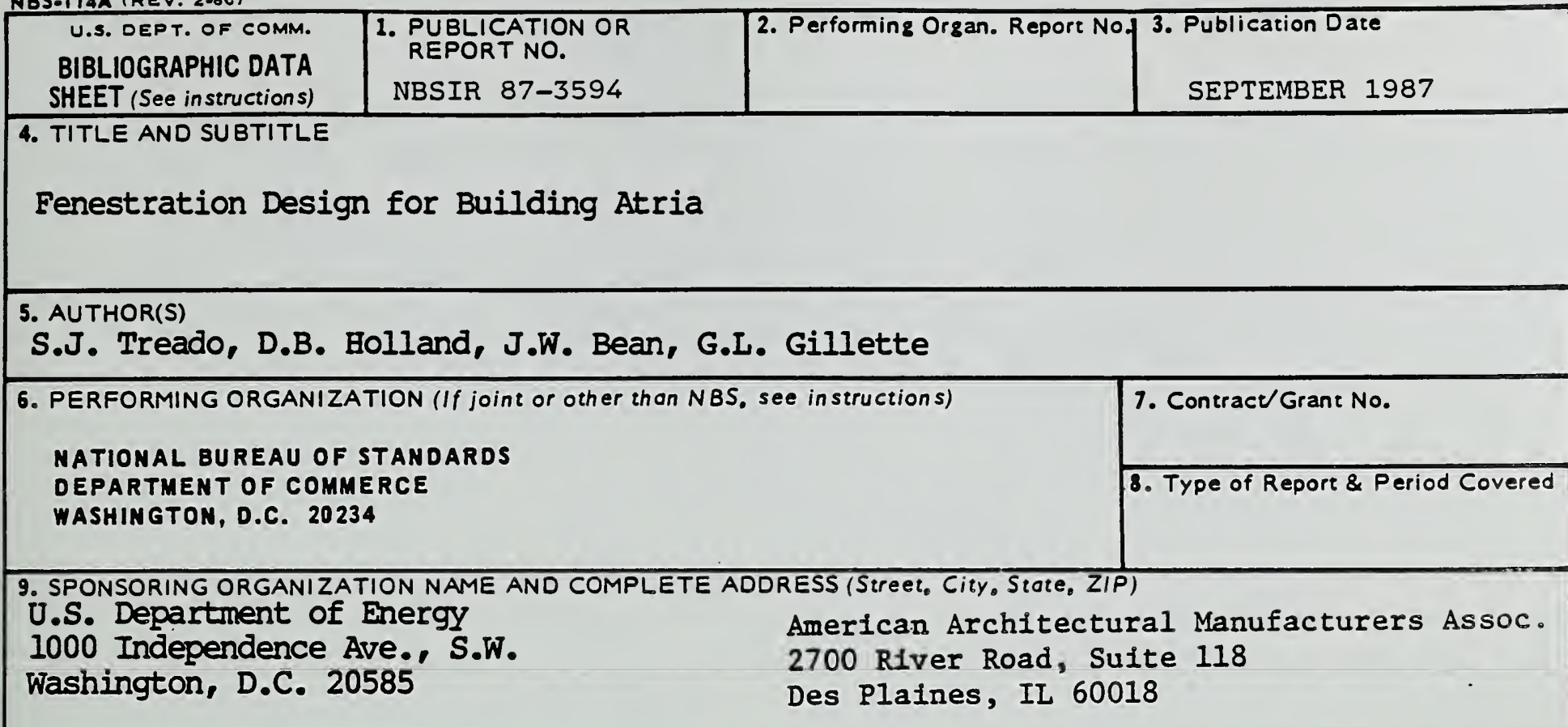

10. SUPPLEMENTARY NOTES

Document describes a computer program; SF-185, FIPS Software Summary, is attached.

11. ABSTRACT (A 200-word or less factual summary of most significant information. If document includes a significant bibliogrophy or literoture survey. mention it here)

The influence of fenestration design on building energy perfomance is evaluated, based on measurements in four atrium buildings and a series of detailed computer simulations using TARP and CEL-1. The impact of glazing area and solar-optical properties is examined for a linear and central atrium building for eight geographical locations. The usefulness of automatic solar shading and heat storage strategies is also investigated. Guidelines are presented for effective design of atrium fenestration.

The results indicate that when daylighting is used, appropriate fenestration design will result in lower building energy requirements than would occur with no fenestration. Reductions in annual building energy requirements of over 20 percent were observed, although the total savings potential varied with geographical location.

12. KEY WORDS (Six to twelve entries; alphabetical order; copitalize only proper names; and separate key words by semicolons) Reywords: atrium; building energy; daylighting; glazing; heat storage; solar shading

$\square$ Order From Superintendent of Documents, U.S. Government Printing Office, Washington, D.C. 20402.

$X$ Order From National Technical Information Service (NTIS), Springfield, VA. 22161

14. NO. OF

PRINTED PAGES

169

15. Price

$\$ 18.95$ 


$$
\text { . }
$$



